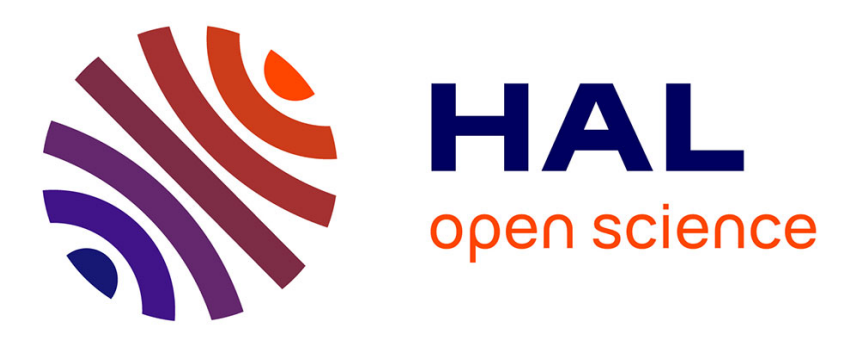

\title{
Hydrochar derived from municipal sludge through hydrothermal processing: A critical review on its formation, characterization, and valorization
} Huan Liu, Ibrahim Alper Basar, Ange Nzihou, Cigdem Eskicioglu

\section{- To cite this version:}

Huan Liu, Ibrahim Alper Basar, Ange Nzihou, Cigdem Eskicioglu. Hydrochar derived from municipal sludge through hydrothermal processing: A critical review on its formation, characterization, and valorization: Review. Water Research, 2021, 199, pp.1-52/117186. 10.1016/j.watres.2021.117186 . hal-03211746

\section{HAL Id: hal-03211746 \\ https://imt-mines-albi.hal.science/hal-03211746}

Submitted on 18 May 2021

HAL is a multi-disciplinary open access archive for the deposit and dissemination of scientific research documents, whether they are published or not. The documents may come from teaching and research institutions in France or abroad, or from public or private research centers.
L'archive ouverte pluridisciplinaire HAL, est destinée au dépôt et à la diffusion de documents scientifiques de niveau recherche, publiés ou non, émanant des établissements d'enseignement et de recherche français ou étrangers, des laboratoires publics ou privés. 
Hydrochar derived from municipal sludge through hydrothermal processing: A critical review on its formation, characterization, and valorization

Huan Liu ${ }^{\mathrm{a}}$, Ibrahim Alper Basar ${ }^{\mathrm{a}}$, Ange Nzihou ${ }^{\mathrm{b}}$, Cigdem Eskicioglu, ${ }^{\mathrm{a},}$

${ }^{a}$ UBC Bioreactor Technology Group, School of Engineering, The University of British Columbia,

Okanagan Campus, 1137 Alumni Avenue, Kelowna, British Columbia V1V 1V7, Canada

b

Université de Toulouse, IMT Mines Albi, RAPSODEE CNRS UMR-5302, Campus Jarlard, Albi 81013

Cedex 09, France

*Corresponding author.

E-mail addresses:

liu@alumni.ubc.ca (H. Liu); alperbasar@alumni.ubc.ca (I.A. Basar); ange.nzihou@mines-albi.fr (A.

Nzihou); cigdem.eskicioglu@ubc.ca (C. Eskicioglu). 


\begin{abstract}
Additional options for the sustainable treatment of municipal sludge are required due to the significant amounts of sludge, high levels of nutrients (e.g., C, N, and P), and trace constituents it contains. Hydrothermal processing of municipal sludge has recently been recognized as a promising technology to efficiently reduce waste volume, recover bioenergy, destroy organic contaminants, and eliminate pathogens. However, a considerable amount of solid residue, called hydrochar, could remain after hydrothermal treatment. This hydrochar can contain abundant amounts of energy (with a higher heating value up to $24 \mathrm{MJ} / \mathrm{kg}$, dry basis), nutrients, and trace elements, as well as surface functional groups. The valorization of sludge-derived hydrochar can facilitate the development and application of hydrothermal technologies. This review summarizes the formation pathways from municipal sludge to hydrochar, specifically, the impact of hydrothermal conditions on reaction mechanisms and product distribution. Moreover, this study comprehensively encapsulates the described characteristics of hydrochar produced under a wide range of conditions: Yield, energy density, physicochemical properties, elemental distribution, contaminants of concern, surface functionality, and morphology. More importantly, this review compares and evaluates the current state of applications of hydrochar: Energy production, agricultural application, adsorption, heterogeneous catalysis, and nutrient recovery. Ultimately, along with the identified challenges and prospects of valorization approaches for sludge-derived hydrochar, conceptual designs of sustainable municipal sludge management are proposed.
\end{abstract}

Keywords: Municipal sludge; hydrochar; hydrothermal conversion; pathway; contaminants; waste valorization 


\section{Abbreviations}

2D-PCIS two-dimensional perturbation correlation infrared spectroscopy

AAEMs alkali and alkaline earth metals

$\mathrm{AD}$

anaerobic digestion

AGS

anaerobic granular sludge

AP

apatite phosphorus

ASTM

American Society for Testing and Materials

BCR

Community Bureau of Reference

BOD

biochemical oxygen demand

Ca-P

calcium phosphates

CEC

cation exchange capacity

COD

chemical oxygen demand

CSTR

continuously stirred tank reactor

daf

dry ash free basis

$\mathrm{db}$

dry basis

DS

digested sludge

DTG

derivative thermogravimetry

EBC

European Biochar Foundation

EDS

energy dispersive X-ray spectrometry

EPA

Environmental Protection Agency

ER

energy recovery

EU

European Union

f1

acid soluble fraction

F1

exchangeable fraction

F2

carbonate-bound fraction

f2

reducible fraction

F3

Fe-Mn oxides fraction

f3

oxidizable fraction

F4

organic matter/sulfide fraction

f4

residual fraction

F5

residual fraction 
$\mathrm{H} / \mathrm{C}$ hydrogen to carbon atomic ratio

HHV higher heating value

HTC hydrothermal carbonization

HTG hydrothermal gasification

HTL hydrothermal liquefaction

HTP hydrothermal processing

ID inner diameter

IP inorganic phosphorus

I-TEQ international toxic equivalent

LHV lower heating value

MPS mixed primary and secondary sludge

MS municipal sludge non-apatite inorganic phosphorus

NMR Nuclear magnetic resonance

$\mathrm{O} / \mathrm{C}$ oxygen to carbon atomic ratio

OFG oxygen-containing functional groups

$\mathrm{OP}$ organic phosphorus

ortho-P orthophosphate

PAHs polycyclic aromatic hydrocarbons

PCBs polychlorinated biphenyls

$\mathrm{PCDD} / \mathrm{Fs} \quad$ polychlorinated dibenzo-dioxins/-furans

PF plug-flow reactor

PFCs perfluorinated compounds

POPs persistent organic pollutants

PPCPs pharmaceuticals, personal care products

PS primary sludge

pyro-P pyrophosphate

SEM scanning electron microscopy

SEPs sequential extraction procedures 
SRT

SAC

SS

$\mathrm{T}$

TCLP

TEM

TEQ

TG

TOC

TS

US

VM

$\mathrm{v} / \mathrm{v}$

WAS

WHSV

wt $\%$

WWTP

XPS

XRD solids retention time

sludge-based activated carbon

secondary sludge

reaction temperature

residence time

toxicity characteristic leaching procedure

transmission electron microscope

toxic equivalent

thermogravimetry

total organic carbon

total solids

United States

volatile matter

volume ratio

waste activated sludge

weight hourly space velocity

percentage by weight

wastewater treatment plant

X-ray photoelectron spectroscopy

X-ray diffractometry 
Table of Contents

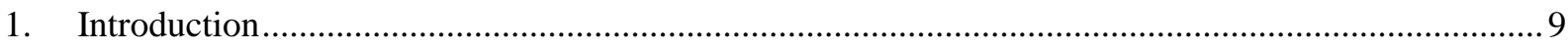

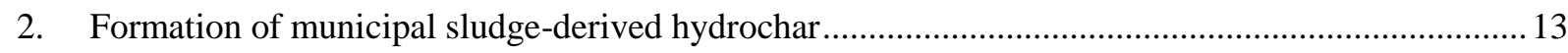

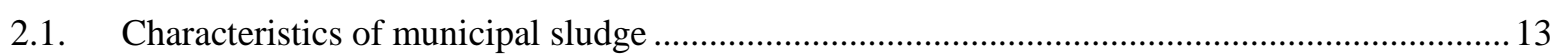

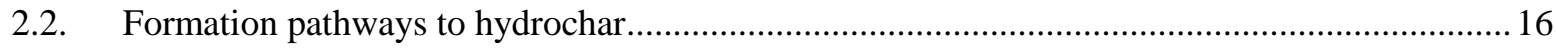

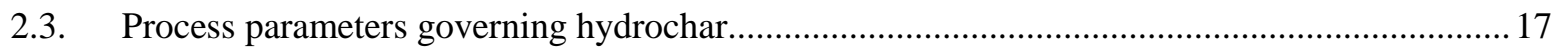

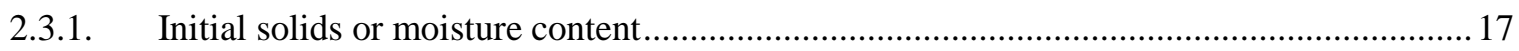

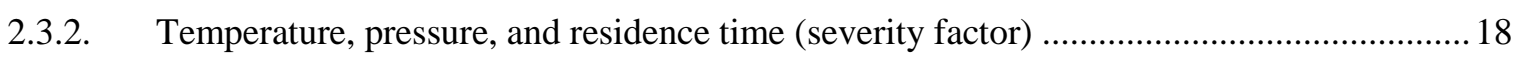

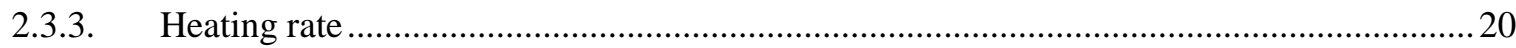

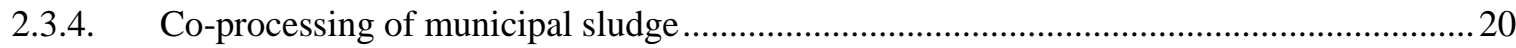

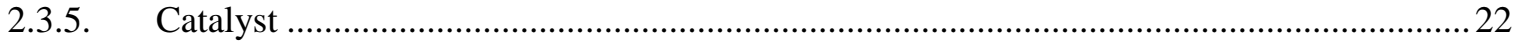

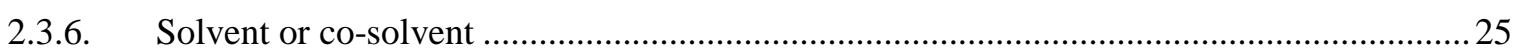

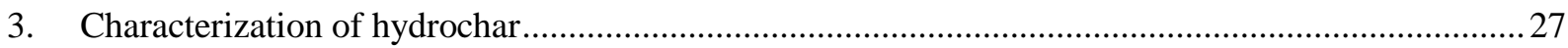

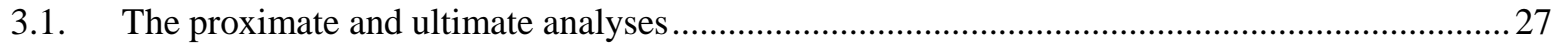

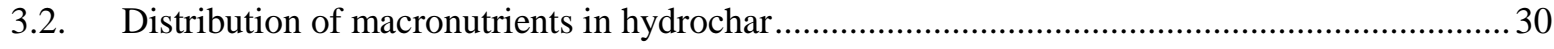

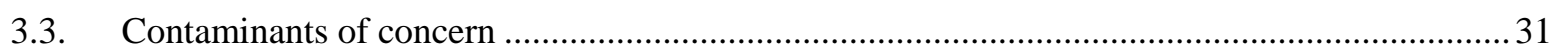

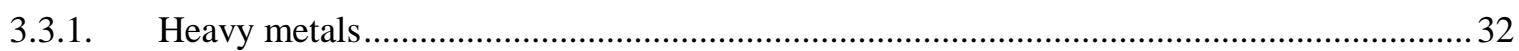

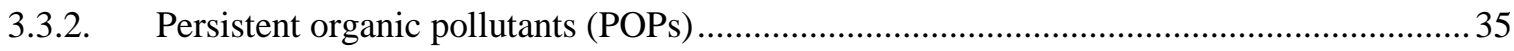

3.4. Characterization of surface functionality and structure …....................................................... 39

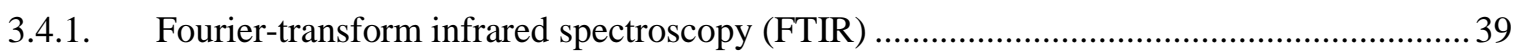

3.4.2. Two-dimensional perturbation correlation infrared spectroscopy (2D-PCIS) ...................... 40

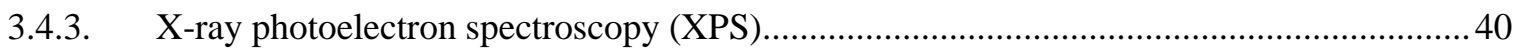

3.4.4. Nuclear magnetic resonance (NMR) spectroscopy ……..................................................... 42

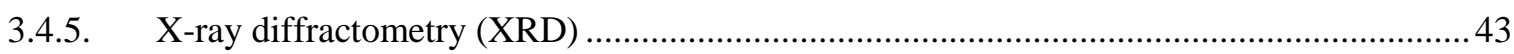

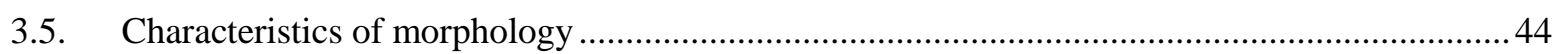

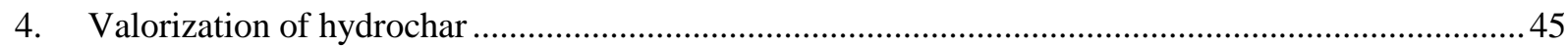

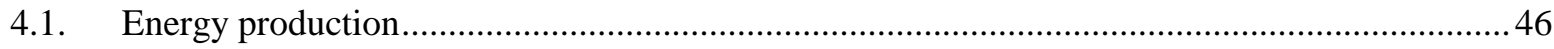

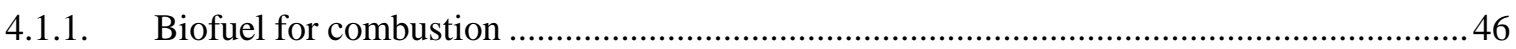

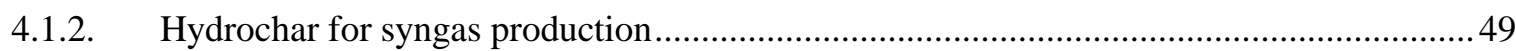

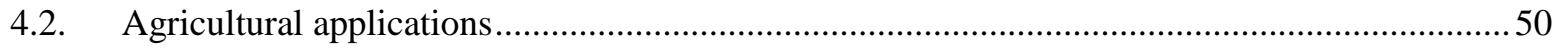

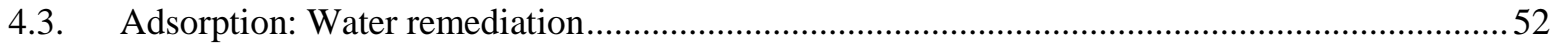

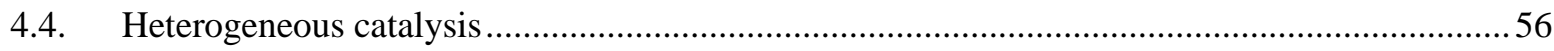

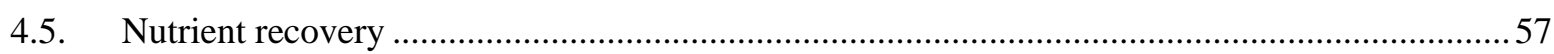

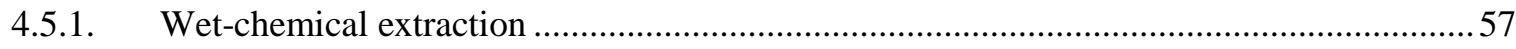

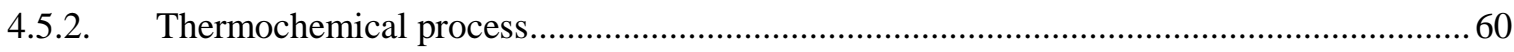


4.5.3. Integrated biotechnology.

61

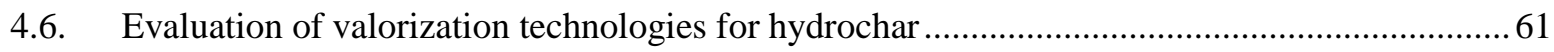

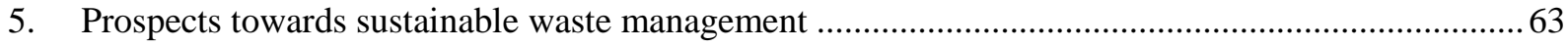

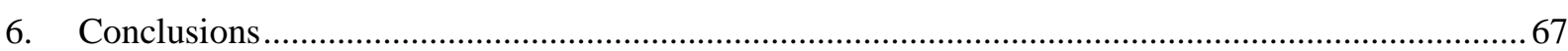

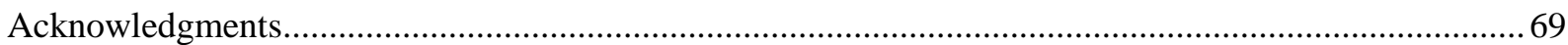

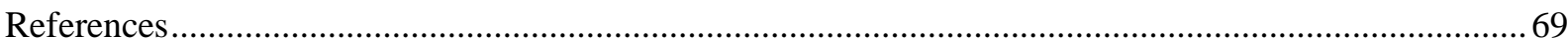




\section{Introduction}

Due to increasing population and rapid urbanization, a significant amount of wastewater solids, often called municipal sludge (MS), are generated at municipal wastewater treatment plants (WWTPs) worldwide (Kor-Bicakci and Eskicioglu, 2019). In China, the annual MS production doubled within five years and reached 5.7 million dry tonnes in 2013 (Yang et al., 2015). In the United States (US), the MS generation rate is nearly 12.7 million dry tonnes per year (2018) (Marrone et al., 2018). The world total production rate of MS was recorded at 45 million dry tonnes per year in 2017 (Gao et al., 2020). Originating from households, food-processing, agricultural, and industrial wastewater and associated biological treatment, MS including primary sludge (PS), secondary sludge (SS), and digested sludge (DS) is a reservoir of organic materials, nitrogen $(\mathrm{N})$, phosphorus $(\mathrm{P})$, and other inorganic nutrients (Zhai et al., 2014a). MS has been identified as a complementary P sink in regions with limited phosphate rock resources (Shi et al., 2019). However, MS, especially non-stabilized sludge, may also contain various hazardous materials, including pathogens (Lopes et al., 2020), organic contaminants, such as polycyclic aromatic hydrocarbons (PAHs) and polychlorinated biphenyls (PCBs) (Brookman et al., 2018), inorganic

pollutants (e.g., heavy metals) (Chen et al., 2020), and emerging contaminants or micropollutants (e.g., antibiotics, hormones, pharmaceuticals, and personal care products) (Taboada-Santos et al., 2019). Considering the magnitude of sludge production and its potential nutrients and hazards, the search for alternative treatment options has been stimulated for decades.

Proper management of MS through conventional disposal methods, such as landfilling, composting, land application, and incineration, requires significant expenditures (Xu et al., 2018). It has been reported that managing MS could cost as much as 57\% of the total operation cost in a WWTP (Ma et al., 2018). Even though anaerobic digestion (AD) treatment has been applied to break down the organic matters in MS and generate biogas (mainly methane), a considerable amount of sludge (approximately $40-50 \%$ of the input) remains and requires appropriate disposal (Zhen et al., 2017). The long solids retention time (SRT) (typically 15 - 20 days) requirement further limits the efficiency of conventional AD treatment. 
Given the increasing sludge amount, conventional treatment methods for MS may not be sustainable in the future.

The high moisture content in sludge (almost $98 \mathrm{wt} \%$ ) causes the biggest handling challenges: The massive volume and consequent high cost of treatment. An emerging technique, hydrothermal processing (HTP), also called hydrothermal conversion, is promising to address these challenges efficiently and economically (Huang et al., 2019). HTP can treat waste with high moisture content through a thermochemical process. This ability is a significant advantage compared to other techniques that require dry feedstocks (e.g., incineration and pyrolysis). It has been reported that the drying cost of MS is the majority energy input of pyrolysis treatment, occupying $65-75 \%$ of the total inputs (Kim and Parker, 2008). Conversely, without drying requirement, HTP could substantially reduce the energy input. HTP utilizes hot pressurized water as a reaction medium to break down large complex organic matters or macromolecules into smaller and simpler units at elevated temperature and pressure (Mathimani and Mallick, 2019). The reaction rate especially raises when the treatment conditions reach the critical point of water $\left(374.3^{\circ} \mathrm{C}\right.$ and $\left.22.1 \mathrm{MPa}\right)$ (He et al., 2014a). Thus, HTP can efficiently decompose organic matters and reduce the volume of residual solids. The dewaterability of MS is also significantly enhanced after HTP treatment, even at low temperatures (e.g., $180{ }^{\circ} \mathrm{C}$ ). Wang et al. (2014) reported that the moisture content of excess sludge was reduced to $27 \%$ after HTP at $180{ }^{\circ} \mathrm{C}$ for $1 \mathrm{~h}$ followed by mechanical dewatering, while over $65 \%$ of moisture was retained when only mechanical dewatering technologies were used. Ahmed et al. (2021) found that after HTP of DS at $190{ }^{\circ} \mathrm{C}$ for $1 \mathrm{~h}$, the capillary suction time decreased by $91 \%$. Moreover, the greatest benefit of HTP is its use to produce renewable biofuels (e.g., coal-like char, biocrude, and syngas) from sludge (Moreno and Espada, 2019). In summary, HTP is used to simultaneously recover energy, promote organic pollutants decomposition, enhance dewaterability and eliminate pathogens (via high-temperature sterilization).

In recent decades, many researchers have focused on sludge valorization using HTP treatment (Merzari et al., 2019). HTP for sludge-to-energy conversion is classified into three main categories based on the treatment temperature, pressure, and featured fuel products: Hydrothermal carbonization (HTC), 
hydrothermal liquefaction (HTL), and hydrothermal gasification (HTG) (as shown in Table 1). Other hydrothermal technologies, such as thermal hydrolysis, wet oxidation, and supercritical water oxidation, do not aim for energy recovery and thus are not considered in this review. In this review, the carbonaceous char produced in the form of solid residue from HTP processes is defined as hydrochar. As can be seen in Table 1, different fuel products or coproducts (i.e., hydrochar, biocrude, syngas, and aqueous phase) are generated in all hydrothermal conditions; however, their yields vary.

Please Insert Table 1 Here

Fig. 1 presents the normal distribution of product yields based on data gathered from numerous HTP studies. As the treatment severity intensifies in the order of HTC, HTL, and HTG, there is a noticeable trend of decreasing yield of solid and aqueous phase products, while the gas yield increases. The biocrude yield tends to be maximized through the HTL of MS. It is noted that a considerable amount of hydrochar remains as a product or coproduct despite the hydrothermal conditions. As the figure shows, average yields of hydrochar are $60.2 \%, 44.7 \%$, and $20.5 \%$, dry basis (db), from HTC, HTL, and HTG treatment of MS, respectively (Fig. 1). However, it should be noted that the yield of hydrochar varies substantially depending on the reaction severity and processing conditions. For example, in a continuous plug-flow HTL system $\left(276-358{ }^{\circ} \mathrm{C}\right.$ for $\left.18-30 \mathrm{~min}\right)$, the hydrochar yield from PS, SS, and DS were $9.5,20.5$, and 36.4\%, db, respectively (Marrone et al., 2018).

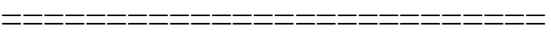

Please Insert Fig. 1 Here

The reduced mass percent of hydrochar causes a high concentration of nutrients (particularly P) and contaminants, such as heavy metals, PAHs, and PCBs (Chanaka Udayanga et al., 2018). Yu et al. (2019) 
reported that almost all P (> 90\%) remained in the hydrochar after HTC treatment of PS. However, due to the accumulation of toxic contaminants (e.g., $\mathrm{Cr}$ and $\mathrm{Ni}$ ), direct recycling of hydrochar as $\mathrm{P}$ fertilizer is restricted by many jurisdictions (Chanaka Udayanga et al., 2018). Direct burning of HTC hydrochar for heat generation would cause a wide distribution of P-rich ash and potential secondary pollution (OliverTomas et al., 2019). Therefore, enrichment of the nutrients and pollutants in hydrochar seems to be a key bottleneck for HTP application to MS. Several studies for P recovery from MS-derived hydrochar and risk assessment of contaminants have been conducted in the past ten years ( $\mathrm{Li}$ et al., 2012; Liu et al., 2018a; Ovsyannikova et al., 2019; vom Eyser et al., 2015). To date, few reviews have detailed the characteristics of MS-derived hydrochar produced under various HTP conditions or mentioned its application opportunities. Therefore, it is necessary to critically and comprehensively investigate current information and expose knowledge gaps of MS-derived hydrochar for its sustainable management.

This review aims to show current knowledge of the properties of MS and its corresponding hydrochar from HTP and to present and evaluate sustainable application processes for MS-derived hydrochar. Recent studies of HTP technique are application-oriented and often issued as technical reports. Consequently, this review involves an extensive search of all related peer-reviewed journal articles, conference proceedings, theses, books, as well as technical reports from bibliometric databases (e.g., Google Scholar, Science Direct, Scopus, and Web of Science). The following keywords have been searched in different combinations: Hydrochar, sludge, municipal sludge, sewage sludge, hydrothermal, hydrothermal conversion, HTC, HTL, HTG, HTP, and supercritical water gasification. The search period is concentrated in the last twenty years because more attention has been paid to HTP treatment of MS since 2000. After rejecting articles referring to industrial sludge or irrelevant hydrothermal processes (e.g., thermal hydrolysis and oxidation) based on title, abstract, and scanning, the remaining articles (in total 319 references) were analyzed thoroughly. Based on collected information from all selected papers, this review is divided into the following sections. Firstly, the formation of hydrochar from MS is comprehensively presented from the perspectives of mechanisms and hydrothermal conditions. Secondly, unique characteristics of MS-derived hydrochar and the associated contaminants of concern are 
summarized to guide the application of hydrochar. Thirdly, this review evaluates current utilizations of MS-derived hydrochar for sustainable management. Lastly, special attention is given to the feasibilities and challenges of each technology for hydrochar valorization.

\section{Formation of municipal sludge-derived hydrochar}

The contents and distributions of hydrothermal products, as well as the reaction pathways, are dependent on the feedstock properties and process conditions, such as initial total solids (TS) of MS, reaction temperature and pressure, residence time, heating and cooling rates, co-feedstock, catalysts, and solvents. Hence, this section comprehensively reviews the formation of MS to hydrochar under the influence of various hydrothermal parameters.

\subsection{Characteristics of municipal sludge}

Generated through different wastewater treatment processes (i.e., primary sedimentation, aeration tank, and AD), MS can be categorized into PS, waste activated sludge (WAS) or SS, and DS. Table 2 summarizes the properties of various types of MS that were studied for energy conversion using HTP technologies. To maintain consistency, the higher heating value (HHV) of MS (and corresponding hydrochar) is calculated by using the correlation formula (Eq. 1) developed by Channiwalaa and Parikh (Channiwala and Parikh, 2002).

$\mathrm{HHV}(\mathrm{MJ} / \mathrm{kg})=0.3491 \mathrm{C}+1.1783 \mathrm{H}+0.1005 \mathrm{~S}-0.1034 \mathrm{O}-0.0151 \mathrm{~N}-0.0211 \mathrm{Ash}$

where $\mathrm{C}, \mathrm{H}, \mathrm{S}, \mathrm{O}, \mathrm{N}$, and ash are mass percentages of material on a dry basis.

Please Insert Table 2 Here

MS received from WWTP clarifiers or centrifuges normally contains around 2-12 wt $\%$ of TS (Kacprzak et al., 2017; Moran, 2018). To maximize the energy conversion rate of HTP, moisture content of MS is typically reduced to minimum levels while not limiting its pumpability using various dewatering 
technologies (e.g., centrifuges and belt presses) (Elliott et al., 2015). As shown in Table 2, all different types of MS are complex heterogeneous mixtures of organic and inorganic matters. The high variety of MS is derived from its specific origin and unique processing conditions. The volatile matters (VM) vary with $37.7-76.6 \%, 33.6-79.3 \%, 25.1-70.0 \%$, db, for PS, WAS, and DS, respectively. Due to the concentrated organic matter, MS has become an attractive source of energy with a higher heating value (HHV) up to $22.2 \mathrm{MJ} / \mathrm{kg}$, db. Such energy content is comparable to low-rank coal, such as lignite (SyedHassan et al., 2017). However, it should be noted that high ash contents of MS and its derived hydrochar could constrain their applicability for direct combustion due to the slagging problems from ash melting.

Fig. 2 illustrates the elemental and other properties of MS reported in numerous HTP studies. Mean and $10^{\text {th }}$ and $90^{\text {th }}$ percentile data of each property are presented. Based on the percentile distribution analysis, MS has a large variety of ash from $19.7 \%$ to $56.6 \%$, db, which could cause a high variation of ash content in hydrochar. Other than ash, MS is composed of $18.9-41.7 \% \mathrm{C}, 3.1-6.5 \% \mathrm{H}, 15.1-33.0 \% \mathrm{O}$, 2.1-6.8\% N, 0.4-2.4\% S, and 1.0-3.8\% P on a dry basis. Most reported MS samples (80\%) have fixed carbon (FC) and HHV of 1.0-12.2\% and 9.7-19.9 MJ/kg, respectively. The average $\mathrm{pH}$ of MS reported in the previous studies is neutral (6.9), within a range of 5.7-8.0.

Please Insert Fig. 2 Here

Unlike other types of biomass that are dominated by a single organic compound, MS can be broadly balanced by carbohydrates (cellulose and hemicellulose), protein, lipids, lignin, and humic substances, with a dry weight percentage of 1.3-62.6, 0.1-26.0, 8.0-43.2, 1.1-35.0 and 3.8-23.9, respectively. Lignocellulosic biomass and macroalgae are mainly composed of carbohydrates (typically $40-50 \%$ and $55-60 \%$, respectively), while microalgae primarily consist of protein (30-60\%) or carbohydrates (2040\%) (Basar et al., 2021). The diverse compositions of MS could lead to complex reaction pathways in HTP and the MS-derived hydrochar with abundant functionalities. Moreover, MS also contains valuable 
inorganic compounds, such as $\mathrm{Na}, \mathrm{K}, \mathrm{Al}, \mathrm{Ca}, \mathrm{Fe}$, and $\mathrm{Mg}$, along with pollutants and potential carcinogens, such as heavy metals, polychlorinated compounds, and PAHs, which tend to be recalcitrant to HTP and accumulated in hydrochar (Brookman et al., 2018; Chanaka Udayanga et al., 2018; Raheem et al., 2018). Therefore, properties of MS-derived hydrochar should be carefully reviewed prior to applications to avoid potential secondary contamination.

Fig. 3 shows the concentration distribution of metals present in MS samples that were used in HTP studies. These metals can be categorized as alkali metals (e.g., $\mathrm{K}$ and $\mathrm{Na}$ ), alkaline earth metals (e.g., $\mathrm{Ca}$ and $\mathrm{Mg}$ ), transition metals (e.g., $\mathrm{Fe}, \mathrm{As}, \mathrm{Cd}, \mathrm{Cr}, \mathrm{Co}, \mathrm{Cu}, \mathrm{Hg}, \mathrm{Mn}, \mathrm{Mo}, \mathrm{Ni}, \mathrm{Pb}$, and $\mathrm{Zn}$ ), and other metals (e.g., $\mathrm{Al}$ and Se). Among the studied samples, most (80\%) MS contains abundant $\mathrm{K}(0.2-1.6 \%)$, Na (0.1$0.5 \%), \mathrm{Ca}(0.3-4.1 \%), \mathrm{Mg}(0.2-1.2 \%), \mathrm{Al}(0.3-4.0 \%), \mathrm{Fe}(0.5-6.3 \%), \mathrm{Cr}(19-151 \mathrm{ppm}), \mathrm{Co}(1-2,700$ ppm), $\mathrm{Cu}$ (127-1,175 ppm), Mn (59-812 ppm), Ni (16-600 ppm), Pb (15-151 ppm), and Zn (303-2,288 ppm) on a dry basis. Several studies have reported that most of these metal ions could have a significant effect, either catalytic or inhibitory, on the decomposition of carbohydrates during HTP treatment (Cao et al., 2015; Chen and Lee, 2020; Hoşgün, 2020; Kong et al., 2008; Kumar et al., 2018; Liu et al., 2017; Lu et al., 2016; Zahari et al., 2020; Shen et al., 2009). Shen et al. (2009) found that alkali and alkaline-earth metal ions could promote the hydrothermal conversion (at $300{ }^{\circ} \mathrm{C}$ ) of glycerin to lactic acid or lactate salts, and the catalytic effectiveness varied on metal ions. Cao et al. (2015) demonstrated that transition metal ions, such as $\mathrm{Cu}(\mathrm{II})$ and $\mathrm{Fe}(\mathrm{III})$ could greatly stimulate the hydrolysis of cellulose into glucose, which was further decomposed into levulinic acid and formic acid under the HTP at $200{ }^{\circ} \mathrm{C}$. Hoşgün (2020) also discovered that $\mathrm{Al}(\mathrm{III})$ had a catalytic effect on the yields of 5-hydroxymethylfurfural and furfural through $\mathrm{HTP}$ (at $200{ }^{\circ} \mathrm{C}$ ) of poppy stalks. On the other hand, inhibitory effects on hydrothermal conversion could occur when transition metal ions exceeded certain concentrations. Kong et al. (2008) reported that with $\mathrm{Cr}(\mathrm{III})$ and $\mathrm{Ni}$ (II) ions increasing from 0 to $800 \mathrm{ppm}$, the yield of lactic acid converted from maize straw, rice husk, and sawdust initially improved, and then decreased under $\mathrm{HTP}$ at $300{ }^{\circ} \mathrm{C}$, while $\mathrm{Cr}$ (III), $\mathrm{Ni}$ (II) and $\mathrm{Zn}$ (II) showed a negative impact on the conversion of wheat bran. However, the effects of existing metals on hydrothermal conversion of MS are still undiscovered. Considering the 
significant load of metal ions in MS, their impacts on HTP should be exposed as they may become catalysts instead of burdens.

Please Insert Fig. 3 Here

\subsection{Formation pathways to hydrochar}

In the past decades, various feedstocks have been studied from HTP, from model compounds, such as cellulose (Sevilla and Fuertes, 2009), to any wet biomass (Wang et al., 2018). As one of the most complex substrates, the generation process of hydrochar from MS can be complicated. Fig. 4 summarizes possible pathways from numerous studies of how major compounds in MS are transferred to the products via HTP as a function of temperature. It is known that the organic components (i.e., carbohydrates, protein, lipids, lignin, and humic substances) in MS are depolymerized into their corresponding monomers, which form intermediates mainly via hydrolysis, decomposition, dehydration, decarboxylation, and deamination. It should be noted that the significant load of metal ions in MS may promote or inhibit the hydrolysis, decomposition, and dehydration of carbohydrates. The intermediates are eventually recombined in hydrochar through aromatization, condensation, and polymerization. However, it is suggested that these reaction pathways occur simultaneously during the HTP of MS. Detailed descriptions of each reaction mechanism can be found in our previous literature review (Basar et al., 2021) and elsewhere (He et al., 2014a; Wang et al., 2019a; Wang et al., 2018). Indeed, diverse products formed through different pathways can largely affect the properties of hydrochar. To broadly evaluate the characteristics and the sustainable applications of hydrochar, it is necessary to investigate how process parameters govern the mechanisms of hydrochar formation.

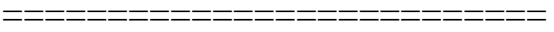

Please Insert Fig. 4 Here 
2.3. Process parameters governing hydrochar

\subsubsection{Initial solids or moisture content}

As the reaction medium, water under HTP conditions principally contributes to the cleavage of hydrogen bonds, especially hydrolysis, due to ionic or free-radical reactions favored by dramatically enhanced water properties (Wang et al., 2019a). The amount of water in feedstock represents a key factor in affecting the reaction pathways and product distribution. Generally, MS with higher initial solid content in HTP exhibits higher hydrochar yield. Xu and Lancaster (2008) reported a higher hydrochar yield when the solid content of feedstock (secondary pulp/paper sludge) increased from $4.8 \mathrm{wt} \%$ to 16.7 wt $\%$ under HTL treatment $\left(280^{\circ} \mathrm{C}\right.$ for $\left.60 \mathrm{~min}\right)$. A decrease in biocrude and an increase in gas were also observed. They indicated that low moisture could restrict the solvolysis/hydration of lignocellulosic compounds and resulted in a higher yield of hydrochar. High solid content may also promote the dehydration reactions of the intermediates/products during HTP and thus enhance the yield of heavy oil fractions (Xu and Lancaster, 2008). Xu et al. (2012) suggested more carbon conversion into hydrochar with the decrease of MS moisture from $94.4 \mathrm{wt} \%$ to $76.2 \mathrm{wt} \%$ under supercritical water conditions $\left(400{ }^{\circ} \mathrm{C}\right.$ for $60 \mathrm{~min}$ ), while no remarkable changes were found on total organic matter conversion to aqueous and gas products. Such enhancement in hydrochar yield could be attributed to devolatilization of biomass or early polymerization when the moisture content is low (Gong et al., 2014a; Karayıldırım et al., 2008; Xu et al., 2012). Wang et al. (2019) also indicated that increased moisture content (82-90\%) promoted the hydrolysis of MS biomass to produce water-soluble organics and suppressed tar and char formation under supercritical conditions $\left(400{ }^{\circ} \mathrm{C}\right.$ for $\left.30 \mathrm{~min}\right)$. Aragón-Briceño et al. (2020) found that increasing solids content (2.5 to $30 \mathrm{wt} \%)$ of DS for HTC treatment $\left(250{ }^{\circ} \mathrm{C}\right.$ for $\left.30 \mathrm{~min}\right)$ gradually enhanced yield (68 to $76 \%$, db), HHV (15.4 to $16.5 \mathrm{MJ} / \mathrm{kg}$ ), and energy recovery (65.9 to $76.7 \%$ ) of hydrochar; it also increased $\mathrm{pH}$, organics, ammonia, total phosphorus, total solids, and total carbon contents in HTC aqueous. From the engineering perspective, using a high solids content (10-25 wt $\%$ ) of feedstock for HTP is critical to enhance the process energy efficiency, achieve net positive energy 
recovery, and improve concentrations of nutrients (e.g., $\mathrm{N}$ and $\mathrm{P}$ ) in hydrochar and aqueous phase to allow efficient recovery.

\subsubsection{Temperature, pressure, and residence time (severity factor)}

Reaction temperature and pressure are the governing parameters of HTP as they control the water state and thus essentially determine the reaction mechanisms. When temperature and pressure are both above the critical point, reaction mechanism alters from ionic in subcritical condition to free-radical reactions under supercritical condition (He et al., 2014a). However, at full-scale with a continuous flow system (often configured as plug flow), pressure is mostly formed autogenously and not controlled but only monitored. To date, no one has systematically studied the impact of pressure on the HTP of MS. Several reviews have suggested that pressure has no major effects on the product distribution from HTP when conditions are within the subcritical or supercritical zone (Gu et al., 2020; Ibrahim and Akilli, 2019). Therefore, the effect of pressure is not further discussed in this review.

From the thermodynamic viewpoint, the degradation of organic macromolecules and recombination of chemical bonds require a significant amount of energy, and therefore temperature is a crucial and limiting factor for HTP treatment. When insufficient energy is provided at low temperatures, the reaction of HTP is often restricted to hydrolysis, while higher temperatures can promote subsequent reactions. The reported optimal temperature range for thermal hydrolysis of MS is $160-180{ }^{\circ} \mathrm{C}$ (Barber, 2016). It is also suggested that carbohydrates and proteins can be hydrothermally decomposed at above $180^{\circ} \mathrm{C}$, while lignin requires higher temperatures $\left(280-500{ }^{\circ} \mathrm{C}\right)$ for degradation (He et al., 2013). The complete decomposition of proteins and lipids also requires high temperatures (300 and $640{ }^{\circ} \mathrm{C}$, respectively). Under the subcritical conditions, a competition between depolymerization and polymerization occurs with increasing temperature and residence time. However, when temperature is above $375^{\circ} \mathrm{C}$, reactions are heavily shifted to the free radical mechanism, including water-gas shift reaction (Watson et al., 2020). Therefore, the yield of gaseous products $\left(\mathrm{CO}_{2}, \mathrm{CO}, \mathrm{H}_{2}\right.$, and alkane gases) can be significantly enhanced.

The distribution of products from HTP is affected by both temperature and residence time to the ultimate extent. To analyze the collective effects of temperature and residence time, a combined 
parameter, the concept of severity factor was developed by Ruyter (1982). The calculation of severity factor (f, dimensionless) in terms of reaction temperature ( $\mathrm{T}$, in Kelvin) and residence time ( $\mathrm{t}$, in seconds) is expressed in Eq. (2):

$$
f=50 t^{0.2} \exp ((-3500) / T)
$$

Fig. 5 illustrates the distribution of HTP products as a function of severity factor from numerous studies. The figure demonstrates that the hydrochar yield significantly decreases with an increase in the reaction severity up to a certain extent. Some variations can be attributed to the use of solvents (e.g., methanol, ethanol, and acetone) and MS compositions (e.g., high ash content) (Huang et al., 2014; Li et al., 2012). Enhanced severity for HTC treatment could promote the decarboxylation process and improve hydrochar quality (e.g., HHV increase and O reduction), but the overall energy recovery of hydrochar may be decreased due to lower yields (Gaur et al., 2020). After a certain severity factor is reached at supercritical water conditions, the hydrochar yield remains around $10 \%$. The reason for this trend is because hydrochar can be converted into other phases at higher reaction severities. Hydrochar tends to accumulate at a low severity factor. It is worth noting that the maximum biocrude yield can be achieved at a point of severity (around 0.5-1) where hydrochar, gas, and aqueous byproducts are all minimized when aiming for an energy-condensed product. A previous study noted that lower hydrochar yields and higher syngas yields with the intensified reaction severity when temperature increased from $170{ }^{\circ} \mathrm{C}$ to $500{ }^{\circ} \mathrm{C}$ for HTP of DS (Ekpo et al., 2016). Qian et al. (2020) studied HTL of primary sludge at various severities. They proposed two possible phases during the HTL: First is the conversion of solids in the PS into biocrude and aqueous phase products, which are then converted to volatiles and gas. The rapidly reduced yield of hydrochar probably resulted from cell rupture and hydrolysis of PS that occurred within several minutes at $300{ }^{\circ} \mathrm{C}$. The hydrochar yield remained constant near the end $(10.8 \mathrm{wt} \%)$ when it reached the ash content in the feedstock (10.3 wt\%) (Qian et al., 2020). Tasca et al. (2019) suggested that condensation of a carbonaceous matrix occurred at higher reaction severity (i.e., higher reaction temperature and residence time), while lower severity did not favor the formation of highly condensed 
aromatic structure. It is also indicated that humus and protein are the main precursors of hydrochar produced at $300-400{ }^{\circ} \mathrm{C}$ (Wang et al., 2019).

Please Insert Fig. 5 Here

\subsubsection{Heating rate}

Heating rate is another parameter that can affect the HTP products. Mostly a high heating rate can favor the destruction of biomass and inhibit the formation of hydrochar. Wang et al. (2019) studied the effects of heating rate $\left(8-50^{\circ} \mathrm{C} / \mathrm{min}\right)$ on the $\mathrm{HTG}$ of $\mathrm{MS}\left(400{ }^{\circ} \mathrm{C}\right.$ for $\left.30 \mathrm{~min}\right)$. Lower yields of char, tar, and water-soluble phase on a carbon basis were observed with higher heating rates. It was suggested that a reduced heating rate could cause a longer reaction period at lower temperatures, which would promote the formation of hydrochar because of insufficient decomposition. However, no effects on gas yield (carbon basis) were reported (Wang et al., 2019). Gong et al. (2018) investigated the effects of both heating rate $\left(3-20^{\circ} \mathrm{C} / \mathrm{min}\right)$ and cooling rate $\left(18-50^{\circ} \mathrm{C} / \mathrm{min}\right)$ on the formation of PAHs at the reaction temperature of $400{ }^{\circ} \mathrm{C}(24 \mathrm{MPa})$ and residence time of $0 \mathrm{~min}$. Total PAHs decreased in both liquid and solid phases with faster heating and cooling. It was also observed that low heating $\left(\leq 6{ }^{\circ} \mathrm{C} / \mathrm{min}\right)$ and cooling rate $\left(\leq 28^{\circ} \mathrm{C} / \mathrm{min}\right)$ promoted the formation of 6-ring PAHs, while more light fractions of PAHs (2-ring and 3-ring) were formed under higher heating and cooling rate (Gong et al., 2018). However, the impacting mechanisms of heating rate have not been clarified in detail. It is generally assumed that slow heating could enhance the reactions of re-polymerization, condensation, oligomerization, etc., and therefore promote the production of hydrochar.

\subsubsection{Co-processing of municipal sludge}

Co-processing of MS with other types of biomass using HTP has attracted much interest recently. It plays the role of utilizing various waste biomass for energy conversion, reforming the properties of feedstock, modifying the yield and quality of products, and creating synergistic effects. Table 3 
summarizes research works on co-HTP of MS with different biomass. The co-processing has been studied for producing energy-condensed hydrochar, biocrude, and syngas via co-HTC, co-HTL, and co-HTG, respectively.

Please Insert Table 3 Here

Most coprocessing studies for MS were done under HTC conditions. It was reported that co-HTC $\left(220{ }^{\circ} \mathrm{C}\right.$ for $12 \mathrm{~h}$ ) of MS with peanut shell could improve HHV and hydrophobicity of the corresponding hydrochar, compared to HTC of MS only (He et al., 2019). Such hydrochar showed a more stable and durable combustion profile. Synergistic decarboxylation and favorable aromatization were reported during the co-HTC process (He et al., 2019). Kim et al. (2017) also suggested that there were enhanced dehydration and decarboxylation reactions for co-HTC of DS with peat. It was indicated that waste biomass with abundant cellulose and lignin could promote decarboxylation, dehydration, and demethylation during the co-HTC with DS (Zhai et al., 2017). Several researchers have also conducted co-HTL of MS with lignocellulosic and microalgae. Some studies found synergistic effects with a higher yield of biocrude and better energy recovery from co-HTL of PS or other MS with lignocellulose compared to individual feedstock (Biller et al., 2018; Leng et al., 2018). It was implied that the cause might be from interactions between the intermediates from MS and lignocellulosic biomass during coprocessing (Leng et al., 2018). However, Huang et al. (2019) did not observe synergistic effects on biocrude yield or conversion rate by co-HTL of MS with rice straw or wood sawdust, probably due to the low contents of protein and lipid in MS. The addition of microalgae in co-HTL with MS was also reported to have beneficial synergistic effects on biocrude yield (Mishra and Mohanty, 2020; Xu et al., 2019). It seems that co-HTL could promote the production of low-boiling fractions in biocrude (Huang et al., 2019; Mishra and Mohanty, 2020). Co-HTG of MS with other biomass seems to lack research interest. To date, only Xu and Antal (1998) studied the co-gasification of DS with corn starch at $340{ }^{\circ} \mathrm{C}$ in the 
presence of a catalyst (coconut shell activated carbon). However, no clear results could be obtained to conclude if there were synergistic effects during the co-HTG.

In summary, co-processing of MS with other types of biomass generally provides synergistic effects on produced hydrochar or biocrude. However, such effects rely on the chemical compositions of the feedstocks and hydrothermal conditions. Co-HTP also creates a novel strategy to overcome the drawbacks of different biomass. For example, adding wood biomass could improve the concentrations of biomass in MS and thus enhance the conversion rate. It is believed that co-HTP of various biomass is beneficial over HTP of individual feedstock. Nevertheless, the mechanisms behind the co-HTP are very limited due to the lack of systematic studies. Therefore, more investigation on chemical interactions during the co-HTP should be performed, which would provide a road map for future process design and optimization.

\subsubsection{Catalyst}

To optimize the yield and quality of featured products and facilitate the conversion rate, various catalysts have been applied to the HTP of MS. A comprehensive summary of recent studies conducted with different catalysts is presented in Table 4. As shown in the table, catalysts applied to HTP of MS include but are not limited to inorganic and organic acids, bases, mineral salts, metal oxides, activated carbon, $\mathrm{Ni}$, and $\mathrm{H}_{2} \mathrm{O}_{2}$.

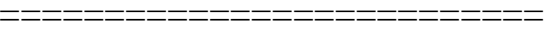

Please Insert Table 4 Here

Generally, an acidic environment could promote the hydrolysis, deamination, and dehydration of MS during HTP, while alkaline catalysts mainly facilitate water-gas shift reaction, denitrogenating, and capturing $\mathrm{CO}_{2}$ under supercritical water conditions (Becker et al., 2019; Gong et al., 2014b; Liu et al., 2020; Zhai et al., 2013). Alkali, as well as other bases, such as ammonia, can catalyze the condensation reactions (Aldol) to produce aromatic compounds from lighter oxygenates, while acid catalyzes the formation of char from carbohydrates. Also, Chen et al. (2020) suggested that an acid environment of 
HTC could promote the protonation effect and enhance structural stability of SS-derived hydrochar with diverse morphology, showing a high removal rate (84\%) of phenols for adsorption. Liu et al. (2020) found that ash content tended to decrease in hydrochar with the increase of initial $\mathrm{pH}$ by adding $\mathrm{KOH}$ during the HTC treatment $\left(270{ }^{\circ} \mathrm{C}\right.$ for $\left.2 \mathrm{~h}\right)$. However, $\mathrm{Li}$ et al. (2017) found that raising initial $\mathrm{pH}(9-11)$ by $\mathrm{Ca}(\mathrm{OH})_{2}$ increased ash content in hydrochar $\left(160^{\circ} \mathrm{C}\right.$ for $\left.1 \mathrm{~h}\right)$, possibly due to enhanced mineral precipitation. An acidic environment was found to promote the production of fatty substances, while the formation of $\mathrm{N}$-containing organic compounds and ketone organics was enhanced at alkaline conditions (Liu et al., 2020). The addition of $\mathrm{K}_{2} \mathrm{CO}_{3}$ could increase biocrude yield and energy recovery from SS under both subcritical $\left(350{ }^{\circ} \mathrm{C}\right.$ for $\left.15 \mathrm{~min}\right)$ and supercritical $\left(400{ }^{\circ} \mathrm{C}\right.$ for $15 \mathrm{~min}$ ) conditions (Shah et al., 2020). However, several studies of $\mathrm{HTL}$ and $\mathrm{HTG}$ have stated that adding $\mathrm{Na}_{2} \mathrm{CO}_{3}$ or $\mathrm{K}_{2} \mathrm{CO}_{3}$ had no significant effects on the quality or yield of biocrude (Suzuki et al., 1988; Suzuki and Nakamura, 1989; Wang et al., 2013). This could be attributed to the high alkalinity of MS, as shown in Table 2. Regardless of the initial reaction $\mathrm{pH}(2-12)$, the nearly neutral $\mathrm{pH}$ of hydrochar also suggested the high buffering capacity of MS (Liu et al., 2020; Wang et al., 2017).

The change of initial $\mathrm{pH}$ by acid or alkaline catalysts could also affect the species of nutrients and heavy metals during HTP. Decreased pH could transform organic phosphorus (OP) to inorganic phosphorus (IP), and apatite phosphorus (AP) to non-apatite inorganic phosphorus (NAIP), while increased pH can foster the precipitation of P during HTC (Shi et al., 2019; Wang et al., 2017; Xu et al., 2018). Studies have suggested using hydrochloric acid $(\mathrm{HCl})$ and sulfuric acid $\left(\mathrm{H}_{2} \mathrm{SO}_{4}\right)$ to solubilize $\mathrm{N}$ and P in HTP aqueous phase, which can be subsequently recovered as fertilizer (e.g., struvite) by precipitation under alkaline conditions (Aragón-Briceño et al., 2021a; Shi et al., 2019). Nevertheless, the high acid consumption to achieve a low pH (e.g., 1.9) only for the sake of P release would not be economically desirable (Lühmann and Wirth, 2020). Increased pH could immobilize heavy metals in hydrochar from $\mathrm{HTL}\left(320^{\circ} \mathrm{C}\right)$ of MS and therefore reduce the associated ecological risk (Huang et al., 2011). However, an opposite observation of the mobilization of $\mathrm{Cu}$ and $\mathrm{Cr}$ was reported with increasing $\mathrm{pH}$ under $\mathrm{HTC}$ condition $\left(270{ }^{\circ} \mathrm{C}\right.$ for $2 \mathrm{~h}$ ) (Zhai et al., 2016). Other catalysts such as $\mathrm{FeCl}_{3}, \mathrm{Al}(\mathrm{OH})_{3}$, and 
sludge-based activated carbon can also inhibit the migration of heavy metals (Xu and Jiang, 2017; Zhai et al., 2014a).

Mineral salts and oxides have been reported to enhance the hydrothermal conversion of MS.

Combined magnesium citrate and $\mathrm{H}_{2} \mathrm{SO}_{4}$ led to more abundant carboxyl groups $(\mathrm{C}-\mathrm{N}, \mathrm{C}-\mathrm{O}$, and $\mathrm{O}=\mathrm{C}-\mathrm{O})$ in hydrochar from $\mathrm{HTC}\left(260{ }^{\circ} \mathrm{C}\right.$ for $\left.1 \mathrm{~h}\right)$. Using $\mathrm{FeCl}_{3}$ and $\mathrm{Al}(\mathrm{OH})_{3}$ promoted the decomposition and hydrolysis of WAS at $180{ }^{\circ} \mathrm{C}$ (Xu and Jiang, 2017). Adding $\mathrm{CaO}$ facilitated the hydrolysis and deamination of organics and the break of aromatic $(\mathrm{C}-\mathrm{C} / \mathrm{C}-\mathrm{H})$ and anomeric $(\mathrm{C}-\mathrm{H}, \mathrm{C}-\mathrm{O}, \mathrm{O}-\mathrm{C}-\mathrm{O}$, and $\mathrm{C}-$ $\mathrm{N}$ ) bonds at $380{ }^{\circ} \mathrm{C}$ ( $\mathrm{He}$ et al., 2016, 2015a). Besides, the $\mathrm{CaO}$ additive also promoted the formation of aromatic $\mathrm{C}-\mathrm{O}$ and $\mathrm{O}=\mathrm{C}-\mathrm{O}$ (He et al., 2016). However, some catalysts $\left(\mathrm{NiMo} / \mathrm{Al}_{2} \mathrm{O}_{3}, \mathrm{CoMo} / \mathrm{Al}_{2} \mathrm{O}_{3}\right.$, activated carbon felt) showed negative effects on energy recovery in HTL, although HHV values of biocrude were improved compared to non-catalytic runs (Prestigiacomo et al., 2019). Therefore, energy recovery rate should be considered as an important criterion in evaluating the impacts of catalysts.

Nickel catalysts are well reported in the enhancement of gasification efficiency. Numerous studies have demonstrated that increased load of nickel could enhance methane and hydrogen yields as well as carbon gasification ratio significantly under HTG conditions due to the promotion of water-gas shift reaction (Afif et al., 2011; Gong et al., 2014b; Sawai et al., 2014; Wang et al., 2017). Other co-catalysts (e.g., $\mathrm{NaOH}, \mathrm{K}_{2} \mathrm{CO}_{3}$, and $\mathrm{H}_{2} \mathrm{O}_{2}$ ) with $\mathrm{Ni}$ have also been reported to further augment the enhancement. The addition of alkaline catalysts to HTG of MS could further promote the water-gas shift reaction and favor $\mathrm{H}_{2}$ production by seizing $\mathrm{CO}_{2}$ (Gong et al., 2014b). Ni catalyst can effectively decrease the generation of phenols, while $\mathrm{H}_{2} \mathrm{O}_{2}$ can promote the degradation of PAHs to form intermediates (Wang et al., 2017). Therefore, the combination of $\mathrm{Ni} / \mathrm{H}_{2} \mathrm{O}_{2}$ could favor the gasification of intermediates to avoid repolymerization to new PAHs. $\mathrm{NaOH}$ and $\mathrm{H}_{2} \mathrm{O}_{2}$ catalysts could also inhibit the formation of char and tar, and thus relieve the fouling of Ni catalysts caused by char (Sawai et al., 2014; Wang et al., 2019). However, adding certain $\mathrm{H}_{2} \mathrm{O}_{2}$ alone would dramatically reduce the yield of combustible gases $\left(\mathrm{H}_{2}, \mathrm{CO}\right.$, and $\mathrm{CH}_{4}$ ) to 0, even though it can achieve the carbon gasification efficiency of 90\% (Qian et al., 2015). One significant drawback of Ni catalysts is their pricy cost and deactivation with service time. It has been 
reported that their catalytic performance is degraded with time due to sulfur fouling and surface deposition of char and tar (Sawai et al., 2014). Therefore, future studies should not just focus on the efficiency of catalysts but also on enhancing their reusability.

From the gathered remarks from HTP studies, catalysts have shown outstanding effects on the reactions in MS treatment. However, detailed reaction pathways caused by various catalysts are still limited. Given the complex compositions of MS, such as high alkalinity and diverse minerals and heavy metals, it is worth investigating the particular mechanism of each potential catalyst. Synergetic effects of co-catalysts are promising to enhance their performance and durability and therefore demand further exploration. It is also more reasonable to incorporate the energy recovery rate into the evaluation criteria.

\subsubsection{Solvent or co-solvent}

Noticeably, most solvents or co-solvents (solvent mixed with water) applied to HTP of MS were for the liquefaction and the production of biocrude. Table 5 summarizes HTP studies that utilized organic solvents as reaction media in MS treatment. The studied solvents include acetone, ethanol, methanol, and n-hexane. It has been demonstrated that the application of solvents or co-solvents could moderate the reaction conditions and enhance the yield and/or caloric value of biocrude at lower reaction temperatures.

Please Insert Table 5 Here

There are several advantages of utilizing solvents in HTP. Firstly, the critical points of these organic solvents are much lower than water and, therefore, can depolymerize biomass at milder temperature and pressure conditions (Perkins et al., 2019). For acetone, ethanol, methanol, and n-hexane, their critical temperatures are $234.9,243.1,239.5$, and $234.5^{\circ} \mathrm{C}$, respectively, while their critical pressures are $4.8,6.3$, 8.1, and 3.0 MPa, respectively. Secondly, organic solvents could dissolve liquefied products with highmolecular-weight more easily than using pure water due to the lower dielectric constants (Lai et al., 2018). Thirdly, polar solvents (e.g., ethanol and methanol) can donate active hydrogen and facilitate the free 
radical and dehydration reactions (Huang et al., 2014). Thus, the produced biocrude would have lower oxygen content. However, when using dipolar solvents, such as acetone, the dehydration reactions are mainly responsible for the deoxygenation process (Leng et al., 2015a). Lastly, using ethanol or methanol can convert acidic components into esters through esterification reaction, and therefore enhance the biocrude quality (Huang et al., 2013). However, the biocrude obtained with acetone is primarily consisted of ketones and $\mathrm{N}$-containing compounds with relatively low calorific values (e.g., $26.7 \mathrm{MJ} / \mathrm{kg}$ ), although acetone treatments consistently lead to higher biocrude yields (Huang et al., 2014; Leng et al., 2015a).

Beneficial synergistic effects of ethanol-water co-solvents on biocrude yield and energy recovery have been reported (Lai et al., 2018). Li et al. (2010) also found that increasing ethanol-water ratios could improve the yield and reduce the O contents of biocrude. However, Prajitno et al. (2018) pointed out that the addition of solvents should be counted for the enhancement since solvents were consumed during the HTL treatment. Therefore, solvents should be considered in the feedstock when calculating yield and energy conversion. Besides, ethanol-water co-solvent could also promote the production of esters (69.1\%) in biocrude compared to pure ethanol (57.4\%) and pure water (43.3\%) HTL (220 ${ }^{\circ} \mathrm{C}$ for $30 \mathrm{~min}$ ) (Lai et al., 2018). This improvement may be attributed to combined ionic, polar non-ionic, and free-radical reactions.

Indeed, the utilization of organic solvents or co-solvents in HTP of MS has significant impacts on the reaction mechanisms. However, the biggest barriers are the industrial implementation and the recovery and recycle of solvents, which requires further validation and investigation. The other consideration is that the higher quality of reactor material may be required due to the supercritical conditions created by solvents. It has been observed that the corrosion of the reactor wall (316 stainless steel) can be caused by supercritical ethanol at 300 and $350{ }^{\circ} \mathrm{C}$ (Chen et al., 2014). Lastly, there are limited studies about the influence of organic solvents on MS-derived hydrochar. Consequently, to comprehensively understand the effects of solvents and evaluate the potential utilization of the corresponding hydrochar, more research should be conducted in hydrochar characterization. 


\section{Characterization of hydrochar}

Diverse MS properties and hydrothermal conditions would result in a hydrochar with various physical and chemical characteristics. It is of critical significance to characterize MS-derived hydrochar since the properties of hydrochar essentially determine its potential applications.

\subsection{The proximate and ultimate analyses}

The proximate and ultimate analyses have been widely applied to the characterization of solid fuels, such as coal. These analyses are also frequently utilized for evaluating the potential use of hydrochar as a fuel resource. The proximate analysis measures the contents of ash, VM, and FC by recording the mass change of hydrochar while heating at high temperatures. Mostly used methods include the American Society for Testing and Materials (ASTM) D3174 (for ash), D3175 (for VM), and D7582 (for proximate analysis) (Danso-Boateng et al., 2015; He et al., 2014b; Lee et al., 2019). FC is usually estimated by calculating the difference between sample mass and ash and VM contents. The ultimate analysis of $\mathrm{C}, \mathrm{H}$, $\mathrm{N}$, and $\mathrm{S}$ can be determined using an elemental analyzer, while $\mathrm{O}$ content is typically estimated by the difference between sample mass and contents of C, H, N, S, and ash (Zheng et al., 2019). The ASTM D5373 can be referred to as a standard method for the ultimate analysis.

Fig. 6a summarizes the physicochemical properties of MS-derived hydrochar reported in numerous studies. Detailed data and reaction conditions of selected studies are presented in Table 6. Due to the heterogeneous nature of MS and substantial range of hydrothermal conditions, the corresponding hydrochar exhibits properties with large varieties. Most studies (80\%) reported hydrochar with ash, VM, FC, and HHV values of $29.3-79.6 \%, 14.2-63.3 \%, 1.1-13.3 \%$, and $3.9-18.9 \mathrm{MJ} / \mathrm{kg}$ on a dry basis, respectively. It seems that high HTP temperatures (e.g., $>280{ }^{\circ} \mathrm{C}$ ) generally cause very high contents, low carbon, low VM, and low HHV in hydrochar. Apart from ash, MS-derived hydrochar is comprised of $12-$ $44.3 \% \mathrm{C}, 1.7-5.6 \% \mathrm{H}, 4.6-25.1 \% \mathrm{O}, 0.9-4.6 \% \mathrm{~N}$, and $0.2-1.7 \% \mathrm{~S}$ on a dry basis. Many studies also reported that the $\mathrm{pH}$ of hydrochar was around neutral (5.8-7.6), with an average of 6.6, regardless of the initial $\mathrm{pH}$ prior to the reaction. Fig. $6 \mathrm{~b}$ compares properties of $\mathrm{MS}$ to its derived hydrochar based on the sludge type used in HTP. For DS, PS, and SS, the derived hydrochar tends to have relatively lower C, 
while hydrochar derived from mixed primary and secondary sludge (MPS) has higher C probably due to mild reaction temperatures (mostly $<280{ }^{\circ} \mathrm{C}$ ) and relatively low ash contents in MPS (averagely $31.2 \%$, db). Regardless of sludge type, hydrochar tends to have lower $\mathrm{H}, \mathrm{O}, \mathrm{N}$, and VM but higher ash contents, while S remains at a similar level to those in MS. Such changes could be caused by the dehydration, decarboxylation, and decomposition of organic matter (e.g., protein), dissolution of low-molecular components, and the transformation into organic vapors or gaseous products. Wang et al. (2020) suggested that nearly $90 \%$ of S in SS after HTP $\left(180-300{ }^{\circ} \mathrm{C}\right)$ remained in hydrochar, and increasing temperature reduced $\mathrm{S}$ in hydrochar and aqueous phase (mainly sulfate) and enhanced gaseous $\mathrm{S}$ formation (e.g., $\mathrm{SO}_{2}$ and $\mathrm{H}_{2} \mathrm{~S}$ ). $\mathrm{FC}$ represents the stable components of char, which increases with the rank of coal. Interestingly we found that average FC contents in hydrochar derived from PS, SS, and MPS all decreased, but it increased in DS-derived hydrochar. Regarding the energy density, PS, SS, and MPS could be good candidates for their relatively high C, VM, and HHV but low ash contents, while SS may lead to high S contents in hydrochar (averagely $1.2 \%, \mathrm{db}$ ). Therefore, combining DS with PS/SS for HTC treatment could potentially produce high-quality coal-like hydrochar. It should also be noted that HTP conditions could largely affect the properties of hydrochar. Fig. 6c compares properties of hydrochar by HTP types. It is found that the properties (mean) in the feedstock MS are at the similar levels, but they are quite different in the derived hydrochar from HTC vs. HTL/HTG. Generally, high reaction temperatures in HTL and HTG intensify the dehydration, decarboxylation, deamination, and decomposition reactions, which lead to further reduction of $\mathrm{C}, \mathrm{H}, \mathrm{O}, \mathrm{N}$, and $\mathrm{VM}$ and increase of remaining ash. HTL and HTG minimize the HHV of hydrochar because most $\mathrm{C}$ is distributed into biocrude and syngas, respectively. Cyclization, aromatization, and re-polymerization are responsible for the enhanced FC due to the formation of stable carbon. Lee et al. (2019) observed that increasing temperature from 180 to $270{ }^{\circ} \mathrm{C}$ decreased the contents of $\mathrm{C}, \mathrm{O}, \mathrm{N}$ and VM, but increased ash and FC values of PS-derived hydrochar, with an HHV of 16.68-19.70 MJ/kg. Wang et al. (2019) also reported the same inclination when reaction temperature increased from 170 to $350{ }^{\circ} \mathrm{C}$. However, the corresponding hydrochar had a fairly low $\mathrm{HHV}$ 
of 3.27-4.77 MJ/kg. It should be noted that the raw MS used by Lee et al. had an initial HHV of 19.68 $\mathrm{MJ} / \mathrm{kg}$, compared to only $5.53 \mathrm{MJ} / \mathrm{kg}$ used by Wang et al. Therefore, the properties of hydrochar are highly dependent on the characteristics of the corresponding MS and HTP conditions. Therefore, the usage of hydrochar will be dependent on how it is formed and the resulted compositions.

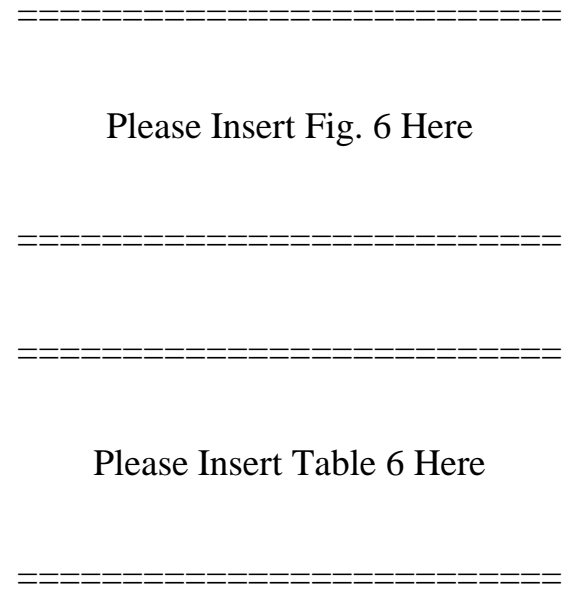

With the determination of $\mathrm{C}, \mathrm{H}$, and $\mathrm{O}$, the atomic ratios of $\mathrm{H} / \mathrm{C}$ and $\mathrm{O} / \mathrm{C}$ are commonly calculated to evaluate the transformation of biomass during the HTP treatment. Specifically, the van Krevelen diagram is graphed to assist the evaluation, where anthracite, coals, lignite, and peat could be applied to compare the coalification extent of hydrochar. Fig. 7 displays the $\mathrm{H} / \mathrm{C}$ and $\mathrm{O} / \mathrm{C}$ ratios of $\mathrm{MS}$ and its derived hydrochar reported by numerous studies. Generally, these ratios are lower in hydrochar than in original MS, and the $\mathrm{H} / \mathrm{C}$ ratio is much higher than $\mathrm{O} / \mathrm{C}$ of hydrochar. This indicates that the reaction pathway of HTP is predominantly regulated by dehydration, followed by decarboxylation, while demethylation is mostly minor (Wang et al., 2018). These reactions can enhance the performance of hydrochar by removing oxygen. Low ratios of $\mathrm{H} / \mathrm{C}$ and $\mathrm{O} / \mathrm{C}$ also suggest high aromaticity of hydrochar (Zhuang et al., 2018). Wang et al. (2019b) studied the impacts of reaction severity on $\mathrm{H} / \mathrm{C}$ and $\mathrm{O} / \mathrm{C}$ ratios and found a strong correlation between the reduction of both ratios and the increase of severity factor $\left(120-300{ }^{\circ} \mathrm{C}\right.$ for 30-180 min). Due to the decarboxylation process in $\mathrm{HTP}, \mathrm{CO}_{2}$ has been reported as the major gas phase under subcritical conditions. However, it should be noted that there is a lack of study on the properties of hydrochar obtained at supercritical conditions. It has been observed that HTC temperatures of 150- 
$280{ }^{\circ} \mathrm{C}$ could generate desirable $\mathrm{H} / \mathrm{C}$ and $\mathrm{O} / \mathrm{C}$ ratios of hydrochar derived from all types of sludge close to the quality of lignite and coal, while higher HTL/HTG temperatures may lead to very low H/C but high $\mathrm{O} / \mathrm{C}$ values.

Please Insert Fig. 7 Here

3.2. Distribution of macronutrients in hydrochar

Macronutrients are abundantly distributed in hydrochar, such as $\mathrm{N}, \mathrm{P}, \mathrm{Na}, \mathrm{K}, \mathrm{Al}, \mathrm{Ca}, \mathrm{Fe}$, and $\mathrm{Mg}$. Their distributions are closely related to the compositions of MS. Fig. 8a illustrates the percentage of each element distributed in hydrochar from various studies (it is noted that some data were over 100\% probably due to experimental errors). Basically, all macronutrients have shown large variations in terms of their presence in MS-derived hydrochar. However, most studies have displayed that $\mathrm{P}(>82 \%), \mathrm{Al}$ (>86\%), $\mathrm{Ca}(>80 \%), \mathrm{Fe}(>72 \%)$, and $\mathrm{Mg}(>82 \%)$ incline to accumulate in hydrochar, while $\mathrm{N}(\sim 39 \%), \mathrm{Na}$ ( 42\%), and $\mathrm{K}(\sim 52 \%)$ seem not. The majority of $\mathrm{C}$ could also be distributed to hydrochar, but it can be significantly reduced by increased $\mathrm{HTP}$ temperature (e.g., $>280^{\circ} \mathrm{C}$ ). It is known that $\mathrm{Al}, \mathrm{Ca}, \mathrm{Fe}$, and $\mathrm{Mg}$ have strong affinity with P, which would form mineral phosphate precipitates during HTP treatment. Therefore, the concentrations of most macronutrients in hydrochar could be significantly increased compared to the substrate (MS). Considering the substantial mass loss of solids after HTP, the total contents of N, Na, and $\mathrm{K}$ would not decrease much but may even increase (Zhang et al., 2014). However, Zhang et al. (2014) discovered that HTP at 190 and $260^{\circ} \mathrm{C}$ could essentially inhibit the bioavailability of $\mathrm{N}, \mathrm{P}$ and $\mathrm{K}$. The concentrations of extractable $\mathrm{NH}_{4}{ }^{+}-\mathrm{N}$ (by $2 \mathrm{M} \mathrm{KCl}$ ), $\mathrm{NO}_{3}{ }^{-}-\mathrm{N}$ (by $2 \mathrm{M} \mathrm{KCl}$ ), $\mathrm{P}$ (by $0.5 \mathrm{M}$ $\mathrm{NaHCO}_{3}$ ), and $\mathrm{K}$ (by $1 \mathrm{M} \mathrm{NH}_{4} \mathrm{OAC}$ ) in hydrochar reduced by over $1,8,8$, and 9 times, respectively, compared to those in MS. The low availability of these nutrients in hydrochar may enhance its behaviors as soil nutrients due to the extended durability. 
Please Insert Fig. 8 Here

As shown in Fig. 8b, the concentrations of macronutrients seem to remain unchanged or increase in hydrochar compared to its original MS. P and Ca exhibit the largest variety in hydrochar with a content range of $0.14-8.1 \%$ and $0.3-22 \%$ on a dry basis, respectively. Most reported ranges of each nutrient in hydrochar are also identified: $\mathrm{Al}(0.3-3.5 \%), \mathrm{Ca}(0.4-4.8 \%), \mathrm{Fe}(0.3-4.2 \%), \mathrm{K}(0.2-0.8 \%), \mathrm{Mg}(0.3-$ $1.3 \%), \mathrm{Na}(0.03-0.4 \%)$, and P $(0.7-5.3 \%)$ on the dry basis. In most cases, SS and DS and their derived hydrochar could have above mean levels of $\mathrm{Al}, \mathrm{Fe}, \mathrm{Mg}$, and P in reported MS. High concentrations of cations could provide hydrochar with adsorption ability for cationic pollutants due to cation exchange (Leng et al., 2015b). The hydrochar with the highest concentration of $\mathrm{P}(8.1 \%$, db) was reported from the HTC of WAS (initial P of $4.1 \%$, db) at $225^{\circ} \mathrm{C}$ for $16 \mathrm{~h}$ (Huang and Tang, 2016). Such hydrochar with high contents of $\mathrm{P}$ could be a promising candidate for fertilizer or nutrient recovery. To further evaluate the nutrient values of hydrochar, atomic ratios of $\mathrm{N}: \mathrm{P}$ versus $\mathrm{C}: \mathrm{N}$ and $\mathrm{N}: \mathrm{P}$ versus $\mathrm{C}: \mathrm{P}$ are plotted in Fig. 9. It appears that most hydrochar has high C:N $(>10)$ but low N:P $(<10)$ ratios (Fig. 9a), which signifies its potential as P-rich fertilizer (Huang et al., 2018). In some cases, hydrochar can also have high C:P (>100) and N:P ( 9) ratios (Fig. 9b), representing a potential N-rich fertilizer (Huang et al., 2018).

Please Insert Fig. 9 Here

\subsection{Contaminants of concern}

Due to the heterogeneous nature of MS, the ultimate destiny of its derived hydrochar is not clear. It has been found that thermal treatment can cause some contaminants to remain in hydrochar. Mostly 
reported contaminants of concern include heavy metals and persistent organic pollutants (POPs), such as PAHs, PCBs, polychlorinated dibenzo-dioxins/-furans (PCDD/Fs) as well as pharmaceuticals.

\subsubsection{Heavy metals}

Heavy metals are known to accumulate in the environment and food chain for their nonbiodegradability. Many municipalities (e.g., British Columbia in Canada) have regulated their concentrations when using stabilized and dewatered MS (biosolids) for land application as fertilizer. Owing to the common presence and toxicity of heavy metals, Canada, the European Union (EU), and the US have implemented criteria for $\mathrm{As}, \mathrm{Cd}, \mathrm{Cr}, \mathrm{Co}, \mathrm{Cu}, \mathrm{Hg}, \mathrm{Mo}, \mathrm{Ni}, \mathrm{Pb}, \mathrm{Se}$, and $\mathrm{Zn}$ (Table 7). These limits should also be adopted for MS-hydrochar before a specific guideline is formed. Table 7 summarizes the total concentration of each heavy metal in MS-derived hydrochar reported in Canada, China, Japan, the $\mathrm{EU}$, and the US. It demonstrates that $\mathrm{Cr}, \mathrm{Cu}, \mathrm{Hg}, \mathrm{Ni}$, and $\mathrm{Zn}$ are found to exceed the land application criteria, while the data of Se are lacking. Previous studies have verified that most heavy metals are concentrated in hydrochar compared to other products from HTP of MS. Fig. 10a compares the total concentrations of commonly found heavy metals in various types of MS and the corresponding hydrochar. It is observed that all MS samples show low mean levels of As, Cd, Co, and Mo, with slightly lower or unchanged concentrations in hydrochar. However, the average contents of $\mathrm{Cr}, \mathrm{Cu}, \mathrm{Ni}$, and $\mathrm{Zn}$ could be sustainably raised in hydrochar compared to the original MS. A previous study ranked the accumulation rate of heavy metals in hydrochar in the following order: $\mathrm{Zn}>\mathrm{Cu}>\mathrm{Cr}>\mathrm{Ni}>\mathrm{Pb}>\mathrm{As}>\mathrm{Hg}>\mathrm{Cd}(\mathrm{L}$. Wang et al., 2019b). Particularly, concerning amount of heavy metals could be present in hydrochar derived from PS ( $\mathrm{Cu}, \mathrm{Ni}$, and $\mathrm{Zn}), \mathrm{SS}(\mathrm{Cr}, \mathrm{Cu}, \mathrm{Hg}, \mathrm{Ni}, \mathrm{Pb}$, and $\mathrm{Zn}), \mathrm{MPS}(\mathrm{Cu}$ and $\mathrm{Hg}$ ), and DS (Cu, $\mathrm{Hg}$, and $\mathrm{Ni}$ ), which should attract more attention.

Please Insert Table 7 Here 
Please Insert Fig. 10 Here

Besides the measurement of total metals, chemical species and leachability are commonly used to determine the mobility and toxicity of heavy metals (Chen et al., 2020; Shao et al., 2020). The chemical speciation of heavy metals has been widely used to evaluate the mobility and bioavailability to the environment and biosphere, while the leaching characteristics can reflect the stability of heavy metals under extreme environmental conditions. To determine the chemical speciation of heavy metals in hydrochar, sequential extraction procedures (SEPs) developed by Tessier and the Community Bureau of Reference (BCR) have been adopted (Li et al., 2012; Yuan et al., 2011). According to the Tessier SEPs, heavy metals are classified into five fractions: Exchangeable fraction (F1), carbonate-bound fraction $(\mathrm{F} 2)$, Fe-Mn oxides fraction (F3), organic matter/sulfide fraction (F4), and residual fraction (F5). According to the BCR extraction, heavy metals are categorized into four fractions: Acid soluble fraction (f1), reducible fraction (f2), oxidizable fraction (f3), and residual fraction (f4). Both procedures have identical categories of metal species. Based on the extraction methods, these fractions can be further described as three groups: readily bioavailable $(\mathrm{F} 1+\mathrm{F} 2$ or $\mathrm{f} 1+\mathrm{f} 2)$, potentially bioavailable $(\mathrm{F} 3+\mathrm{F} 4$ or $\mathrm{f} 3)$, and non-bioavailable $(\mathrm{F} 5$ or f4) (Shi et al., 2013).

Fig. 10b illustrates the ternary plot of the fractional distribution of various heavy metals reported in MS and the consequent hydrochar. Most metals (As, $\mathrm{Cd}, \mathrm{Cr}, \mathrm{Cu}, \mathrm{Ni}, \mathrm{Pb}$, and $\mathrm{Zn}$ ) have demonstrated that their readily bioavailable forms can be converted into potentially bioavailable and/or non-bioavailable fractions during the HTP treatment, therefore reducing the toxicity and bioavailability. It also displays that increasing reaction temperature and residence time could further inhibit the bioavailability of heavy metals in hydrochar (Chen et al., 2014; Fei et al., 2019b). However, such a trend seems to be reversed after approaching the critical point of water. Li et al. (2012) found that the readily bioavailable forms of $\mathrm{Cd}, \mathrm{Pb}$, and $\mathrm{Zn}$, as well as their total contents, increased with increasing temperature (from 375 to $400{ }^{\circ} \mathrm{C}$ ). 
$\mathrm{Xu}$ et al. (2011) also reported the readily bioavailable $\mathrm{Cd}, \mathrm{Cr}$, and As dramatically enhanced from $0.7 \%$ to $14 \%, 0.4 \%$ to $3 \%$, and $1.3 \%$ to $12.6 \%$, respectively, after reaction condition raised from subcritical $\left(350{ }^{\circ} \mathrm{C}\right)$ to supercritical $\left(400{ }^{\circ} \mathrm{C}\right)$. Huang et al. $(2021)$ found that HTC treatment $\left(150-275^{\circ} \mathrm{C}\right)$ could transform metals into insoluble sulfides (e.g., $\mathrm{Cu}-\mathrm{Fe}$ - or $\mathrm{Zn}$-Fe-sulfides) and completely reduce high-toxic $\mathrm{Cr}(\mathrm{VI})$ into low-toxic $\mathrm{Cr}(\mathrm{III})$ in hydrochar derived from WAS and DS. Besides, Lu et al. (2021) reported that co-HTC of MS with lignocellulosic biomass (e.g., cellulose, lignin, and xylan) could further promote the immobilization of heavy metals (e.g., $\mathrm{Cr}, \mathrm{Cu}, \mathrm{Ni}$, and $\mathrm{Zn}$ ) along with improved fuel quality of hydrochar. In general, the bioavailability and toxicity of heavy metals are highly reduced after HTP compared to raw MS.

With the availability of characterizing metal fractions, various risk assessment methods are established. The ecological risk index assessment, geo-accumulation index, and risk assessment code have been used to evaluate the risks associated with heavy metals. Detailed explanations have been summarized by Huang and Yuan (2016). By applying these methods, numerous studies have found the overall bioavailability and ecotoxicity of heavy metals in hydrochar are decreased compared to raw MS (Chen et al., 2014; Shao et al., 2015; Shi et al., 2014, 2013; Zhai et al., 2016). Therefore, HTP can be considered as a promising detoxification technology for municipal biosolids.

Toxicity characteristic leaching procedure (TCLP) is another approach to assess the leachability of heavy metals under various conditions (acidic, neutral, and alkaline). The US Environmental Protection Agency (EPA) Method 1311 can be referred to as a standard procedure. Liu et al. found that HTC at $200{ }^{\circ} \mathrm{C}$ for 30 min reduced the leachable amount of $\mathrm{Cd}, \mathrm{Cr}, \mathrm{Cu}, \mathrm{Mn}, \mathrm{Ni}, \mathrm{Pb}$, and $\mathrm{Zn}$ from 0.77, 2.84, 3.1, $154.57,23,11.44$, and $25.39 \mathrm{mg} / \mathrm{kg}$ in digested sludge to $0.26,1.36,0.7,121.34,7.25,10.34$ and 12.58 $\mathrm{mg} / \mathrm{kg}$ in hydrochar, respectively. However, the leachable $\mathrm{Hg}$ slightly increased from 0.2 to $0.3 \mathrm{mg} / \mathrm{kg}$ (Liu et al., 2018b). Fei et al. (2019b) identified the decreased leachability of $\mathrm{Cu}, \mathrm{Ni}$, and $\mathrm{Zn}$ with the increasing reaction temperature of HTP for MPS-derived hydrochar. It was also discovered that HTP had greater inhibition on leachable $\mathrm{Zn}$ than pyrolysis. Shi et al., (2014) obtained a decline of $\mathrm{Cd}, \mathrm{Cr}, \mathrm{Cu}, \mathrm{Ni}$, $\mathrm{Pb}$, and $\mathrm{Zn}$ in the leachate from DS-derived hydrochar with 94\%, 74\%, 97\%, 72\%, 11\%, and 86\%, 
respectively, after $\mathrm{HTC}$ at $280{ }^{\circ} \mathrm{C}$ for $1 \mathrm{~h}$, compared to raw digested sludge. It was also found that hydroxyapatite addition could further reduce the leachability of Cd during the HTC treatment (200 and $280^{\circ} \mathrm{C}$ ) (Shi et al., 2014). Adding $\mathrm{NaOH}$ also showed a reduction in leachable $\mathrm{Cu}$ and $\mathrm{Zn}$ in hydrochar generated at $320{ }^{\circ} \mathrm{C}$ (Huang et al., 2011). In summary, the HTP process has demonstrated effective ways for immobilizing heavy metals and thus reducing the toxicity of hydrochar. However, the challenge is if the abovementioned risks will be changed when hydrochar is applied to soil under potential synergetic effects from the environment. This requires additional efforts to be clarified prior to land utilization.

\subsubsection{Persistent organic pollutants (POPs)}

Many organic compounds have been identified in MS with over 100 pollutants attributed to pharmaceuticals, personal care products (PPCPs), pesticides, and their metabolites. Many of these contaminants are known to be highly persistent, even under intensive thermal treatment conditions. The presence of PAHs, PCBs, PCDDs, and PCDFs has brought researchers' concerns to the surface when considering the utilization of hydrochar.

\subsubsection{Polycyclic aromatic hydrocarbons $(P A H s)$}

The US EPA has identified 16 PAHs as priority contaminants, including acenaphthene, acenaphthylene, anthracene, benzo[a]anthracene, benzo[a]pyrene, benzo[b]fluoranthene, benzo[g,h,i]perylene, benzo[k]fluoranthene, chrysene, dibenz[a,h]anthracene, fluoranthene, fluorene, indeno[1,2,3-c,d]pyrene, naphthalene, phenanthrene, and pyrene (Hu et al., 2021). Those PAHs with four or more benzene rings are considered carcinogenic, i.e., benzo[a]anthracene, benzo[a]pyrene, benzo[b]fluoranthene, benzo[g,h,i]perylene, benzo[k]fluoranthene, chrysene, dibenz[a,h]anthracene, indeno[1,2,3-c,d]pyrene, and pyrene. Fig. 11 illustrates the total PAHs in MS and its derived hydrochar from hydrothermal studies. Most current studies have confirmed that HTP treatment causes concentrated PAHs (4.2-19 mg/kg) in hydrochar under both subcritical and supercritical water conditions. Wiedner et al. (2013) investigated various types of feedstock for HTC and found MS-derived hydrochar had the highest total PAHs $(12.1 \mathrm{mg} / \mathrm{kg}$ ) over any other types of biomass (e.g., maize, food waste, manure digestate, and grass greenery). They also reported that hydrochar had a higher portion of 2-ring PAHs 
compared to raw biomass. Gong et al. (2018) studied the PAHs formation from MS through HTP at subcritical $\left(220-325{ }^{\circ} \mathrm{C}\right)$ and supercritical $\left(375-400{ }^{\circ} \mathrm{C}\right)$ water conditions. It was found that total PAHs in hydrochar increased gradually with increasing reaction temperature and reached the highest $(12.1 \mathrm{mg} / \mathrm{kg})$ at $400{ }^{\circ} \mathrm{C}$. Interestingly, slow heating and cooling processes could enhance the formation of heavy PAHs (4-6 rings), which essentially was resulted from the extended total reaction time and severity (Gong et al., 2018). They also examined the changes of PAHs during the HTG of MPS from various WWTPs (Gong et al., 2016b). These MPS samples were initially dominated by 3-ring and 4-ring PAHs, but then shifted to 2-ring and 3-ring PAHs after $\mathrm{HTG}$ at $400{ }^{\circ} \mathrm{C}$ for $1 \mathrm{~h}$. A positive linear correlation was identified between the total PAHs in hydrochar and the initial contents of VM, humic substances and lignin, and crude fat and carbohydrate in MPS. However, an opposite trend was found with the initial pH of MPS (Gong et al., 2016b). The wide range of total PAHs in MPS (3-15.5 mg/kg) also caused a large variety in hydrochar (3.8-28.5 mg/kg) under the same HTG condition. The possible reaction pathway of the formation of PAHs is included in Fig. 4. Wang et al. (2017) discovered adding catalysts such as $\mathrm{Ni}$ and $\mathrm{H}_{2} \mathrm{O}_{2}$ could inhibit the formation of PAHs. Liu et al. (2021) found adding 3-9 \%, db of $\mathrm{CaO}$ to $\mathrm{MS}$ for $\mathrm{HTC}\left(200{ }^{\circ} \mathrm{C}\right.$ for $10 \mathrm{~h}$ ) could reduce PAHs (by 5.6-16\%) and TEQ (by 2.9-3.5\%) of hydrochar by inhibiting free radical reaction. Melo et al. (2019) reported a significant rise of almost each PAH compound in hydrochar $\left(190{ }^{\circ} \mathrm{C}\right)$ compared to initial biosolids feedstock, with the total PAHs increased from $3.7 \mathrm{mg} / \mathrm{kg}$ to 21.2 $\mathrm{mg} / \mathrm{kg}$. However, one study found that most PAHs (> 89\%) from HTL $\left(240-360{ }^{\circ} \mathrm{C}\right.$ for $\left.0-60 \mathrm{~min}\right)$ were distributed into biocrude produced, while MS-derived hydrochar only contained $1.4-1.8 \mathrm{mg} / \mathrm{kg}$ of PAHs possibly due to the solvent (dichloromethane) extraction, thus leachable contents and toxic equivalent (TEQ) of PAHs of hydrochar and associated environmental risk were reduced compared to MS (Chang et al., 2021). It seems that the formation of PAHs in hydrochar is governed by the feedstock compositions (e.g., initial PAHS and organic components) and HTP treatment conditions (mainly reaction temperature and severity). European Biochar Foundation (EBC) has established a guideline for the application of biochar and defined a threshold of PAHs (12 mg/kg) for basic grade biochar (EBC, 2019). Such a limit is set specifically for biochar, which has shown effective binding of PAHs. However, to date, there is no 
research available about the PAHs released from MS-derived hydrochar. Therefore, further research on the risks associated with PAHs is necessary to provide a legal framework and benchmark prior to the application of hydrochar.

Please Insert Fig. 11 Here

\subsubsection{Polychlorinated biphenyls (PCBs) and polychlorinated dibenzo-dioxins/-furans ( $P C D D / F s)$}

Low levels of PCBs and PCDD/Fs have been commonly detected in MS, which are mainly originated from disinfectants, solvents, oil and grease, pesticides, and other industrial and household products (Fijalkowski et al., 2017). For soil protection, PCBs, dioxins, and furans in biochar are also regulated by the EBC: $0.2 \mathrm{mg} / \mathrm{kg}$ for PCBs and $20 \mathrm{ng} / \mathrm{kg}$ by international toxic equivalent (I-TEQ) for dioxins and furans (EBC, 2019). Some researchers have started the investigation of how PCBs and PCDD/Fs react during the HTP treatment of MS. Wiedner et al., (2013) examined various types of feedstock for HTP at $230{ }^{\circ} \mathrm{C}$ for $15 \mathrm{~min}$, followed by $180^{\circ} \mathrm{C}$ for $75 \mathrm{~min}$. MS-derived hydrochar showed the top level of I-TEQ (14.2 ng/kg) for PCDD/Fs among all tested biomass (all others below $6 \mathrm{ng} / \mathrm{kg}$ ). Brookman et al. (2018) investigated the effects of $\mathrm{HTC}\left(200-240{ }^{\circ} \mathrm{C}\right.$ for $\left.5 \mathrm{~h}\right)$ on PCBs and PCDD/Fs. Results presented that total PCDDs increased from $1.24 \mathrm{mg} / \mathrm{kg}$ in raw DS to $1.43 \mathrm{mg} / \mathrm{kg}$ in hydrochar obtained at $200{ }^{\circ} \mathrm{C}$, but then suddenly decreased with increasing temperature to $0.12 \mathrm{mg} / \mathrm{kg}$ at $240{ }^{\circ} \mathrm{C}$. Differently, the total PCDFs in hydrochar gradually decreased with increasing temperature and reached a minimum of $0.012 \mathrm{mg} / \mathrm{kg}$ at $240{ }^{\circ} \mathrm{C}$ compared to that of MS $(0.11 \mathrm{mg} / \mathrm{kg})$. However, total PCBs remained identical in hydrochar from all conditions (4.33-4.43 mg/kg), compared to $4.81 \mathrm{mg} / \mathrm{kg}$ in MS. When considering the toxicity by TEQ, the total TEQ of PCBs and PCDD/Fs was raised 9 times with increasing temperature from $5.36 \mathrm{ng} / \mathrm{kg}$ in MS to $46.09 \mathrm{ng} / \mathrm{kg}$ in hydrochar obtained at $240{ }^{\circ} \mathrm{C}$. This was mostly contributed by PCDDs, whose TEQ increased significantly from an initial $2.72 \mathrm{ng} / \mathrm{kg}$ to a final $44.5 \mathrm{ng} / \mathrm{kg}$ (Brookman et al., 2018). On one hand, it appears that HTC could dechlorinate POPs. On the other hand, the low chlorinated congeners 
with high toxicity index raise the overall TEQ of these contaminants. However, the overall risk from PCBs and PCDD/Fs cannot be concluded due to limited studies. Therefore, the toxicity of POPs in hydrochar should be carefully examined prior to its utilization. Detailed studies of various reaction conditions should also be further explored.

\subsubsection{Other persistent organic pollutants (POPs)}

Emerging contaminants, such as PPCPs and perfluorinated compounds (PFCs), have attracted more attention recently (Fijalkowski et al., 2017). The reason is related to their wide use in industrial and consumer applications and associated health concerns, such as endocrine disruption resulted from PPCPs and reduced female fertility and sperm quality caused by PFCs. vom Eyser et al. (2015) spiked various pharmaceuticals into SS to investigate the impacts of HTC (210 for $4 \mathrm{~h})$ on them. They found that HTC could remove over $68 \%$ of carbamazepine, clarithromycin, diclofenac, erythromycin, propranolol, and roxithromycin, and $42 \%$ of metoprolol from hydrochar compared to raw feedstock. However, the content of phenazone rather slightly increased from $210 \mu \mathrm{g} / \mathrm{kg}$ to $230 \mu \mathrm{g} / \mathrm{kg}$ after HTC. It was indicated that the precursors might be converted to phenazone by reversible chemical bonds and thus caused such an increase (vom Eyser et al., 2015). However, there was no convincing evidence. Due to the persistence, hydrophobicity, and electrostatic interactions, PFAs can accumulate in MS and their fate in HTP is of great interest. A recent study investigated the effects of HTL on PFAs in mixed primary and secondary sludge and found that: 1) High reaction severity $\left(350{ }^{\circ} \mathrm{C}\right.$ for $\left.90 \mathrm{~min}\right)$ degraded $>99 \%$ fluorinated carboxylic acid structures but limited sulfonic acid structures; 2) minerals in sludge solids could catalyze the transformation of PFAs; and 3) hydrochar and aqueous had minimal undegraded PFAs, which were mostly distributed into biocrude, demanding monitoring/purification during upgrading ( $Y u$ et al., 2020). The Pacific Northwest National Laboratory observed that all analyzed PFCs and most PPCPs in PS and SS were removed after the HTL process (reaction conditions not reported) (Mitroshkov et al., 2019). However, some PPCPs, such as ibuprofen, diclofenac, and 4-tert-octylphenol were still present in wet hydrochar (comparable to initial contents). The differences of PFAs from the above two studies may be attributed to the initial concentrations. One pilot-scale HTL (at 325 or $350{ }^{\circ} \mathrm{C}$ for $5 \mathrm{~min}$ ) study achieved 
99\% destruction for most pharmaceuticals and pesticides detected in the original MS (Silva Thomsen et al., 2020). With limited studies, we can infer that although HTP treatment can destroy most PPCPs and PFCs, there is a considerable amount of POPs remaining in hydrochar. Therefore, further investigation is necessary for guiding the establishment of environmental criteria.

3.4. Characterization of surface functionality and structure

\subsubsection{Fourier-transform infrared spectroscopy (FTIR)}

FTIR is the most used technique for characterizing the surface functionality of hydrochar. It can semiquantitatively display the change of surface functional groups and thus explain potential reactions during the HTP treatment. Table 8 summarizes the observed peaks in FTIR spectra of MS-derived hydrochar and potential corresponding components. Compared to the MS feedstock, the - $\mathrm{OH}$ stretching between 3600 $3200 \mathrm{~cm}^{-1}$ in hydrochar tends to be weakened, which is typically caused by dehydration reactions (Gai et al., 2016a). This is consistent with the reduced $\mathrm{H} / \mathrm{C}$ and $\mathrm{O} / \mathrm{C}$ ratios shown in the van Krevelen diagram (Fig. 7). The disappeared or declined $-\mathrm{C}-\mathrm{H}$ stretching may suggest the demethylation or condensation reactions during the HTP treatment (Leng et al., 2015b). After HTP, the absence of band at 1120-1050

$\mathrm{cm}^{-1}$ could be attributed to decarboxylation reactions, which causes the break of $-\mathrm{C}-\mathrm{O}$ bond (Kim et al., 2017). The decreased intensity of the $-\mathrm{C}=\mathrm{N}$ stretching could reflect the hydrolysis reaction during the HTP (Peng et al., 2016). The enhanced intensity of $-\mathrm{C}=\mathrm{C}$ stretching generally indicates the formation of aromatic compounds (Kim et al., 2017; Peng et al., 2016). It was suggested that the decomposition of amides should be responsible for the fading $-\mathrm{N}-\mathrm{H}$ band by the formation of ammonia (Chen et al., 2013b). The decomposition of amide I may also enhance the $-\mathrm{C}=\mathrm{O}$ peaks and form $\mathrm{CO}_{2}$ and $\mathrm{CO}(\mathrm{Chen}$ et al., 2013b). By comparing the intensity changes of FTIR bands between MS and its derived hydrochar, potential reactions could be inferred. However, it should be noted that some peaks may be overlapped by others. For example, the vibration of carboxylates $(-\mathrm{C}=\mathrm{O})$ and carboxylic acids $(-\mathrm{C}-\mathrm{O})$ can cause overlaps to amide I and amide III bands, respectively (Zhao et al., 2013). Overall, FTIR spectra have shown the reduced oxygenated surface functional groups but increased aromatic functional groups in hydrochar compared to the MS feedstock. The condensed carbon structure and abundant functional 
groups could improve the $\mathrm{C}$ sequestration, $\mathrm{C}$ stability, and surface activity of hydrochar, indicating high potential of water and nutrient retention for soil amendment and decent adsorption capacity for water remediation.

Please Insert Table 8 Here

\subsubsection{Two-dimensional perturbation correlation infrared spectroscopy (2D-PCIS)}

As abovementioned, the peak overlapping in FTIR spectra limits its analytical discussion, whereas the 2D-PCIS can provide an enhanced resolution of significant peaks and overcome this issue. 2D-PCIS elucidates the quantitative similarity or dissimilarity variations and explains chemical bonds according to Noda's rules (Harvey et al., 2012). Zhuang et al. (2018) first applied this technique to characterize MS and its derived hydrochar. The synchronous and asynchronous spectra of $-\mathrm{C}-\mathrm{H}$ were reflected in $3100-$ $2800 \mathrm{~cm}^{-1}$, while stretches of $-\mathrm{C}=\mathrm{O},-\mathrm{C}-\mathrm{C}$, and $-\mathrm{C}-\mathrm{O}$ were displayed in the ranges of $1800-1650,1650$ 1500 , and $1300-1000 \mathrm{~cm}^{-1}$, respectively. With the assistance of the 2D-PCIS and calculated relative intensities, they were able to deduce that the aliphatic chain was cyclized before the demethylation from aromatics during the HTP. The demethylation started first at low temperature $\left(120^{\circ} \mathrm{C}\right)$, while aliphatic methylene was cracked at higher temperatures $\left(180-300{ }^{\circ} \mathrm{C}\right)$, and subsequently bound onto the aromatic structures through polymerization and condensation. Over $180^{\circ} \mathrm{C}$, the intensity of aromatic $-\mathrm{C}-\mathrm{C}$ decreased with the increase of polyaromatic $-\mathrm{C}-\mathrm{C}$ simultaneously, possibly due to the accelerated aromatization. The rapid reduction of $-\mathrm{C}-\mathrm{O}$ bonds was also observed with increasing reaction temperature, indicating the route of aromatic condensation (Zhuang et al., 2018). Overall, 2D-PCIS can effectively display the changes of surface functional groups and thus facilitate the explanation of reaction pathways during HTP.

3.4.3.X-ray photoelectron spectroscopy (XPS) 
XPS is a useful tool to analyze the outer surface of hydrochar and determine the atomic composition and functional forms more accurately than FTIR. Depending on the spectra used, such as C1s (Zhuang et al., 2018), N1s (He et al., 2015b), S2p (Wang et al., 2020), and Fe(2p) (Zhang and Hay, 2020), C, N, S, and Fe containing compounds can be identified, respectively. Zhuang et al. (2018) detected five Cfunctional groups in MS and the corresponding hydrochar $\left(180-300{ }^{\circ} \mathrm{C}\right.$ for $\left.30-120 \mathrm{~min}\right):-\underline{\mathrm{C}}-\mathrm{H},-\underline{\mathrm{C}}-(\mathrm{C}$, $\mathrm{H}) /-\underline{\mathrm{C}}=\mathrm{C},-\underline{\mathrm{C}}-(\mathrm{O}, \mathrm{N}),-\underline{\mathrm{C}}=\mathrm{O}$ and $\mathrm{O}=\underline{\mathrm{C}}-\mathrm{O}$. Based on the calculated relative intensity, it was found that the sum of $-\underline{\mathrm{C}}-\mathrm{C}$ and $-\underline{\mathrm{C}}=\mathrm{C}$ fractions in derived hydrochar significantly increased with reaction severity and reached the maximum $(43 \%)$ at $300{ }^{\circ} \mathrm{C}$ for $120 \mathrm{~min}$. Such enhancement was attributed to the decomposition of aliphatic carbon in carbohydrates or proteins and the formed aromatic compounds by condensation and polymerization (Zhuang et al., 2018). He et al. (2016) also observed these same carbon peaks between $280-290 \mathrm{eV}$. They found that $-\underline{\mathrm{C}}-(\mathrm{C}, \mathrm{H})(60.24 \%)$ was initially dominant in MS but without the presence of $\mathrm{O}=\underline{\mathrm{C}}-\mathrm{O}$. With the increasing temperature from 260 to $380{ }^{\circ} \mathrm{C}$, the portions $-\underline{\mathrm{C}}-\mathrm{H}$ and $-\underline{\mathrm{C}}-(\mathrm{O}, \mathrm{N})$ gradually raised and became principal at $380^{\circ} \mathrm{C}$, while the $\mathrm{O}=\underline{\mathrm{C}}-\mathrm{O}$ group was not present until the addition of $\mathrm{CaO}$ during the reaction. It was indicated that $\mathrm{CaO}$ catalyst could promote the hydrolysis of nitrile-N and deamination of pyridine-N (He et al., 2016). However, Melo et al. (2019) only identified three carbon groups in biosolids and hydrochar: Hydroxyl $(-\mathrm{C}-\mathrm{OH} /-\mathrm{C}-\mathrm{O})$, aliphatic/aromatic $(-\mathrm{C}-\mathrm{C} /-\mathrm{C}-\mathrm{H})$, and $\mathrm{sp}^{2} \mathrm{C}$. They stated more O-rich functional groups and aliphatic and aromatic $\mathrm{C}$ in hydrochar (obtained at $190{ }^{\circ} \mathrm{C}$ and $\mathrm{pH}=4.5$ for $4 \mathrm{~h}$ ) than the feedstock (Melo et al., 2019).

The N1s XPS spectra (390-410 eV) can present the evolution of N-containing functional groups during HTP treatment. Zhuang et al. (2017) found only two N groups (amino and inorganic N) in MS but three more new peaks (quaternary-N, pyrrole-N, and pyridine-N) in hydrochar obtained at $210-300{ }^{\circ} \mathrm{C}$ for $0.5-8 \mathrm{~h}$. It was observed that the inorganic $\mathrm{N}$ was completely dissolved and disappeared in hydrochar after $240{ }^{\circ} \mathrm{C}$. The conversion of amino-N to quaternary- $\mathrm{N}$ was also displayed, possibly resulted from the enhanced hydrolysis and polymerization and ring condensation of amino-N (Zhuang et al., 2017). He et al. (2015b) used digested sludge with mostly protein-N (90.3\%) and some pyridine-N and inorganic $\mathrm{N}$. The pyridine- $\mathrm{N}$ content raised gradually with increasing reaction temperature and became dominant $(25.2 \%)$ 
at $380{ }^{\circ} \mathrm{C}$, with the reduced protein-N $(18.5 \%)$. The Diels-Alder reaction was inferred in charge (He et al., 2015b). Liu et al. (2017a) obtained compositions of mainly protein-N, pyridine-N, pyrrole-N, and some inorganic-N in MS. A new peak (nitrile-N) was identified in hydrochar with the absence of inorganic-N after $\mathrm{HTC}$ at $200{ }^{\circ} \mathrm{C}$ for $30 \mathrm{~min}$. Generally, deamination is attributed to the inorganic-N and some protein$\mathrm{N}$, while polymerization and cyclization promoted by high HTP temperatures (e.g., $300-350{ }^{\circ} \mathrm{C}$ ) would form more stable nitrile- $\mathrm{N}$ and heterocyclic- $\mathrm{N}$ (pyrrole- $\mathrm{N}$ and pyridine- $\mathrm{N}$ ) that are mainly concentrated in hydrochar (T. Liu et al., 2017a; Wu et al., 2020).

Similarly, the S2p spectra (160-175 eV) are used to identify S-containing compounds. So far, only Wang et al. (2020) attempted to discover the transformation pathway of S for HTP of secondary sludge at 180-300 ${ }^{\circ} \mathrm{C}$ for $30 \mathrm{~min}$. Six organic (mercaptan, sulfide, sulfone, sulfoxide, and thiophene) and one inorganic (sulfate) S-compounds were found in the secondary sludge. Sulfide which was major in the sludge (39.44\%) decreased rapidly with the increasing reaction temperature and reached a minimum of $17.14 \%$ in hydrochar $\left(200{ }^{\circ} \mathrm{C}\right)$. On the contrary, the portion of thiophene enhanced from $22.19 \%$ in the sludge to $37.48 \%$ in hydrochar $\left(300{ }^{\circ} \mathrm{C}\right)$ which was the dominant species. This change may result from poly-condensation of sulfide, sulfoxide, and sulfone. Meanwhile, the decomposition and transformation of organic $\mathrm{S}$ forms into inorganic species was also indicated by the significantly increased sulfate content (from $0.07 \%$ to $20.96 \%$ ). In the end, Wang et al. (2020) proposed a potential reaction pathway for sulfur during HTP treatment. In summary, XPS analysis can identify specific elemental compounds and thus reflect potential evolution associated with these elements.

\subsubsection{Nuclear magnetic resonance (NMR) spectroscopy}

NMR spectra is an advanced technology to quantify the species distribution of various elements (e.g., $\mathrm{C}, \mathrm{N}$, and $\mathrm{P}$ ) in both solid and liquid phases. The ${ }^{13} \mathrm{C}$ NMR provides the relative contribution of each carbon molecular such as alkyl C, O-alkyl C, alkene C, anomeric C, aryl C, carboxyl C, and carbonyl C by the chemical shifts (Zhang et al., 2017). Similarly, ${ }^{15}$ N NMR presents the distribution of N species, e.g., pyrrole $\mathrm{N}$ and amide N. Paneque et al. (2017) applied both ${ }^{13} \mathrm{C}$ and ${ }^{15} \mathrm{~N}$ NMR and found that both primary and secondary sludge were mainly composed of alkyl C (43.1\% and 37.6\%, respectively) and amide $\mathrm{N}$ 
(77.6\% and $82.8 \%$, respectively). With increasing reaction severity $\left(200-260{ }^{\circ} \mathrm{C}\right.$ and $\left.0.5-3 \mathrm{~h}\right)$, hydrochar had continuously increased contents of alkyl C, O/N-aryl C, aryl C, and pyrrole $\mathrm{N}$, but decreased proportions of carboxyl/amide $\mathrm{C}$ and $\mathrm{O}$-alkyl $\mathrm{C}$ and amide $\mathrm{N}$. These findings indicated that higher reaction severity of HTC promoted the hydrolysis, dehydration, decarboxylation, and aromatization (Paneque et al., 2017). Zhang et al. (2018) also obtained enhanced aromaticity of hydrochar (44.3\%) after HTP at $300{ }^{\circ} \mathrm{C}$ for 30 min compared to MS (7.0\%) feedstock by using ${ }^{13} \mathrm{C}$ NMR. Wiedner et al. compared the $\mathrm{C}$ groups in hydrochar derived from HTC of different biomass. They found that MS-derived hydrochar was one of the groups with the highest alkyl C (39\%) and carboxyl C (18\%) but the lowest Oalkyl C (24\%) and aryl C (19\%), compared to those generated from maize silage and grass greenery (except for the biogas digestate) (Wiedner et al., 2013). Generally, the ${ }^{13} \mathrm{C}$ NMR shows that MS-derived hydrochar has reduced oxygen-containing organic $\mathrm{C}$ but improved aromaticity than its feedstock (Wang et al., 2017; Zhang et al., 2014).

${ }^{31} \mathrm{P}$ NMR has been used to determine the speciation of $\mathrm{P}$ in hydrochar. Huang and Tang (2015) found both WAS and its derived hydrochar (at $225^{\circ} \mathrm{C}$ for $24 \mathrm{~h}$ ) were primarily composed of orthophosphate (ortho-P), but a low portion of $\mathrm{P}$ in hydrochar was observed (30.9\%) in solid-state NMR analysis. This suggested that more P was formed with metal complexes. However, the liquid-state NMR spectra of the extract showed that the hydrochar contained 100\% of ortho-P (Huang and Tang, 2015). Shi et al. (2019) combined ${ }^{31} \mathrm{P}$ NMR spectra with the NaOH/EDTA extraction. It was reported that the pyrophosphate (pyro-P) was more in hydrochar obtained at $170-260{ }^{\circ} \mathrm{C}$ than that of MS feedstock. This is probably caused by the hydrolysis of organic phosphorus (monoester-P) into pyro-P. However, the pyro-P disappeared in hydrochar from $320^{\circ} \mathrm{C}$. Besides, most $\mathrm{P}$ was transferred into inorganic forms (nearly 100\%) after HTP treatment (Shi et al., 2019). It seems that liquid-state ${ }^{31}$ P NMR combined with extraction is a better way to characterize the speciation of $\mathrm{P}$ in hydrochar owing to the dominance of inorganic $\mathrm{P}$.

\subsubsection{X-ray diffractometry (XRD)}


XRD is commonly used for the analysis of the crystal structure of hydrochar. Wang et al. (2017) observed various minerals in both digested sludge and its derived hydrochar $\left(200-230{ }^{\circ} \mathrm{C}\right.$ for $\left.2 \mathrm{~h}\right)$, such as quartz $\left(\mathrm{SiO}_{2}\right)$, kaolinite, and muscovite. With XRD analysis, they investigated the behaviors of $\mathrm{P}$ minerals among different hydrothermal conditions. It was found that $\mathrm{AlPO}_{4}$ was the predominant $\mathrm{P}$ form at all conditions, while AP increased in an alkaline environment. However, it should be noted that XRD cannot detect the phosphate minerals in amorphous phase, which is combined with $\mathrm{Ca}, \mathrm{Al}, \mathrm{Fe}$, and others (Wang et al., 2017). XRD results also indicated that at supercritical water conditions ( $400{ }^{\circ} \mathrm{C}$ for $30 \mathrm{~min}$ ) alkaline additives $\left(\mathrm{Na}_{2} \mathrm{CO}_{3}\right.$ and $\left.\mathrm{K}_{2} \mathrm{CO}_{3}\right)$ could react with $\mathrm{Ca}^{2+}$ and $\mathrm{Al}^{3+}$ to form calcium carbonate, analcime, and kalsilite, while phosphate originally combined with $\mathrm{Ca}$ and $\mathrm{Al}$ minerals could be mobilized into aqueous (Wang et al., 2019). XRD could verify the transformation of mineral species. Minerals of $\mathrm{Ca}_{3}\left(\mathrm{PO}_{4}\right)_{2}$ and $\mathrm{Ca}_{7} \mathrm{Mg}_{2}\left(\mathrm{PO}_{4}\right)_{6}$ were found in MS-derived hydrochar when $\mathrm{CaO}$ was added in $\mathrm{HTC}$ treatment $(200-$ $260{ }^{\circ} \mathrm{C}$ ), suggesting a directional production of Ca-P (Xu et al., 2018). Wang et al. (2020) also used XRD and observed higher intensity and more peaks of $\mathrm{CaSO}_{4}$ in hydrochar than that in MS, reflecting that $\mathrm{HTC}$ (180-300 ${ }^{\circ} \mathrm{C}$ ) was likely to transform unstable organic sulfur species (mercaptan and sulfide) to sulfate. XRD patterns also showed the presence of complex combinations of alkali and alkaline earth metals (AAEMs) in MS-derived hydrochar obtained at $600{ }^{\circ} \mathrm{C}$ and $23 \mathrm{MPa}$ for $1 \mathrm{~h}$ (Sawai et al., 2014). Mostly, XRD analysis is used to assist the elucidation of reactions related to various minerals during HTP treatment.

\subsection{Characteristics of morphology}

Scanning electron microscopy (SEM) or SEM coupled with energy dispersive X-ray spectrometry (SEM-EDS) is mostly applied to visualize the surface morphology of hydrochar and the present elements. Wang et al. (2018) utilized SEM-EDS and observed many granular and massive substances (such as coke and char) attached to the surface of Ni catalyst for HTG treatment, which eventually led to the deactivated catalyst. Zhang et al. (2017) found the structure features of hydrochar $\left(220^{\circ} \mathrm{C}\right)$ derived from MS and pinewood sawdust were distinctly different. MS-derived hydrochar MS was fragmented of clustered aggregates, while hydrochar resulted from pinewood sawdust still had sharp edges and flat plates, similar 
to the features of raw sawdust. Chen et al. (2013b) reported the formation of porous structures and bubbles in hydrochar obtained at $350{ }^{\circ} \mathrm{C}$ compared to the close-knit structure of MS. However, more porous structures were formed with the destroying of bubbles when reaction temperature raised to $425^{\circ} \mathrm{C}$, probably caused by the release of gas. On the contrary, hydrochar produced at low temperature $\left(260{ }^{\circ} \mathrm{C}\right)$ was mostly non-porous (Khoshbouy et al., 2019). Other studies also observed dense and low porosity of hydrochar obtained at low temperatures $\left(180-200{ }^{\circ} \mathrm{C}\right)$. However, the structure of hydrochar was ruptured with a rougher surface after HTC, compared to MS (Saetea and Tippayawong, 2013; Zhuang et al., 2020c). Liu et al. (2017b) suggested that acid washing ( $\mathrm{HCl}$ and $\mathrm{HF}$ ) of hydrochar could largely enhance pore size and develop a multiple-pores structure with rich mesopores. Generally, SEM results show that MS-derived structure shifts from dense to more porous with increasing reaction temperature.

Transmission electron microscope (TEM) is another technique that can display the surface morphology. Liu et al. (2017b) used TEM imaging to investigate the effects of acid washing on MSderived hydrochar. A higher amount of mesopores and channels were found in hydrochar after washing with $2 \mathrm{M}$ of $\mathrm{HCl}$ and $20 \mathrm{wt} \%$ of $\mathrm{HF}$, compared to that washed with $\mathrm{HCl}$ only. El-Deen and Zhang also used TEM analysis to prove the coating of dense nanoparticles on hydrochar after HTC of MS at $200{ }^{\circ} \mathrm{C}$ with catalysts (glucose and $\mathrm{FeSO}_{4} \cdot 7 \mathrm{H}_{2} \mathrm{O}$ ) (El-Deen and Zhang, 2012). However, to date, there is a lack of HTP studies investigated with TEM.

\section{Valorization of hydrochar}

Initial studies on sludge-to-hydrochar were primarily focused on carbonization to provide alternative solid fuel. However, considering the abundant characteristics of hydrochar, the applications of hydrochar have been broadened in recent studies. MS-derived hydrochar has been valorized in energy production, agricultural application, water remediation, catalysis, and nutrient recovery. Nevertheless, many other potential applications have not been adopted to MS-derived hydrochar, such as carbon sequestration, gas adsorption, energy storage (batteries, supercapacitors, and fuel cells), and biochemical applications (Titirici et al., 2012). 


\subsection{Energy production}

\subsubsection{Biofuel for combustion}

Hydrothermal treatment has been proven to convert waste biomass into promising solid fuels with high energy density, i.e., a coal-like material. In recent studies, MS-derived hydrochar has shown both $\mathrm{HHV}$ and $\mathrm{H} / \mathrm{C}$, and $\mathrm{O} / \mathrm{C}$ ratios moving towards natural lignite (He et al., 2014b). As a result, many researchers have attempted to apply hydrochar in combustion or co-combustion mostly via thermogravimetry (TG) and derivative thermogravimetry (DTG) tests (Ahn et al., 2020). Table 9 catalogs the application of MS-derived hydrochar to energy production with key findings. As shown in the table, most studies focused on combustion. Considering the low hydrochar yield at high temperature and corresponding energy investment, it is suggested to use a mild HTC condition $\left(\leq 280{ }^{\circ} \mathrm{C}\right)$ to produce solid biofuel. Among reported studies, the best potential hydrochar fuel was produced from a SS at $260{ }^{\circ} \mathrm{C}$ for $1 \mathrm{~h}$ (Khoshbouy et al., 2019). It showed the highest HHV (23.3 MJ/kg) and relatively low ash content (26.6\%) and ratios of $\mathrm{H} / \mathrm{C}(1.15)$ and $\mathrm{O} / \mathrm{C}(0.13)$. Compared to the feedstock (MS), hydrochar has shown several improvements during combustion: Reduced ignition temperature and burnout temperature, lower activation energies, more stable flame, longer combustion process, and significant $\mathrm{NO}_{\mathrm{X}}$ and $\mathrm{SO}_{2}$ emission reduction (He et al., 2013; Wang et al., 2019). The reasons include but are not limited to the enhancement of HHV, FC, and C content, and the reduction of $\mathrm{N}$ and $\mathrm{S}$ contents, VM, H/C, and $\mathrm{O} / \mathrm{C}$ ratios. Some studies also compared hydrochar with coals regarding combustion performance. Parshetti et al. (2013) added hydrochar to low-rank coal and found a reduction in emission gas $\left(\mathrm{CO}_{2}, \mathrm{CO}\right.$, and $\left.\mathrm{CH}_{4}\right)$. He et al. (2014b) blended hydrochar with different coals. In terms of the combustion performance and burnout efficiency, co-combustion showed positive synergistic effects with moderate-rank coal, but negative synergistic effects with low/high-rank coals. However, the detailed mechanisms behind the cocombustion should be further studied.

Please Insert Table 9 Here 
Challenges are also expected when using MS-derived hydrochar for combustion. Firstly, to produce energy-dense hydrochar, the feedstock should be highly selective. As demonstrated in Section 2.1, MS has a large variability in properties, such as $\mathrm{C}, \mathrm{O}, \mathrm{HHV}, \mathrm{VM}$, and ash contents. Statistical analysis shows that the HHV of hydrochar is substantially related to the properties of MS. Fig. 12 explains the correlations among properties of hydrochar and the corresponding MS. The HHV of hydrochar is negatively governed by its ash content (adjusted $R^{2}=0.70$, Fig. 12a). The ash content of hydrochar is positively impacted by that of the feedstock (adjusted $\mathrm{R}^{2}=0.69$, Fig. 12b), and thus the HHV of hydrochar is negatively correlated to the ash content of MS (adjusted $\mathrm{R}^{2}=0.48$, Fig. 12c). Meanwhile, the HHV of hydrochar is positively affected by the HHV of its feedstock (adjusted $\mathrm{R}^{2}=0.74$, Fig. 12d). Consequently, a feedstock with high HHV but low ash content is preferable to produce a promising solid biofuel through HTP treatment. Some studies showed that co-HTC of MS with other types of biomass might overcome the drawback of low HHV but high ash content of hydrochar (He et al., 2019; C. Zheng et al., 2019). Secondly, the balance between HHV value of hydrochar and the corresponding energy recovery rate (defined as the percentage of energy in hydrochar recovered from MS) should be maintained. As shown in Fig. 13a, more than half of the studies reported a low HHV (<15 MJ/kg, db) or low energy recovery rate $(<60 \%)$ of MS-derived hydrochar. It also seems that the energy recovery rate is positively related to the $\mathrm{HHV}$ of hydrochar with a polynomial relationship (adjusted $\mathrm{R}^{2}=0.93$ ). Therefore, future studies should pay attention to optimize the treatment conditions to enhance both hydrochar HHV and energy recovery rate. Besides, energy densification expressed as the HHV ratio between hydrochar and the feedstock MS is targeted to be $>1$ for solid fuel production. Through a scatter matrix analysis (Fig. 13b), it is found that to achieve energy densification, the preferable HTC conditions should be controlled at $150-300{ }^{\circ} \mathrm{C}$ and severity factor $<0.5$. Thirdly, issues of ash slagging and fouling and the generation of harmful gases seem to be inevitable while combusting hydrochar. Due to the ash accumulation and concentrated AAEMs, such as $\mathrm{Ca}, \mathrm{K}, \mathrm{Mg}$, and $\mathrm{Na}$, hydrochar can have a high alkali index (>0.34), which would certainly cause slagging and fouling during combustion (Smith et al., 2016). Even though HTP 
reduces the $\mathrm{N}$ and $\mathrm{S}$ contents in hydrochar, high $\mathrm{NO}_{\mathrm{X}}$ and $\mathrm{SO}_{2}$ emission of hydrochar combustion was found comparable to coal and wood pellet (Ahn et al., 2020). On the other hand, high deformation (1220$\left.1240{ }^{\circ} \mathrm{C}\right)$ and flow $\left(1440-1470{ }^{\circ} \mathrm{C}\right)$ temperatures of hydrochar ash could inhibit the formation of $\mathrm{NO}_{\mathrm{X}}$ (Smith et al., 2016). Thus, future studies should focus on balancing the ash content of hydrochar and the potential emission. Blending low-ash biomass (e.g., lignocellulose) with MS for co-HTC could probably mitigate the concerning of ash, along with syncretistic effects on the improvement of hydrochar quality. Lastly, potential nutrient loss and secondary contamination can be caused by combustion. Due to the low melting point of $\mathrm{P}_{2} \mathrm{O}_{5}\left(340{ }^{\circ} \mathrm{C}\right), \mathrm{P}$ is likely to spread in fly ash by complexing with other elements, including $\mathrm{Al}, \mathrm{Ca}, \mathrm{Fe}, \mathrm{Mg}$, and $\mathrm{Si}$ (Ahn et al., 2020). The highest $\mathrm{P}$ concentration in hydrochar, derived from WAS, was reported as $8.1 \%$, db, which can be the best candidate for P fertilizer or P recovery (Huang and Tang, 2016). Direct burning such hydrochar would cause a significant loss and higher cost for recollecting P. Besides, combustion of MS-derived hydrochar can also cause emissions of heavy metals concentrated fly ash, such as Hg and Cd (Lumley et al., 2014; Shi et al., 2014). Therefore, nutrient loss and emission control must be considered when evaluating the combustion behaviors of hydrochar. Also, not all hydrochar products apply to combustion. In HTL/HTG treatment, minerals are concentrated in hydrochar while carbon is minimized, causing the hydrochar with poor quality as solid fuel. It is preferred to process such hydrochar for P recovery.

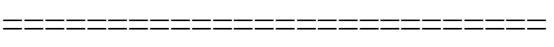

Please Insert Fig. 12 Here

Please Insert Fig. 13 Here 
In conclusion, MS-derived hydrochar has many limitations to be a solid biofuel, which needs to be optimized with low ash contents, high energy density, and improved combustion performance. Co-HTC and co-combustion seem to be a trend of overcoming the drawbacks of MS-derived hydrochar and valorizing the asset for combustion. Moreover, challenges during combustion, such as ash slagging and fouling, harmful emissions, and nutrient loss, require more comprehensive evaluation.

\subsubsection{Hydrochar for syngas production}

Syngas production via pyrolysis or steam gasification is another process to utilize energy in MSderived hydrochar. As shown in Table 9, numerous studies have examined the gasification of hydrochar for generating gas rich with $\mathrm{H}_{2}, \mathrm{CO}$, and $\mathrm{CH}_{4}$. Most hydrochar used in gasification or pyrolysis was produced with a low hydrothermal temperature $\left(\leq 240^{\circ} \mathrm{C}\right)$ and residence time $(\leq 1 \mathrm{~h})$. It is suggested that high hydrothermal severity (e.g., high reaction temperature and long residence time) could reduce $\mathrm{H}_{2}$ production as a result of the sharp decline of carboxyl and hydroxyl groups in hydrochar (Zheng et al., 2019). Compared to direct gasification of MS, hydrochar could result in gases with better quality (up to 9.6 $\mathrm{MJ} / \mathrm{Nm}^{3}$ of lower heating value and $56 \%$ of $\mathrm{H}_{2}$ in the product) and gasification efficiency (up to $91 \%$ ) (Gai et al., 2016b; Zhuang et al., 2020b). Unlike the fouling effects of AAEMs in combustion, metals such as $\mathrm{Ca}, \mathrm{Fe}, \mathrm{K}, \mathrm{Mg}, \mathrm{Na}$, and $\mathrm{Ni}$ in hydrochar have been reported to show catalytic effects on gasification (Gai et al., 2016b). Zhuang et al. reported that their impacts on gasification conversion rates followed the order: $\mathrm{Na}>\mathrm{K}>\mathrm{Mg}>\mathrm{Ca}>\mathrm{Fe}$ (Zhuang et al., 2020c). They also found that $\mathrm{Na}$ and $\mathrm{K}$ mainly contributed to $\mathrm{CO}_{2}$ generation during gasification. Regarding syngas production, only one study analyzed pyrolysis, and it seems the gas was mainly composed of $\mathrm{CO}_{2}$ (more than half of the total gas). Most studies have shown that gasification can produce high-quality syngas and achieve a high carbon conversion rate or gasification efficiency. Besides, one study also suggested that gasification can be coupled with $\mathrm{P}$ recovery through thermochemical conversion. It was reported that $\mathrm{P}_{2} \mathrm{O}_{5}$ could be completely converted into gas phase after $600{ }^{\circ} \mathrm{C}$, and a total P recovery of over $80 \%$ can be achieved (Feng et al., 2018). 
However, considering the high temperature required for gasification (typically $700-1000{ }^{\circ} \mathrm{C}$ ), there is a concern about both capital investment and energy consumption. An energy return on investment is urgently required to evaluate the performance of gasification of MS-derived hydrochar. The catalytic effect of AAEMs in hydrochar also needs further exploration, as it could be inhibited by the melting of abundant $\mathrm{Si}$ and $\mathrm{Al}$ and resulted in the blocking of active sites (Zhuang et al., 2020c). Besides, the gasified residue could be concentrated with PAHs and heavy metals, which requires proper management (Zhuang et al., 2020b).

\subsection{Agricultural applications}

With abundant nutrients and functionality, the valorization of hydrochar as a sustainable fertilizer and soil amendment has attracted attention. Fei et al. (2019b) suggested that hydrochar $\left(150-300{ }^{\circ} \mathrm{C}\right.$ for $\left.2 \mathrm{~h}\right)$ tended to have lower available nutrients (i.e., $1.58-6.87 \mathrm{~g} / \mathrm{kg}$ of $\mathrm{N}, 0.27-0.9 \mathrm{~g} / \mathrm{kg}$ of $\mathrm{P}$, and $0.26-0.87 \mathrm{~g} / \mathrm{kg}$ of K), compared to MS feedstock and pyrochar. These values are still far higher than those of typical agricultural soil: $\mathrm{N}(0.01-0.49 \mathrm{~g} / \mathrm{kg}), \mathrm{P}(<0.02 \mathrm{~g} / \mathrm{kg})$, and $\mathrm{K}(<0.1-0.27 \mathrm{~g} / \mathrm{kg})$. High cation exchange capacity (CEC) values $(11.8-25.3 \mathrm{cmol} / \mathrm{kg}$ ) of hydrochar were also obtained. It should be noted that 20 $\mathrm{cmol} / \mathrm{kg}$ is very high for soil CEC, which represents a high capacity of attracting ammonium and trace elements (Fei et al., 2019b). Fei et al. also found that most P was immobilized with an available portion of $0.42 \mathrm{~g} / \mathrm{kg}$ in hydrochar after HTC treatment $\left(150-250{ }^{\circ} \mathrm{C}\right.$ for $\left.2 \mathrm{~h}\right)$. Interestingly, hydrochar turned into a P adsorbent when environmental P content was above $20 \mathrm{mg} / \mathrm{L}$, which can be readily released. Adding Prich hydrochar also nearly doubled soil available P by $8.9 \mathrm{mg} / \mathrm{kg}$ during 1-10 days incubation (Fei et al., 2019a). Therefore, hydrochar is considered a feasible and value-added soil amendment. Also, the inhibited availability of nutrients could benefit the long-term application of hydrochar due to the slow release of nutrients (Fei et al., 2019a). It should be noted that most MS-derived hydrochar has low N/P ratios (e.g., less than 10) (Fig. 9a), and therefore complementary $\mathrm{N}$ fertilizers may be required for better fertilization when using hydrochar as a fertilizer.

Some lab-scale experiments have been done to evaluate the feasibility of hydrochar application as a soil amendment. Chu et al. (2020) applied digested sludge-derived hydrochar $\left(260{ }^{\circ} \mathrm{C}\right.$ for $\left.1 \mathrm{~h}\right)$ as $\mathrm{N}$ - 
fertilizer (240 kg urea-N/ha) to paddy soil columns for rice (Oryza sativa L. Nangeng 46) growth. It was found that the addition of hydrochar could significantly enhance the soil ammonium-N retention, inhibit the ammonium-N loss in floodwater, and thus improve rice production. These effects could be due to the low surface $\mathrm{pH}(7.09-7.78)$ and pore diameter $(1.19-3.05 \mathrm{~nm})$, large adsorption pore volume $(0.14-0.20$ $\mathrm{cm}^{3} / \mathrm{g}$ ), and abundant carboxyl functional groups of hydrochar (Chu et al., 2020). Melo et al. (2018) conducted a pot experiment to assess the plant and soil response to biosolids-derived hydrochar $\left(190{ }^{\circ} \mathrm{C}\right.$ for $4 \mathrm{~h}$ ). The soil CEC, water holding capacity and the availability of nutrients (organic C, hot water extractable $\mathrm{C}$, ammonium, nitrate, total $\mathrm{N}$ and $\mathrm{P}, \mathrm{Ca}$ and $\mathrm{Fe}$ ) and trace elements $(\mathrm{Cu}$ and $\mathrm{Zn}$ ) were found to be positively correlated with hydrochar application rates $(0.2-1.6 \mathrm{wt} \%)$ by the end of harvest. However, the $\mathrm{Mg}$ availability and soil $\mathrm{C} / \mathrm{N}$ ratio decreased with increasing hydrochar addition. Applying $0.8 \mathrm{wt} \%$ of hydrochar resulted in equal and 96\% higher total dry matter of plant biomass (Phaseolus beans), compared to that of the mineral fertilizer, during the first and second harvest, respectively (Melo et al., 2018). Melo et al. also investigated the influence of hydrochar on the germination of rice, beans, and radish. Adding $0.5 \mathrm{wt} \%$ and $3 \mathrm{wt} \%$ of hydrochar resulted in the maximum yields of beans and rice, respectively. However, the yield of radish linearly decreased with increasing application rates of hydrochar (Melo et al., 2019). MS-derived hydrochar appears to be beneficial as a soil amendment for its positive impacts on soil properties and crop yield, but it would vary depending on the soil and plants. Therefore, more assessments, including both pot and field trials, are necessary for a comprehensive evaluation and understanding of long-term impacts, prior to the application of hydrochar to the agricultural scale.

Besides the uncertainty of hydrochar performance on agricultural production, potential toxic effects associated with the concentrated contaminants, such as heavy metals and POPs, are creating concerns. Yue et al. (2017) examined the transformation of heavy metals during a 60-day incubation with MSderived hydrochar as a soil amendment. Adding $5 \mathrm{wt} \%$ of hydrochar to the agricultural soil (noncontaminated) significantly increased total metals ( $\mathrm{As}, \mathrm{Cd}, \mathrm{Cr}, \mathrm{Cu}, \mathrm{Pb}$, and $\mathrm{Zn}$ ) in soil. Additionally, after 60 days of incubation, the oxidable and residual fractions of heavy metals were greatly mobilized into 
readily bioavailable forms (acid-soluble and reducible fractions) (Yue et al., 2017). It seems that although heavy metals are highly immobilized in hydrochar initially, they can be re-mobilized during soil application. This could particularly pose risks to the food chain when applying hydrochar to agriculture. On the contrary, another study showed that the application of hydrochar derived from WAS could promote the immobilization of $\mathrm{Cd}$ in contaminated soil (Ren et al., 2017). With the favor of hydrochar amendment, $\mathrm{Cd}$ was restrained from being assimilated from contaminated soil to the aboveground (up to $15 \%$ reduction) and underground (up to 58\% reduction) parts of cabbage. It was also found that hydrochar addition largely enhanced the abundance of soil microorganisms (Ren et al., 2017). So far, only one study has conducted a limited ecotoxicological assessment. With the application of biosolids-derived hydrochar $\left(190{ }^{\circ} \mathrm{C}\right.$ for $4 \mathrm{~h}$ ) up to $80 \mathrm{Mg} / \mathrm{ha}$ or $4 \mathrm{wt} \%$, no acute toxicity to earthworms was identified, although earthworms showed significant preference to control soil rather than hydrochar amended (Melo et al., 2017). Limited reports have shown that using MS-derived hydrochar may pose environmental and human health risks but probably depending on the hydrochar properties, soil properties, and soil biota. More detailed studies are required to address such concerns for the valorization of hydrochar.

Last but not least, public and farmer perception is another big challenge when using MS-derived hydrochar for agricultural application. Historically, MS (biosolids) presents a negative public perception due to the environmental concerns from its contaminants. It is not surprising that Melo et al. found only $51 \%$ of surveyed rural producers would use biosolids-derived hydrochar (Melo et al., 2019). In the future, long-term field trials should be performed to clarify the interactions among hydrochar, soil properties, plant growth, and crop quality. More investment in the safe use of hydrochar in agriculture is also beneficial for its valorization.

\subsection{Adsorption: Water remediation}

MS-derived hydrochar with abundant oxygen-functional groups makes it promising for adsorption or as a precursor of activated carbon. Several researchers have directly applied hydrochar for water remediation or convert hydrochar into activated carbon. Table 10 summarizes available isotherms or models for the evaluation of adsorption performance. The adsorption isotherms are used to quantify the 
affinity of an adsorbent to the adsorbate and describe adsorbent-adsorbate interactions. Langmuir isotherm describes the equilibrium as a reversible chemical reaction, assuming a fixed number of sites on a monolayer where adsorption can take place without adsorbate interactions (Leng et al., 2015b). Freundlich isotherm describes heterogeneous surfaces and multilayer adsorption, which allows for adsorbate interactions (Ferrentino et al., 2020a). Sips isotherm is the combined Langmuir-Freundlich form that also predicts heterogenous adsorption, but it describes the process with a finite limit at high enough concentrations (Alatalo et al., 2013). Temkin isotherm considers the adsorbent-adsorbate interactions, assuming that the adsorption heat or free energy is dependent on the surface coverage (Xia et al., 2019). Absorption kinetics modeling has been widely used to indicate adsorption mechanisms. Pseudo-first-order describes the adsorption occurring through interface diffusion, assuming that the adsorption rate is directly proportional to the difference of equilibrium concentration and adsorption time. Pseudo-second-order represents an adsorption process controlled by chemisorption. Intraparticle-diffusion model can be used to identify the rate-limiting step in the three-stage adsorption process: 1) Surface diffusion through interparticle or boundary layer; 2) intra-particle diffusion into micropores; and 3) equilibrium stage with pore diffusion or solid surface diffusion of adsorbate molecules to interior surface/sites of adsorbent (T. Liu et al., 2017b). Most kinetics studies have shown that the adsorption of MS-derived hydrochar follows pseudo-second-order, and intra-particle diffusion is the rate-limiting step.

Please Insert Table 10 Here

Table 11 compares the physicochemical properties of hydrochar based adsorbents in current studies and their application. Alatalo et al. (2013) directly applied DS-derived hydrochar to heavy metals removal from wastewater. It was reported that the hydrochar can only effectively remove $\mathrm{Pb}$ (II) (up to $80 \%$ ) but not $\mathrm{Cr}(\mathrm{VI})$, $\mathrm{As}(\mathrm{III})$, or $\mathrm{As}(\mathrm{V})$. The adsorption for $\mathrm{Pb}(\mathrm{II})$ well fitted Slips (Langmuir-Freundlich) isotherm $\left(\mathrm{R}^{2}=0.86\right)$ with a maximum adsorption capacity of $12.97 \mathrm{mg} / \mathrm{g}$ (Alatalo et al., 2013). Luo et al. (2020) 
also showed that $\mathrm{HTC}$ of WAS at a low temperature $\left(120^{\circ} \mathrm{C}\right)$ could produce hydrochar with $\mathrm{MgAl}-$

layered double hydroxides composites, an efficient adsorbent of $\mathrm{Pb}(\mathrm{II})\left(\mathrm{q}_{\mathrm{m}}=19-86 \mathrm{mg} / \mathrm{g}\right)$. This indicates that MS-derived hydrochar is a capable adsorbent. Leng et al., (2015b) also demonstrated that hydrochar had effective adsorption of Malachite green and Methylene blue from the liquid. Although hydrochar had low surface area and pore volume, the abundant oxygen-functional groups (e.g., carboxyl, carbonylic, lactonic, and phenolic groups) were found responsible for the adsorption, plus exchanging hydrochar cations (e.g., releasing $\mathrm{Ca}^{2+}, \mathrm{K}^{+}, \mathrm{Mg}^{2+}, \mathrm{Na}^{+}$, and $\mathrm{Zn}^{2+}$ ) with cationic Malachite green (Leng et al., 2015b). Ferrentino et al. (2020) also found that DS-derived hydrochar was efficient in adsorbing Methylene blue, and they suggested a complex sorption process of physical-chemical adsorption, acid-base, and redox equilibria. However, it is noted that, without activation, hydrochar from HTC treatment tends to have a low surface area $\left(\leq 31 \mathrm{~m}^{2} / \mathrm{g}\right)$, which could restrict its adsorption capacity $(<71 \mathrm{mg} / \mathrm{g}$ of Methylene blue). El-Deen and Zhang (2012) first converted MS into a carbon nanocomposite with HTC treatment. They found that the novel nanocomposite could completely remove $0.5 \mathrm{mg} / \mathrm{L}$ of $\mathrm{As}(\mathrm{V})$ within $30 \mathrm{~min}$ at a wastewater $\mathrm{pH}$ of 5-7. The adsorbed As could also be easily released later; thus, the nanocomposite can be reused (El-Deen and Zhang, 2012). However, the adsorption capability $(2.1 \mathrm{mg} / \mathrm{g})$ was still limited.

Please Insert Table 11 Here

To improve the performance of SS-derived hydrochar, several studies utilized chemical, thermal, and thermochemical processes to produce activated carbon. Through chemical activation with $2 \mathrm{M} \mathrm{KOH}$ solution, DS-derived hydrochar showed nearly 3 times higher adsorption capacity of Methylene blue $(140.1 \mathrm{mg} / \mathrm{g})$ and much higher adsorption rate than inactivated; such improvement was favored by the enhanced homogenization of hydrochar surface by alkali washing, although the surface area was not significantly improved (Ferrentino et al., 2020a). Thermal and thermochemical activation processes have 
been found to significantly improve the surface area (up to 270 times) and pore volume (up to 58 times), providing intensive active sites, thus enhancing the adsorption capacity of hydrochar. The pore size of hydrochar $(2-20 \mathrm{~nm})$ has been found mostly in the range of mesopores $(2-50 \mathrm{~nm})$, and activation has not been discovered effective in improving it. Khoshbouy et al. (2019) generated SS-based activated hydrochar under various conditions. They reported that thermochemically activated hydrochar had the best adsorption properties and results compared to non-activated and thermally activated hydrochar. The activated hydrochar showed superior results $\left(\mathrm{q}_{\mathrm{m}}=588.2 \mathrm{mg} / \mathrm{g}\right)$ for methylene blue removal compared with commercial activated carbons $\left(\mathrm{q}_{\mathrm{m}}=210 \mathrm{mg} / \mathrm{g}\right)$ (Khoshbouy et al., 2019). Liu et al. (2017b) also performed a thermochemical activation to MS-derived hydrochar and observed more abundant mesopores and large pores after activation. The activated hydrochar exhibited excellent adsorption capacity of azo dye (440.5 mg/g). Tu et al. (2021) reported that thermochemical activation of MS/coconut shell-derived hydrochar enhanced the adsorption capacity of Methylene blue from 140 to $623 \mathrm{mg} / \mathrm{g}$ by highly improved surface area (from 22 to $874 \mathrm{~m}^{2} / \mathrm{g}$ ) and pore volume (from 0.13 to $0.57 \mathrm{~cm}^{3} / \mathrm{g}$ ) of hydrochar. They also found that the activated hydrochar could be reused for ten cycles by washing with $25 \%$ ethanol solution without affecting the adsorption properties significantly. Noticeably, all reported non-activated hydrochar and activated hydrochar were found to well fit Langmuir isotherm and pseudo-second-order model, indicating that hydrochar based adsorbents likely adsorb organic pollutants and metal cations as a monolayer with chemisorption as the rate limiting step.

Indeed, MS-derived hydrochar has shown a gifted ability in adsorption application due to the oxygenrich functional groups. However, its capacity is typically restricted for the very low surface area and porosity. Most studied hydrochar was generated under mild conditions $\left(\leq 280^{\circ} \mathrm{C}\right)$, while the performance of hydrochar from a more severe environment should also be analyzed since more porous structures could be formed. Limited studies have shown that activated hydrochar could have comparable performance to commercial activated carbons. Therefore, further efforts are required to develop cost-effective and promising adsorbent from MS-derived hydrochar. Last but not least, the release of pre-existing contaminants (e.g., heavy metals and POPs) remains unknown during the adsorption process. 


\subsection{Heterogeneous catalysis}

The development of green catalysts has attracted extensive interest for a sustainable environment. Many studies suggest that hydrochar derived from biomass, such as macroalgae and lignocellulose, as a catalyst could promote $\mathrm{H}_{2}$ production during gasification and facilitate the degradation of organic pollutants (Khan et al., 2019). Concurrently, previous studies also demonstrated that AAEMs existed in MS-derived hydrochar significantly contributed to gas composition from gasification, with catalytic effects observed (Zhuang et al., 2020c). More details can be found in Section 4.1.2. However, there is a lack of validation of using MS-derived hydrochar as a catalyst for gasification or HTG process.

Magnetic hydrochar converted from MS provides another alternative environmentally friendly reuse approach. Such material acts as a heterogeneous catalyst in Fenton and Fenton-like treatment of organic pollutants, e.g., textile wastewater (Zhang et al., 2018). However, many catalysts face issues of iron leaching and deactivation, with a large amount of ferric sludge produced after reaction (Zhou et al., 2015). Yuan and Dai (2014) first developed a facile synthesis of mesoporous material from MS with Fe(II) solution and calcination at $350{ }^{\circ} \mathrm{C}$. The magnetic material exhibited significant improvement and stability as a catalyst for photo-Fenton reaction. Following similar protocols, Zhou et al. (2015) also obtained a magnetic catalyst from paper mill sludge. The excellent stability of catalytic activity and negligible iron leaching were reported during the degradation of Methylene blue through a Fenton-like treatment. Favored by these previous studies, Zhang et al. successfully produced a magnetic hydrochar by coprocessing SS with ferric sludge under various HTC conditions $\left(160-240{ }^{\circ} \mathrm{C}\right.$ for $2-10 \mathrm{~h}$ ). The sludgebased magnetic hydrochar showed great catalytic effects on the Methylene blue degradation in Fenton reaction. However, the removal efficiencies of chemical oxygen demand (COD) and total organic carbon (TOC) only reached $47 \%$ and $49 \%$, respectively, when it was applied to real wastewater from a dyeing process (Zhang et al., 2018). Similarly, Zhang and Hay (2020) synthesized a magnetic hydrochar from biosolids with $\mathrm{Fe}(\mathrm{III})$ and glucose under $\mathrm{HTC}$ condition $\left(180^{\circ} \mathrm{C}\right.$ for $6 \mathrm{~h}$ at $\left.\mathrm{pH}=11\right)$. It was found that the magnetic hydrochar had 10 times bigger pores $(180 \mathrm{~nm})$ than that of non-magnetic hydrochar $(17 \mathrm{~nm})$, although they showed close surface area (around $49 \mathrm{~m}^{2} / \mathrm{g}$ ). The magnetic hydrochar also presented an 
improved enzyme immobilization, which was likely contributed by the larger pores. After 10 wash cycles, magnetic hydrochar still maintained a high activity (> 60\%) on enzymes (laccase and horseradish peroxidase). Moreover, much lower acute toxicity was identified for magnetic hydrochar compared to previously reported carbon-based materials (Zhang and Hay, 2020).

In summary, MS-derived hydrochar seems to be a promising alternative heterogeneous catalyst, which can have high catalytic activity, long-term stability, and low toxicity produced from an economically friendly condition. However, limited studies are available to validate these advantages.

\subsection{Nutrient recovery}

Nutrient (particularly P) recovery is a promising approach to valorize hydrochar. P has been included in the Critical Raw Material List by EU (European Commission, 2018). Its recovery and recycling from waste streams, such as MS and its derived hydrochar, is practical in replacing primary phosphate rock consumption and mitigating eutrophication. Previous studies have demonstrated that most $\mathrm{P}(>81 \%)$ is accumulated in hydrochar after HTP of MS, with a reported average concentration of $2.8 \%, \mathrm{db}$ (see Section 3.2). Among reported studies, the highest $\mathrm{P}$ content $(8.1 \%, \mathrm{db})$ in hydrochar was derived from WAS, which was comparable to commercial P source, phosphate rock (a mineral deposit containing 1115\% of P) (Huang and Tang, 2016; Kroiss et al., 2011). Such abundant P resource could be irretrievably lost without proper recovery, causing both environmental challenges and nutrient loss. Previous studies have demonstrated the potential of P recovery from hydrochar (Huang et al., 2017). Recently, some traditional and emerging technologies have been applied to MS-derived hydrochar for $\mathrm{P}$ and/or $\mathrm{N}$ recovery: Wet chemical extraction, thermochemical process, and integrated biological recovery (Table 12).

Please Insert Table 12 Here

\subsubsection{Wet-chemical extraction}


Wet-chemical extraction and/or coupled with precipitation is the most common method for nutrient recovery from MS-derived hydrochar, as shown in Table 12. The reason is because of its simple procedure and relatively low expenditure (Meng et al., 2019). Our recent review article has detailed the feasibilities and challenges of P recovery from hydrochar using wet-chemical processes (H. Liu et al., 2021). P can be leached from hydrochar by both acidic and alkali solutions. Followed by precipitation or crystallization of liquid extracts, $\mathrm{P}$ and/or $\mathrm{N}$ can be recovered in the form of struvite and calcium phosphates (Ca-P), by adding $\mathrm{Mg}^{2+}$ and $\mathrm{NH}_{4}{ }^{+}$or $\mathrm{Ca}^{2+}$ solutions, respectively, with adjusted $\mathrm{pH}$. Detailed recovery mechanisms can be found elsewhere (Meng et al., 2019; Peng et al., 2018; Tansel et al., 2018). A typical nutrient recovery procedure for MS-derived hydrochar is illustrated in Fig. 14.

Please Insert Fig. 14 Here

Among the studies of nutrient recovery from MS-derived hydrochar, acidic extraction $(\mathrm{pH} \leq 2)$ is commonly used due to its high efficiency. One study found that oxalic and sulfuric acids can effectively extract P from hydrochar with $80-95 \%$ of $\mathrm{P}$ leached, but no further precipitation of solid fertilizer was conducted (Acelas et al., 2014). Several studies have performed struvite production with acidic leachate from hydrochar and ammonium-rich HTP aqueous phase (320-2,970 mg/L) (Becker et al., 2019; Ovsyannikova et al., 2020; Zhai et al., 2014b). A high P recovery rate (82-98\%) can be reached in batch scales. It was also suggested that the obtained P precipitate could be further purified into struvite $\left(\mathrm{MgNH}_{4} \mathrm{PO}_{4} \cdot 6 \mathrm{H}_{2} \mathrm{O}\right)($ Becker et al., 2019). However, co-dissolution of heavy metals along with $\mathrm{P}$ is inevitable during acidic extraction, which causes the concerns of heavy metals contents in recovery products as fertilizers. Detailed studies about heavy metals co-leaching and co-precipitation are necessary to address such concerns.

An improved extraction procedure was developed to minimize the risk of having heavy metals in the recovered Ca-P (Zhai et al., 2014b). Activated alumina power was added into the acidic leachate of 
hydrochar to adsorb $\mathrm{P}$, which was subsequently released in an acid solution. Followed by the calcium precipitation, the recovered calcium phosphate was found to have less than $5 \%$ of $\mathrm{Cu}, \mathrm{Pb}$, and $\mathrm{Zn}$. A high recovery rate (> 85\% of P from MS) was also achieved (Zhai et al., 2014b). Compared to acidic extraction, direct alkaline extraction is a promising alternative to avoid the co-recovery of heavy metals. However, this process is highly selective on P species in hydrochar, as only NAIP can be extracted at alkalic conditions ( $\mathrm{pH} \geq 12$ ) (Cao et al., 2019; Falayi, 2019). Therefore, NAIP content indicates if it is feasible to use alkalic extraction for P recovery. One study showed a very high extraction efficiency (> 89\% of total P) from hydrochar $\left(20{ }^{\circ} \mathrm{C}\right.$ for $\left.4 \mathrm{~h}\right)$ using $\mathrm{KOH}$ solution $(\mathrm{pH} \geq 12)$, which was probably caused by the use of poly-aluminum sulfate during sludge sedimentation in the WWTP. A solid K-P fertilizer, Kstruvite $\left(\mathrm{MgKPO}_{4} \cdot 6 \mathrm{H}_{2} \mathrm{O}\right)$, was produced by subsequent precipitation with a high $\mathrm{P}$ recovery efficiency (> 92\% from raw sludge) (Li et al., 2020). Many studies found that alkaline-extractable $\mathrm{P}$ in sludge-derived hydrochar was below 60\% (especially for those produced under higher HTP temperatures), limiting the wide application of alkalic extraction (Shi et al., 2019; Y. Xu et al., 2018; Zhai et al., 2014b). Our previous review identified that sequential procedures by coupling acidic and alkalic extraction (e.g., procedures established by Zhai et al. (2014b)) could achieve promising P extraction efficiencies (7091\%), separate metals from P extracts, and produce qualified P fertilizers and potentially clean hydrochar (H. Liu et al., 2021).

Compared to batch-scale-based hydrochar, the nutrient recovery rate in the continuous flow operation does not seem satisfactory. Ovsyannikova et al. (2020) used hydrochar and aqueous phase from a pilotscale continuous flow $\mathrm{HTL}$ treatment $\left(350^{\circ} \mathrm{C}, 22 \mathrm{MPa}\right.$, and $\left.60 \mathrm{~L} / \mathrm{h}\right)$ of primary sludge for nutrient recovery. The total recovery for $\mathrm{N}$ and $\mathrm{P}$ based on the original sludge was only $6.8 \%$ and $23.7 \%$, respectively. It should be noted that the recovery rates were high based on precipitation (99\% of P and $79 \%$ of $\mathrm{NH}_{4}-\mathrm{N}$ ). Interestingly, there was also $2 \%$ of $\mathrm{K}$ recovered from the sludge in the struvite precipitates. The low overall recovery rate was attributed to the dispersion of P-containing particles into the biocrude (Ovsyannikova et al., 2020). 
Overall, wet-chemical technology is promising to recover nutrients from hydrochar and associated HTP aqueous phase. Laboratory studies have demonstrated that a high extraction rate and total recovery rate of $\mathrm{P}$ can be achieved simultaneously. It is believed that a way to higher $\mathrm{P}$ recovery rate can be accomplished with the optimization of the continuous-flow HTP operations. However, preliminary cost analysis has shown that struvite precipitation coupled with HTC treatment of MPS can marginally make a profit, and the costliest part was the use of expensive Mg chemicals (Munir et al., 2017). Therefore, alternative methods should be developed for optimizing nutrient recovery. Many other research gaps are required to be filled, such as the risk of contaminant accumulation in the recovered fertilizer, the reusability and disposal of post-recovery filtrate, the utilization of processed residue (i.e., hydrochar after P leaching), the profitability of each extraction process, etc. After P recovery, additional improvements of hydrochar should be counted to provide integrated benefits. For example, acid washing $(1 \mathrm{~N} \mathrm{HCl})$ could reduce ash in DS-derived hydrochar by 50\%, thus enhancing C, FC, and HHV by 70\%, 167\%, and 53\%, respectively, and providing high-quality solid biofuel (Marin-Batista et al., 2020). By removing most heavy metals with acidic extraction, hydrochar may also be directly used as soil amendment. Moreover, a sound hydrochar adsorbent could be formed due to the improved adsorption performance by both acid and alkaline treatments (see Section 4.3).

\subsubsection{Thermochemical process}

Thermochemical technique provides an alternative method for P recovery from MS-derived hydrochar. It can avoid the problematic metals present in wet-chemical extraction process. Favored by the low melting point of $\mathrm{P}_{2} \mathrm{O}_{5}\left(340{ }^{\circ} \mathrm{C}\right), \mathrm{P}$ in hydrochar can be vaporized under heated conditions, and thus recovered in the form of settled ash (Ahn et al., 2020). So far, only Feng et al. evaluated the feasibility of $\mathrm{P}$ recovery through thermochemical process, steam gasification of hydrochar derived from waste activated sludge (Feng et al., 2018). It was found that phosphorus oxides can be completely converted into gas phase after $560{ }^{\circ} \mathrm{C}$, and AP was the primary form in the gasification ash. However, compared to direct gasification of MS, the total P recovery rate was not enhanced and stayed low (22-56\%) (Feng et al., 2018). Chlorine donor is widely used to improve the thermochemical recovery process, but no further 
studies about its application to hydrochar. Besides, it remains invalid whether heavy metals are eliminated from P-rich ash produced by hydrochar. Lastly, high energy demand and equipment requirements also limit the application of thermochemical treatment for P recovery.

\subsubsection{Integrated biotechnology}

With the growing interest in green and sustainable infrastructures, emerging technologies of coupling HTP with biological treatment have received much attention. Aida et al. (2016) first designed a system of algal cultivation using hydrochar and HTL aqueous. The scheme was mainly composed of: 1) HTC treatment of MS to produce nutrient-rich liquid; 2) conversion of $\mathrm{P}$ and cellulose-rich hydrochar into nutrient-rich glucose solution; 3) cultivation of microalgae with HTC aqueous and glucose solution; 4) production of biocrude from grown microalgae using HTL process. The preliminary results showed positive growth of microalgae using the integrated biological process (Aida et al., 2016). Therefore, nutrients can be cycled for microalgae cultivation during continuous treatment. The new green biotechnology provides an effective solid reduction approach with feasible ability of recycling nutrients. However, as an emerging technology, it also faces many challenges: The nutrient utilization efficiencies are unknown; the cultivation procedure requires care to balance nutrients; the contaminants in MS may inhibit the algal growth; the associated costs are not analyzed. Concurrently, another study integrated algal growth using MS, and HTL of cultivated algae followed by struvite extraction and showed promising performance (5.9\% of $\mathrm{N}$ and $71.6 \%$ of P recovery) (Abeysiriwardana-Arachchige et al., 2020). Therefore, the potential of emerging biotechnology, such as integrated algae cultivation, should not be underestimated.

\subsection{Evaluation of valorization technologies for hydrochar}

The abundant functions of MS-derived hydrochar provide numerous opportunities for its valorization. The utilization approaches for hydrochar are compared in Fig. 15. A summary of technical prospects for these processes is provided below:

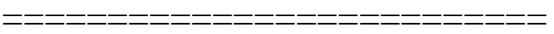


I. Combustion using hydrochar as a biofuel is a promising direction in terms of the commercialization potential. Further optimization of energy density and combustion performance by co-HTC or cocombustion of hydrochar shows a way to enhance its market value. Addressing issues of ash slagging and fouling and harmful emissions is also beneficial. Besides, it is necessary to identify the nutrient potential and hazardous components of the post-combustion products, such as fly ash and bottom ash, from the perspective of a sustainable environment.

II. Gasification to syngas production undergoes a high energy demand and expenditure (both capital and operating costs) associated with rigorous reactor requirements and catalyst assistance. Coupling energy gas production with $\mathrm{P}$ recovery through gasification may relieve the cost issue. However, gas separation/purification processes are required to become a mainstream treatment. Many other quandaries are still surrounding the understanding of gasification reactions, yield enhancement, ideal design, continuous feeding techniques, gas cleanup, and byproducts (ash) disposal.

III. Agricultural application of hydrochar has shown its positive effects on soil properties and crop yield. However, such impacts may largely rely on the soil and plants, and thus require extensive and longterm studies to validate prior to field application. The relationships are not clarified between hydrochar application and the response of soil, microbial community, and plants. It appears that the availability of nutrients in hydrochar is inhibited, which will benefit the slow release process and long-term application. However, the fertilization efficiency and associated runoff issues need further investigation. Moreover, since pre-existing contaminants, such as heavy metals and POPs, are likely to accumulate in hydrochar, the safe use of hydrochar in agriculture must be developed and demonstrated. This will also help address public and specifically farmers' concerns.

IV. Adsorption capacity is an important feature of hydrochar. It has shown positive effects in water remediation, with excellent activated carbon derived from hydrochar. However, the direct adsorption 
of hydrochar is still limited and thus requires further optimization and systematic investigation. It is also necessary to recognize the potential release of pre-existing contaminants, such as heavy metals and POPs, during the adsorption process.

V. Utilized as a heterogeneous catalyst is a special ability of hydrochar. Due to the presence of AAEMs, hydrochar displays the catalytic potential in gasification process. Magnetic hydrochar derived from MS provides a green and sustainable catalyst in Fenton-like reactions. However, there are limited studies about the catalytic mechanisms and application. Certainly, hydrochar is worthy of investigation as a catalyst for its high catalytic activity, long-term stability, and low toxicity.

VI. Nutrient recovery is a sound promise for the valorization of hydrochar. It could lead to a costeffective, efficient, profitable, easy, and simple operation. Wet-chemical extraction and precipitation are mostly used for their simple process, low expenditure, and high efficiency. However, they do require additional chemicals and equipment. Optimization of the chemical usage and search for cheap alternative chemicals would improve the profitability. Towards a sustainable approach, other gaps should also be fulfilled: The purity of recovered fertilizer, the reusability and disposal of postrecovery filtrate, and the usage of hydrochar after extraction. Following P recovery, the modified hydrochar could be investigated for solid biofuel, soil amendment, adsorbent, and catalyst to develop an integrated utilization approach.

\section{Prospects towards sustainable waste management}

Hydrothermal conversion is a promising technology in dealing with the challenges of MS treatment. The valorization of its byproducts, such as hydrochar and aqueous phase, is a critical and necessary first step. Among hydrothermal processes, HTC and HTL have shown their promising commercial potential for sludge decomposition and energy production. Through the literature review, a research trend of coupling HTP (particularly HTC/HTL) of MS and AD of HTP aqueous is identified, which could enhance the overall energy recovery, sustainability, environmental performance, and upscaling potential. Despite the energy recovered into hydrochar and biocrude by HTC and HTL, respectively, a large amount of organic matter is converted into the aqueous phase (with an average dry basis yield of 39 and 23\%, 
respectively), requiring proper treatment or valorization. Fig. 16 compares the main characteristics of HTC aqueous and HTL aqueous from various types of sludge. Despite the MS type, both HTC and HTL aqueous showed high contents of COD (13-98 vs. 48-83 g/L) and TOC (9-38 vs. 14-27 g/L) on average, suggesting that further valorization of aqueous (e.g., biogas production by AD) would benefit the energy recovery of the HTP system. It should be noted that COD and TOC could proportionally increase with feedstock TS contents, which raised from 9.6 to $72.3 \mathrm{~g} / \mathrm{L}$ and from 3.6 to $29.8 \mathrm{~g} / \mathrm{L}$, respectively, in HTC aqueous from DS when sludge TS increased from 2.5 to 30\% (Aragón-Briceño et al., 2020). Previous literature review has reported that AD of HTP aqueous typically could achieve a specific methane yield of $200 \mathrm{~mL} \mathrm{CH}_{4} / \mathrm{g} \mathrm{COD}$, corresponding to over 50\% energy recovery from the aqueous (Watson et al., 2020). Due to the hydrolysis and deamination of protein in MS, HTC and HTL aqueous also contains a large amount of ammonia (0.6-4.1 vs. 2.2-5 g/L), which are typically higher in SS and DS derived aqueous. Meanwhile, most $\mathrm{P}(>82 \%)$ is concentrated in hydrochar, which can be extracted and mixed with ammonia rich HTP aqueous to produce struvite as a fertilizer for N/P recovery. Studies have found that the recovery of N/P by struvite from HTP aqueous could enhance the performance of AD, probably due to the removal of ammonia and co-precipitation of other inhibitors (e.g., phenolics) (P. Wang et al., 2021; W. Wang et al., 2017). Conceptual designs of integrating HTC-AD or HTL-AD, nutrient recovery, and subsequent hydrochar valorization are illustrated in Fig. 17.

Please Insert Fig. 16 Here

Please Insert Fig. 17 Here 
HTC is mostly applied to DS that contains a high content of non-biodegradable organics, which can be solubilized into HTC aqueous and recycled into AD with enhanced biodegradability. Consequently, the volume of remaining solids (hydrochar) for management could be significantly reduced. Many studies have suggested that HTC at mild conditions (e.g., $180-250{ }^{\circ} \mathrm{C}$ for $<1 \mathrm{~h}$ ) could compromise between energy consumption, dewaterability, hydrochar production, and methane production $\left(92-356 \mathrm{~mL} \mathrm{CH}_{4} / \mathrm{g}\right.$ COD) from HTC aqueous (Ahmed et al., 2021a, 2021b; Aragón-Briceño et al., 2017, 2021a, 2021b, 2020; Ferrentino et al., 2020b; Gaur et al., 2020; Medina-Martos et al., 2020). Danso-Boateng et al. (2015) found that Maillard reactions between monosaccharides and amino acids initiated at $\mathrm{HTC}$ of $180{ }^{\circ} \mathrm{C}$ for over 15 min, which could form non-biodegradable and/or AD inhibitors (e.g., aldehydes, furans, pyrroles, pyrazines, and pyridines) in the aqueous. However, increasing temperature from 160 to $250{ }^{\circ} \mathrm{C}(30 \mathrm{~min})$ could enhance the formation of 191 to $716 \mathrm{mg}$ COD/L equivalent volatile fatty acids from DS HTC aqueous, which are intermediate compounds in methane production (Aragón-Briceño et al., 2017). Therefore, HTC reaction conditions should be optimized for coupling HTC-AD. Through a system energy balance study for HTC-AD, Aragón-Briceño et al. (2020) found that higher TS contents in feedstock DS were favorable for net system electricity and heat production, which became positive at TS $\geq 10 \%$ when energy ( $>65 \%$ based on feedstock) in hydrochar was included. However, if hydrochar contained energy was omitted, HTC-AD would consume $0.01 \mathrm{~kW}$ of electricity and $0.06 \mathrm{~kW}$ of heat per $\mathrm{kg}$ of solids input even at 30\% TS. Example of overall C and energy distribution is shown in Fig. 17a. Energy production and valorization of hydrochar in the HTC-AD scenario are critical steps for building a sustainable system in WWTPs. We recommend integrating nutrient recovery to the system to enhance the overall benefits and sustainability, especially in regions lack of P resource (e.g., EU). More importantly, the ash removal during P extraction step could make hydrochar a more capable solid biofuel. The potential of using hydrochar as a soil amender, absorbent, and heterogeneous catalyst has been demonstrated in the Section 4. However, the concerns of transferring POPs and heavy metals from hydrochar to struvite should be addressed before it can be used as a fertilizer. 
MPS is a preferable feedstock for HTL as it likely contains balanced protein (dominant in SS) and carbohydrates (major in PS), which promotes Maillard reactions to achieve high yields and energy recovery into biocrude (Basar et al., 2021). Using HTL, where C is maximized to biocrude and P is enriched in hydrochar to allow its recovery, represents a justifiable operation for MS treatment. Through several techno-economic analyses, Pacific Northwest National Laboratory in the US has concluded that HTL of MPS (20-25\% TS) is very promising in producing economically competitive and environmentally sustainable biocrude, while significantly reducing management costs and environmental risks associated to sludge solids (Li et al., 2021; Seiple et al., 2020, 2017; Snowden-Swan et al., 2017, 2016). However, HTL aqueous still contains a large portion of solubilized C (e.g., 20\% of total input), which could contribute 9\% BOD and 18\% ammonia load to the WWTP (Snowden-Swan et al., 2017). Simply return HTL aqueous to the WWTP headworks would significantly increase aeration cost and may lead to toxicity impacts and exceed discharge limits due to high ammonia concentrations. Many studies have proposed to valorize $\mathrm{HTL}$ aqueous by $\mathrm{AD}$, with a specific methane yield of $36-259 \mathrm{~mL} \mathrm{CH}_{4} / \mathrm{g} \mathrm{COD}$ (Hao et al., 2020; Posmanik et al., 2017b; Usman et al., 2019b, 2020; P. Wang et al., 2021). However, inhibitory effects, such as delay, reduced rate, or even complete inhibition on $\mathrm{AD}$ performance, have been widely reported by the increase of HTL aqueous loading rates (Watson et al., 2020). Many organics (e.g., furans, ketones, phenols, and N-heterocyclic compounds) and inorganics (e.g., ammonia and chloride salts) in HTL aqueous can inhibit AD activities (mainly acetogenesis and methanogenesis). High temperatures (e.g., 300-350 ${ }^{\circ} \mathrm{C}$ ) used in HTL could promote the formation of recalcitrant compounds, such as melanoidins, $\mathrm{N}$-heterocyclics, and phenols, which are mainly responsible for AD inhibition. Wang et al. (2021) observed no methane generation and 1-8\% COD removal for $\mathrm{AD}$ (at $35^{\circ} \mathrm{C}, \mathrm{pH} 7-8$ for 28 days) of raw $\mathrm{HTL}$ aqueous from MS ( $325^{\circ} \mathrm{C}$ for $30 \mathrm{~min}$ ). Most other studies were conducted on diluted (4-10 times) HTL aqueous to obtain positive methane yields. Therefore, efficient treatment of HTL aqueous is considered the critical step in HTL-AD configuration. Studies have shown that adding granular activated carbon (Usman et al., 2019b) and hydrochar (Usman et al., 2020) to diluted HTL aqueous for $\mathrm{AD}$ could improve methane yield by up to 30 and $52 \%$, respectively, due to enhanced 
degradation of aromatic, N-heterocyclic, and phenolic compounds. A promising treatment was achieved by Wang et al. (2021), who used struvite precipitation for ammonia removal (82\%) and biochar for phenols removal (70\%) and reached a specific methane yield up to $225 \mathrm{~mL} \mathrm{CH}_{4} / \mathrm{g}$ COD from non-diluted HTL aqueous by mesophilic AD, while only struvite precipitation could achieve a specific methane yield up to $115 \mathrm{~mL} \mathrm{CH}_{4} / \mathrm{g}$ COD. Shanmugam et al. (2017) also found struvite precipitation improved methane production by 3.5 times from AD of diluted HTL aqueous from algae compared to non-treated. To achieve sustainable management of MS, an interwoven system is conceptually designed to integrate HTL$\mathrm{AD}$ and nutrient recovery with hydrochar valorization in Fig. 17b. However, the long-term operation of $\mathrm{AD}$ for HTL aqueous is still challenging due to the accumulation of inhibitors and possible operational failure. This need to be addressed before the system can be applied to full-scale.

\section{Conclusions}

HTP has been recognized as one of the most efficient technologies in sludge-to-energy conversion for handling the challenge of waste MS management. Hydrochar, as the solid residue, is the main product of all three hydrothermal processes (i.e., HTC, HTL, and HTG). Its valorization improves the environmental and financial sustainability of sludge treatment by HTP. This review aims to guide future studies by summarizing the effects of reaction conditions on hydrochar formation, comparing the key characteristics of hydrochar, and highlighting the potential valorization routes with critical evaluations. The major findings of this review are listed below.

- High TS content (10-25 wt\%) in MS feedstock for HTP is beneficial to hydrochar yields, process energy efficiency and energy recovery, and concentrated nutrients in hydrochar (e.g., P) and aqueous phase (e.g., organics and $\mathrm{N}$ ) for efficient recovery.

- Hydrothermal temperature is crucial in determining reaction pathways, while combined effects of temperature and residence time govern hydrochar yields, which significantly decrease with increasing severity factor and remain around $10 \%, \mathrm{db}$ at severity factor $>1$.

- Co-HTC and co-HTL of MS with other types of biomass have synergistic effects on quality and/or yield of hydrochar and biocrude, respectively. Co-HTC with low-ash biomass, such as lignocellulose, 
could reduce ash, enhance HHV, and mitigate the concerns of heavy metals in hydrochar, representing a promising technique to generate desirable solid biofuel.

- Numerous catalysts have been examined in HTP to serve various purposes (e.g., dewaterability, conversion rate, and energy and nutrient recovery), but their reusability and the balance between costs and outcome should be evaluated.

- Using organic solvents or co-solvents in HTL could reduce reaction temperature and enhance biocrude yield and energy recovery. However, the biggest barriers of industrial implementation and solvent recycling should be addressed. The impacts of solvents on MS-derived hydrochar also lack studies.

- Hydrochar has diverse physicochemical properties that highly depend on initial characteristics of MS and treatment conditions. Therefore, the assignment of hydrochar utilization should be different from case to case. Mixing various types of sludge to achieve low ash and high C, FC, and HHV could be desirable for producing biofuel hydrochar under HTC conditions, while DS and SS derived hydrochar from HTL/HTG treatment could be suitable for efficient P recovery.

- Hydrochar has been extensively studied for solid biofuel production, but its other application means should be expanded for valorization, including but not limited to land application, adsorption, catalysis, and nutrient recovery.

- Energy densification (>1) of hydrochar likely occurs at HTP temperature of $150-300{ }^{\circ} \mathrm{C}$ and severity factor $<0.5$. However, the high ash contents $(19-57 \%, \mathrm{db})$ could limit the direct combustion of hydrochar due to possible ash fouling.

- Energy production from hydrochar is necessary for net positive energy recovery in HTC-AD scenario, while proper treatment for HTL aqueous is challenging for HTL-AD case.

- Coupling P extraction from hydrochar and struvite precipitation with HTP aqueous is critical for both HTC-AD and HTL-AD scenarios for multiple benefits: 1) Recycling non-renewable critical material $(\mathrm{P}) ; 2$ ) reducing ammonia level in HTP aqueous and enhancing biogas production from AD; 3 ) 
decreasing contents of ash and heavy metals in hydrochar to promote its subsequent valorization, such as upgraded biofuel, soil amender, activated carbon, and catalyst; and 4) improving the overall energy recovery, environmental performance, system sustainability, and commercialization potential.

\section{Declaration of Competing Interest}

The authors declare that they have no known competing financial interests or personal relationships that could have appeared to influence the work reported in this paper.

\section{Acknowledgments}

This research was funded by the Natural Sciences and Engineering Research Council of Canada (NSERC) and Metro Vancouver Industrial Research Chair Program in Advanced Resource Recovery from Wastewater (IRCPJ 548816-18). The authors would also like to thank the handling Editor and anonymous reviewers for their insightful comments and suggestions, which greatly improved this article.

\section{References}

Abeysiriwardana-Arachchige, I.S.A., Munasinghe-Arachchige, S.P., Delanka-Pedige, H.M.K., Nirmalakhandan, N., 2020. Removal and recovery of nutrients from municipal sewage: Algal vs. conventional approaches. Water Res. 175, 115709. https://doi.org/10.1016/j.watres.2020.115709

Acelas, N.Y., López, D.P., Wim Brilman, D.W.F., Kersten, S.R.A., Kootstra, A.M.J., 2014. Supercritical water gasification of sewage sludge: Gas production and phosphorus recovery. Bioresour. Technol. 174, 167-175. https://doi.org/10.1016/j.biortech.2014.10.003

Afif, E., Azadi, P., Farnood, R., 2011. Catalytic hydrothermal gasification of activated sludge. Appl. Catal. B Environ. 105, 136-143. https://doi.org/10.1016/j.apcatb.2011.04.003

Ahmed, M., Andreottola, G., Elagroudy, S., Negm, M.S., Fiori, L., 2021a. Coupling hydrothermal carbonization and anaerobic digestion for sewage digestate management: Influence of hydrothermal treatment time on dewaterability and bio-methane production. J. Environ. Manage. 281, 111910. https://doi.org/10.1016/j.jenvman.2020.111910

Ahmed, M., Sartori, F., Merzari, F., Fiori, L., Elagroudy, S., Negm, M.S., Andreottola, G., 2021 b. Anaerobic degradation of digestate based hydrothermal carbonization products in a continuous hybrid fixed bed anaerobic filter. Bioresour. Technol. 330, 124971. https://doi.org/10.1016/j.biortech.2021.124971

Ahn, H., Kim, D., Lee, Y., 2020. Combustion characteristics of sewage sludge solid fuels produced by drying and hydrothermal carbonization in a fluidized bed. Renew. Energy 147, 957-968. https://doi.org/10.1016/j.renene.2019.09.057

Aida, T.M., Nonaka, T., Fukuda, S., Kujiraoka, H., Kumagai, Y., Maruta, R., Ota, M., Suzuki, I., Watanabe, M.M., Inomata, H., Smith, R.L., 2016. Nutrient recovery from municipal sludge for microalgae cultivation with two-step hydrothermal liquefaction. Algal Res. 18, 61-68. https://doi.org/10.1016/j.algal.2016.06.009 
Alatalo, S.M., Repo, E., Mäkilä, E., Salonen, J., Vakkilainen, E., Sillanpää, M., 2013. Adsorption behavior of hydrothermally treated municipal sludge $\&$ pulp and paper industry sludge. Bioresour. Technol. 147, 71-76. https://doi.org/10.1016/j.biortech.2013.08.034

Ali Shah, A., Sohail Toor, S., Hussain Seehar, T., Sadetmahaleh, K.K., Helmer Pedersen, T., Haaning Nielsen, A., Aistrup Rosendahl, L., 2021. Bio-crude production through co-hydrothermal processing of swine manure with sewage sludge to enhance pumpability. Fuel 288. https://doi.org/10.1016/j.fuel.2020.119407

Alipour, M., Asadi, H., Chen, C., Rashti, M.R., 2021. Bioavailability and eco-toxicity of heavy metals in chars produced from municipal sewage sludge decreased during pyrolysis and hydrothermal carbonization. Ecol. Eng. 162, 106173. https://doi.org/10.1016/j.ecoleng.2021.106173

Amrullah, A., Matsumura, Y., 2018. Supercritical water gasification of sewage sludge in continuous reactor. Bioresour. Technol. 249, 276-283. https://doi.org/10.1016/j.biortech.2017.10.002

Anastasakis, K., Biller, P., Madsen, R.B., Glasius, M., Johannsen, I., 2018. Continuous Hydrothermal Liquefaction of Biomass in a Novel Pilot Plant with Heat Recovery and Hydraulic Oscillation. Energies 11, 1-23. https://doi.org/10.3390/en11102695

Aragón-Briceño, C., Ross, A.B., Camargo-Valero, M.A., 2017. Evaluation and comparison of product yields and bio-methane potential in sewage digestate following hydrothermal treatment. Appl. Energy 208, 1357-1369. https://doi.org/10.1016/j.apenergy.2017.09.019

Aragón-Briceño, C.I., Grasham, O., Ross, A.B., Dupont, V., Camargo-Valero, M.A., 2020. Hydrothermal carbonization of sewage digestate at wastewater treatment works: Influence of solid loading on characteristics of hydrochar, process water and plant energetics. Renew. Energy 157, 959-973. https://doi.org/10.1016/j.renene.2020.05.021

Aragón-Briceño, C.I., Pozarlik, A.K., Bramer, E.A., Niedzwiecki, L., Pawlak-Kruczek, H., Brem, G., 2021a. Hydrothermal carbonization of wet biomass from nitrogen and phosphorus approach: A review. Renew. Energy 171, 401-415. https://doi.org/10.1016/j.renene.2021.02.109

Aragón-Briceño, C.I., Ross, A.B., Camargo-Valero, M.A., 2021b. Mass and energy integration study of hydrothermal carbonization with anaerobic digestion of sewage sludge. Renew. Energy 167, 473483. https://doi.org/10.1016/j.renene.2020.11.103

Azadi, P., Afif, E., Foroughi, H., Dai, T., Azadi, F., Farnood, R., 2013. Catalytic reforming of activated sludge model compounds in supercritical water using nickel and ruthenium catalysts. Appl. Catal. B Environ. 134-135, 265-273. https://doi.org/10.1016/j.apcatb.2013.01.022

Barber, W.P.F., 2016. Thermal hydrolysis for sewage treatment: A critical review. Water Res. 104, 53-71. https://doi.org/10.1016/j.watres.2016.07.069

Basar, I.A., Liu, H., Carrere, H., Trably, E., Eskicioglu, C., 2021. A review on key design and operational parameters to optimize and develop hydrothermal liquefaction of biomass for biorefinery applications. Green Chem. https://doi.org/10.1039/D0GC04092D

Becker, G.C., Wüst, D., Köhler, H., Lautenbach, A., Kruse, A., 2019. Novel approach of phosphatereclamation as struvite from sewage sludge by utilising hydrothermal carbonization. J. Environ. Manage. 238, 119-125. https://doi.org/10.1016/j.jenvman.2019.02.121

Belete, Y.Z., Leu, S., Boussiba, S., Zorin, B., Posten, C., Thomsen, L., Wang, S., Gross, A., Bernstein, R., 2019. Characterization and utilization of hydrothermal carbonization aqueous phase as nutrient source for microalgal growth. Bioresour. Technol. 290, 121758. https://doi.org/10.1016/j.biortech.2019.121758

Berge, N.D., Ro, K.S., Mao, J., Flora, J.R.V., Chappell, M.A., Bae, S., 2011. Hydrothermal carbonization of municipal waste streams. Environ. Sci. Technol. 45, 5696-5703. 
https://doi.org/10.1021/es2004528

Bhatt, D., Shrestha, A., Dahal, R.K., Acharya, B., Basu, P., MacEwen, R., 2018. Hydrothermal carbonization of biosolids from Waste water treatment plant. Energies 11. https://doi.org/10.3390/en11092286

Biller, P., Johannsen, I., dos Passos, J.S., Ottosen, L.D.M., 2018. Primary sewage sludge filtration using biomass filter aids and subsequent hydrothermal co-liquefaction. Water Res. 130, 58-68. https://doi.org/10.1016/j.watres.2017.11.048

Breulmann, M., van Afferden, M., Müller, R.A., Schulz, E., Fühner, C., 2017. Process conditions of pyrolysis and hydrothermal carbonization affect the potential of sewage sludge for soil carbon sequestration and amelioration. J. Anal. Appl. Pyrolysis 124, 256-265. https://doi.org/10.1016/j.jaap.2017.01.026

Brookman, H., Gievers, F., Zelinski, V., Ohlert, J., Loewen, A., 2018. Influence of hydrothermal carbonization on composition, formation and elimination of biphenyls, dioxins and furans in sewage sludge. Energies 11. https://doi.org/10.3390/en11061582

Cao, J., Wu, Y., Zhao, J., Jin, S., Aleem, M., Zhang, Q., Fang, F., Xue, Z., Luo, J., 2019. Phosphorus recovery as vivianite from waste activated sludge via optimizing iron source and $\mathrm{pH}$ value during anaerobic fermentation. Bioresour. Technol. 293, 122088. https://doi.org/10.1016/j.biortech.2019.122088

Cao, X., Peng, X., Sun, S., Zhong, L., Chen, W., Wang, S., Sun, R.C., 2015. Hydrothermal conversion of xylose, glucose, and cellulose under the catalysis of transition metal sulfates. Carbohydr. Polym. 118, 44-51. https://doi.org/10.1016/j.carbpol.2014.10.069

Catallo, W.J., Comeaux, J.L., 2008. Reductive hydrothermal treatment of sewage sludge. Waste Manag. 28, 2213-2219. https://doi.org/10.1016/j.wasman.2007.10.005

Chanaka Udayanga, W.D., Veksha, A., Giannis, A., Lisak, G., Chang, V.W.C., Lim, T.T., 2018. Fate and distribution of heavy metals during thermal processing of sewage sludge. Fuel 226, 721-744. https://doi.org/10.1016/j.fuel.2018.04.045

Chang, Y., Xiao, X., Huang, H., Xiao, Y.-D., Fang, H.-S., He, J.-B., Zhou, C.-H., 2021. Transformation characteristics of polycyclic aromatic hydrocarbons during hydrothermal liquefaction of sewage sludge. J. Supercrit. Fluids 170, 105158. https://doi.org/10.1016/j.supflu.2020.105158

Channiwala, S.A., Parikh, P.P., 2002. A unified correlation for estimating HHV of solid, liquid and gaseous fuels. Fuel 81, 1051-1063. https://doi.org/10.1016/S0016-2361(01)00131-4

Chen, C., Liu, G., An, Q., Lin, L., Shang, Y., Wan, C., 2020. From wasted sludge to valuable biochar by low temperature hydrothermal carbonization treatment: Insight into the surface characteristics. J. Clean. Prod. 263, 121600. https://doi.org/10.1016/j.jclepro.2020.121600

Chen, D., Dou, Y., Tang, Q., Huang, Y., Song, M., Zhou, J., Fu, L., 2020. New insight on the combined effects of hydrothermal treatment and $\mathrm{FeSO} 4 / \mathrm{Ca}(\mathrm{ClO}) 2$ oxidation for sludge dewaterability improvement: From experimental to theoretical investigation. Fuel Process. Technol. 197. https://doi.org/10.1016/j.fuproc.2019.106196

Chen, G., Tian, S., Liu, B., Hu, M., Ma, W., Li, X., 2020. Stabilization of heavy metals during copyrolysis of sewage sludge and excavated waste. Waste Manag. 103, 268-275. https://doi.org/10.1016/j.wasman.2019.12.031

Chen, H., Rao, Y., Cao, L., Shi, Y., Hao, S., Luo, G., Zhang, S., 2019. Hydrothermal conversion of sewage sludge: Focusing on the characterization of liquid products and their methane yields. Chem. Eng. J. 357, 367-375. https://doi.org/10.1016/j.cej.2018.09.180

Chen, H., Zhai, Y., Xu, B., Xiang, B., Zhu, L., Qiu, L., Liu, X., Li, C., Zeng, G., 2014. Fate and risk 
assessment of heavy metals in residue from co-liquefaction of Camellia oleifera cake and sewage sludge in supercritical ethanol. Bioresour. Technol. 167, 578-581.

https://doi.org/10.1016/j.biortech.2014.06.048

Chen, W.T., Zhang, Y., Zhang, J., Yu, G., Schideman, L.C., Zhang, P., Minarick, M., 2014.

Hydrothermal liquefaction of mixed-culture algal biomass from wastewater treatment system into bio-crude oil. Bioresour. Technol. 152, 130-139. https://doi.org/10.1016/j.biortech.2013.10.111

Chen, Y., Chen, H., Thring, R.W., Liu, H., Zhou, J., Tao, Y., Li, J., 2020. Immobilization of Chromium Contaminated Soil by Co-pyrolysis with Rice Straw. Water, Air, Soil Pollut. 231, 200. https://doi.org/10.1007/s11270-020-04581-3

Chen, Y., Guo, L., Cao, W., Jin, H., Guo, S., Zhang, X., 2013a. Hydrogen production by sewage sludge gasification in supercritical water with a fluidized bed reactor. Int. J. Hydrogen Energy 38, 1299112999. https://doi.org/10.1016/j.jihydene.2013.03.165

Chen, Y., Guo, L., Jin, H., Yin, J., Lu, Y., Zhang, X., 2013b. An experimental investigation of sewage sludge gasification in near and super-critical water using a batch reactor, in: International Journal of Hydrogen Energy. pp. 12912-12920. https://doi.org/10.1016/j.ijhydene.2013.05.076

Chen, Y.W., Lee, H.V., 2020. Recent progress in homogeneous Lewis acid catalysts for the transformation of hemicellulose and cellulose into valuable chemicals, fuels, and nanocellulose. Rev. Chem. Eng. 36, 215-235. https://doi.org/10.1515/revce-2017-0071

Chu, Q., Xue, L., Singh, B.P., Yu, S., Müller, K., Wang, H., Feng, Y., Pan, G., Zheng, X., Yang, L., 2020. Sewage sludge-derived hydrochar that inhibits ammonia volatilization, improves soil nitrogen retention and rice nitrogen utilization. Chemosphere 245, 125558. https://doi.org/10.1016/j.chemosphere.2019.125558

Conti, F., Toor, S.S., Pedersen, T.H., Seehar, T.H., Nielsen, A.H., Rosendahl, L.A., 2020. Valorization of animal and human wastes through hydrothermal liquefaction for biocrude production and simultaneous recovery of nutrients. Energy Convers. Manag. 216, 112925. https://doi.org/10.1016/j.enconman.2020.112925

Couto, E.A., Pinto, F., Varela, F., Reis, A., Costa, P., Calijuri, M.L., 2018. Hydrothermal liquefaction of biomass produced from domestic sewage treatment in high-rate ponds. Renew. Energy 118, 644653. https://doi.org/10.1016/j.renene.2017.11.041

Danso-Boateng, E., Shama, G., Wheatley, A.D., Martin, S.J., Holdich, R.G., 2015. Hydrothermal carbonisation of sewage sludge: Effect of process conditions on product characteristics and methane production. Bioresour. Technol. 177, 318-327. https://doi.org/10.1016/j.biortech.2014.11.096

De la Rubia, M.A., Villamil, J.A., Rodriguez, J.J., Borja, R., Mohedano, A.F., 2018. Mesophilic anaerobic co-digestion of the organic fraction of municipal solid waste with the liquid fraction from hydrothermal carbonization of sewage sludge. Waste Manag. 76, 315-322. https://doi.org/10.1016/j.wasman.2018.02.046

Do, T.X., Mujahid, R., Lim, H.S., Kim, J.-K., Lim, Y.-I., Kim, J., 2020. Techno-economic analysis of bio heavy-oil production from sewage sludge using supercritical and subcritical water. Renew. Energy 151, 30-42. https://doi.org/10.1016/j.renene.2019.10.138

EBC, 2019. European Biochar Certificate - Guidelines for a Sustainable Production of Biochar, European Biochar Foundation (EBC). https://doi.org/10.13140/RG.2.1.4658.7043

Ekpo, U., Ross, A.B., Camargo-Valero, M.A., Williams, P.T., 2016. A comparison of product yields and inorganic content in process streams following thermal hydrolysis and hydrothermal processing of microalgae, manure and digestate. Bioresour. Technol. 200, 951-960. https://doi.org/10.1016/j.biortech.2015.11.018 
El-Deen, S.E.A.S., Zhang, F., 2012. Synthesis of Sludge@Carbon Nanocomposite for the Recovery of as (V) from Wastewater, in: Procedia Environmental Sciences. pp. 378-390.

https://doi.org/10.1016/j.proenv.2012.10.054

Elliott, D.C., Biller, P., Ross, A.B., Schmidt, A.J., Jones, S.B., 2015. Hydrothermal liquefaction of biomass: Developments from batch to continuous process. Bioresour. Technol. 178, 147-156. https://doi.org/10.1016/j.biortech.2014.09.132

Escala, M., Zumbühl, T., Koller, C., Junge, R., Krebs, R., 2013. Hydrothermal carbonization as an energy-efficient alternative to established drying technologies for sewage sludge: A feasibility study on a laboratory scale. Energy and Fuels 27, 454-460. https://doi.org/10.1021/ef3015266

European Commission, 2018. Report on Critical Raw Materials and the Circular Economy. Brussels.

Fakkaew, K., Koottatep, T., Polprasert, C., 2018. Faecal sludge treatment and utilization by hydrothermal carbonization. J. Environ. Manage. 216, 421-426. https://doi.org/10.1016/j.jenvman.2017.09.031

Falayi, T., 2019. Alkaline recovery of phosphorous from sewage sludge and stabilisation of sewage sludge residue. Waste Manag. 84, 166-172. https://doi.org/10.1016/j.wasman.2018.11.041

Fan, Y.J., Zhu, W., Gong, M., Su, Y., Zhang, H.W., Zeng, J.N., 2016. Catalytic gasification of dewatered sewage sludge in supercritical water: Influences of formic acid on hydrogen production. Int. J. Hydrogen Energy 41, 4366-4373. https://doi.org/10.1016/j.ijhydene.2015.11.071

Fei, Y., Zhao, D., Cao, Y., Huot, H., Tang, Y., Zhang, H., Xiao, T., 2019a. Phosphorous Retention and Release by Sludge-Derived Hydrochar for Potential Use as a Soil Amendment. J. Environ. Qual. 48, 502-509. https://doi.org/10.2134/jeq2018.09.0328

Fei, Y., Zhao, D., Liu, Y., Zhang, W., Tang, Y., Huang, X., Wu, Q., Wang, Y., Xiao, T., Liu, C., 2019 b. Feasibility of sewage sludge derived hydrochars for agricultural application: Nutrients (N, P, K) and potentially toxic elements $(\mathrm{Zn}, \mathrm{Cu}, \mathrm{Pb}, \mathrm{Ni}, \mathrm{Cd})$. Chemosphere 236, 124841. https://doi.org/10.1016/j.chemosphere.2019.124841

Feng, Y., Ma, K., Yu, T., Bai, S., Pei, D., Bai, T., Zhang, Q., Yin, L., Hu, Y., Chen, D., 2018. Phosphorus Transformation in Hydrothermal Pretreatment and Steam Gasification of Sewage Sludge. Energy and Fuels 32, 8545-8551. https://doi.org/10.1021/acs.energyfuels.8b01860

Ferrentino, R., Ceccato, R., Marchetti, V., Andreottola, G., Fiori, L., 2020a. Sewage sludge hydrochar: An option for removal of methylene blue from wastewater. Appl. Sci. 10, 3445. https://doi.org/10.3390/app10103445

Ferrentino, R., Merzari, F., Fiori, L., Andreottola, G., 2020b. Coupling hydrothermal carbonization with anaerobic digestion for sewage sludge treatment: Influence of HTC liquor and hydrochar on biomethane production. Energies 13, 6262. https://doi.org/10.3390/en13236262

Fijalkowski, K., Rorat, A., Grobelak, A., Kacprzak, M.J., 2017. The presence of contaminations in sewage sludge - The current situation. J. Environ. Manage. 203, 1126-1136. https://doi.org/10.1016/j.jenvman.2017.05.068

Fiori, L., Valbusa, M., Castello, D., 2012. Supercritical water gasification of biomass for H2 production: Process design. Bioresour. Technol. 121, 139-147. https://doi.org/10.1016/j.biortech.2012.06.116

Gai, C., Chen, M., Liu, T., Peng, N., Liu, Z., 2016a. Gasification characteristics of hydrochar and pyrochar derived from sewage sludge. Energy 113, 957-965. https://doi.org/10.1016/j.energy.2016.07.129

Gai, C., Guo, Y., Liu, T., Peng, N., Liu, Z., 2016b. Hydrogen-rich gas production by steam gasification of hydrochar derived from sewage sludge. Int. J. Hydrogen Energy 41, 3363-3372. https://doi.org/10.1016/j.ijhydene.2015.12.188 
Gao, N., Kamran, K., Quan, C., Williams, P.T., 2020. Thermochemical conversion of sewage sludge: A critical review. Prog. Energy Combust. Sci. 79, 100843. https://doi.org/10.1016/j.pecs.2020.100843

Gao, N., Li, Z., Quan, C., Miskolczi, N., Egedy, A., 2019. A new method combining hydrothermal carbonization and mechanical compression in-situ for sewage sludge dewatering: Bench-scale verification. J. Anal. Appl. Pyrolysis 139, 187-195. https://doi.org/10.1016/j.jaap.2019.02.003

Gaur, R.Z., Khoury, O., Zohar, M., Poverenov, E., Darzi, R., Laor, Y., Posmanik, R., 2020. Hydrothermal carbonization of sewage sludge coupled with anaerobic digestion: Integrated approach for sludge management and energy recycling. Energy Convers. Manag. 224, 113353. https://doi.org/10.1016/j.enconman.2020.113353

Gong, M., Nanda, S., Romero, M.J., Zhu, W., Kozinski, J.A., 2017. Subcritical and supercritical water gasification of humic acid as a model compound of humic substances in sewage sludge. J. Supercrit. Fluids 119, 130-138. https://doi.org/10.1016/j.supflu.2016.08.018

Gong, M., Wang, Y., Fan, Y., Zhu, W., Zhang, H., Su, Y., 2018. Polycyclic aromatic hydrocarbon formation during the gasification of sewage sludge in sub- and supercritical water: Effect of reaction parameters and reaction pathways. Waste Manag. 72, 287-295. https://doi.org/10.1016/j.wasman.2017.11.024

Gong, M., Zhu, W., Fan, Y., Zhang, H., Su, Y., 2016a. Influence of the reactant carbon-hydrogen-oxygen composition on the key products of the direct gasification of dewatered sewage sludge in supercritical water. Bioresour. Technol. 208, 81-86. https://doi.org/10.1016/j.biortech.2016.02.070

Gong, M., Zhu, W., Xu, Z.R., Zhang, H.W., Yang, H.P., 2014a. Influence of sludge properties on the direct gasification of dewatered sewage sludge in supercritical water. Renew. Energy 66, 605-611. https://doi.org/10.1016/j.renene.2014.01.006

Gong, M., Zhu, W., Zhang, H., Su, Y., Fan, Y., 2016b. Polycyclic aromatic hydrocarbon formation from gasification of sewage sludge in supercritical water: The concentration distribution and effect of sludge properties. J. Supercrit. Fluids 113, 112-118. https://doi.org/10.1016/j.supflu.2016.03.021

Gong, M., Zhu, W., Zhang, H.W., Ma, Q., Su, Y., Fan, Y.J., 2014b. Influence of NaOH and Ni catalysts on hydrogen production from the supercritical water gasification of dewatered sewage sludge. Int. J. Hydrogen Energy 39, 19947-19954. https://doi.org/10.1016/j.ijhydene.2014.10.051

Gu, X., Martinez-Fernandez, J.S., Pang, N., Fu, X., Chen, S., 2020. Recent development of hydrothermal liquefaction for algal biorefinery. Renew. Sustain. Energy Rev. 121. https://doi.org/10.1016/j.rser.2020.109707

Guo, Y., Wang, S., Gong, Y., Xu, D., Tang, X., Ma, H., 2010. Partial oxidation of municipal sludge with activited carbon catalyst in supercritical water. J. Hazard. Mater. 180, 137-144. https://doi.org/10.1016/j.jhazmat.2010.04.005

Hao, S., Ren, S., Zhou, N., Chen, H., Usman, M., He, C., Shi, Q., Luo, G., Zhang, S., 2020. Molecular composition of hydrothermal liquefaction wastewater from sewage sludge and its transformation during anaerobic digestion. J. Hazard. Mater. 383, 121163. https://doi.org/10.1016/j.jhazmat.2019.121163

Harvey, O.R., Herbert, B.E., Kuo, L.-J., Louchouarn, P., 2012. Generalized Two-Dimensional Perturbation Correlation Infrared Spectroscopy Reveals Mechanisms for the Development of Surface Charge and Recalcitrance in Plant-Derived Biochars. https://doi.org/10.1021/es302971d

He, C., Chen, C.L., Giannis, A., Yang, Y., Wang, J.Y., 2014a. Hydrothermal gasification of sewage sludge and model compounds for renewable hydrogen production: A review. Renew. Sustain. Energy Rev. 39, 1127-1142. https://doi.org/10.1016/j.rser.2014.07.141

He, C., Giannis, A., Wang, J.Y., 2013. Conversion of sewage sludge to clean solid fuel using 
hydrothermal carbonization: Hydrochar fuel characteristics and combustion behavior. Appl. Energy 111, 257-266. https://doi.org/10.1016/j.apenergy.2013.04.084

He, C., Tang, C., Liu, W., Dai, L., Qiu, R., 2020. Co-pyrolysis of sewage sludge and hydrochar with coals: Pyrolytic behaviors and kinetics analysis using TG-FTIR and a discrete distributed activation energy model. Energy Convers. Manag. 203, 112226. https://doi.org/10.1016/j.enconman.2019.112226

He, C., Wang, K., Giannis, A., Yang, Y., Wang, J.Y., 2015a. Products evolution during hydrothermal conversion of dewatered sewage sludge in sub- and near-critical water: Effects of reaction conditions and calcium oxide additive. Int. J. Hydrogen Energy 40, 5776-5787. https://doi.org/10.1016/j.ijhydene.2015.03.006

He, C., Wang, K., Yang, Y., Amaniampong, P.N., Wang, J.Y., 2015b. Effective nitrogen removal and recovery from dewatered sewage sludge using a novel integrated system of accelerated hydrothermal deamination and air stripping. Environ. Sci. Technol. 49, 6872-6880. https://doi.org/10.1021/acs.est.5b00652

He, C., Wang, K., Yang, Y., Wang, J.Y., 2014b. Utilization of sewage-sludge-derived hydrochars toward efficient cocombustion with different-rank coals: Effects of subcritical water conversion and blending scenarios. Energy and Fuels 28, 6140-6150. https://doi.org/10.1021/ef501386g

He, C., Zhang, Z., Ge, C., Liu, W., Tang, Y., Zhuang, X., Qiu, R., 2019. Synergistic effect of hydrothermal co-carbonization of sewage sludge with fruit and agricultural wastes on hydrochar fuel quality and combustion behavior. Waste Manag. 100, 171-181. https://doi.org/10.1016/j.wasman.2019.09.018

He, C., Zhao, J., Yang, Y., Wang, J.Y., 2016. Multiscale characteristics dynamics of hydrochar from hydrothermal conversion of sewage sludge under sub- and near-critical water. Bioresour. Technol. 211, 486-493. https://doi.org/10.1016/j.biortech.2016.03.110

Hoşgün, E.Z., 2020. One-pot hydrothermal conversion of poppy stalks over metal chloride catalysts. Biomass Convers. Biorefinery. https://doi.org/10.1007/s13399-020-00682-5

Hu, G., Liu, H., Chen, C., Hou, H., Li, J., Hewage, K., Sadiq, R., 2021. Low-temperature thermal desorption and secure landfill for oil-based drill cuttings management: Pollution control, human health risk, and probabilistic cost assessment. J. Hazard. Mater. 410, 124570. https://doi.org/10.1016/j.jhazmat.2020.124570

Huang, H. jun, Chang, Y. chao, Lai, F. ying, Zhou, C. fei, Pan, Z. qian, Xiao, X. feng, Wang, J. xin, Zhou, C. huo, 2019. Co-liquefaction of sewage sludge and rice straw/wood sawdust: The effect of process parameters on the yields/properties of bio-oil and biochar products. Energy 173, 140-150. https://doi.org/10.1016/j.energy.2019.02.071

Huang, H. jun, Yuan, X. zhong, Zhu, H. na, Li, H., Liu, Y., Wang, X. li, Zeng, G. ming, 2013. Comparative studies of thermochemical liquefaction characteristics of microalgae, lignocellulosic biomass and sewage sludge. Energy 56, 52-60. https://doi.org/10.1016/j.energy.2013.04.065

Huang, H., Yuan, X., Zeng, G., Zhu, H., Li, H., Liu, Z., Jiang, H., Leng, L., Bi, W., 2011. Quantitative evaluation of heavy metals' pollution hazards in liquefaction residues of sewage sludge. Bioresour. Technol. 102, 10346-10351. https://doi.org/10.1016/j.biortech.2011.08.117

Huang, H.J., Yuan, X.Z., 2016. The migration and transformation behaviors of heavy metals during the hydrothermal treatment of sewage sludge. Bioresour. Technol. 200, 991-998. https://doi.org/10.1016/j.biortech.2015.10.099

Huang, H.J., Yuan, X.Z., Li, B.T., Xiao, Y.D., Zeng, G.M., 2014. Thermochemical liquefaction characteristics of sewage sludge in different organic solvents. J. Anal. Appl. Pyrolysis 109, 176-184. https://doi.org/10.1016/j.jaap.2014.06.015 
Huang, J., Wang, P., Niu, Y., Yu, H., Ma, F., Xiao, G., Xu, X., 2018. Changes in C:N:P stoichiometry modify $\mathrm{N}$ and $\mathrm{P}$ conservation strategies of a desert steppe species Glycyrrhiza uralensis. Sci. Rep. 8, 1-9. https://doi.org/10.1038/s41598-018-30324-w

Huang, J., Wang, Z., Qiao, Y., Wang, B., Yu, Y., Xu, M., 2020. Transformation of nitrogen during hydrothermal carbonization of sewage sludge: Effects of temperature and $\mathrm{Na} / \mathrm{Ca}$ acetates addition. Proc. Combust. Inst. 000, 1-10. https://doi.org/10.1016/j.proci.2020.06.075

Huang, R., Fang, C., Lu, X., Jiang, R., Tang, Y., 2017. Transformation of phosphorus during (hydro)thermal treatments of solid Biowastes: Reaction mechanisms and implications for $\mathrm{P}$ reclamation and recycling. Environ. Sci. Technol. 51, 10284-10298. https://doi.org/10.1021/acs.est.7b02011

Huang, R., Tang, Y., 2016. Evolution of phosphorus complexation and mineralogy during (hydro)thermal treatments of activated and anaerobically digested sludge: Insights from sequential extraction and $\mathrm{P}$ K-edge XANES. Water Res. 100, 439-447. https://doi.org/10.1016/j.watres.2016.05.029

Huang, R., Tang, Y., 2015. Speciation Dynamics of Phosphorus during (Hydro)Thermal Treatments of Sewage Sludge. Environ. Sci. Technol. 49, 14466-14474. https://doi.org/10.1021/acs.est.5b04140

Huang, R., Tang, Y., Luo, L., 2021. Thermochemistry of sulfur during pyrolysis and hydrothermal carbonization of sewage sludges. Waste Manag. 121, 276-285. https://doi.org/10.1016/j.wasman.2020.12.004

Huang, R., Zhang, B., Saad, E.M., Ingall, E.D., Tang, Y., 2018. Speciation evolution of zinc and copper during pyrolysis and hydrothermal carbonization treatments of sewage sludges. Water Res. 132, 260-269. https://doi.org/10.1016/j.watres.2018.01.009

Ibrahim, A.B.A., Akilli, H., 2019. Supercritical water gasification of wastewater sludge for hydrogen production. Int. J. Hydrogen Energy 44, 10328-10349. https://doi.org/10.1016/j.jijhydene.2019.02.184

Inoue, S., Sawayama, S., Dote, Y., Ogi, T., 1997. Behaviour of nitrogen during liquefaction of dewatered sewage sludge. Biomass and Bioenergy 12, 473-475. https://doi.org/10.1016/S09619534(97)00017-2

Itoh, S., Suzuki, A., Nakamura, T., Yokoyama, S. ya, 1994. Production of heavy oil from sewage sludge by direct thermochemical liquefaction. Desalination 98, 127-133. https://doi.org/10.1016/00119164(94)00137-5

Kacprzak, M., Neczaj, E., Fijałkowski, K., Grobelak, A., Grosser, A., Worwag, M., Rorat, A., Brattebo, H., Almås, Å., Singh, B.R., 2017. Sewage sludge disposal strategies for sustainable development. Environ. Res. 156, 39-46. https://doi.org/10.1016/j.envres.2017.03.010

Kapusta, K., 2018. Effect of ultrasound pretreatment of municipal sewage sludge on characteristics of bio-oil from hydrothermal liquefaction process. Waste Manag. 78, 183-190. https://doi.org/10.1016/j.wasman.2018.05.043

Karayıldırım, T., Sınağ, A., Kruse, A., 2008. Char and Coke Formation as Unwanted Side Reaction of the Hydrothermal Biomass Gasification. Chem. Eng. Technol. 31, 1561-1568. https://doi.org/10.1002/ceat.200800278

Khan, T.A., Saud, A.S., Jamari, S.S., Rahim, M.H.A., Park, J.W., Kim, H.J., 2019. Hydrothermal carbonization of lignocellulosic biomass for carbon rich material preparation: A review. Biomass and Bioenergy 130, 105384. https://doi.org/10.1016/j.biombioe.2019.105384

Khoshbouy, R., Takahashi, F., Yoshikawa, K., 2019. Preparation of high surface area sludge-based activated hydrochar via hydrothermal carbonization and application in the removal of basic dye. Environ. Res. 175, 457-467. https://doi.org/10.1016/j.envres.2019.04.002 
Kim, D., Lee, K., Park, K.Y., 2014. Hydrothermal carbonization of anaerobically digested sludge for solid fuel production and energy recovery. Fuel 130, 120-125. https://doi.org/10.1016/j.fuel.2014.04.030

Kim, D., Park, S., Park, K.Y., 2017. Upgrading the fuel properties of sludge and low rank coal mixed fuel through hydrothermal carbonization. Energy 141, 598-602. https://doi.org/10.1016/j.energy.2017.09.113

Kim, Y., Parker, W., 2008. A technical and economic evaluation of the pyrolysis of sewage sludge for the production of bio-oil. Bioresour. Technol. 99, 1409-1416. https://doi.org/10.1016/j.biortech.2007.01.056

Kong, L., Li, G., Wang, H., He, W., Ling, F., 2008. Hydrothermal catalytic conversion of biomass for lactic acid production. J. Chem. Technol. Biotechnol. 83, 383-388. https://doi.org/10.1002/jctb.1797

Koottatep, T., Fakkaew, K., Tajai, N., Pradeep, S. V., Polprasert, C., 2016. Sludge stabilization and energy recovery by hydrothermal carbonization process. Renew. Energy 99, 978-985. https://doi.org/10.1016/j.renene.2016.07.068

Kor-Bicakci, G., Eskicioglu, C., 2019. Recent developments on thermal municipal sludge pretreatment technologies for enhanced anaerobic digestion. Renew. Sustain. Energy Rev. 110, 423-443. https://doi.org/10.1016/j.rser.2019.05.002

Kroiss, H., Rechberger, H., Egle, L., 2011. Phosphorus in Water Quality and Waste Management, in: Integrated Waste Management - Volume II. InTech, pp. 181-214. https://doi.org/10.5772/18482

Kumar, K., Parveen, F., Patra, T., Upadhyayula, S., 2018. Hydrothermal conversion of glucose to levulinic acid using multifunctional ionic liquids: Effects of metal ion co-catalysts on the product yield. New J. Chem. 42, 228-236. https://doi.org/10.1039/c7nj03146g

Lai, F. ying, Chang, Y. chao, Huang, H. jun, Wu, G. qiang, Xiong, J. bo, Pan, Z. qian, Zhou, C. fei, 2018. Liquefaction of sewage sludge in ethanol-water mixed solvents for bio-oil and biochar products. Energy 148, 629-641. https://doi.org/10.1016/j.energy.2018.01.186

Lee, J., Sohn, D., Lee, K., Park, K.Y., 2019. Solid fuel production through hydrothermal carbonization of sewage sludge and microalgae Chlorella sp. from wastewater treatment plant. Chemosphere 230, 157-163. https://doi.org/10.1016/j.chemosphere.2019.05.066

Leng, L., Li, Jun, Yuan, X., Li, Jingjing, Han, P., Hong, Y., Wei, F., Zhou, W., 2018. Beneficial synergistic effect on bio-oil production from co-liquefaction of sewage sludge and lignocellulosic biomass. Bioresour. Technol. 251, 49-56. https://doi.org/10.1016/j.biortech.2017.12.018

Leng, L., Yuan, X., Chen, X., Huang, H., Wang, H., Li, H., Zhu, R., Li, S., Zeng, G., 2015a. Characterization of liquefaction bio-oil from sewage sludge and its solubilization in diesel microemulsion. Energy 82, 218-228. https://doi.org/10.1016/j.energy.2015.01.032

Leng, L., Yuan, X., Huang, H., Jiang, H., Chen, X., Zeng, G., 2014. The migration and transformation behavior of heavy metals during the liquefaction process of sewage sludge. Bioresour. Technol. 167, 144-150. https://doi.org/10.1016/j.biortech.2014.05.119

Leng, L., Yuan, X., Huang, H., Shao, J., Wang, H., Chen, X., Zeng, G., 2015b. Bio-char derived from sewage sludge by liquefaction: Characterization and application for dye adsorption. Appl. Surf. Sci. 346, 223-231. https://doi.org/10.1016/j.apsusc.2015.04.014

Li, C., Wang, X., Zhang, G., Yu, G., Lin, J., Wang, Y., 2017. Hydrothermal and alkaline hydrothermal pretreatments plus anaerobic digestion of sewage sludge for dewatering and biogas production: Bench-scale research and pilot-scale verification. Water Res. 117, 49-57. https://doi.org/10.1016/j.watres.2017.03.047

Li, H., Yuan, X., Zeng, G., Huang, D., Huang, H., Tong, J., You, Q., Zhang, J., Zhou, M., 2010. The 
formation of bio-oil from sludge by deoxy-liquefaction in supercritical ethanol. Bioresour. Technol. 101, 2860-2866. https://doi.org/10.1016/j.biortech.2009.10.084

Li, L., Xu, Z.R., Zhang, C., Bao, J., Dai, X., 2012. Quantitative evaluation of heavy metals in solid residues from sub- and super-critical water gasification of sewage sludge. Bioresour. Technol. 121, 169-175. https://doi.org/10.1016/j.biortech.2012.06.084

Li, R., Ma, Z., Yang, T., Li, B., Wei, L., Sun, Y., 2018. Sub-supercritical liquefaction of municipal wet sewage sludge to produce bio-oil: Effect of different organic-water mixed solvents. J. Supercrit. Fluids 138, 115-123. https://doi.org/10.1016/j.supflu.2018.04.011

Li, S., Jiang, Y., Snowden-Swan, L.J., Askander, J.A., Schmidt, A.J., Billing, J.M., 2021. Technoeconomic uncertainty analysis of wet waste-to-biocrude via hydrothermal liquefaction. Appl. Energy 283, 116340. https://doi.org/10.1016/j.apenergy.2020.116340

Li, S., Zeng, W., Jia, Z., Wu, G., Xu, H., Peng, Y., 2020. Phosphorus species transformation and recovery without apatite in $\mathrm{FeCl} 3$-assisted sewage sludge hydrothermal treatment. Chem. Eng. J. 399, 125735. https://doi.org/10.1016/j.cej.2020.125735

Lishan, X., Tao, L., Yin, W., Zhilong, Y., Jiangfu, L., 2018. Comparative life cycle assessment of sludge management: A case study of Xiamen, China. J. Clean. Prod. 192, 354-363. https://doi.org/10.1016/j.jclepro.2018.04.171

Liu, C., Xu, J., Hu, J., Zhang, H., Xiao, R., 2017. Metal Ion-Catalyzed Hydrothermal Liquefaction of Calcium Lignosulfonate in Subcritical Water. Chem. Eng. Technol. 40, 1092-1100. https://doi.org/10.1002/ceat.201600650

Liu, H., Hu, G., Basar, I.A., Li, J., Lyczko, N., Nzihou, A., Eskicioglu, C., 2021. Phosphorus recovery from municipal sludge-derived ash and hydrochar through wet-chemical technology: A review towards sustainable waste management. Chem. Eng. J. 417, 129300. https://doi.org/10.1016/j.cej.2021.129300

Liu, M., Duan, Y., Bikane, K., Zhao, L., 2017. Effect of waste liquid produced from the hydrothermal treatment of both low-rank coal and sludge on the slurryability of coal sludge slurry. Fuel 203, 1-10. https://doi.org/10.1016/j.fuel.2017.04.091

Liu, R., Tian, W., Kong, S., Meng, Y., Wang, H., Zhang, J., 2018. Effects of inorganic and organic acid pretreatments on the hydrothermal liquefaction of municipal secondary sludge. Energy Convers. Manag. 174, 661-667. https://doi.org/10.1016/j.enconman.2018.08.058

Liu, T., Guo, Y., Peng, N., Lang, Q., Xia, Y., Gai, C., Liu, Z., 2017a. Nitrogen transformation among char, tar and gas during pyrolysis of sewage sludge and corresponding hydrochar. J. Anal. Appl. Pyrolysis 126, 298-306. https://doi.org/10.1016/j.jaap.2017.05.017

Liu, T., Guo, Y., Peng, N., Lang, Q., Xia, Y., Gai, C., Zheng, Q., Liu, Z., 2018a. Identification and quantification of polycyclic aromatic hydrocarbons generated during pyrolysis of sewage sludge: Effect of hydrothermal carbonization pretreatment. J. Anal. Appl. Pyrolysis 130, 249-255. https://doi.org/10.1016/j.jaap.2018.01.021

Liu, T., Lang, Q., Xia, Y., Chen, Z., Li, D., Ma, J., Gai, C., Liu, Z., 2019. Combination of hydrothermal carbonization and oxy-fuel combustion process for sewage sludge treatment: Combustion characteristics and kinetics analysis. Fuel 242, 265-276. https://doi.org/10.1016/j.fuel.2019.01.035

Liu, T., Li, Y., Peng, N., Lang, Q., Xia, Y., Gai, C., Zheng, Q., Liu, Z., 2017b. Heteroatoms doped porous carbon derived from hydrothermally treated sewage sludge: Structural characterization and environmental application. J. Environ. Manage. 197, 151-158. https://doi.org/10.1016/j.jenvman.2017.03.082

Liu, T., Liu, Z., Zheng, Q., Lang, Q., Xia, Y., Peng, N., Gai, C., 2018b. Effect of hydrothermal 
carbonization on migration and environmental risk of heavy metals in sewage sludge during pyrolysis. Bioresour. Technol. 247, 282-290. https://doi.org/10.1016/j.biortech.2017.09.090

Liu, T., Tian, L., Liu, Z., He, J., Fu, H., Huang, Q., Xue, H., Huang, Z., 2021. Distribution and toxicity of polycyclic aromatic hydrocarbons during $\mathrm{CaO}$-assisted hydrothermal carbonization of sewage sludge. Waste Manag. 120, 616-625. https://doi.org/10.1016/j.wasman.2020.10.025

Liu, X., Zhai, Y., Li, S., Wang, B., Wang, T., Liu, Y., Qiu, Z., Li, C., 2020. Hydrothermal carbonization of sewage sludge: Effect of feed-water $\mathrm{pH}$ on hydrochar's physicochemical properties, organic component and thermal behavior. J. Hazard. Mater. 388, 122084. https://doi.org/10.1016/j.jhazmat.2020.122084

Lopes, B.C., Machado, E.C., Rodrigues, H.F., Leal, D., Calábria De Araújo, J., Teixeira De Matos, A., 2020. Environmental Technology Effect of alkaline treatment on pathogens, bacterial community and antibiotic resistance genes in different sewage sludges for potential agriculture use Effect of alkaline treatment on pathogens, bacterial community and antibiotic. Environ. Technol. 41, 529-538. https://doi.org/10.1080/09593330.2018.1505960

Lu, J., Zhang, J., Zhu, Z., Zhang, Y., Zhao, Y., Li, R., Watson, J., Li, B., Liu, Z., 2017. Simultaneous production of biocrude oil and recovery of nutrients and metals from human feces via hydrothermal liquefaction. Energy Convers. Manag. 134, 340-346.

https://doi.org/10.1016/j.enconman.2016.12.052

Lu, X., Ma, X., Chen, X., 2021. Co-hydrothermal carbonization of sewage sludge and lignocellulosic biomass: Fuel properties and heavy metal transformation behaviour of hydrochars. Energy 221, 119896. https://doi.org/10.1016/j.energy.2021.119896

Lu, Xiuyang, Fu, J., Xu, X., Lu, Xilei, 2016. Hydrothermal Decomposition of Carbohydrates to Levulinic Acid with Catalysis by Ionic Liquids. Ind. Eng. Chem. Res. 55, 11044-11051. https://doi.org/10.1021/acs.iecr.6b02478

Lühmann, T., Wirth, B., 2020. Sewage sludge valorization via hydrothermal carbonization: Optimizing dewaterability and phosphorus release. Energies 13, 1-16. https://doi.org/10.3390/en13174417

Lumley, N.P.G., Ramey, D.F., Prieto, A.L., Braun, R.J., Cath, T.Y., Porter, J.M., 2014. Techno-economic analysis of wastewater sludge gasification: A decentralized urban perspective. Bioresour. Technol. 161, 385-394. https://doi.org/10.1016/j.biortech.2014.03.040

Luo, X., Huang, Z., Lin, J., Li, X., Qiu, J., Liu, J., Mao, X., 2020. Hydrothermal carbonization of sewage sludge and in-situ preparation of hydrochar/MgAl-layered double hydroxides composites for adsorption of Pb(II). J. Clean. Prod. 258, 120991. https://doi.org/10.1016/j.jclepro.2020.120991

Ma, H., Guo, Y., Qin, Y., Li, Y.Y., 2018. Nutrient recovery technologies integrated with energy recovery by waste biomass anaerobic digestion. Bioresour. Technol. 269, 520-531. https://doi.org/10.1016/j.biortech.2018.08.114

Ma, J., Chen, M., Yang, T., Liu, Z., Jiao, W., Li, D., Gai, C., 2019a. Gasification performance of the hydrochar derived from co-hydrothermal carbonization of sewage sludge and sawdust. Energy 173, 732-739. https://doi.org/10.1016/j.energy.2019.02.103

Ma, J., Luo, H., Li, Y., Liu, Z., Li, D., Gai, C., Jiao, W., 2019b. Pyrolysis kinetics and thermodynamic parameters of the hydrochars derived from co-hydrothermal carbonization of sawdust and sewage sludge using thermogravimetric analysis. Bioresour. Technol. 282, 133-141. https://doi.org/10.1016/j.biortech.2019.03.007

Maddi, B., Panisko, E., Wietsma, T., Lemmon, T., Swita, M., Albrecht, K., Howe, D., 2017. Quantitative Characterization of Aqueous Byproducts from Hydrothermal Liquefaction of Municipal Wastes, Food Industry Wastes, and Biomass Grown on Waste. ACS Sustain. Chem. Eng. 5, 2205-2214. https://doi.org/10.1021/acssuschemeng.6b02367 
Malhotra, M., Garg, A., 2020. Hydrothermal carbonization of centrifuged sewage sludge: Determination of resource recovery from liquid fraction and thermal behaviour of hydrochar. Waste Manag. 117, 114-123. https://doi.org/10.1016/j.wasman.2020.07.026

Malins, K., Kampars, V., Brinks, J., Neibolte, I., Murnieks, R., Kampare, R., 2015. Bio-oil from thermochemical hydro-liquefaction of wet sewage sludge. Bioresour. Technol. 187, 23-29. https://doi.org/10.1016/j.biortech.2015.03.093

Marin-Batista, J.D., Mohedano, A.F., Rodríguez, J.J., de la Rubia, M.A., 2020. Energy and phosphorous recovery through hydrothermal carbonization of digested sewage sludge. Waste Manag. 105, 566574. https://doi.org/10.1016/j.wasman.2020.03.004

Marrone, P.A., 2016. Genifuel Hydrothermal Processing Bench-Scale Technology Evaluation Project. Alexandria, VA.

Marrone, P.A., Elliott, D.C., Billing, J.M., Hallen, R.T., Hart, T.R., Kadota, P., Moeller, J.C., Randel, M.A., Schmidt, A.J., 2018. Bench-scale evaluation of hydrothermal processing technology for conversion of wastewater solids to fuels. Water Environ. Res. 90, 329-342. https://doi.org/10.2175/106143017x15131012152861

Mathimani, T., Mallick, N., 2019. A review on the hydrothermal processing of microalgal biomass to biooil - Knowledge gaps and recent advances. J. Clean. Prod. 217, 69-84. https://doi.org/10.1016/j.jclepro.2019.01.129

Medina-Martos, E., Istrate, I.R., Villamil, J.A., Gálvez-Martos, J.L., Dufour, J., Mohedano, Á.F., 2020. Techno-economic and life cycle assessment of an integrated hydrothermal carbonization system for sewage sludge. J. Clean. Prod. 277. https://doi.org/10.1016/j.jclepro.2020.122930

Melo, T.M., Bottlinger, M., Schulz, E., Leandro, W.M., Botelho de Oliveira, S., Menezes de Aguiar Filho, A., El-Naggar, A., Bolan, N., Wang, H., Ok, Y.S., Rinklebe, J., 2019. Management of biosolidsderived hydrochar (Sewchar): Effect on plant germination, and farmers' acceptance. J. Environ. Manage. 237, 200-214. https://doi.org/10.1016/j.jenvman.2019.02.042

Melo, T.M., Bottlinger, M., Schulz, E., Leandro, W.M., de Aguiar Filho, A.M., Ok, Y.S., Rinklebe, J., 2017. Effect of biosolid hydrochar on toxicity to earthworms and brine shrimp. Environ. Geochem. Health 39, 1351-1364. https://doi.org/10.1007/s10653-017-9995-5

Melo, T.M., Bottlinger, M., Schulz, E., Leandro, W.M., Menezes de Aguiar Filho, A., Wang, H., Ok, Y.S., Rinklebe, J., 2018. Plant and soil responses to hydrothermally converted sewage sludge (sewchar). Chemosphere 206, 338-348. https://doi.org/10.1016/j.chemosphere.2018.04.178

Meng, X., Huang, Q., Xu, J., Gao, H., Yan, J., 2019. A review of phosphorus recovery from different thermal treatment products of sewage sludge. Waste Dispos. Sustain. Energy 1, 99-115. https://doi.org/10.1007/s42768-019-00007-x

Merzari, F., Goldfarb, J., Andreottola, G., Mimmo, T., Volpe, M., Fiori, L., 2020. Hydrothermal carbonization as a strategy for sewage sludge management: Influence of process withdrawal point on hydrochar properties. Energies 13, 2890. https://doi.org/10.3390/en13112890

Merzari, F., Langone, M., Andreottola, G., Fiori, L., 2019. Methane production from process water of sewage sludge hydrothermal carbonization. A review. Valorising sludge through hydrothermal carbonization. Crit. Rev. Environ. Sci. Technol. 49, 947-988. https://doi.org/10.1080/10643389.2018.1561104

Mishra, S., Mohanty, K., 2020. Co-HTL of domestic sewage sludge and wastewater treatment derived microalgal biomass - An integrated biorefinery approach for sustainable biocrude production. Energy Convers. Manag. 204, 112312. https://doi.org/10.1016/j.enconman.2019.112312

Mitroshkov, A. V., Zhong, L., Thomas, L.M.P., 2019. Analysis of Perfluorinated, Pharmaceutical, 
Personal Care Compounds and Heavy Metals in Waste Water Sludge using GC-MS/MS and Multicollector ICP-MS. U.S. Department of Energy, Richland, WA (United States).

https://doi.org/10.2172/1494304

Mittapalli, S., Sharma, H.B., Dubey, B.K., 2021. Hydrothermal carbonization of anaerobic granular sludge and co-pelletization of hydrochar with yard waste. Bioresour. Technol. Reports 14, 100691. https://doi.org/10.1016/j.biteb.2021.100691

Molton, P.M., Fassbender, A.G., Brown, M.., 1986. STORS: the sludge-to-oil reactor system. Cincinnati, $\mathrm{OH}, \mathrm{USA}$.

Moran, S., 2018. Sludge characterization and treatment objectives, in: An Applied Guide to Water and Effluent Treatment Plant Design. Elsevier, pp. 255-263. https://doi.org/10.1016/b978-0-12-8113097.00021-7

Moreno, J., Espada, J.J., 2019. Chapter 10 Environmental and techno-economic assessment of thermochemical treatment systems for sludge, in: Wastewater Treatment Residues as Resources for Biorefinery Products and Biofuels. Elsevier, pp. 201-223. https://doi.org/10.1016/B978-0-12816204-0.00010-2

Mujahid, R., Riaz, A., Insyani, R., Kim, J., 2020. A centrifugation-first approach for recovering highyield bio-oil with high calorific values in biomass liquefaction: A case study of sewage sludge. Fuel 262, 116628. https://doi.org/10.1016/j.fuel.2019.116628

Munir, M.T., Li, B., Boiarkina, I., Baroutian, S., Yu, W., Young, B.R., 2017. Phosphate recovery from hydrothermally treated sewage sludge using struvite precipitation. Bioresour. Technol. 239, 171179. https://doi.org/10.1016/j.biortech.2017.04.129

Nazari, L., Yuan, Z., Ray, M.B., Xu, C. (Charles), 2017. Co-conversion of waste activated sludge and sawdust through hydrothermal liquefaction: Optimization of reaction parameters using response surface methodology. Appl. Energy 203, 1-10. https://doi.org/10.1016/j.apenergy.2017.06.009

Oliver-Tomas, B., Hitzl, M., Owsianiak, M., Renz, M., 2019. Evaluation of hydrothermal carbonization in urban mining for the recovery of phosphorus from the organic fraction of municipal solid waste. Resour. Conserv. Recycl. 147, 111-118. https://doi.org/10.1016/j.resconrec.2019.04.023

Ovsyannikova, E., Arauzo, P.J., Becker, G., Kruse, A., 2019. Experimental and thermodynamic studies of phosphate behavior during the hydrothermal carbonization of sewage sludge. Sci. Total Environ. 692, 147-156. https://doi.org/10.1016/j.scitotenv.2019.07.217

Ovsyannikova, E., Kruse, A., Becker, G.C., 2020. Feedstock-Dependent Phosphate Recovery in a PilotScale Hydrothermal Liquefaction Bio-Crude Production. Energies 13, 379. https://doi.org/10.3390/en13020379

Paneque, M., De la Rosa, J.M., Kern, J., Reza, M.T., Knicker, H., 2017. Hydrothermal carbonization and pyrolysis of sewage sludges: What happen to carbon and nitrogen? J. Anal. Appl. Pyrolysis 128, 314-323. https://doi.org/10.1016/j.jaap.2017.09.019

Park, M., Kim, N., Lee, S., Yeon, S., Seo, J.H., Park, D., 2019. A study of solubilization of sewage sludge by hydrothermal treatment. J. Environ. Manage. 250, 109490. https://doi.org/10.1016/j.jenvman.2019.109490

Parmar, K.R., Ross, A.B., 2019. Integration of hydrothermal carbonisation with anaerobic digestion; Opportunities for valorisation of digestate. Energies 12. https://doi.org/10.3390/en12091586

Parshetti, G.K., Liu, Z., Jain, A., Srinivasan, M.P., Balasubramanian, R., 2013. Hydrothermal carbonization of sewage sludge for energy production with coal. Fuel 111, 201-210. https://doi.org/10.1016/j.fuel.2013.04.052

Peng, C., Zhai, Y., Zhu, Y., Xu, B., Wang, T., Li, C., Zeng, G., 2016. Production of char from sewage 
sludge employing hydrothermal carbonization: Char properties, combustion behavior and thermal characteristics. Fuel 176, 110-118. https://doi.org/10.1016/j.fuel.2016.02.068

Peng, L., Dai, H., Wu, Y., Peng, Y., Lu, X., 2018. A comprehensive review of phosphorus recovery from wastewater by crystallization processes. Chemosphere 197, 768-781. https://doi.org/10.1016/j.chemosphere.2018.01.098

Perkins, G., Batalha, N., Kumar, A., Bhaskar, T., Konarova, M., 2019. Recent advances in liquefaction technologies for production of liquid hydrocarbon fuels from biomass and carbonaceous wastes. Renew. Sustain. Energy Rev. 115, 109400. https://doi.org/10.1016/j.rser.2019.109400

Posmanik, R., Labatut, R.A., Kim, A.H., Usack, J.G., Tester, J.W., Angenent, L.T., 2017a. Coupling hydrothermal liquefaction and anaerobic digestion for energy valorization from model biomass feedstocks. Bioresour. Technol. 233, 134-143. https://doi.org/10.1016/j.biortech.2017.02.095

Posmanik, R., Labatut, R.A., Kim, A.H., Usack, J.G., Tester, J.W., Angenent, L.T., 2017b. Coupling hydrothermal liquefaction and anaerobic digestion for energy valorization from model biomass feedstocks. Bioresour. Technol. 233, 134-143. https://doi.org/10.1016/j.biortech.2017.02.095

Prajitno, H., Park, J., Ryu, C., Park, H.Y., Lim, H.S., Kim, J., 2018. Effects of solvent participation and controlled product separation on biomass liquefaction: A case study of sewage sludge. Appl. Energy 218, 402-416. https://doi.org/10.1016/j.apenergy.2018.03.008

Prestigiacomo, C., Costa, P., Pinto, F., Schiavo, B., Siragusa, A., Scialdone, O., Galia, A., 2019. Sewage sludge as cheap alternative to microalgae as feedstock of catalytic hydrothermal liquefaction processes. J. Supercrit. Fluids 143, 251-258. https://doi.org/10.1016/j.supflu.2018.08.019

Prestigiacomo, C., Laudicina, V.A., Siragusa, A., Scialdone, O., Galia, A., 2020. Hydrothermal liquefaction of waste biomass in stirred reactors: One step forward to the integral valorization of municipal sludge. Energy 201, 117606. https://doi.org/10.1016/j.energy.2020.117606

Qian, L., Wang, S., Savage, P.E., 2020. Fast and isothermal hydrothermal liquefaction of sludge at different severities: Reaction products, pathways, and kinetics. Appl. Energy 260, 114312. https://doi.org/10.1016/j.apenergy.2019.114312

Qian, L., Wang, S., Savage, P.E., 2017. Hydrothermal liquefaction of sewage sludge under isothermal and fast conditions. Bioresour. Technol. 232, 27-34. https://doi.org/10.1016/j.biortech.2017.02.017

Qian, L., Wang, S., Xu, D., Guo, Y., Tang, X., Wang, L., 2015. Treatment of sewage sludge in supercritical water and evaluation of the combined process of supercritical water gasification and oxidation. Bioresour. Technol. 176, 218-224. https://doi.org/10.1016/j.biortech.2014.10.125

Raheem, A., Sikarwar, V.S., He, J., Dastyar, W., Dionysiou, D.D., Wang, W., Zhao, M., 2018. Opportunities and challenges in sustainable treatment and resource reuse of sewage sludge: A review. Chem. Eng. J. 337, 616-641. https://doi.org/10.1016/j.cej.2017.12.149

Ren, J., Wang, F., Zhai, Y., Zhu, Y., Peng, C., Wang, T., Li, C., Zeng, G., 2017. Effect of sewage sludge hydrochar on soil properties and Cd immobilization in a contaminated soil. Chemosphere 189, 627633. https://doi.org/10.1016/j.chemosphere.2017.09.102

Ruyter, H.P., 1982. Coalification model. Fuel 61, 1182-1187. https://doi.org/10.1016/00162361(82)90017-5

Saetea, P., Tippayawong, N., 2013. Recovery of Value-Added Products from Hydrothermal Carbonization of Sewage Sludge. ISRN Chem. Eng. 2013, 1-6. https://doi.org/10.1155/2013/268947

Sawai, O., Nunoura, T., Yamamoto, K., 2014. Supercritical water gasification of sewage sludge using bench-scale batch reactor: Advantages and drawbacks. J. Mater. Cycles Waste Manag. 16, 82-92. https://doi.org/10.1007/s10163-013-0144-7 
Seiple, T.E., Coleman, A.M., Skaggs, R.L., 2017. Municipal wastewater sludge as a sustainable bioresource in the United States. J. Environ. Manage. 197, 673-680. https://doi.org/10.1016/j.jenvman.2017.04.032

Seiple, T.E., Skaggs, R.L., Fillmore, L., Coleman, A.M., 2020. Municipal wastewater sludge as a renewable, cost-effective feedstock for transportation biofuels using hydrothermal liquefaction. J. Environ. Manage. 270, 110852. https://doi.org/10.1016/j.jenvman.2020.110852

Sevilla, M., Fuertes, A.B., 2009. The production of carbon materials by hydrothermal carbonization of cellulose. Carbon N. Y. 47, 2281-2289. https://doi.org/10.1016/j.carbon.2009.04.026

Shah, A.A., Toor, S.S., Conti, F., Nielsen, A.H., Rosendahl, L.A., 2020. Hydrothermal liquefaction of high ash containing sewage sludge at sub and supercritical conditions. Biomass and Bioenergy 135, 105504. https://doi.org/10.1016/j.biombioe.2020.105504

Shan, Y.Q., Deng, X.Q., Luque, R., Xu, Z.X., Yan, L., Duan, P.G., 2020. Hydrothermal carbonization of activated sewage sludge over ammonia-treated Fenton sludge to produce hydrochar for clean fuel use. Green Chem. 22, 5077-5083. https://doi.org/10.1039/d0gc01701a

Shanmugam, S.R., Adhikari, S., Shakya, R., 2017. Nutrient removal and energy production from aqueous phase of bio-oil generated via hydrothermal liquefaction of algae. Bioresour. Technol. 230, 43-48. https://doi.org/10.1016/j.biortech.2017.01.031

Shao, J., Yuan, X., Leng, L., Huang, H., Jiang, L., Wang, H., Chen, X., Zeng, G., 2015. The comparison of the migration and transformation behavior of heavy metals during pyrolysis and liquefaction of municipal sewage sludge, paper mill sludge, and slaughterhouse sludge. Bioresour. Technol. 198, 16-22. https://doi.org/10.1016/j.biortech.2015.08.147

Shao, S., Liu, H., Tai, X., Zheng, F., Li, J., Li, Y., 2020. Speciation and migration of heavy metals in sediment cores of urban wetland: bioavailability and risks. Environ. Sci. Pollut. Res. 27, 2391423925. https://doi.org/10.1007/s11356-020-08719-y

Shen, Z., Jin, F., Zhang, Y., Wu, B., Kishita, A., Tohji, K., Kishida, H., 2009. Effect of alkaline catalysts on hydrothermal conversion of glycerin into lactic acid. Ind. Eng. Chem. Res. 48, 8920-8925. https://doi.org/10.1021/ie900937d

Shi, W., Feng, C., Huang, W., Lei, Z., Zhang, Z., 2014. Study on interaction between phosphorus and cadmium in sewage sludge during hydrothermal treatment by adding hydroxyapatite. Bioresour. Technol. 159, 176-181. https://doi.org/10.1016/j.biortech.2014.02.108

Shi, W., Liu, C., Ding, D., Lei, Z., Yang, Y., Feng, C., Zhang, Z., 2013. Immobilization of heavy metals in sewage sludge by using subcritical water technology. Bioresour. Technol. 137, 18-24. https://doi.org/10.1016/j.biortech.2013.03.106

Shi, Y., Luo, G., Rao, Y., Chen, H., Zhang, S., 2019. Hydrothermal conversion of dewatered sewage sludge: Focusing on the transformation mechanism and recovery of phosphorus. Chemosphere 228, 619-628. https://doi.org/10.1016/j.chemosphere.2019.04.109

Silva, R.D.V.K., Lei, Z., Shimizu, K., Zhang, Z., 2020. Hydrothermal treatment of sewage sludge to produce solid biofuel: Focus on fuel characteristics. Bioresour. Technol. Reports 11, 100453. https://doi.org/10.1016/j.biteb.2020.100453

Silva Thomsen, L.B., Carvalho, P.N., dos Passos, J.S., Anastasakis, K., Bester, K., Biller, P., 2020. Hydrothermal liquefaction of sewage sludge; energy considerations and fate of micropollutants during pilot scale processing. Water Res. 183, 116101. https://doi.org/10.1016/j.watres.2020.116101

Smith, A.M., Singh, S., Ross, A.B., 2016. Fate of inorganic material during hydrothermal carbonisation of biomass: Influence of feedstock on combustion behaviour of hydrochar. Fuel 169, 135-145. https://doi.org/10.1016/j.fuel.2015.12.006 
Snowden-Swan, L.J., Zhu, Y., Bearden, M.D., Seiple, T.E., Jones, S.B., Schmidt, A.J., Billing, J.M., Hallen, R.T., Hart, T.R., Liu, J., Albrecht, K.O., Fox, S.P., Maupin, G.D., Elliott, D.C., 2017. Conceptual Biorefinery Design and Research Targeted for 2022: Hydrothermal Liquefaction Processing of Wet Waste to Fuels.

Snowden-Swan, L.J., Zhu, Y., Jones, S.B., Elliott, D.C., Schmidt, A.J., Hallen, R.T., Billing, J.M., Hart, T.R., Fox, S.P., Maupin, G.D., 2016. Hydrothermal Liquefaction and Upgrading of Municipal Wastewater Treatment Plant Sludge: A Preliminary Techno-Economic Analysis. Richland, WA (United States). https://doi.org/10.2172/1327165

Song, E., Park, S., Kim, H., 2019. Upgrading hydrothermal carbonization (HTC) hydrochar from sewage sludge. Energies 12. https://doi.org/10.3390/en12122383

Su, Y., Liu, D., Gong, M., Zhu, W., Yu, Y., Gu, H., 2019. Investigation on the decomposition of chemical compositions during hydrothermal conversion of dewatered sewage sludge. Int. J. Hydrogen Energy 44, 26933-26942. https://doi.org/10.1016/j.ijhydene.2019.08.182

Suzuki, A., Nakamura, T., 1989. Effect of Operating Parameters on Thermochemical Liquefaction of Sewage Sludge. J. Chem. Eng. Japan 23, 6-11.

Suzuki, A., Nakamura, T., Yokoyama, S. ya, Ogi, T., Koguchi, K., 1988. Conversion of sewage sludge to heavy oil by direct thermochemical liquefaction. J. Chem. Eng. Japan 21, 288-293. https://doi.org/10.1252/jcej.21.288

Syed-Hassan, S.S.A., Wang, Y., Hu, S., Su, S., Xiang, J., 2017. Thermochemical processing of sewage sludge to energy and fuel: Fundamentals, challenges and considerations. Renew. Sustain. Energy Rev. 80, 888-913. https://doi.org/10.1016/j.rser.2017.05.262

Taboada-Santos, A., Braz, G.H.R., Fernandez-Gonzalez, N., Carballa, M., Lema, J.M., 2019. Thermal hydrolysis of sewage sludge partially removes organic micropollutants but does not enhance their anaerobic biotransformation. Sci. Total Environ. 690, 534-542. https://doi.org/10.1016/j.scitotenv.2019.06.492

Tansel, B., Lunn, G., Monje, O., 2018. Struvite formation and decomposition characteristics for ammonia and phosphorus recovery: A review of magnesium-ammonia-phosphate interactions. Chemosphere 194, 504-514. https://doi.org/10.1016/j.chemosphere.2017.12.004

Tasca, A.L., Puccini, M., Gori, R., Corsi, I., Galletti, A.M.R., Vitolo, S., 2019. Hydrothermal carbonization of sewage sludge: A critical analysis of process severity, hydrochar properties and environmental implications. Waste Manag. 93, 1-13. https://doi.org/10.1016/j.wasman.2019.05.027

Tasca, A.L., Stefanelli, E., Raspolli Galletti, A.M., Gori, R., Mannarino, G., Vitolo, S., Puccini, M., 2020. Hydrothermal Carbonization of Sewage Sludge: Analysis of Process Severity and Solid Content. Chem. Eng. Technol. 43, 2382-2392. https://doi.org/10.1002/ceat.202000095

Titirici, M.M., White, R.J., Falco, C., Sevilla, M., 2012. Black perspectives for a green future: Hydrothermal carbons for environment protection and energy storage. Energy Environ. Sci. 5, 6796-6822. https://doi.org/10.1039/c2ee21166a

Tong, S., Zhang, S., Yin, H., Wang, J., Chen, M., 2021. Study on co-hydrothermal treatment combined with pyrolysis of rice straw/sewage sludge: Biochar properties and heavy metals behavior. J. Anal. Appl. Pyrolysis 155, 105074. https://doi.org/10.1016/j.jaap.2021.105074

Tu, W., Liu, Y., Xie, Z., Chen, M., Ma, L., Du, G., Zhu, M., 2021. A novel activation-hydrochar via hydrothermal carbonization and $\mathrm{KOH}$ activation of sewage sludge and coconut shell for biomass wastes: Preparation, characterization and adsorption properties. J. Colloid Interface Sci. 593, 390407. https://doi.org/10.1016/j.jcis.2021.02.133

Usman, M., Chen, H., Chen, K., Ren, S., Clark, J.H., Fan, J., Luo, G., Zhang, S., 2019a. Characterization 
and utilization of aqueous products from hydrothermal conversion of biomass for bio-oil and hydrochar production: A review. Green Chem. 21, 1553-1572. https://doi.org/10.1039/c8gc03957g

Usman, M., Hao, S., Chen, H., Ren, S., Tsang, D.C.W., O-Thong, S., Luo, G., Zhang, S., 2019b. Molecular and microbial insights towards understanding the anaerobic digestion of the wastewater from hydrothermal liquefaction of sewage sludge facilitated by granular activated carbon (GAC). Environ. Int. 133, 105257. https://doi.org/10.1016/j.envint.2019.105257

Usman, M., Shi, Z., Ren, S., Ngo, H.H., Luo, G., Zhang, S., 2020. Hydrochar promoted anaerobic digestion of hydrothermal liquefaction wastewater: Focusing on the organic degradation and microbial community. Chem. Eng. J. 399, 125766. https://doi.org/10.1016/j.cej.2020.125766

Vardon, D.R., Sharma, B.K., Scott, J., Yu, G., Wang, Z., Schideman, L., Zhang, Y., Strathmann, T.J., 2011. Chemical properties of biocrude oil from the hydrothermal liquefaction of Spirulina algae, swine manure, and digested anaerobic sludge. Bioresour. Technol. 102, 8295-8303. https://doi.org/10.1016/j.biortech.2011.06.041

Villamil, J.A., Mohedano, A.F., Rodriguez, J.J., De la Rubia, M.A., 2019. Anaerobic co-digestion of the aqueous phase from hydrothermally treated waste activated sludge with primary sewage sludge. A kinetic study. J. Environ. Manage. 231, 726-733. https://doi.org/10.1016/j.jenvman.2018.10.031

Villamil, J.A., Mohedano, A.F., San Martín, J., Rodriguez, J.J., de la Rubia, M.A., 2020. Anaerobic codigestion of the process water from waste activated sludge hydrothermally treated with primary sewage sludge. A new approach for sewage sludge management. Renew. Energy 146, 435-443. https://doi.org/10.1016/j.renene.2019.06.138

vom Eyser, C., Palmu, K., Schmidt, T.C., Tuerk, J., 2015. Pharmaceutical load in sewage sludge and biochar produced by hydrothermal carbonization. Sci. Total Environ. 537, 180-186. https://doi.org/10.1016/j.scitotenv.2015.08.021

Waldmüller, W., Herdzik, S., Gaderer, M., 2021. Combined filtration and oxalic acid leaching for recovering phosphorus from hydrothermally carbonized sewage sludge. J. Environ. Chem. Eng. 9, 104800. https://doi.org/10.1016/j.jece.2020.104800

Wang, C., Zhu, W., Chen, C., Zhang, H., Fan, Y., Mu, B., Zhong, J., 2019. Behavior of Phosphorus in Catalytic Supercritical Water Gasification of Dewatered Sewage Sludge: The Conversion Pathway and Effect of Alkaline Additive. Energy and Fuels 33, 1290-1295. https://doi.org/10.1021/acs.energyfuels.8b04054

Wang, C., Zhu, W., Chen, C., Zhang, H., Lin, N., Su, Y., 2018. Influence of reaction conditions on the catalytic activity of a nickel during the supercritical water gasification of dewatered sewage sludge. J. Supercrit. Fluids 140, 356-363. https://doi.org/10.1016/j.supflu.2018.07.018

Wang, C., Zhu, W., Fan, X., 2021. Char derived from sewage sludge of hydrothermal carbonization and supercritical water gasification: Comparison of the properties of two chars. Waste Manag. 123, 8896. https://doi.org/10.1016/j.wasman.2021.01.027

Wang, C., Zhu, W., Gong, M., Su, Y., Fan, Y., 2017. Influence of H2O2 and Ni catalysts on hydrogen production and PAHs inhibition from the supercritical water gasification of dewatered sewage sludge. J. Supercrit. Fluids 130, 183-188. https://doi.org/10.1016/j.supflu.2017.08.009

Wang, C., Zhu, W., Zhang, H., Chen, C., Fan, X., Su, Y., 2019. Char and tar formation during hydrothermal gasification of dewatered sewage sludge in subcritical and supercritical water: Influence of reaction parameters and lumped reaction kinetics. Waste Manag. 100, 57-65. https://doi.org/10.1016/j.wasman.2019.09.011

Wang, H., Yang, Z., Li, X., Liu, Y., 2020. Distribution and transformation behaviors of heavy metals and phosphorus during hydrothermal carbonization of sewage sludge. Environ. Sci. Pollut. Res. 27, 17109-17122. https://doi.org/10.1007/s11356-020-08098-4 
Wang, L., Chang, Y., Li, A., 2019a. Hydrothermal carbonization for energy-efficient processing of sewage sludge: A review. Renew. Sustain. Energy Rev. 108, 423-440.

https://doi.org/10.1016/j.rser.2019.04.011

Wang, L., Chang, Y., Liu, Q., 2019b. Fate and distribution of nutrients and heavy metals during hydrothermal carbonization of sewage sludge with implication to land application. J. Clean. Prod. 225, 972-983. https://doi.org/10.1016/j.jclepro.2019.03.347

Wang, L., Chang, Y., Zhang, X., Yang, F., Li, Y., Yang, X., Dong, S., 2020. Hydrothermal cocarbonization of sewage sludge and high concentration phenolic wastewater for production of solid biofuel with increased calorific value. J. Clean. Prod. 255, 120317. https://doi.org/10.1016/j.jclepro.2020.120317

Wang, L., Li, A., Chang, Y., 2017. Relationship between enhanced dewaterability and structural properties of hydrothermal sludge after hydrothermal treatment of excess sludge. Water Res. 112, 72-82. https://doi.org/10.1016/j.watres.2017.01.034

Wang, L., Li, A., Chang, Y., 2016. Hydrothermal treatment coupled with mechanical expression at increased temperature for excess sludge dewatering: Heavy metals, volatile organic compounds and combustion characteristics of hydrochar. Chem. Eng. J. 297, 1-10. https://doi.org/10.1016/j.cej.2016.03.131

Wang, L., Zhang, L., Li, A., 2014. Hydrothermal treatment coupled with mechanical expression at increased temperature for excess sludge dewatering: Influence of operating conditions and the process energetics. Water Res. 65, 85-97. https://doi.org/10.1016/j.watres.2014.07.020

Wang, P., Sakhno, Y., Adhikari, S., Peng, H., Jaisi, D., Soneye, T., Higgins, B., Wang, Q., 2021. Effect of ammonia removal and biochar detoxification on anaerobic digestion of aqueous phase from municipal sludge hydrothermal liquefaction. Bioresour. Technol. 326, 124730. https://doi.org/10.1016/j.biortech.2021.124730

Wang, R., Lei, H., Liu, S., Ye, X., Jia, J., Zhao, Z., 2021. The redistribution and migration mechanism of nitrogen in the hydrothermal co-carbonization process of sewage sludge and lignocellulosic wastes. Sci. Total Environ. 776, 145922. https://doi.org/10.1016/j.scitotenv.2021.145922

Wang, R., Wang, C., Zhao, Z., Jia, J., Jin, Q., 2019. Energy recovery from high-ash municipal sewage sludge by hydrothermal carbonization: Fuel characteristics of biosolid products. Energy 186, 115848. https://doi.org/10.1016/j.energy.2019.07.178

Wang, S., Persson, H., Yang, W., Jönsson, P.G., 2020. Pyrolysis study of hydrothermal carbonizationtreated digested sewage sludge using a Py-GC/MS and a bench-scale pyrolyzer. Fuel 262, 116335. https://doi.org/10.1016/j.fuel.2019.116335

Wang, T., Zhai, Y., Zhu, Y., Li, C., Zeng, G., 2018. A review of the hydrothermal carbonization of biomass waste for hydrochar formation: Process conditions, fundamentals, and physicochemical properties. Renew. Sustain. Energy Rev. 90, 223-247. https://doi.org/10.1016/j.rser.2018.03.071

Wang, T.T., Zhai, Y., Zhu, Y., Peng, C., Wang, T.T., Xu, B., Li, C., Zeng, G., 2017. Feedwater pH affects phosphorus transformation during hydrothermal carbonization of sewage sludge. Bioresour. Technol. 245, 182-187. https://doi.org/10.1016/j.biortech.2017.08.114

Wang, W., Ren, X., Yang, K., Hu, Z., Yuan, S., 2017. Inhibition of ammonia on anaerobic digestion of synthetic coal gasification wastewater and recovery using struvite precipitation. J. Hazard. Mater. 340, 152-159. https://doi.org/10.1016/j.jhazmat.2017.07.002

Wang, W., Yu, Q., Meng, H., Han, W., Li, J., Zhang, J., 2018. Catalytic liquefaction of municipal sewage sludge over transition metal catalysts in ethanol-water co-solvent. Bioresour. Technol. 249, 361-367. https://doi.org/10.1016/j.biortech.2017.09.205 
Wang, X., Chi, Q., Liu, X., Wang, Y., 2019. Influence of pyrolysis temperature on characteristics and environmental risk of heavy metals in pyrolyzed biochar made from hydrothermally treated sewage sludge. Chemosphere 216, 698-706. https://doi.org/10.1016/j.chemosphere.2018.10.189

Wang, Y., Chen, G., Li, Y., Yan, B., Pan, D., 2013. Experimental study of the bio-oil production from sewage sludge by supercritical conversion process. Waste Manag. 33, 2408-2415. https://doi.org/10.1016/j.wasman.2013.05.021

Wang, Z., Lin, W., Song, W., 2012. Liquid product from hydrothermal treatment of cellulose by direct GC/MS analysis. Appl. Energy 97, 56-60. https://doi.org/10.1016/j.apenergy.2011.11.077

Wang, Z., Zhai, Y., Wang, T., Peng, C., Li, S., Wang, B., Liu, X., Li, C., 2020. Effect of temperature on the sulfur fate during hydrothermal carbonization of sewage sludge. Environ. Pollut. 260, 114067. https://doi.org/10.1016/j.envpol.2020.114067

Watson, J., Wang, T., Si, B., Chen, W.T., Aierzhati, A., Zhang, Y., 2020. Valorization of hydrothermal liquefaction aqueous phase: pathways towards commercial viability. Prog. Energy Combust. Sci. 77, 100819. https://doi.org/10.1016/j.pecs.2019.100819

Weijin, G., Zizheng, Z., Yue, L., Qingyu, W., Lina, G., 2019. Hydrogen production and phosphorus recovery via supercritical water gasification of sewage sludge in a batch reactor. Waste Manag. 96, 198-205. https://doi.org/10.1016/j.wasman.2019.07.023

Wiedner, K., Rumpel, C., Steiner, C., Pozzi, A., Maas, R., Glaser, B., 2013. Chemical evaluation of chars produced by thermochemical conversion (gasification, pyrolysis and hydrothermal carbonization) of agro-industrial biomass on a commercial scale. Biomass and Bioenergy 59, 264-278. https://doi.org/10.1016/j.biombioe.2013.08.026

Wilk, M., 2016. A novel method of sewage sludge pre-treatment-HTC, in: E3S Web of Conferences. https://doi.org/10.1051/e3sconf/20161000103

Wilk, M., Magdziarz, A., Jayaraman, K., Szymańska-Chargot, M., Gökalp, I., 2019. Hydrothermal carbonization characteristics of sewage sludge and lignocellulosic biomass. A comparative study. Biomass and Bioenergy 120, 166-175. https://doi.org/10.1016/j.biombioe.2018.11.016

Wu, B., Berg, S.M., Remucal, C.K., Strathmann, T.J., 2020. Evolution of N-Containing Compounds during Hydrothermal Liquefaction of Sewage Sludge. ACS Sustain. Chem. Eng. 8, 18303-18313. https://doi.org/10.1021/acssuschemeng.0c07060

Wu, S. yong, Liu, F. qi, Huang, S., Wu, Y. qing, Gao, J. sheng, 2017. Direct n-hexane extraction of wet sewage sludge at thermal and pressurized conditions: A preliminary investigation on its process and product characteristics. Fuel Process. Technol. 156, 90-97. https://doi.org/10.1016/j.fuproc.2016.07.020

Xia, Y., Yang, T., Zhu, N., Li, D., Chen, Z., Lang, Q., Liu, Z., Jiao, W., 2019. Enhanced adsorption of $\mathrm{Pb}$ (II) onto modified hydrochar: Modeling and mechanism analysis. Bioresour. Technol. 288, 121593. https://doi.org/10.1016/j.biortech.2019.121593

Xu, C., Lancaster, J., 2008. Conversion of secondary pulp/paper sludge powder to liquid oil products for energy recovery by direct liquefaction in hot-compressed water. Water Res. 42, 1571-1582. https://doi.org/10.1016/j.watres.2007.11.007

Xu, D., Lin, G., Liu, L., Wang, Y., Jing, Z., Wang, S., 2018. Comprehensive evaluation on product characteristics of fast hydrothermal liquefaction of sewage sludge at different temperatures. Energy 159, 686-695. https://doi.org/10.1016/j.energy.2018.06.191

Xu, D., Wang, Y., Lin, G., Guo, S., Wang, S., Wu, Z., 2019. Co-hydrothermal liquefaction of microalgae and sewage sludge in subcritical water: Ash effects on bio-oil production. Renew. Energy 138, 1143-1151. https://doi.org/10.1016/j.renene.2019.02.020 
Xu, X., Antal, M.J., 1998. Gasification of Sewage Sludge and Other Biomass for Hydrogen Production in Supercritical Water. Environ. Prog. 17, 215-220. https://doi.org/10.1002/ep.670170411

Xu, X., Jiang, E., 2017. Treatment of urban sludge by hydrothermal carbonization. Bioresour. Technol. 238, 182-187. https://doi.org/10.1016/j.biortech.2017.03.174

Xu, X., Matsumura, Y., Stenberg, J., Antal, M.J., 1996. Carbon-catalyzed gasification of organic feedstocks in supercritical Water. Ind. Eng. Chem. Res. 35, 2522-2530. https://doi.org/10.1021/ie950672b

Xu, Y., Yang, F., Zhang, L., Wang, X., Sun, Y., Liu, Q., Qian, G., 2018. Migration and transformation of phosphorus in municipal sludge by the hydrothermal treatment and its directional adjustment. Waste Manag. 81, 196-201. https://doi.org/10.1016/j.wasman.2018.10.011

Xu, Z., Zhu, W., Bao, J., Chen, J., 2011. The fate of heavy metal during subcritical and supercritical water gasification of sewage sludge, in: 2011 International Symposium on Water Resource and Environmental Protection. IEEE, pp. 1260-1263. https://doi.org/10.1109/ISWREP.2011.5893247

Xu, Z.R., Zhu, W., Gong, M., Zhang, H.W., 2013. Direct gasification of dewatered sewage sludge in supercritical water. Part 1: Effects of alkali salts. Int. J. Hydrogen Energy 38, 3963-3972. https://doi.org/10.1016/j.ijhydene.2013.01.164

Xu, Z.R., Zhu, W., Li, M., 2012. Influence of moisture content on the direct gasification of dewatered sludge via supercritical water. Int. J. Hydrogen Energy 37, 6527-6535. https://doi.org/10.1016/j.ijhydene.2012.01.086

Xu, Z.X., Shan, Y.Q., Zhang, Z., Deng, X.Q., Yang, Y., Luque, R., Duan, P.G., 2020a. Hydrothermal carbonization of sewage sludge: Effect of inorganic salts on hydrochar's physicochemical properties. Green Chem. 22, 7010-7022. https://doi.org/10.1039/d0gc02615h

Xu, Z.X., Song, H., Li, P.J., He, Z.X., Wang, Q., Wang, K., Duan, P.G., 2020b. Hydrothermal carbonization of sewage sludge: Effect of aqueous phase recycling. Chem. Eng. J. 387, 123410. https://doi.org/10.1016/j.cej.2019.123410

Xu, Z.X., Song, H., Zhang, S., Tong, S.Q., He, Z.X., Wang, Q., Li, B., Hu, X., 2019. Co-hydrothermal carbonization of digested sewage sludge and cow dung biogas residue: Investigation of the reaction characteristics. Energy 187, 115972. https://doi.org/10.1016/j.energy.2019.115972

Xue, X., Chen, D., Song, X., Dai, X., 2015. Hydrothermal and Pyrolysis Treatment for Sewage Sludge: Choice from Product and from Energy Benefit, in: Physics Procedia. Elsevier B.V., pp. 301-304. https://doi.org/10.1016/j.egypro.2015.02.064

Yang, G., Zhang, G., Wang, H., 2015. Current state of sludge production, management, treatment and disposal in China. Water Res. 78, 60-73. https://doi.org/10.1016/j.watres.2015.04.002

Yang, T., Liu, X., Li, R., Li, B., Kai, X., 2019. Hydrothermal liquefaction of sewage sludge to produce bio-oil: Effect of co-pretreatment with subcritical water and mixed surfactants. J. Supercrit. Fluids 144, 28-38. https://doi.org/10.1016/j.supflu.2018.10.005

Yin, F., Chen, H., Xu, G., Wang, G., Xu, Y., 2015. A detailed kinetic model for the hydrothermal decomposition process of sewage sludge. Bioresour. Technol. 198, 351-357. https://doi.org/10.1016/j.biortech.2015.09.033

Yu, J., Guo, M., Xu, X., Guan, B., 2014. The role of temperature and $\mathrm{CaCl} 2$ in activated sludge dewatering under hydrothermal treatment. Water Res. 50, 10-17. https://doi.org/10.1016/j.watres.2013.11.034

Yu, J., Nickerson, A., Li, Y., Fang, Y., Strathmann, T.J., 2020. Fate of per- and polyfluoroalkyl substances (PFAS) during hydrothermal liquefaction of municipal wastewater treatment sludge. Environ. Sci. Water Res. Technol. 6, 1388-1399. https://doi.org/10.1039/c9ew01139k 
Yu, Y., Lei, Z., Yang, Xi, Yang, Xiaojing, Huang, W., Shimizu, K., Zhang, Z., 2018. Hydrothermal carbonization of anaerobic granular sludge: Effect of process temperature on nutrients availability and energy gain from produced hydrochar. Appl. Energy 229, 88-95.

https://doi.org/10.1016/j.apenergy.2018.07.088

Yu, Y., Yang, X., Lei, Z., Yu, R., Shimizu, K., Chen, N., Feng, C., Zhang, Z., 2019. Effects of three macroelement cations on P mobility and speciation in sewage sludge derived hydrochar by using hydrothermal treatment. Bioresour. Technol. Reports 7, 100231. https://doi.org/10.1016/j.biteb.2019.100231

Yuan, S.J., Dai, X.H., 2014. Facile synthesis of sewage sludge-derived mesoporous material as an efficient and stable heterogeneous catalyst for photo-Fenton reaction. Appl. Catal. B Environ. 154155, 252-258. https://doi.org/10.1016/j.apcatb.2014.02.031

Yuan, X., Huang, H., Zeng, G., Li, H., Wang, J., Zhou, C., Zhu, H., Pei, X., Liu, Zhifeng, Liu, Zhantao, 2011. Total concentrations and chemical speciation of heavy metals in liquefaction residues of sewage sludge. Bioresour. Technol. 102, 4104-4110. https://doi.org/10.1016/j.biortech.2010.12.055

Yuan, X., Leng, L., Huang, H., Chen, X., Wang, H., Xiao, Z., Zhai, Y., Chen, H., Zeng, G., 2015. Speciation and environmental risk assessment of heavy metal in bio-oil from liquefaction/pyrolysis of sewage sludge. Chemosphere 120, 645-652. https://doi.org/10.1016/j.chemosphere.2014.10.010

Yue, Y., Yao, Y., Lin, Q., Li, G., Zhao, X., 2017. The change of heavy metals fractions during hydrochar decomposition in soils amended with different municipal sewage sludge hydrochars. J. Soils Sediments 17, 763-770. https://doi.org/10.1007/s11368-015-1312-2

Zahari, S.M.S.N.S., Zulastry, N.A., Azman, H.H., 2020. A Preliminary Study of Catalytic Hydrothermal Conversion of Cellulose to Lactic Acid: Effects of Reaction Temperature and Metal Ion Catalyst, in: Journal of Physics: Conference Series. https://doi.org/10.1088/1742-6596/1551/1/012014

Zhai, Y., Chen, H., Xu, B.B., Xiang, B., Chen, Z., Li, C., Zeng, G., 2014a. Influence of sewage sludgebased activated carbon and temperature on the liquefaction of sewage sludge: Yield and composition of bio-oil, immobilization and risk assessment of heavy metals. Bioresour. Technol. 159, 72-79. https://doi.org/10.1016/j.biortech.2014.02.049

Zhai, Y., Liu, X., Zhu, Y., Peng, C., Wang, T., Zhu, L., Li, C., Zeng, G., 2016. Hydrothermal carbonization of sewage sludge: The effect of feed-water $\mathrm{pH}$ on fate and risk of heavy metals in hydrochars. Bioresour. Technol. 218, 183-188. https://doi.org/10.1016/j.biortech.2016.06.085

Zhai, Y., Peng, C., Xu, B., Wang, T., Li, C., Zeng, G., Zhu, Y., 2017. Hydrothermal carbonisation of sewage sludge for char production with different waste biomass: Effects of reaction temperature and energy recycling. Energy 127, 167-174. https://doi.org/10.1016/j.energy.2017.03.116

Zhai, Y., Wang, C., Chen, H., Li, C., Zeng, G., Pang, D., Lu, P., 2013. Digested sewage sludge gasification in supercritical water, in: Waste Management and Research. pp. 393-400. https://doi.org/10.1177/0734242X12471097

Zhai, Y., Xiang, B., Chen, H., Xu, B., Zhu, L., Li, C., Zeng, G., 2014b. Recovery of phosphorus from sewage sludge in combination with the supercritical water process. Water Sci. Technol. 70, 11081114. https://doi.org/10.2166/wst.2014.344

Zhang, C., Ma, X., Zheng, C., Huang, T., Lu, X., Tian, Y., 2020. Co-hydrothermal Carbonization of Water Hyacinth and Sewage Sludge: Effects of Aqueous Phase Recirculation on the Characteristics of Hydrochar. Energy and Fuels 34, 14147-14158. https://doi.org/10.1021/acs.energyfuels.0c01991

Zhang, H., Hay, A.G., 2020. Magnetic biochar derived from biosolids via hydrothermal carbonization: Enzyme immobilization, immobilized-enzyme kinetics, environmental toxicity. J. Hazard. Mater. 384, 121272. https://doi.org/10.1016/j.jhazmat.2019.121272 
Zhang, H., Xue, G., Chen, H., Li, X., 2018. Magnetic biochar catalyst derived from biological sludge and ferric sludge using hydrothermal carbonization: Preparation, characterization and its circulation in Fenton process for dyeing wastewater treatment. Chemosphere 191, 64-71. https://doi.org/10.1016/j.chemosphere.2017.10.026

Zhang, J. hong, Lin, Q. mei, Zhao, X. rong, 2014. The hydrochar characters of municipal sewage sludge under different hydrothermal temperatures and durations. J. Integr. Agric. 13, 471-482. https://doi.org/10.1016/S2095-3119(13)60702-9

Zhang, L., Xu, C. (Charles), Champagne, P., 2010. Energy recovery from secondary pulp/paper-mill sludge and sewage sludge with supercritical water treatment. Bioresour. Technol. 101, 2713-2721. https://doi.org/10.1016/j.biortech.2009.11.106

Zhang, X., Zhang, L., Li, A., 2017. Hydrothermal co-carbonization of sewage sludge and pinewood sawdust for nutrient-rich hydrochar production: Synergistic effects and products characterization. J. Environ. Manage. 201, 52-62. https://doi.org/10.1016/j.jenvman.2017.06.018

Zhang, X.P., Zhang, C., Li, X., Yu, S.H., Tan, P., Fang, Q.Y., Chen, G., 2018. A two-step process for sewage sludge treatment: Hydrothermal treatment of sludge and catalytic hydrothermal gasification of its derived liquid. Fuel Process. Technol. 180, 67-74. https://doi.org/10.1016/j.fuproc.2018.08.012

Zhao, P., Chen, H., Ge, S., Yoshikawa, K., 2013. Effect of the hydrothermal pretreatment for the reduction of no emission from sewage sludge combustion. Appl. Energy 111, 199-205. https://doi.org/10.1016/j.apenergy.2013.05.029

Zhao, P., Shen, Y., Ge, S., Yoshikawa, K., 2014. Energy recycling from sewage sludge by producing solid biofuel with hydrothermal carbonization. Energy Convers. Manag. 78, 815-821. https://doi.org/10.1016/j.enconman.2013.11.026

Zhen, G., Lu, X., Kato, H., Zhao, Y., Li, Y.Y., 2017. Overview of pretreatment strategies for enhancing sewage sludge disintegration and subsequent anaerobic digestion: Current advances, full-scale application and future perspectives. Renew. Sustain. Energy Rev. 69, 559-577. https://doi.org/10.1016/j.rser.2016.11.187

Zheng, C., Ma, X., Yao, Z., Chen, X., 2019. The properties and combustion behaviors of hydrochars derived from co-hydrothermal carbonization of sewage sludge and food waste. Bioresour. Technol. 285, 121347. https://doi.org/10.1016/j.biortech.2019.121347

Zheng, X., Chen, W., Ying, Z., Huang, J., Ji, S., Wang, B., 2019. Thermodynamic investigation on gasification performance of sewage sludge-derived hydrochar: Effect of hydrothermal carbonization. Int. J. Hydrogen Energy 44, 10374-10383. https://doi.org/10.1016/j.ijhydene.2019.02.200

Zheng, X., Ye, Y., Jiang, Z., Ying, Z., Ji, S., Chen, W., Wang, B., Dou, B., 2020a. Enhanced transformation of phosphorus $(\mathrm{P})$ in sewage sludge to hydroxyapatite via hydrothermal carbonization and calcium-based additive. Sci. Total Environ. 738, 139786. https://doi.org/10.1016/j.scitotenv.2020.139786

Zheng, X., Zheng, X., Jiang, Z., Ying, Z., Ying, Z., Ye, Y., Chen, W., Wang, B., Wang, B., Dou, B., Dou, B., 2020b. Migration and Transformation of Phosphorus during Hydrothermal Carbonization of Sewage Sludge: Focusing on the Role of $\mathrm{pH}$ and Calcium Additive and the Transformation Mechanism. ACS Sustain. Chem. Eng. 8, 7806-7814. https://doi.org/10.1021/acssuschemeng.0c00031

Zhou, G., Chen, Z., Fang, F., He, Y., Sun, H., Shi, H., 2015. Fenton-like degradation of Methylene Blue using paper mill sludge-derived magnetically separable heterogeneous catalyst: Characterization and mechanism. J. Environ. Sci. (China) 35, 20-26. https://doi.org/10.1016/j.jes.2015.01.026

Zhu, W., Xu, Z.R., Li, L., He, C., 2011. The behavior of phosphorus in sub-and super-critical water 
gasification of sewage sludge. Chem. Eng. J. 171, 190-196.

https://doi.org/10.1016/j.cej.2011.03.090

Zhuang, X., Huang, Y., Song, Y., Zhan, H., Yin, X., Wu, C., 2017. The transformation pathways of nitrogen in sewage sludge during hydrothermal treatment. Bioresour. Technol. 245, 463-470. https://doi.org/10.1016/j.biortech.2017.08.195

Zhuang, X., Song, Y., Zhan, H., Bi, X.T., Yin, X., Wu, C., 2020a. Pyrolytic conversion of biowastederived hydrochar: Decomposition mechanism of specific components. Fuel 266. https://doi.org/10.1016/j.fuel.2020.117106

Zhuang, X., Song, Y., Zhan, H., Yin, X., Wu, C., 2020b. Gasification performance of biowaste-derived hydrochar: The properties of products and the conversion processes. Fuel 260. https://doi.org/10.1016/j.fuel.2019.116320

Zhuang, X., Song, Y., Zhan, H., Yin, X., Wu, C., 2020c. Influences of microstructural alternations and inorganic catalysis on the thermochemical conversion of biowaste-derived hydrochar. Fuel Process. Technol. 199, 106304. https://doi.org/10.1016/j.fuproc.2019.106304

Zhuang, X., Zhan, H., Huang, Y., Song, Y., Yin, X., Wu, C., 2018. Conversion of industrial biowastes to clean solid fuels via hydrothermal carbonization (HTC): Upgrading mechanism in relation to coalification process and combustion behavior. Bioresour. Technol. 267, 17-29. https://doi.org/10.1016/j.biortech.2018.07.002

Zhuang, X., Zhan, H., Song, Y., Yin, X., Wu, C., 2019. Structure-reactivity relationships of biowastederived hydrochar on subsequent pyrolysis and gasification performance. Energy Convers. Manag. 199, 112014. https://doi.org/10.1016/j.enconman.2019.112014 
Table 1 Typical treatment conditions of three types of hydrothermal treatment for municipal sludge and their products ${ }^{\mathrm{a}}$

\begin{tabular}{|c|c|c|c|c|c|c|}
\hline $\begin{array}{l}\text { HTP } \\
\text { type }\end{array}$ & $\begin{array}{l}\text { Temperature } \\
\text { range }\left({ }^{\circ} \mathrm{C}\right)\end{array}$ & $\begin{array}{l}\text { Pressure } \\
\text { range } \\
(\mathrm{MPa})\end{array}$ & $\begin{array}{l}\text { Retention } \\
\text { time (min) }\end{array}$ & $\begin{array}{l}\text { Water } \\
\text { state }\end{array}$ & $\begin{array}{l}\text { Featured } \\
\text { products and } \\
\text { yield }(\%)^{b}\end{array}$ & Coproducts and yield $(\%)^{\mathrm{b}}$ \\
\hline HTC & $150-280$ & $0.1-11$ & $30-960$ & $\begin{array}{l}\text { Sub- } \\
\text { critical }\end{array}$ & $\begin{array}{l}\text { Hydrochar (4- } \\
94)\end{array}$ & $\begin{array}{l}\text { Aqueous phase (12-63), } \\
\text { biocrude }(6-38) \text { and gas } \\
\left.\text { (mainly } \mathrm{CO}_{2}, 1-19\right)\end{array}$ \\
\hline HTL & $280-375$ & $8-22$ & $10-180$ & $\begin{array}{l}\text { Sub- / } \\
\text { near- } \\
\text { critical }\end{array}$ & Biocrude (8-44) & $\begin{array}{l}\text { Aqueous phase (8- 62), } \\
\text { hydrochar }(5-80) \text { and gas } \\
\left.\text { (mainly } \mathrm{CO}_{2}, 1-26\right)\end{array}$ \\
\hline HTG & $>375$ & $>22.1$ & $0-60$ & $\begin{array}{l}\text { Super- } \\
\text { critical }\end{array}$ & $\begin{array}{l}\text { Syngas (rich in } \\
\mathrm{H}_{2} \text { or } \mathrm{CH}_{4}, 7- \\
52 \text { ) }\end{array}$ & $\begin{array}{l}\text { Aqueous phase (2-58), } \\
\text { biocrude }(2-46) \text { and } \\
\text { hydrochar }(8-69)\end{array}$ \\
\hline
\end{tabular}

${ }^{\mathrm{a}} \mathrm{HTP}=$ hydrothermal processing; $\mathrm{HTC}=$ hydrothermal carbonization; $\mathrm{HTL}=$ hydrothermal liquefaction; HTG = hydrothermal gasification; references (Aida et al., 2016; Aragón-Briceño et al., 2017; Berge et al., 2011; Biller et al., 2018; Chen et al., 2014; Couto et al., 2018; Danso-Boateng et al., 2015; Escala et al., 2013; Fakkaew et al., 2018; Fei et al., 2019a, 2019b; Feng et al., 2018; He et al., 2019, 2013; Huang et al., 2013, 2014; Huang et al., 2018; Huang and Tang, 2016; Inoue et al., 1997; Khoshbouy et al., 2019; Lee et al., 2019; Leng et al., 2018, 2015b; Li et al., 2010, 2012; M. Liu et al., 2017; Liu et al., 2018; Liu et al., 2019; Ma et al., 2019a, 2019b; Mishra and Mohanty, 2020; Molton et al., 1986; Nazari et al., 2017; Ovsyannikova et al., 2020; Paneque et al., 2017; Parmar and Ross, 2019; Peng et al., 2016; Qian et al., 2020; Ren et al., 2017; Saetea and Tippayawong, 2013a; Shah et al., 2020; Shao et al., 2015; Shi et al., 2019; Smith et al., 2016; Song et al., 2019; Su et al., 2019; L. Wang et al., 2017; Wang et al., 2016, 2019, 2013; Wang et al., 2020; Xu et al., 2019, 2018; Xu and Jiang, 2017; Yu et al., 2019, 2018; Zhai et al., 2017; Zhang et al., 2010; Zhang et al., 2018; Zhuang et al., 2020b, 2020a, 2018, 2017).

${ }^{\mathrm{b}}$ Yield $(\%)=($ mass of each product $/$ mass of feedstock $) \times 100$, dry basis. 
Table 2 Characteristics of various municipal sludge reported in hydrothermal treatment ${ }^{\mathrm{a}}$

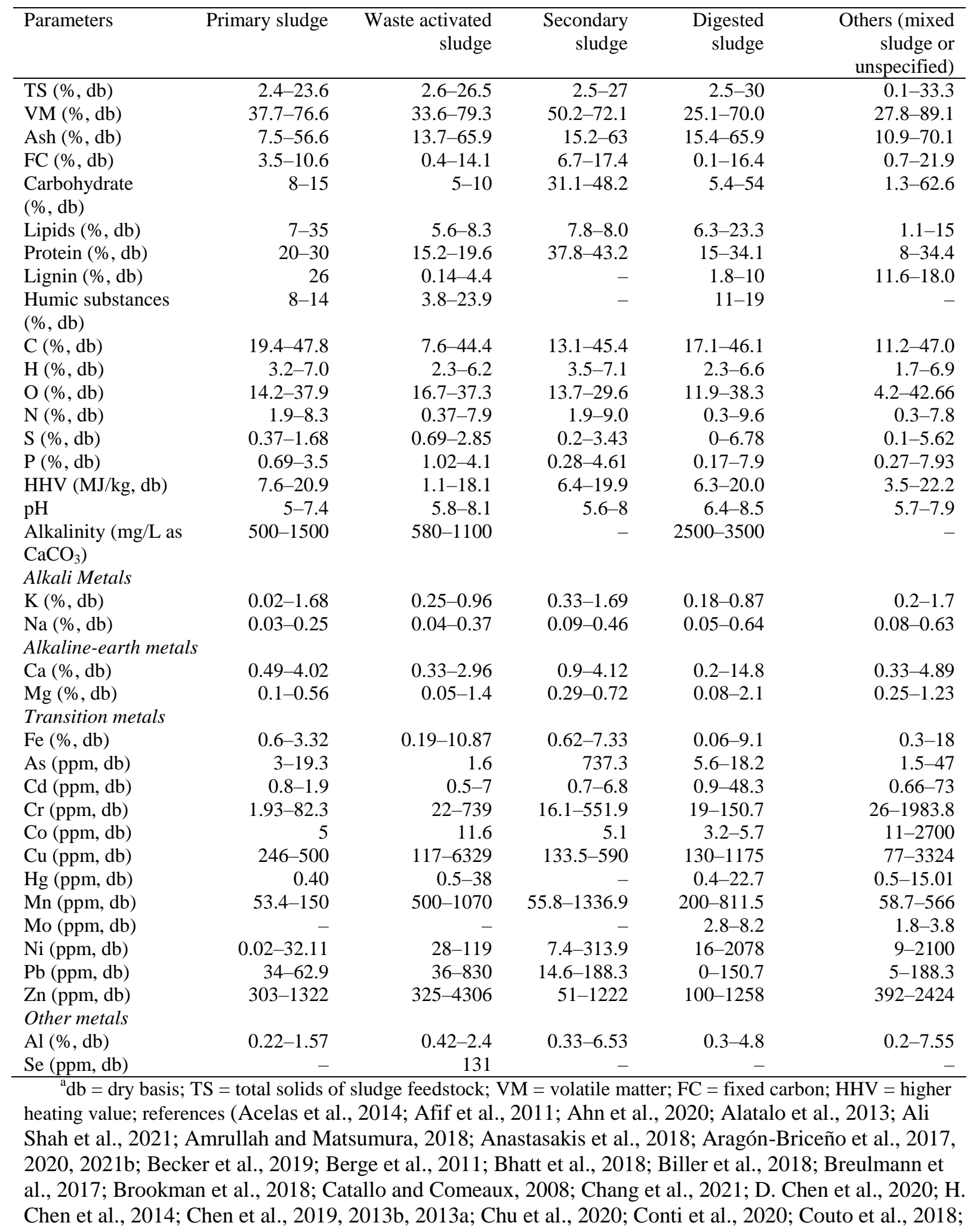


Danso-Boateng et al., 2015; De la Rubia et al., 2018; Do et al., 2020; Ekpo et al., 2016; El-Deen and Zhang, 2012; Escala et al., 2013; Fakkaew et al., 2018; Fan et al., 2016; Fei et al., 2019b, 2019a; Feng et al., 2018; Ferrentino et al., 2020a; Fiori et al., 2012; Gai et al., 2016b, 2016a; Gao et al., 2019; Gaur et al., 2020; Gong et al., 2014b, 2016a, 2016b, 2018; Guo et al., 2010; He et al., 2013, 2014b, 2015b, 2016, 2019, 2020; Huang et al., 2011, 2013, 2014; R. Huang et al., 2018; Huang and Tang, 2015, 2016; Inoue et al., 1997; Itoh et al., 1994; Kapusta, 2018; Khoshbouy et al., 2019; Kim et al., 2014, 2017; Koottatep et al., 2016; Lai et al., 2018; Lee et al., 2019; Leng et al., 2014, 2015b, 2018; Li et al., 2017, 2010, 2012, 2018; Lishan et al., 2018; M. Liu et al., 2017; R. Liu et al., 2018; T. Liu et al., 2017a, 2017b, 2018b, 2018a; Liu et al., 2019, 2020; Ma et al., 2019a, 2019b; Malhotra and Garg, 2020; Malins et al., 2015; Marin-Batista et al., 2020; Marrone et al., 2018; Melo et al., 2018, 2019; Merzari et al., 2020; Mishra and Mohanty, 2020; Mittapalli et al., 2021; Molton et al., 1986; Mujahid et al., 2020; Munir et al., 2017; Nazari et al., 2017; Ovsyannikova et al., 2019, 2020; Paneque et al., 2017; Park et al., 2019; Parmar and Ross, 2019; Parshetti et al., 2013; Peng et al., 2016; Prajitno et al., 2018; Prestigiacomo et al., 2019, 2020; Qian et al., 2015, 2017, 2020; Ren et al., 2017; Saetea and Tippayawong, 2013; Sawai et al., 2014; Shah et al., 2020; Shan et al., 2020; Shao et al., 2015; Shi et al., 2013, 2014, 2019; Silva et al., 2020; Smith et al., 2016; Song et al., 2019; Su et al., 2019; Suzuki and Nakamura, 1989; Tasca et al., 2020; Tong et al., 2021; Usman et al., 2019b; Vardon et al., 2011; Villamil et al., 2020; vom Eyser et al., 2015; Waldmüller et al., 2021; C. Wang et al., 2017; Wang et al., 2019, 2019; C. Wang et al., 2021; H. Wang et al., 2020; Wang et al., 2016; L. Wang et al., 2017, 2019b, 2020; Wang et al., 2019; S. Wang et al., 2020; T. T. Wang et al., 2017; W. Wang et al., 2018; Wang et al., 2019, 2013; Z. Wang et al., 2020; Weijin et al., 2019; Wiedner et al., 2013; Wilk, 2016; Wilk et al., 2019; Wu et al., 2017; D. Xu et al., 2018, 2019; Xu et al., 1996; Xu and Antal, 1998; Xu and Jiang, 2017; Y. Xu et al., 2018; Xu et al., 2011, 2012, 2013; Z. X. Xu et al., 2019; Xu et al., 2020b; Xue et al., 2015; Yang et al., 2019; Yin et al., 2015; Yu et al., 2014, 2019; Yuan et al., 2011, 2015; Yue et al., 2017; Zhai et al., 2013, 2014a, 2014b, 2016, 2017; Zhang et al., 2010, 2017; X. P. Zhang et al., 2018; Zhao et al., 2013, 2014; C. Zheng et al., 2019; Zhu et al., 2011; Zhuang et al., 2017, 2018, 2019, 2020b, 2020a, 2020c) 
Table 3 Summary of studies on co-hydrothermal processing of municipal sludge with other types of biomass $^{\mathrm{a}}$

\begin{tabular}{|c|c|c|c|c|c|}
\hline $\begin{array}{l}\text { Feedstock } \\
\text { mixture }\end{array}$ & $\begin{array}{l}\text { MS in } \\
\text { feedstock } \\
\text { mixture (wt } \%)\end{array}$ & $\begin{array}{l}\text { HTP } \\
\text { conditions }\end{array}$ & Reactor & Remarks & Reference \\
\hline $\begin{array}{l}\text { MS + rice } \\
\text { straw, peanut } \\
\text { shell, orange } \\
\text { peel, or fallen } \\
\text { leaves }\end{array}$ & $25-75$ & $220^{\circ} \mathrm{C}, 12 \mathrm{~h}$ & $\begin{array}{l}100- \\
\mathrm{mL} \\
\text { batch }\end{array}$ & $\begin{array}{l}\text { - Hydrochar derived from MS with } \\
75 \% \text { of peanut shells showed the } \\
\text { highest fuel ratio }(0.79) \text {, carbon } \\
\text { content }(50 \%) \text {, and HHV ( } 21.72 \\
\mathrm{MJ} / \mathrm{kg} \text { ); } \\
\text { - } 25 \% \text { and } 50 \% \text { of peanut shells led } \\
\text { to the most favorable } \\
\text { aromatization and induced more - } \\
\mathrm{C}=\mathrm{O} \text { and }-\mathrm{OH} \text { than }-\mathrm{COOH} \text { in } \\
\text { hydrochar due to synergistic } \\
\text { decarboxylation. }\end{array}$ & $\begin{array}{l}\text { (He et al., } \\
2019)\end{array}$ \\
\hline DS + peat & $25-75$ & $\begin{array}{l}200-250{ }^{\circ} \mathrm{C}, 1 \\
\mathrm{~h}\end{array}$ & $\begin{array}{l}1-\mathrm{L} \\
\text { batch }\end{array}$ & $\begin{array}{l}\text { - Co-HTC of MS with peat } \\
\text { enhanced the dehydration and } \\
\text { decarboxylation reactions; } \\
\text { - Bonds of }-\mathrm{C}=\mathrm{O} \text { and }-\mathrm{C}=\mathrm{C} \text { were } \\
\text { formed in hydrochar from co- } \\
\text { HTC. }\end{array}$ & $\begin{array}{l}\text { (Kim et } \\
\text { al., 2017) }\end{array}$ \\
\hline $\begin{array}{l}\text { FS + cassava } \\
\text { pulp, leaves, pig } \\
\text { manure, or rice } \\
\text { husks }\end{array}$ & $25-75$ & $220{ }^{\circ} \mathrm{C}, 5 \mathrm{~h}$ & $\begin{array}{l}1-\mathrm{L} \\
\text { batch }\end{array}$ & $\begin{array}{l}\text { - Co-HTC improved HHV of } \\
\text { hydrochar compared to HTC of FS } \\
\text { only. }\end{array}$ & $\begin{array}{l}\text { (Koottatep } \\
\text { et al., } \\
2016)\end{array}$ \\
\hline $\begin{array}{l}\text { PS + Chlorella } \\
\text { sp. }\end{array}$ & 90 & $\begin{array}{l}180-270{ }^{\circ} \mathrm{C}, 30 \\
\min \end{array}$ & $\begin{array}{l}1-\mathrm{L} \\
\text { batch }\end{array}$ & $\begin{array}{l}\text { - The } \mathrm{H} / \mathrm{C} \text { and } \mathrm{O} / \mathrm{C} \text { ratios of } \\
\text { hydrochar from co-HTC decreased } \\
\text { with the increasing temperature. }\end{array}$ & $\begin{array}{l}\text { (Lee et al., } \\
\text { 2019) }\end{array}$ \\
\hline MS + sawdust & $25-75$ & $220^{\circ} \mathrm{C}, 1 \mathrm{~h}$ & Batch & $\begin{array}{l}\text { - Co-HTC showed higher HHV and } \\
\text { yield of hydrochar than that from } \\
\text { HTC of MS only; } \\
\text { - Enhanced aromatic degree was } \\
\text { observed in hydrochar from co- } \\
\text { HTC compared to that from HTC } \\
\text { of MS only. }\end{array}$ & $\begin{array}{l}\text { (Ma et al., } \\
\text { 2019a) }\end{array}$ \\
\hline MS + sawdust & $25-75$ & $220{ }^{\circ} \mathrm{C}, 1 \mathrm{~h}$ & Batch & $\begin{array}{l}\text { - Co-HTC significantly improved } \\
\text { the devolatilization performance of } \\
\text { hydrochar, compared to HTC of } \\
\text { MS only. }\end{array}$ & $\begin{array}{l}\text { (Ma et al., } \\
\text { 2019b) }\end{array}$ \\
\hline $\begin{array}{l}\text { WAS + } \\
\text { phenolic } \\
\text { compounds }\end{array}$ & $3.2-33.3$ (daf) & $\begin{array}{l}140-260^{\circ} \mathrm{C}, \\
2-10 \mathrm{~h}\end{array}$ & $\begin{array}{l}250- \\
\mathrm{mL} \\
\text { batch }\end{array}$ & $\begin{array}{l}\text { - Phenolic compounds were } \\
\text { incorporated in hydrochar from co- } \\
\text { HTC; } \\
\text { - Adding phenolic compounds to } \\
\text { MS during HTC increased yield, } \\
\text { VM, FC, and HHV of hydrochar } \\
\text { but decreased ash content. }\end{array}$ & $\begin{array}{l}\text { (Wang et } \\
\text { al., 2020) }\end{array}$ \\
\hline MS + cornstalk & $50-80$ & $\begin{array}{l}190-280{ }^{\circ} \mathrm{C}, \\
1-8 \mathrm{~h}\end{array}$ & $\begin{array}{l}1-\mathrm{L} \\
\text { batch }\end{array}$ & $\begin{array}{l}\text { - Co-HTC showed synergistic effect } \\
\text { on yield and energy recovery of } \\
\text { hydrochar; } \\
\text { - Aromatic clusters and melanoidins } \\
\text { could polymerize and form N- } \\
\text { containing polyaromatic char. }\end{array}$ & $\begin{array}{l}\text { (R. Wang } \\
\text { et al., } \\
\text { 2021) }\end{array}$ \\
\hline
\end{tabular}




\begin{tabular}{|c|c|c|c|c|c|}
\hline $\begin{array}{l}\text { Feedstock } \\
\text { mixture }\end{array}$ & $\begin{array}{l}\text { MS in } \\
\text { feedstock } \\
\text { mixture (wt } \%)\end{array}$ & $\begin{array}{l}\text { HTP } \\
\text { conditions }\end{array}$ & Reactor & Remarks & Reference \\
\hline $\begin{array}{l}\text { DS + cow dung } \\
\text { biogas residue }\end{array}$ & $25-75$ & $\begin{array}{l}200-280^{\circ} \mathrm{C}, \\
1-5 \mathrm{~h}\end{array}$ & $\begin{array}{l}50-\mathrm{mL} \\
\text { batch }\end{array}$ & $\begin{array}{l}\text { - Co-HTC promoted the hydrolysis } \\
\text { of protein; } \\
\text { - Dehydration was the main reaction } \\
\text { during the co-HTC; } \\
\text { - High temperature could enhance } \\
\text { the degree of coalification of co- } \\
\text { HTC. }\end{array}$ & $\begin{array}{l}\text { (Xu et al., } \\
2019)\end{array}$ \\
\hline $\begin{array}{l}\text { MS + sawdust, } \\
\text { corncob, } \\
\text { cornstalk, or } \\
\text { rape straw }\end{array}$ & 50 & $\begin{array}{l}220-260{ }^{\circ} \mathrm{C}, 1 \\
\mathrm{~h}\end{array}$ & $\begin{array}{l}500- \\
\mathrm{mL} \\
\text { batch }\end{array}$ & $\begin{array}{l}\text { Hydrochar derived from MS with } \\
\text { sawdust showed the greatest } \\
\text { reduction in O/C ratio; } \\
\text { Energy recovery rate of hydrochar } \\
\text { from co-HTC of MS with each } \\
\text { waste biomass was following } \\
\text { corncob> cornstalk> sawdust> } \\
\text { rape straw. }\end{array}$ & $\begin{array}{l}\text { (Zhai et } \\
\text { al., 2017) }\end{array}$ \\
\hline $\begin{array}{l}\text { MS + pinewood } \\
\text { sawdust }\end{array}$ & $25-75$ & $220^{\circ} \mathrm{C}$ & $\begin{array}{l}250- \\
\mathrm{mL} \\
\text { batch }\end{array}$ & $\begin{array}{l}\text { - The addition of } 50 \% \text { pinewood } \\
\text { showed the maximum hydrochar } \\
\text { yield, C retention, and organics } \\
\text { retaining; } \\
\text { - Co-HTC improved nutrients such } \\
\text { as N and P in hydrochar; } \\
\text { - Co-HTC promoted the } \\
\text { development of aromaticity and } \\
\text { surface structure. }\end{array}$ & $\begin{array}{l}\text { (Zhang et } \\
\text { al., 2017) }\end{array}$ \\
\hline $\begin{array}{l}\text { MS + water } \\
\text { hyacinth }\end{array}$ & 50 & $220^{\circ} \mathrm{C}, 1 \mathrm{~h}$ & $\begin{array}{l}250- \\
\mathrm{mL} \\
\text { batch }\end{array}$ & $\begin{array}{l}\text { - Co-HTC of MS with } \\
\text { lignocellulosic biomass improved } \\
\text { hydrochar yield and quality } \\
\text { (higher HHV and power } \\
\text { consumption index and lowered } \\
\text { ash content); } \\
\text { - Co-HTC promoted immobilization } \\
\text { of } \mathrm{Cd} \text { and } \mathrm{Pb} \text {. }\end{array}$ & $\begin{array}{l}\text { (Zhang et } \\
\text { al., 2020) }\end{array}$ \\
\hline $\begin{array}{l}\text { MS + food } \\
\text { waste }\end{array}$ & $30-70$ & $180^{\circ} \mathrm{C}, 1 \mathrm{~h}$ & Batch & $\begin{array}{l}\text { - Co-HTC could significantly } \\
\text { increase C content and HHV of } \\
\text { hydrochar. }\end{array}$ & $\begin{array}{l}\text { (Zheng et } \\
\text { al., 2019) }\end{array}$ \\
\hline $\begin{array}{l}\text { DS + swine } \\
\text { manure }\end{array}$ & $20 / 50 / 80$ & $350^{\circ} \mathrm{C}, 15 \mathrm{~min}$ & $\begin{array}{l}10-\mathrm{mL} \\
\text { batch }\end{array}$ & $\begin{array}{l}\text { Co-HTL enhanced feedstock } \\
\text { pumpability, energy recovery (58- } \\
68 \% \text { ) of biocrude, and hydrochar } \\
\text { yield. }\end{array}$ & $\begin{array}{l}\text { (Ali Shah } \\
\text { et al., } \\
\text { 2021) }\end{array}$ \\
\hline $\begin{array}{l}\text { PS }+ \\
\text { lignocellulosic } \\
\text { biomass }\end{array}$ & - & $340^{\circ} \mathrm{C}, 20 \mathrm{~min}$ & $\begin{array}{l}20-\mathrm{mL} \\
\text { batch }\end{array}$ & $\begin{array}{l}\text { Energy recovery to bio-crude } \\
(75 \%) \text { from co-HTL was increased } \\
\text { compared to HTL of individual } \\
\text { feedstock. }\end{array}$ & $\begin{array}{l}\text { (Biller et } \\
\text { al., 2018) }\end{array}$ \\
\hline $\begin{array}{l}\text { MS + rice straw } \\
\text { or wood } \\
\text { sawdust }\end{array}$ & 50 & $\begin{array}{l}220-300{ }^{\circ} \mathrm{C} \\
0-60 \text { min (in } \\
\text { ethanol) }\end{array}$ & $\begin{array}{l}300- \\
\mathrm{mL} \\
\text { batch }\end{array}$ & $\begin{array}{l}\text { - Synergistic effects on biocrude } \\
\text { yield and conversion rate were not } \\
\text { observed during the co-HTL; } \\
\text { - Introducing rice straw or wood } \\
\text { sawdust to HTL of MS can } \\
\text { decrease N and S contents but } \\
\text { cause more phenolic compounds in } \\
\text { biocrude; } \\
\text { - Adding rice straw or wood }\end{array}$ & $\begin{array}{l}\text { (Huang et } \\
\text { al., 2019) }\end{array}$ \\
\hline
\end{tabular}




\begin{tabular}{|c|c|c|c|c|c|}
\hline $\begin{array}{l}\text { Feedstock } \\
\text { mixture }\end{array}$ & $\begin{array}{l}\text { MS in } \\
\text { feedstock } \\
\text { mixture }(\mathrm{wt} \%)\end{array}$ & $\begin{array}{l}\text { HTP } \\
\text { conditions }\end{array}$ & Reactor & Remarks & Reference \\
\hline $\begin{array}{l}\text { MS + rice straw } \\
\text { or wood } \\
\text { sawdust }\end{array}$ & $25-75$ & $\begin{array}{l}300^{\circ} \mathrm{C}, 20 \mathrm{~min} \\
\text { (in ethanol) }\end{array}$ & $\begin{array}{l}500- \\
\mathrm{mL} \\
\text { batch }\end{array}$ & $\begin{array}{l}\text { sawdust to HTL did not affect the } \\
\text { polarity but reduced the } \\
\text { aromaticity of hydrochar. } \\
\text { - Synergistic effects with higher } \\
\text { yield and better fuel properties of } \\
\text { biocrude from co-HTL were } \\
\text { observed; } \\
\text { - No beneficial effects from co-HTL } \\
\text { were observed on hydrochar yield. }\end{array}$ & $\begin{array}{l}\text { (Leng et } \\
\text { al., 2018) }\end{array}$ \\
\hline $\begin{array}{l}\mathrm{PS}+ \\
\text { Monoraphidium } \\
\text { sp. }(\mathrm{KMC} 4)\end{array}$ & $25-75$ & $\begin{array}{l}275-350{ }^{\circ} \mathrm{C} \\
15-60 \mathrm{~min}\end{array}$ & $\begin{array}{l}100- \\
\mathrm{mL} \\
\text { batch }\end{array}$ & $\begin{array}{l}\text { - A maximum biocrude yield of } 39 \\
\text { wt } \% \text { (energy recovery of } 77 \% \text { ) } \\
\text { was obtained from co-HTL of PS } \\
\text { with } 75 \% \text { KMC4 at } 325^{\circ} \mathrm{C} \text { for } 45 \\
\text { min; } \\
\text { - Co-HTL dramatically promoted } \\
\text { the production of low-boiling } \\
\text { fractions in biocrude. }\end{array}$ & $\begin{array}{l}\text { (Mishra } \\
\text { and } \\
\text { Mohanty, } \\
\text { 2020) }\end{array}$ \\
\hline $\begin{array}{l}\mathrm{MS}+ \\
\text { microalgae } \\
(\text { Chlorella })\end{array}$ & $25-75$ & $340^{\circ} \mathrm{C}, 30 \mathrm{~min}$ & $\begin{array}{l}4.9-\mathrm{mL} \\
\text { batch }\end{array}$ & $\begin{array}{l}\text { Synergistic effects of higher } \\
\text { biocrude yield and lower } \\
\text { hydrochar yield from co-HTL } \\
\text { were observed. }\end{array}$ & $\begin{array}{l}\text { (Xu et al., } \\
2019 \text { ) }\end{array}$ \\
\hline $\begin{array}{l}\mathrm{DS}+\text { corn } \\
\text { starch }\end{array}$ & $40-50$ & $\begin{array}{l}340^{\circ} \mathrm{C}, 74- \\
113 \mathrm{~min}(2 \\
\mathrm{g} / \mathrm{min})\end{array}$ & $\begin{array}{l}\text { Tubular } \\
(6.22 \\
\text { mm ID } \\
\times 1.016 \\
\mathrm{~m} \\
\text { length) }\end{array}$ & $\begin{array}{l}\text { - Results showed that WHSV } \\
\text { between } 1.5 \text { and } 3.1 \mathrm{hr}^{-1} \text { had no } \\
\text { noticeable effect on co-HTG; } \\
\text { - Co-HTG of MS with corn starch } \\
\text { had slightly more } \mathrm{H}_{2} \text { and less } \mathrm{CH}_{4} \\
\text { in gas composition than HTG of } \\
\text { corn starch only; } \\
\text { - Co-HTG resulted in less TOC } \\
\text { yield than HTG of corn starch } \\
\text { only. }\end{array}$ & $\begin{array}{l}\text { (Xu and } \\
\text { Antal, } \\
1998)\end{array}$ \\
\hline
\end{tabular}

${ }^{\mathrm{a}} \mathrm{DS}$ = digested sludge; FS = fecal sludge; MS = municipal sludge; PS = primary sludge; WAS = waste activated sludge; daf = dry ash free basis; ID = inner diameter; HHV = higher heating value; HTC = hydrothermal carbonization; HTL = hydrothermal liquefaction; WHSV = weight hourly space velocity; HTG = hydrothermal gasification; $\mathrm{TOC}=$ total organic carbon . 
Table 4 Summary of recent hydrothermal studies conducted with different municipal sludge and catalysts $^{\mathrm{a}}$

\begin{tabular}{|c|c|c|c|c|c|}
\hline $\begin{array}{l}\text { MS } \\
\text { Type }\end{array}$ & Catalyst & $\begin{array}{l}\text { HTP } \\
\text { conditions }\end{array}$ & Reactor & Remarks & Reference \\
\hline DS & $\begin{array}{l}\text { Nitric acid, } \\
\mathrm{pH}=4\end{array}$ & $\begin{array}{l}190 / \\
220^{\circ} \mathrm{C}, 2 \\
\mathrm{~h}\end{array}$ & $\begin{array}{l}220-\mathrm{mL} \\
\text { batch }\end{array}$ & $\begin{array}{l}\text { - Adding nitric acid to HTC of MS } \\
\text { increased N and O content but decreased } \\
\text { ash in hydrochar; } \\
\text { - Addition of nitric acid enhanced } \\
\text { ammonium and nitrate in aqueous phase } \\
\text { from HTC. }\end{array}$ & $\begin{array}{l}\text { (Becker et al., } \\
\text { 2019) }\end{array}$ \\
\hline MS & $\begin{array}{l}\mathrm{FeSO}_{4} \cdot 7 \mathrm{H}_{2} \mathrm{O} \\
+\mathrm{Ca}(\mathrm{ClO})_{2}\end{array}$ & $\begin{array}{l}150- \\
210^{\circ} \mathrm{C}, 1 \\
\mathrm{~h}\end{array}$ & 2-L batch & $\begin{array}{l}\text { - Best sludge dewaterability was obtained at } \\
180^{\circ} \mathrm{C} \text {, with } 0.04 \mathrm{~g} \mathrm{Ca}(\mathrm{ClO})_{2} / \mathrm{g} \text { dry MS } \\
\text { and } \mathrm{FeSO}_{4} \cdot 7 \mathrm{H}_{2} \mathrm{O} / \mathrm{Ca}(\mathrm{ClO})_{2} \text { molar ratio of } \\
1.25 ; \\
\text { - Combined catalyst in } \mathrm{HTC} \text { helped break } \\
\text { floc structure and remove the O-functional } \\
\text { groups of extracellular polymeric } \\
\text { substances. }\end{array}$ & $\begin{array}{l}\text { (Chen et al., } \\
2020)\end{array}$ \\
\hline DS & $\begin{array}{l}1 \mathrm{wt} \% \\
\text { magnesium } \\
\text { citrate and/or } \\
1 \mathrm{wt} \% \mathrm{H}_{2} \mathrm{SO}_{4}\end{array}$ & $\begin{array}{l}260^{\circ} \mathrm{C}, 1 \\
\mathrm{~h}\end{array}$ & - & $\begin{array}{l}\text { More abundant carboxyl groups }(\mathrm{C}-\mathrm{N}, \mathrm{C}- \\
\mathrm{O} \text {, and } \mathrm{O}=\mathrm{C}-\mathrm{O}) \text { in hydrochar were } \\
\text { produced with combined catalyst than } \\
\text { magnesium citrate alone or non-catalyzed } \\
\text { HTC. }\end{array}$ & $\begin{array}{l}\text { (Chu et al., } \\
2020)\end{array}$ \\
\hline MS & $\begin{array}{l}2.5 \mathrm{~g} \text { glucose } \\
+1 \mathrm{~g} \\
\mathrm{FeSO}_{4} \cdot 7 \mathrm{H}_{2} \mathrm{O}\end{array}$ & $\begin{array}{l}160- \\
200^{\circ} \mathrm{C} \\
24-48 \mathrm{~h}\end{array}$ & $\begin{array}{l}50-\mathrm{mL} \\
\text { batch }\end{array}$ & $\begin{array}{l}\text { - Hydrochar nanocomposite was optimized } \\
\text { using } \mathrm{FeSO}_{4} \cdot 7 \mathrm{H}_{2} \mathrm{O} \text { at } 200{ }^{\circ} \mathrm{C} \text { for } 24 \mathrm{~h} \text {; } \\
\text { - Optimized hydrochar showed an } \\
\text { adsorption capacity of } \mathrm{As}(\mathrm{V})(2.1 \mathrm{mg} / \mathrm{g}) \text {. }\end{array}$ & $\begin{array}{l}\text { (El-Deen and } \\
\text { Zhang, 2012) }\end{array}$ \\
\hline DS & $\begin{array}{l}30 \mathrm{~g} \text { citric } \\
\text { acid }\end{array}$ & $\begin{array}{l}205^{\circ} \mathrm{C}, 7 \\
\mathrm{~h}\end{array}$ & $\begin{array}{l}25-\mathrm{L} \\
\text { batch }\end{array}$ & $\begin{array}{l}\text { - Citric acid had a negligible effect on ratios } \\
\text { of } \mathrm{H} / \mathrm{C} \text { and } \mathrm{O} / \mathrm{C} \text { in hydrochar compared to } \\
\text { non-catalyzed. }\end{array}$ & $\begin{array}{l}\text { (Escala et al., } \\
\text { 2013) }\end{array}$ \\
\hline WAS & $10 \mathrm{wt} \% \mathrm{CaO}$ & $\begin{array}{l}200 / \\
260{ }^{\circ} \mathrm{C} \\
0.5 \mathrm{~h}\end{array}$ & 2-L batch & $\begin{array}{l}\text { - } \mathrm{CaO} \text { addition at } 260^{\circ} \mathrm{C} \text { had a lower } \mathrm{VM} \\
\text { content in hydrochar compared to that } \\
\text { from } 200^{\circ} \mathrm{C} \text {; } \\
\text { - } \mathrm{CaO} \text { addition significantly promoted the } \\
\text { transformation of NAIP to AP forms. }\end{array}$ & $\begin{array}{l}\text { (Feng et al., } \\
2018 \text { ) }\end{array}$ \\
\hline MS & $\mathrm{Na} / \mathrm{Ca}$-acetate & $\begin{array}{l}160- \\
250^{\circ} \mathrm{C}\end{array}$ & $\begin{array}{l}500-\mathrm{mL} \\
\text { batch }\end{array}$ & $\begin{array}{l}\text { - Na-acetate slightly enhanced polypeptide- } \\
\mathrm{N} \text { in HTC aqueous by promoting protein } \\
\text { hydrolysis; } \\
\text { - Ca-acetate reduced N content in hydrochar } \\
\text { and increased ammonia in HTC aqueous } \\
\text { by enhancing protein hydrolysis and } \\
\text { deamination. }\end{array}$ & $\begin{array}{l}\text { (Huang et al., } \\
2020 \text { ) }\end{array}$ \\
\hline FS & $\begin{array}{l}\text { Acetic acid, } \\
\text { lithium } \\
\text { chloride, } \\
\text { borax or } \\
\text { zeolite }\end{array}$ & $\begin{array}{l}180- \\
250^{\circ} \mathrm{C} \\
0.5-10 \mathrm{~h}\end{array}$ & 1-L batch & $\begin{array}{l}\text { - At } 220^{\circ} \mathrm{C} \text { for } 5 \mathrm{~h} \text {, the highest hydrochar } \\
\text { yield }(77 \%) \text { was generated with lithium } \\
\text { chloride; } \\
\text { - Maximum hydrochar } \mathrm{HHV} \text { of } 28.5 \mathrm{MJ} / \mathrm{kg} \\
\text { was obtained with sludge/acetic } \\
\text { acid/cassava pulp mixing mass ratio of } \\
1 / 0.4 / 1 \text { at } 220^{\circ} \mathrm{C} \text { for } 0.5 \mathrm{~h} \text {. }\end{array}$ & $\begin{array}{l}\text { (Koottatep et } \\
\text { al., 2016) }\end{array}$ \\
\hline MS & $\begin{array}{l}\mathrm{Ca}(\mathrm{OH})_{2}, \\
\mathrm{pH}=9-11\end{array}$ & $\begin{array}{l}160^{\circ} \mathrm{C}, 1 \\
\mathrm{~h}\end{array}$ & 2-L batch & $\begin{array}{l}\text { - Raising initial } \mathrm{pH} \text { increased ash but } \\
\text { reduced VM, C, H, N, and O contents in } \\
\text { hydrochar; }\end{array}$ & $\begin{array}{l}\text { (Li et al., } \\
\text { 2017) }\end{array}$ \\
\hline
\end{tabular}




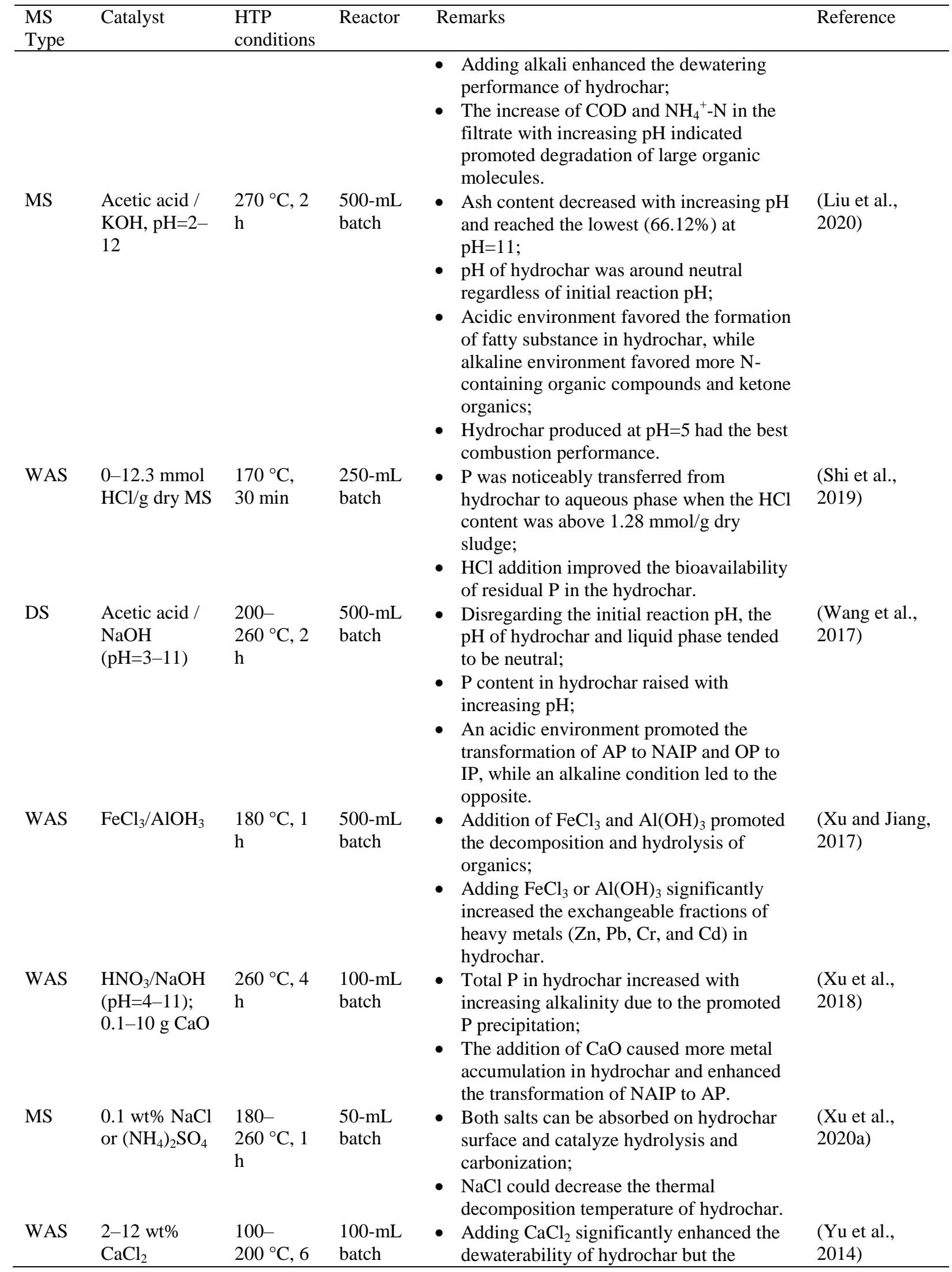




\begin{tabular}{|c|c|c|c|c|c|}
\hline $\begin{array}{l}\text { MS } \\
\text { Type }\end{array}$ & Catalyst & $\begin{array}{l}\text { HTP } \\
\text { conditions }\end{array}$ & Reactor & Remarks & Reference \\
\hline PS & $\begin{array}{l}5 \text { or } 10 \mathrm{mmol} \\
\mathrm{FeCl}_{3}, \mathrm{CaCl}_{2} \\
\text { or } \mathrm{AlCl}_{3}\end{array}$ & $\begin{array}{l}200^{\circ} \mathrm{C}, 1 \\
\mathrm{~h}\end{array}$ & $\begin{array}{l}200-\mathrm{mL} \\
\text { batch }\end{array}$ & $\begin{array}{l}\text { improvement became neglected at over } \\
180{ }^{\circ} \mathrm{C} \text {; } \\
\text { - A continuous enhancement of } \\
\text { dewaterability was observed till the dose } \\
\text { of } \mathrm{CaCl}_{2} \text { reached } 6 \mathrm{wt} \% \\
\text { - All added metal cations promoted P } \\
\text { immobilization during HTC; } \\
\text { - Both } \mathrm{Al}^{3+} \text { and } \mathrm{Fe}^{3+} \text { addition enhanced the } \\
\text { formation of NAIP and decreased AP in } \\
\text { hydrochar; } \\
\text { - Adding } \mathrm{Ca}^{2+} \text { significantly improved AP } \\
\text { content in hydrochar. }\end{array}$ & $\begin{array}{l}\text { (Yu et al., } \\
\text { 2019) }\end{array}$ \\
\hline SS & $\begin{array}{l}\text { Acetic acid or } \\
\mathrm{KOH}(\mathrm{pH}=2- \\
12)\end{array}$ & $\begin{array}{l}270^{\circ} \mathrm{C}, 2 \\
\mathrm{~h}\end{array}$ & $\begin{array}{l}500-\mathrm{mL} \\
\text { batch }\end{array}$ & $\begin{array}{l}\text { - Generally, alkaline environment } \\
\text { immobilized heavy metals }(\mathrm{Pb}, \mathrm{Ni}, \mathrm{Cd} \text {, } \\
\text { and } \mathrm{Zn} \text { ) in hydrochar; } \\
\text { - } \mathrm{Cu} \text { and } \mathrm{Cr} \text { were mobilized with increasing } \\
\text { feedwater } \mathrm{pH} \text { (except for } \mathrm{pH}=12 \text { ). }\end{array}$ & $\begin{array}{l}\text { (Zhai et al., } \\
\text { 2016) }\end{array}$ \\
\hline MS & $2-8 \mathrm{wt} \% \mathrm{CaO}$ & $\begin{array}{l}160- \\
280^{\circ} \mathrm{C}, 2 \\
\mathrm{~h}\end{array}$ & $\begin{array}{l}500-\mathrm{mL} \\
\text { batch }\end{array}$ & $\begin{array}{l}\text { - Increased HTC temperature enriched P } \\
\text { and formed more AP in hydrochar; } \\
\text { - Adding 2-4\% CaO during HTC } \\
\text { significantly improved P-bioavailability in } \\
\text { hydrochar. }\end{array}$ & $\begin{array}{l}\text { (Zheng et al., } \\
\text { 2020a) }\end{array}$ \\
\hline MS & $\begin{array}{l}0.1-1.6 \mathrm{wt} \% \\
\mathrm{CaCl}_{2}\end{array}$ & $\begin{array}{l}280^{\circ} \mathrm{C}, 2 \\
\mathrm{~h}\end{array}$ & $\begin{array}{l}500-\mathrm{mL} \\
\text { batch }\end{array}$ & $\begin{array}{l}\text { Over } 80 \% \mathrm{P} \text { was enriched in hydrochar } \\
\text { regardless of initial } \mathrm{MS} \mathrm{pH}(3-11) \text {; } \\
\text { - Adding } 0.8-1.6 \mathrm{wt} \% \mathrm{CaCl}_{2} \text { favored } \\
\text { complete transformation of NAIP into AP } \\
\left(\text { mainly } \mathrm{Ca}_{3}\left(\mathrm{PO}_{4}\right)_{2} \text { and } \mathrm{CaHPO}_{4}\right) \text {. }\end{array}$ & $\begin{array}{l}\text { (Zheng et al., } \\
\text { 2020b) }\end{array}$ \\
\hline MS & $0.5 \mathrm{~g} \mathrm{NaOH}$ & $320^{\circ} \mathrm{C}$ & 1-L batch & $\begin{array}{l}\text { - Adding } \mathrm{NaOH} \text { greatly reduced leachable } \\
\mathrm{Cu}, \mathrm{Cd} \text {, and } \mathrm{Zn} \text { in hydrochar compared to } \\
\text { non-catalyzed; } \\
\text { - Adding } \mathrm{NaOH} \text { lowered the overall } \\
\text { ecological risk index of heavy metals in } \\
\text { hydrochar. }\end{array}$ & $\begin{array}{l}\text { (Huang et al., } \\
\text { 2011) }\end{array}$ \\
\hline MS & $\begin{array}{l}5 \mathrm{wt} \% \mathrm{NaOH} \\
\mathrm{Na}_{2} \mathrm{CO}_{3} \\
\mathrm{Ca}(\mathrm{OH})_{2} \text { or } \\
\mathrm{FeSO}_{4}\end{array}$ & $\begin{array}{l}220^{\circ} \mathrm{C} \text {, } \\
30 \text { min (in } \\
\text { ethanol- } \\
\text { water) }\end{array}$ & $\begin{array}{l}300-\mathrm{mL} \\
\text { batch }\end{array}$ & $\begin{array}{l}\text { - The addition of } \mathrm{NaOH} \text { and } \mathrm{Na}_{2} \mathrm{CO}_{3} \\
\text { improved the biocrude yield from } \mathrm{HTP} \text {; } \\
\text { - Adding } \mathrm{Na}_{2} \mathrm{CO}_{3} \text { reduced } \mathrm{HHV} \text { and energy } \\
\text { conversion rate of biocrude. }\end{array}$ & $\begin{array}{l}\text { (Lai et al., } \\
\text { 2018) }\end{array}$ \\
\hline SS & $\begin{array}{l}\text { Inorganic } \\
\left(\mathrm{HCl}, \mathrm{HNO}_{3} \text {, }\right. \\
\text { and } \mathrm{H}_{2} \mathrm{SO}_{4} \text { ) } \\
\text { and organic } \\
\text { (formic, } \\
\text { acetic and } \\
\text { oxalic) acids } \\
\text { for prewash }\end{array}$ & $\begin{array}{l}300{ }^{\circ} \mathrm{C}, \\
40 \mathrm{~min}\end{array}$ & 1-L batch & $\begin{array}{l}\text { - Compared to no pretreatment, hydrochar } \\
\text { yields decreased from MS prewashed by } \\
\text { inorganic acids but increased from organic } \\
\text { acid prewashing, which was consistent } \\
\text { with the change of ash content in } \\
\text { feedstock; } \\
\text { - } \mathrm{HCl} \text { pre-treatment obtained the highest } \\
\text { yield ( } 26.75 \%), \mathrm{HHV}(36 \mathrm{MJ} / \mathrm{kg}) \text {, and } \\
\text { energy recovery ( } 45 \%) \text { of biocrude and } \\
\text { promoted the formation of light oil. }\end{array}$ & $\begin{array}{l}\text { (Liu et al., } \\
\text { 2018) }\end{array}$ \\
\hline MS & $\begin{array}{l}5 \text { wt } \% \\
\mathrm{Na}_{2} \mathrm{CO}_{3} \\
\mathrm{Raney}_{\text {-nickel, }} \\
\mathrm{FeSO}_{4} \text {, or } \\
\mathrm{MoS}_{2}\end{array}$ & $\begin{array}{l}200- \\
350{ }^{\circ} \mathrm{C}, \\
10-100 \\
\min \end{array}$ & 1-L batch & $\begin{array}{l}\text { - Catalysis enhanced the HHV and energy } \\
\text { recovery of biocrude compared to without } \\
\text { catalyst; } \\
\text { - Using } \mathrm{FeSO}_{4} \text { as a catalyst achieved the } \\
\text { highest yield of biocrude }(45.58 \%) \text {, } \\
\text { energy recovery }(67.63 \%) \text {, and total }\end{array}$ & $\begin{array}{l}\text { (Malins et al., } \\
\text { 2015) }\end{array}$ \\
\hline
\end{tabular}




\begin{tabular}{|c|c|c|c|c|c|}
\hline $\begin{array}{l}\text { MS } \\
\text { Type }\end{array}$ & Catalyst & $\begin{array}{l}\text { HTP } \\
\text { conditions }\end{array}$ & Reactor & Remarks & Reference \\
\hline & & & & conversion $(68.21 \%)$. & \\
\hline MS & $\begin{array}{l}10 \mathrm{wt} \% \\
\mathrm{NiMo}-\mathrm{Al}_{2} \mathrm{O}_{3}, \\
\text { CoMo- } \mathrm{Al}_{2} \mathrm{O}_{3} \\
\text { or activated } \\
\text { carbon felt }\end{array}$ & $\begin{array}{l}325^{\circ} \mathrm{C} \\
30 \mathrm{~min},\end{array}$ & $\begin{array}{l}16-\mathrm{mL} \\
\text { batch }\end{array}$ & $\begin{array}{l}\text { Compared to non-catalyzed HTL, } \\
\text { catalysis removed O in biocrude; } \\
\text { Biocrude obtained with activated carbon } \\
\text { felt had the highest HHV ( } 38.19 \mathrm{MJ} / \mathrm{kg}) \text {; } \\
\text { Energy recovery rates were reduced by } \\
\text { catalysts due to the decreased biocrude } \\
\text { yields. }\end{array}$ & $\begin{array}{l}\text { (Prestigiacomo } \\
\text { et al., 2019) }\end{array}$ \\
\hline SS & $2 \% \mathrm{~K}_{2} \mathrm{CO}_{3}$ & $\begin{array}{l}350 / \\
400^{\circ} \mathrm{C} \\
15 \mathrm{~min}\end{array}$ & $\begin{array}{l}10-\mathrm{mL} \\
\text { batch }\end{array}$ & $\begin{array}{l}\text { The addition of } \mathrm{K}_{2} \mathrm{CO}_{3} \text { improved biocrude } \\
\text { yield but decreased hydrochar yield under } \\
\text { both subcritical and supercritical } \\
\text { conditions; } \\
\text { - The highest energy recovery }(74.60 \%) \text { of } \\
\text { biocrude was obtained under } 350{ }^{\circ} \mathrm{C} \text { with } \\
\text { catalyst. }\end{array}$ & $\begin{array}{l}\text { (Shah et al., } \\
2020)\end{array}$ \\
\hline $\begin{array}{l}\text { DS, } \\
\text { WAS, } \\
\text { MPS }\end{array}$ & $\begin{array}{l}0-20 \% \\
\mathrm{Na}_{2} \mathrm{CO}_{3}\end{array}$ & $\begin{array}{l}300^{\circ} \mathrm{C}, 0 \\
\min \end{array}$ & $\begin{array}{l}\text { 300-mL } \\
\text { batch }\end{array}$ & $\begin{array}{l}\text { - Adding catalyst had no significant effects } \\
\text { on biocrude quality; } \\
\text { - Without catalyst addition, HTL of MS can } \\
\text { achieve satisfactory results. }\end{array}$ & $\begin{array}{l}\text { (Suzuki et al., } \\
\text { 1988) }\end{array}$ \\
\hline MPS & $5 \% \mathrm{Na}_{2} \mathrm{CO}_{3}$ & $\begin{array}{l}250- \\
300^{\circ} \mathrm{C}, 0 \\
/ 60 \mathrm{~min}\end{array}$ & $\begin{array}{l}300-\mathrm{mL} \\
\text { batch }\end{array}$ & $\begin{array}{l}\text { - Adding catalyst had no significant effects } \\
\text { on biocrude yield; } \\
\text { - Adding } \mathrm{Na}_{2} \mathrm{CO}_{3} \text { significantly increased } \\
\text { BOD and } \mathrm{COD} \text { in aqueous phase at almost } \\
\text { all conditions; } \\
\text { - At severer HTP conditions, the aqueous } \\
\text { phase was more biodegradable. }\end{array}$ & $\begin{array}{l}\text { (Suzuki and } \\
\text { Nakamura, } \\
\text { 1989) }\end{array}$ \\
\hline MPS & $\begin{array}{l}0-10 \mathrm{wt} \% \\
\mathrm{Na}_{2} \mathrm{CO}_{3}\end{array}$ & $\begin{array}{l}350- \\
450{ }^{\circ} \mathrm{C} \\
0-30 \mathrm{~min}\end{array}$ & 2-L batch & $\begin{array}{l}\text { - Catalyst amount had no significant effects } \\
\text { on biocrude yield. }\end{array}$ & $\begin{array}{l}\text { (Wang et al., } \\
\text { 2013) }\end{array}$ \\
\hline SS & $\begin{array}{l}6 \mathrm{~g} \mathrm{CuSO}_{4} \\
\mathrm{ZnSO}_{4} \\
\mathrm{CoSO}_{4} \text {, or } \\
\mathrm{FeSO}_{4}\end{array}$ & $\begin{array}{l}270{ }^{\circ} \mathrm{C} \\
30 \mathrm{~min}\end{array}$ & $\begin{array}{l}600-\mathrm{mL} \\
\text { batch }\end{array}$ & $\begin{array}{l}\text { - Adding } \mathrm{CuSO}_{4} \text { achieved the maximum } \\
\text { biocrude yield }(47.45 \%) \text { and conversion } \\
\text { rate }(97.74 \%) \text {; } \\
\text { - } \mathrm{S} \text { and } \mathrm{N} \text { contents in biocrude obtained } \\
\text { with } \mathrm{CuSO}_{4} \text { were reduced by } 55.0 \% \text { and } \\
14.6 \% \text {, respectively, compared to non- } \\
\text { catalysis. }\end{array}$ & $\begin{array}{l}\text { (Wang et al., } \\
\text { 2018) }\end{array}$ \\
\hline MS & $\begin{array}{l}3.4 \text { g sludge- } \\
\text { based } \\
\text { activated } \\
\text { carbon (SAC) }\end{array}$ & $\begin{array}{l}350 / \\
400^{\circ} \mathrm{C} \\
30 \mathrm{~min}\end{array}$ & $\begin{array}{l}500-\mathrm{mL} \\
\text { batch }\end{array}$ & $\begin{array}{l}\text { SAC obtained from pyrolysis with longer } \\
\text { retention time had a better effect on the } \\
\text { increase of } \mathrm{HHV} \text { and yield of biocrude } \\
\text { from } \mathrm{HTP} \text {; } \\
\text { Adding SAC to } \mathrm{HTP} \text {, the risk of } \mathrm{Cu}, \mathrm{Zn} \text {, } \\
\text { and } \mathrm{Pb} \text { was reduced at } 350{ }^{\circ} \mathrm{C} \text {, whereas } \\
\text { the risk of } \mathrm{Cd}, \mathrm{Cu} \text {, and } \mathrm{Zn} \text { was decreased } \\
\text { at } 400{ }^{\circ} \mathrm{C} \text {. }\end{array}$ & $\begin{array}{l}\text { (Zhai et al., } \\
\text { 2014a) }\end{array}$ \\
\hline WAS & $\begin{array}{l}0-1.8 \mathrm{~g} \\
\text { Raney nickel } \\
\text { / g dry MS }\end{array}$ & $\begin{array}{l}380^{\circ} \mathrm{C} \\
15 \mathrm{~min}\end{array}$ & $\begin{array}{l}50-\mathrm{mL} \\
\text { batch }\end{array}$ & $\begin{array}{l}\text { - Carbon gasification ratios increased with } \\
\text { increasing catalyst addition and achieved } \\
69 \% \text { at } 1.8 \mathrm{~g} \text { catalyst/g dry MS; } \\
\text { - With increased catalyst loading, methane } \\
\text { yields linearly increased while hydrogen } \\
\text { yield reached a maximum at } 1.5 \mathrm{~g} \\
\text { catalyst/g dry MS. }\end{array}$ & $\begin{array}{l}\text { (Afif et al., } \\
2011 \text { ) }\end{array}$ \\
\hline MS & $0.1-0.9 \mathrm{wt} \%$ & $540^{\circ} \mathrm{C}$ & Fluidized & - Among the tested catalysts, $\mathrm{K}_{2} \mathrm{CO}_{3}$ had a & (Chen et al., \\
\hline
\end{tabular}




\begin{tabular}{|c|c|c|c|c|c|}
\hline $\begin{array}{l}\text { MS } \\
\text { Type }\end{array}$ & Catalyst & $\begin{array}{l}\text { HTP } \\
\text { conditions }\end{array}$ & Reactor & Remarks & Reference \\
\hline & $\begin{array}{l}\mathrm{KOH}, \mathrm{K}_{2} \mathrm{CO}_{3} \\
\mathrm{NaOH}, \text { or } \\
\mathrm{Na}_{2} \mathrm{CO}_{3}\end{array}$ & $25 \mathrm{~g} / \mathrm{min}$ & $\begin{array}{l}\text { bed }(915 \\
\text { mm } \\
\text { length } \times \\
30 \mathrm{~mm} \\
\text { ID) }\end{array}$ & $\begin{array}{l}\text { better enhancement on gasification } \\
\text { efficiency; } \\
\text { - Catalytic improvement on hydrogen } \\
\text { production followed the order: } \mathrm{KOH}> \\
\mathrm{K}_{2} \mathrm{CO}_{3}>\mathrm{NaOH}>\mathrm{Na}_{2} \mathrm{CO}_{3} \text {. }\end{array}$ & 2013a) \\
\hline MS & $\begin{array}{l}0-6 \mathrm{wt} \% \\
\text { formic acid }\end{array}$ & $\begin{array}{l}400^{\circ} \mathrm{C}, \\
30 \mathrm{~min}\end{array}$ & Batch & $\begin{array}{l}\text { - Increasing load of formic acid } \\
\text { significantly improved hydrogen yield } \\
\text { from } 0.16 \text { to } 10.07 \mathrm{~mol} / \mathrm{kg} \text { organic matter. }\end{array}$ & $\begin{array}{l}\text { (Fan et al., } \\
\text { 2016) }\end{array}$ \\
\hline MS & $\begin{array}{l}0-5 \mathrm{wt} \% \\
\mathrm{NaOH} / \mathrm{Ni}\end{array}$ & $\begin{array}{l}400^{\circ} \mathrm{C} \\
10 \mathrm{~min}\end{array}$ & $\begin{array}{l}100-\mathrm{mL} \\
\text { batch }\end{array}$ & $\begin{array}{l}\text { The addition of } 3.33 \mathrm{wt} \% \mathrm{Ni} \text { and } 1.67 \\
\text { wt } \% \mathrm{NaOH} \text { reached the maximum yield of } \\
\text { hydrogen ( } 4.8 \mathrm{~mol} / \mathrm{kg} \text { organic matter), } \\
\text { which was almost } 5 \text { times higher than that } \\
\text { from non-catalytic HTG. }\end{array}$ & $\begin{array}{l}\text { (Gong et al., } \\
\text { 2014b) }\end{array}$ \\
\hline MS & $\begin{array}{l}\mathrm{H}_{2} \mathrm{O}_{2} \\
\left(\mathrm{O}_{2} / \mathrm{COD}=\right. \\
0-0.5) / 1 \\
\text { wt\% activated } \\
\text { carbon }\end{array}$ & $\begin{array}{l}360- \\
425^{\circ} \mathrm{C} \\
30-120 \\
\min \end{array}$ & $\begin{array}{l}572-\mathrm{mL} \\
\text { batch }\end{array}$ & $\begin{array}{l}\text { - Adding activated carbon effectively } \\
\text { enhanced the } \mathrm{H}_{2} \text { production at low } \mathrm{H}_{2} \mathrm{O}_{2} \\
\text { concentration; } \\
\text { - More } \mathrm{H}_{2} \mathrm{O}_{2} \text { addition enhanced COD } \\
\text { removal in aqueous phase but resulted in } \\
\text { increased } \mathrm{CO}_{2} \text { yield and decreased } \\
\text { combustible gas products. }\end{array}$ & $\begin{array}{l}\text { (Guo et al., } \\
\text { 2010) }\end{array}$ \\
\hline DS & $\begin{array}{l}\mathrm{CaO}(\mathrm{Ca} / \mathrm{C}= \\
0.05-0.2)\end{array}$ & $\begin{array}{l}380^{\circ} \mathrm{C}, \\
20 \mathrm{~min}\end{array}$ & 1-L batch & $\begin{array}{l}\text { Adding } \mathrm{CaO} \text { to } \mathrm{HTG} \text { increased ash } \\
\text { content and decreased } \mathrm{HHV} \text { of hydrochar; } \\
\text { With } \mathrm{Ca} / \mathrm{C} \text { molar ratio of } 2, \mathrm{H}_{2} \text { yield } \\
\text { increased nearly } 6 \text { times compared to non- } \\
\text { catalyzed HTG. }\end{array}$ & $\begin{array}{l}\text { (He et al., } \\
\text { 2015a) }\end{array}$ \\
\hline MS & $\begin{array}{l}\mathrm{CaO}(\mathrm{Ca} / \mathrm{C}= \\
0.05-0.2)\end{array}$ & $\begin{array}{l}380^{\circ} \mathrm{C}, \\
20 \mathrm{~min}\end{array}$ & 1-L batch & $\begin{array}{l}\text { - The addition of } \mathrm{CaO} \text { led to the lowest } \mathrm{N} / \mathrm{C} \\
(0.029) \text { and aromaticity }(27.8 \%) \text { in } \\
\text { hydrochar }\end{array}$ & $\begin{array}{l}\text { (He et al., } \\
2016 \text { ) }\end{array}$ \\
\hline MS & $\begin{array}{l}\mathrm{H}_{2} \mathrm{O}_{2} \\
\left(\mathrm{O}_{2} / \mathrm{COD}=\right. \\
0-4)\end{array}$ & $\begin{array}{l}400- \\
600^{\circ} \mathrm{C} \\
20 \mathrm{~min}\end{array}$ & - & $\begin{array}{l}\text { - Increasing load of oxidants improved } \\
\text { carbon gasification efficiency from } 17 \% \\
\text { to } 90 \% \text {, but dramatically decreased the } \\
\text { yield of combustible gases }\left(\mathrm{H}_{2}, \mathrm{CO} \text {, and }\right. \\
\left.\mathrm{CH}_{4}\right) \text { from } 3.6 \mathrm{~mol} / \mathrm{kg} \text { to } 0 \text {. }\end{array}$ & $\begin{array}{l}\text { (Qian et al., } \\
\text { 2015) }\end{array}$ \\
\hline WAS & $\begin{array}{l}10-200 \% \mathrm{Ni} \\
\text { on silica- } \\
\text { alumina or } \\
10 \% \mathrm{~K}_{2} \mathrm{CO}_{3}\end{array}$ & $\begin{array}{l}600^{\circ} \mathrm{C} \\
60 \mathrm{~min}\end{array}$ & 3-L batch & $\begin{array}{l}\text { - Ni catalyst could improve gasification; } \\
\text { - The deposition of salts and char could } \\
\text { degrade the catalytic performance. }\end{array}$ & $\begin{array}{l}\text { (Sawai et al., } \\
\text { 2014) }\end{array}$ \\
\hline MS & $\begin{array}{l}0-8 \mathrm{wt} \% \\
\mathrm{Na}_{2} \mathrm{CO}_{3} / \\
\mathrm{K}_{2} \mathrm{CO}_{3}\end{array}$ & $\begin{array}{l}400^{\circ} \mathrm{C}, \\
30 \mathrm{~min}\end{array}$ & $\begin{array}{l}100-\mathrm{mL} \\
\text { batch }\end{array}$ & $\begin{array}{l}\text { With the addition of } 2-8 \text { wt } \% \text { alkaline } \\
\text { catalysts, the migration of } P \text { from } \\
\text { hydrochar to aqueous phase was enhanced } \\
\text { from } 41.0 \text { to } 2214.5 \mathrm{mg} / \mathrm{L} \text {. }\end{array}$ & $\begin{array}{l}\text { (Wang et al., } \\
\text { 2019) }\end{array}$ \\
\hline MS & $\begin{array}{l}0-10 \mathrm{wt} \% \\
\mathrm{Ni} / \mathrm{H}_{2} \mathrm{O}_{2}\end{array}$ & $\begin{array}{l}400^{\circ} \mathrm{C} \\
60 \mathrm{~min}\end{array}$ & $\begin{array}{l}100-\mathrm{mL} \\
\text { batch }\end{array}$ & $\begin{array}{l}\text { - The combined catalysts of } \mathrm{H}_{2} \mathrm{O}_{2} \text { and } \mathrm{Ni} \\
\text { had better enhancement on } \mathrm{H}_{2} \text { production } \\
\text { and inhibiting the formation of PAHs than } \\
\text { individual catalyst; } \\
\text { - The growth of } \mathrm{Ni} / \mathrm{H}_{2} \mathrm{O}_{2} \text { ratio increased } \\
\text { PAHs with } 4-6 \text { rings from } 13 \% \text { to } 44 \% \text { in } \\
\text { total PAHs. }\end{array}$ & $\begin{array}{l}\text { (Wang et al., } \\
\text { 2017) }\end{array}$ \\
\hline MS & $\begin{array}{l}5 \text { wt } \% \mathrm{NaOH} \text {, } \\
\mathrm{Ni} \text { or } \mathrm{H}_{2} \mathrm{O}_{2}\end{array}$ & $\begin{array}{l}400{ }^{\circ} \mathrm{C} \\
30 \mathrm{~min}\end{array}$ & $\begin{array}{l}100-\mathrm{mL} \\
\text { batch }\end{array}$ & $\begin{array}{l}\text { - Adding } \mathrm{NaOH} \text { and } \mathrm{H}_{2} \mathrm{O}_{2} \text { catalysts } \\
\text { inhibited the formation of char and tar; } \\
\text { - Ni catalyst promoted gas production } \\
\text { through steam-reforming reactions. }\end{array}$ & $\begin{array}{l}\text { (Wang et al., } \\
\text { 2019) }\end{array}$ \\
\hline MS & $0-8 \mathrm{wt} \%$ & $450^{\circ} \mathrm{C}$ & $100-\mathrm{mL}$ & - Adding alkali salts, except for $\mathrm{Ca}(\mathrm{OH})_{2}$, & (Xu et al., \\
\hline
\end{tabular}




\begin{tabular}{|c|c|c|c|c|c|}
\hline $\begin{array}{l}\text { MS } \\
\text { Type }\end{array}$ & Catalyst & $\begin{array}{l}\text { HTP } \\
\text { conditions }\end{array}$ & Reactor & Remarks & Reference \\
\hline & $\begin{array}{l}\mathrm{K}_{2} \mathrm{CO}_{3}, \mathrm{KOH} \\
\mathrm{Ca}(\mathrm{OH})_{2} \\
\mathrm{Na}_{2} \mathrm{CO}_{3} \text { or } \\
\mathrm{NaOH}\end{array}$ & $30 \mathrm{~min}$ & batch & $\begin{array}{l}\text { enhanced } \mathrm{H}_{2} \text { yield and suppressed char } \\
\text { formation by alkaline catalyzed } \\
\text { hydrolysis; } \\
\text { Alkali salts had no significant effects on } \\
\text { organic matter or total phenol contents in } \\
\text { aqueous phase. }\end{array}$ & 2013) \\
\hline MS & $\begin{array}{l}\text { Coconut shell } \\
\text { activated } \\
\text { carbon }\end{array}$ & $\begin{array}{l}650^{\circ} \mathrm{C} \\
\text { WHSV } \\
0.5 \mathrm{~h}^{-1}\end{array}$ & $\begin{array}{l}\text { Tubular } \\
(4.75 \mathrm{~mm} \\
\text { ID } \times 0.41 \\
\text { m length })\end{array}$ & $\begin{array}{l}\text { - High gasification efficiency }(98 \%) \text { was } \\
\text { observed with the carbon catalyst, but no } \\
\text { control comparison. }\end{array}$ & $\begin{array}{l}\text { (Xu et al., } \\
1996)\end{array}$ \\
\hline DS & $2.6 \mathrm{~g} \mathrm{~K}_{2} \mathrm{CO}_{3}$ & $\begin{array}{l}400{ }^{\circ} \mathrm{C}, \\
30 \mathrm{~min}\end{array}$ & $\begin{array}{l}500-\mathrm{mL} \\
\text { batch }\end{array}$ & $\begin{array}{l}\text { - The addition of } \mathrm{K}_{2} \mathrm{CO}_{3} \text { achieved } 4 \text { times } \\
\text { higher carbon gasification efficiency } \\
(20.02 \%) \text { compared to non-catalysis; } \\
\text { - Adding } \mathrm{K}_{2} \mathrm{CO}_{3} \text { greatly increased the yield } \\
\text { of } \mathrm{CO}_{2} \text { and } \mathrm{CH}_{4} \text {. }\end{array}$ & $\begin{array}{l}\text { (Zhai et al., } \\
\text { 2013) }\end{array}$ \\
\hline \multicolumn{6}{|c|}{ 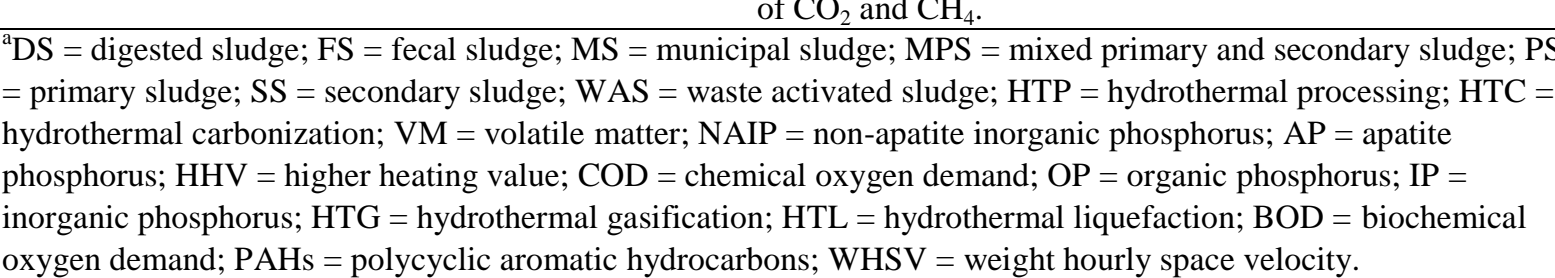 } \\
\hline
\end{tabular}


Table 5 Summary of hydrothermal studies using different sludge with organic solvents ${ }^{\mathrm{a}}$

\begin{tabular}{|c|c|c|c|c|c|}
\hline $\begin{array}{l}\text { MS } \\
\text { type }\end{array}$ & $\begin{array}{l}\text { Solvent/co- } \\
\text { solvent }\end{array}$ & $\begin{array}{l}\text { HTP } \\
\text { conditions }\end{array}$ & Reactor & Remarks & Reference \\
\hline MS & Ethanol & $\begin{array}{l}300 / 350^{\circ} \mathrm{C}, \\
30 \mathrm{~min}\end{array}$ & $\begin{array}{l}500-\mathrm{mL} \\
\text { batch }\end{array}$ & $\begin{array}{l}\text { - Heavy metals were effectively immobilized in } \\
\text { hydrochar from supercritical ethanol; } \\
\text { - Supercritical ethanol process etched the reactor } \\
\text { wall. }\end{array}$ & $\begin{array}{l}\text { (Chen et } \\
\text { al., 2014) }\end{array}$ \\
\hline MS & $\begin{array}{l}\text { Ethanol or } \\
\text { ethanol- } \\
\text { water }\end{array}$ & $\begin{array}{l}300^{\circ} \mathrm{C}, 10 \\
\min \end{array}$ & $\begin{array}{l}500-\mathrm{mL} \\
\text { batch }\end{array}$ & $\begin{array}{l}\text { - Higher yield of biocrude was obtained from HTL in } \\
\text { ethanol-water co-solvent }(15.1 \mathrm{wt} \%) \text { than pure } \\
\text { ethanol }(10.9 \mathrm{wt} \%) \text {; } \\
\text { - HTL with pure ethanol had higher content of esters } \\
\text { and abundant dibutyl phthalate }(54.77 \%) \text { in } \\
\text { biocrude; } \\
\text { - Hexadecanoic acid and ethyl ester }(42.88 \%) \text { are } \\
\text { dominant in biocrude produced from HTL with co- } \\
\text { solvent. }\end{array}$ & $\begin{array}{l}\text { (Huang et } \\
\text { al., 2019) }\end{array}$ \\
\hline SS & $\begin{array}{l}\text { Methanol, } \\
\text { ethanol, } \\
\text { and } \\
\text { acetone }\end{array}$ & $\begin{array}{l}260-380{ }^{\circ} \mathrm{C}, \\
20 \min \end{array}$ & $\begin{array}{l}500-\mathrm{mL} \\
\text { batch }\end{array}$ & $\begin{array}{l}\text { - The highest conversion rates for methanol, ethanol, } \\
\text { and acetone treatments were obtained at } 320{ }^{\circ} \mathrm{C} \text {, } \\
\text { which were } 54.6 \%, 53.7 \% \text {, and } 51.4 \% \text {, } \\
\text { respectively; } \\
\text { - The biocrude yields for ethanol and acetone } \\
\text { treatments increased with increasing temperature } \\
\text { and achieved } 43.82 \% \text { and } 45.65 \% \text {, respectively, at } \\
380{ }^{\circ} \mathrm{C} \text {; } \\
\text { - The biocrude yield for methanol treatment reached } \\
\text { the maximum of } 32.78 \% \text { at } 280{ }^{\circ} \mathrm{C} \text { but reduced } \\
\text { with further increased temperature; } \\
\text { - Higher HHV values of biocrude were obtained in } \\
\text { methanol }(37.69 \mathrm{MJ} / \mathrm{kg}) \text { and ethanol }(38.42 \mathrm{MJ} / \mathrm{kg}) \\
\text { treatments than that from acetone }(26.74 \mathrm{MJ} / \mathrm{kg}) \\
\text { treatment at } 360{ }^{\circ} \mathrm{C} \text {. }\end{array}$ & $\begin{array}{l}\text { (Huang et } \\
\text { al., 2014) }\end{array}$ \\
\hline MS & Ethanol & $\begin{array}{l}350^{\circ} \mathrm{C}, 20 \\
\min \end{array}$ & $\begin{array}{l}500-\mathrm{mL} \\
\text { batch }\end{array}$ & $\begin{array}{l}\text { - In supercritical ethanol, the yield and HHV of } \\
\text { biocrude from MS reached up to } 39.5 \% \text { with an } \\
\mathrm{HHV} \text { of } 36.14 \mathrm{MJ} / \mathrm{kg} \text {, which were higher than } \\
\text { those from rice straw and Spirulina sp. }\end{array}$ & $\begin{array}{l}\text { (Huang et } \\
\text { al., 2013) }\end{array}$ \\
\hline MS & $\begin{array}{l}\text { Ethanol- } \\
\text { water }(0- \\
100 \% \mathrm{v} / \mathrm{v})\end{array}$ & $\begin{array}{l}220^{\circ} \mathrm{C}, 30 \\
\min \end{array}$ & $\begin{array}{l}300-\mathrm{mL} \\
\text { batch }\end{array}$ & $\begin{array}{l}\text { - Synergistic effects were present in ethanol-water } \\
\text { co-solvents; } \\
\text { - Maximum biocrude yield }(36 \%) \text { was reached at an } \\
\text { ethanol-water ratio of } 75 \%(\mathrm{v} / \mathrm{v}) \text {; } \\
\text { - Higher energy recovery of biocrude }(75.5 \%) \text { was } \\
\text { achieved at an ethanol-water ratio of } 50 \%(\mathrm{v} / \mathrm{v}) \\
\text { than pure ethanol }(62.4 \%) \text { or water }(56.4 \%) \text {; } \\
\text { - Pure ethanol led to the lowest yield of biocrude } \\
(26 \%) \text { but the highest yield of hydrochar }(66 \%) \text {. }\end{array}$ & $\begin{array}{l}\text { (Lai et } \\
\text { al., 2018) }\end{array}$ \\
\hline MS & Ethanol & $\begin{array}{l}300^{\circ} \mathrm{C}, 20 \\
\min \end{array}$ & $\begin{array}{l}500-\mathrm{mL} \\
\text { batch }\end{array}$ & $\begin{array}{l}\text { - Synergistic effects of co-processing of MS with } \\
\text { other biomass were present in supercritical ethanol. }\end{array}$ & $\begin{array}{l}\text { (Leng et } \\
\text { al., 2018) }\end{array}$ \\
\hline WAS & $\begin{array}{l}\text { Methanol, } \\
\text { ethanol, or } \\
\text { acetone }\end{array}$ & $\begin{array}{l}280-380{ }^{\circ} \mathrm{C}, \\
20 \min \end{array}$ & $\begin{array}{l}500-\mathrm{mL} \\
\text { batch }\end{array}$ & $\begin{array}{l}\text { - O content and } \mathrm{O} / \mathrm{C} \text { ratio in biocrude from acetone } \\
\text { treatment were relatively higher than those from } \\
\text { methanol and ethanol treatments; } \\
\text { - Ketones }(6.8-9.9 \%) \text { and esters }(20.5-30.0 \%) \text { were } \\
\text { the main compounds in biocrude from acetone } \\
\text { treatment; } \\
\text { - Biocrude from methanol and ethanol treatments }\end{array}$ & $\begin{array}{l}\text { (Leng et } \\
\text { al., } \\
2015 a)\end{array}$ \\
\hline
\end{tabular}




\begin{tabular}{|c|c|c|c|c|c|}
\hline $\begin{array}{l}\text { MS } \\
\text { type }\end{array}$ & $\begin{array}{l}\text { Solvent/co- } \\
\text { solvent }\end{array}$ & $\begin{array}{l}\text { HTP } \\
\text { conditions } \\
\end{array}$ & Reactor & Remarks & Reference \\
\hline & & & & $\begin{array}{l}\text { was mainly composed of esters, with } 70.4-74.9 \% \\
\text { of methyl esters and } 60.1-73.5 \% \text { of ethyl esters, } \\
\text { respectively. }\end{array}$ & \\
\hline MS & $\begin{array}{l}\text { Ethanol or } \\
\text { acetone }\end{array}$ & $\begin{array}{l}280-360{ }^{\circ} \mathrm{C}, \\
20 \min \end{array}$ & $\begin{array}{l}\text { 500-mL } \\
\text { batch }\end{array}$ & $\begin{array}{l}\text { Higher biocrude yield and hydrochar yield were } \\
\text { obtained in acetone than those in ethanol under } \\
\text { each treatment temperature. }\end{array}$ & $\begin{array}{l}\text { (Leng et } \\
\text { al., 2014) }\end{array}$ \\
\hline SS & $\begin{array}{l}\text { Methanol, } \\
\text { ethanol, or } \\
\text { acetone }\end{array}$ & $\begin{array}{l}260-380^{\circ} \mathrm{C}, \\
20 \min \end{array}$ & $\begin{array}{l}\text { 500-mL } \\
\text { batch }\end{array}$ & $\begin{array}{l}\text { Hydrochar yields in acetone }(48.65-53.12 \%) \text { were } \\
\text { relatively higher than those in ethanol }(46.29- \\
50.41 \%) \text { and methanol }(45.38-51.22 \%) \text {; } \\
\text { - Hydrochar produced from different solvents } \\
\text { showed an adsorption performance on cationic dyes } \\
\text { following the order: acetone > ethanol > methanol; } \\
\text { - Lower temperatures favored the adsorption } \\
\text { performance of hydrochar due to abundant surface } \\
\text { functional groups, although the surface areas and } \\
\text { pore volumes were low. }\end{array}$ & $\begin{array}{l}\text { (Leng et } \\
\text { al., } \\
2015 b)\end{array}$ \\
\hline SS & $\begin{array}{l}50 \% \mathrm{v} / \mathrm{v} \\
\text { methanol- } \\
\text { water or n- } \\
\text { hexane- } \\
\text { water }\end{array}$ & $\begin{array}{l}300-360{ }^{\circ} \mathrm{C}, \\
0-60 \mathrm{~min}\end{array}$ & $\begin{array}{l}500-\mathrm{mL} \\
\text { batch }\end{array}$ & $\begin{array}{l}\text { - HHV values of biocrude obtained in co-solvents } \\
\text { (34.1-36.5 MJ/kg) were much higher than that } \\
\text { from pure water }(28.5 \mathrm{MJ} / \mathrm{kg}) \text { due to the significant } \\
\text { reduction of O contents; } \\
\text { - Decreased HHV and increased ash contents of } \\
\text { hydrochar were found from HTP with co-solvents } \\
\text { compared to pure water; } \\
\text { - Ester content in biocrude was enhanced in } \\
\text { methanol-water treatment due to the esterification; } \\
\text { - Aliphatic compounds in biocrude increased in n- } \\
\text { hexane-water treatment due to the high solubility of } \\
\text { n-hexane. }\end{array}$ & $\begin{array}{l}\text { (Li et al., } \\
\text { 2018) }\end{array}$ \\
\hline MS & $\begin{array}{l}\text { Ethanol- } \\
\text { water }(0- \\
100 \% \mathrm{v} / \mathrm{v})\end{array}$ & $\begin{array}{l}260-400{ }^{\circ} \mathrm{C}, \\
20 \min \end{array}$ & $\begin{array}{l}1-\mathrm{L} \\
\text { batch }\end{array}$ & $\begin{array}{l}\text { - Increased ethanol-water ratios enhanced the yield } \\
\text { but reduced O contents of biocrude; } \\
\text { - In pure ethanol, biocrude yield increased while } \\
\text { hydrochar yield first decreased and then raised with } \\
\text { the increase of reaction temperature. }\end{array}$ & $\begin{array}{l}\text { (Li et al., } \\
2010)\end{array}$ \\
\hline MS & $\begin{array}{l}\text { Water, } \\
\text { methanol, } \\
\text { ethanol, or } \\
\text { mixture }\end{array}$ & $\begin{array}{l}300-400{ }^{\circ} \mathrm{C}, \\
10-120 \mathrm{~min}\end{array}$ & $\begin{array}{l}\text { 140-mL } \\
\text { batch }\end{array}$ & $\begin{array}{l}\text { - Alcohol solvents were consumed and reacted with } \\
\text { the reaction intermediates during HTL; } \\
\text { - Three fractions (light, medium, and heavy) of } \\
\text { biocrude were extracted from the HTL products, } \\
\text { and over } 100 \% \text { energy recovery was achieved; } \\
\text { - Light biocrude was mainly comprised of } \\
\text { methylated short-chain esters when using methanol, } \\
\text { while ketones and alcohols were the primary } \\
\text { compounds when using ethanol; } \\
\text { - In terms of gas temperature distribution and } \\
\text { radiative heat flu, mixing MS-derived biocrude } \\
\text { with heavy fuel oil showed comparable } \\
\text { performance to pure heavy fuel oil. }\end{array}$ & $\begin{array}{l}\text { (Prajitno } \\
\text { et al., } \\
2018)\end{array}$ \\
\hline MS & Methanol & $\begin{array}{l}300^{\circ} \mathrm{C}, 30 \\
\min \end{array}$ & $\begin{array}{l}\text { 500-mL } \\
\text { batch }\end{array}$ & $\begin{array}{l}\text { Environmental toxicity/risk of } \mathrm{Cu}, \mathrm{Cr} \text {, and } \mathrm{Zn} \text { in } \\
\mathrm{MS} \text { could be reduced through supercritical } \\
\text { methanol liquefaction. }\end{array}$ & $\begin{array}{l}\text { (Shao et } \\
\text { al., 2015) }\end{array}$ \\
\hline SS & $\begin{array}{l}\text { Ethanol- } \\
\text { water }\end{array}$ & $\begin{array}{l}210-330^{\circ} \mathrm{C}, \\
0-8 \mathrm{~h}\end{array}$ & $\begin{array}{l}600-\mathrm{mL} \\
\text { batch }\end{array}$ & $\begin{array}{l}\text { - The maximum biocrude yield }(47.45 \%) \text { and } \\
\text { liquefaction conversion }(97.74 \%) \text { were achieved at } \\
270{ }^{\circ} \mathrm{C} \text { for } 30 \mathrm{~min} \text {, in ethanol-water }(50 \%, \mathrm{v} / \mathrm{v}) \text { and } \\
\text { with } \mathrm{CuSO}_{4} \text { as the catalyst; }\end{array}$ & $\begin{array}{l}\text { (Wang et } \\
\text { al., 2018) }\end{array}$ \\
\hline
\end{tabular}




\begin{tabular}{|c|c|c|c|c|c|}
\hline $\begin{array}{l}\text { MS } \\
\text { type }\end{array}$ & $\begin{array}{l}\text { Solvent/co- } \\
\text { solvent }\end{array}$ & $\begin{array}{l}\text { HTP } \\
\text { conditions }\end{array}$ & Reactor & Remarks & Reference \\
\hline MS & $\begin{array}{l}\text { N-hexane- } \\
\text { water }\end{array}$ & $\begin{array}{l}150-340^{\circ} \mathrm{C}, \\
90 \mathrm{~min}\end{array}$ & $\begin{array}{l}1-\mathrm{L} \\
\text { batch }\end{array}$ & $\begin{array}{l}\text { - Biocrude yield and liquefaction conversion } \\
\text { increased with increasing volume ratios of } \\
\text { ethanol/water and reached maximum values at } 50 \% \\
\text { v/v. } \\
\text { - Direct n-hexane extraction obtained biocrude yields } \\
\text { of } 22.8-24.2 \% \text { with a low O content (3.5-6.0\%); } \\
\text { - Many solvent-soluble organics (asphaltenes and } \\
\text { preasphaltenes) were still present in hydrochar } \\
\text { from HTP at } 260-340{ }^{\circ} \mathrm{C} \text {. }\end{array}$ & $\begin{array}{l}\text { (Wu et } \\
\text { al., 2017) }\end{array}$ \\
\hline WAS & $\begin{array}{l}\text { Methanol- } \\
\text { water }\end{array}$ & $\begin{array}{l}\text { Pre- } \\
\text { treatment } \\
\text { with 5-20\% } \\
\text { surfactant at } \\
160-200{ }^{\circ} \mathrm{C} \\
+340{ }^{\circ} \mathrm{C} \text { for } \\
40 \mathrm{~min}\end{array}$ & $\begin{array}{l}\text { 500-mL } \\
\text { batch }\end{array}$ & $\begin{array}{l}\text { - The cetyl trimethyl ammonium bromide pre- } \\
\text { treatment significantly enhanced the alcohol } \\
\text { content in biocrude; } \\
\text { - The fatty alcohol polyoxyethylene ether pre- } \\
\text { treatment remarkably increased the portion of } \\
\text { hydrocarbons and their derivatives in biocrude; } \\
\text { - Pre-treatment with mixed surfactants doubled the } \\
\text { yield of biocrude and reduced its acid content by } \\
\text { 95\%. }\end{array}$ & $\begin{array}{l}\text { (Yang et } \\
\text { al., 2019) }\end{array}$ \\
\hline MS & $\begin{array}{l}\text { Acetone/ } \\
\text { ethanol }\end{array}$ & $\begin{array}{l}360^{\circ} \mathrm{C}, 20 \\
\min \end{array}$ & $\begin{array}{l}500-\mathrm{mL} \\
\text { batch }\end{array}$ & $\begin{array}{l}\text { The exchangeable fraction of heavy metals was } \\
\text { consistently higher in biocrude from HTL with } \\
\text { ethanol and especially for } \mathrm{Zn}(72.32 \%) \text {, compared } \\
\text { to biocrude from HTL with acetone }(28.28 \%) \text {. }\end{array}$ & $\begin{array}{l}\text { (Yuan et } \\
\text { al., 2015) }\end{array}$ \\
\hline MS & Acetone & $320^{\circ} \mathrm{C}$ & $\begin{array}{l}1-\mathrm{L} \\
\text { batch }\end{array}$ & $\begin{array}{l}\text { - The mobility and availability of heavy metals are } \\
\text { significantly reduced under supercritical acetone } \\
\text { conditions. }\end{array}$ & $\begin{array}{l}\text { (Yuan et } \\
\text { al., 2011) }\end{array}$ \\
\hline
\end{tabular}

${ }^{\mathrm{a}} \mathrm{MS}$ = municipal sludge; $\mathrm{SS}=$ secondary sludge; WAS = waste activated sludge; HTP = hydrothermal processing; $\mathrm{HTL}=$ hydrothermal liquefaction; $\mathrm{HHV}=$ higher heating value; $\mathrm{v} / \mathrm{v}=$ volume ratio. 
Table 6 Physicochemical properties of municipal sludge-derived hydrochar obtained under various hydrothermal conditions from selected studies ${ }^{\mathrm{a}}$

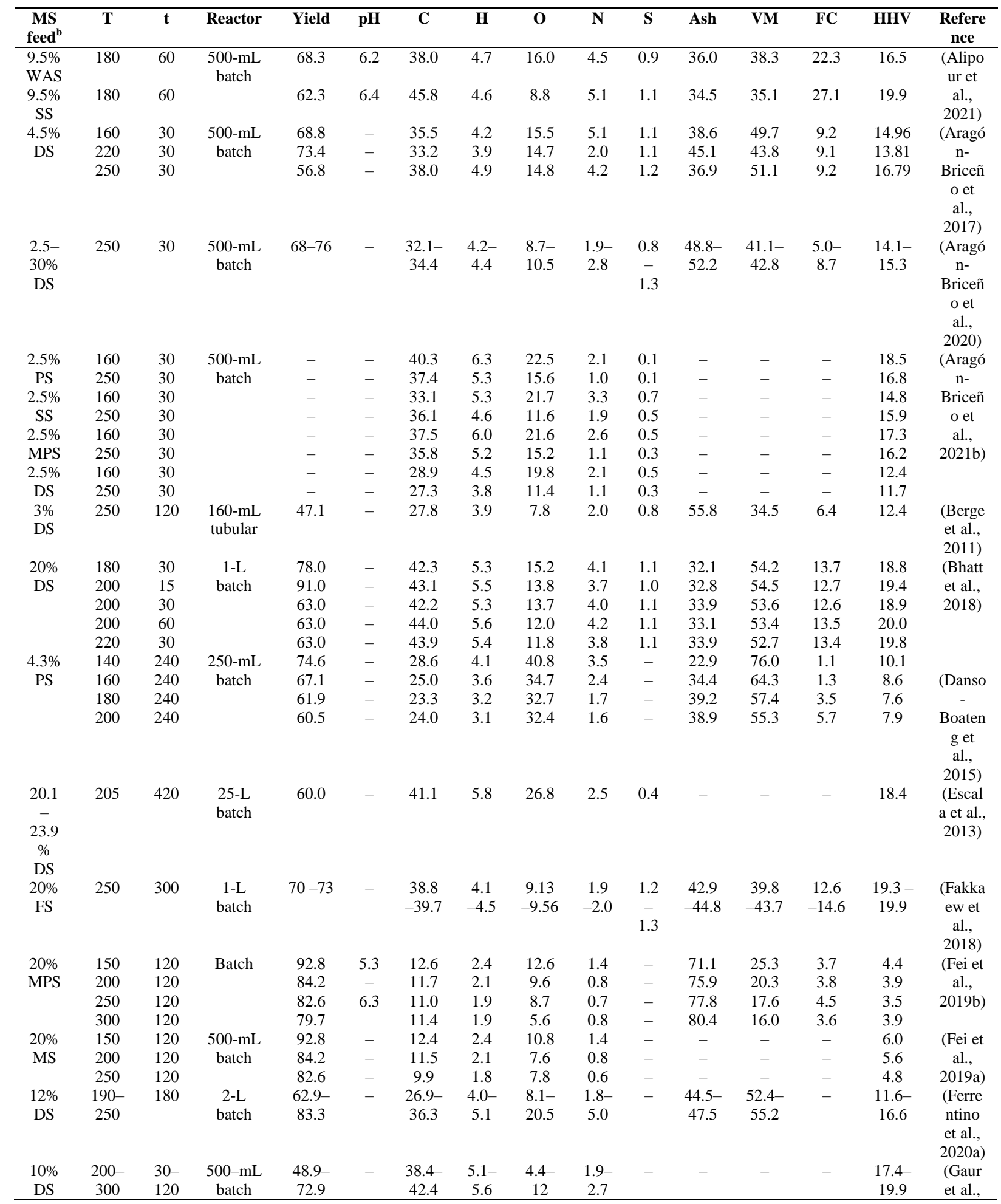




\begin{tabular}{|c|c|c|c|c|c|c|c|c|c|c|c|c|c|c|c|}
\hline $\begin{array}{c}\text { MS } \\
\text { feed }^{\mathrm{b}}\end{array}$ & $\mathbf{T}$ & t & Reactor & Yield & pH & $\mathbf{C}$ & $\mathbf{H}$ & O & $\mathbf{N}$ & $\mathbf{S}$ & Ash & VM & FC & HHV & $\begin{array}{c}\text { Refere } \\
\text { nce }\end{array}$ \\
\hline 14.3 & 200 & 240 & $125-\mathrm{mL}$ & 53.9 & - & 33.3 & 4.4 & 18.5 & 2.1 & 3.8 & 43.9 & 50.6 & 5.5 & 14.3 & $\begin{array}{l}2020) \\
\text { (He et }\end{array}$ \\
\hline$\%$ & 200 & 360 & batch & 58.7 & - & 33.2 & 4.3 & 17.8 & 2.1 & 3.8 & 44.4 & 50.3 & 5.4 & 14.2 & al., \\
\hline \multirow[t]{3}{*}{ DS } & 200 & 480 & & 59.8 & - & 32.6 & 4.2 & 17.6 & 2.2 & 3.8 & 44.7 & 48.8 & 6.6 & 13.9 & 2013) \\
\hline & 200 & 600 & & 60.2 & - & 32.5 & 4.1 & 17.4 & 2.2 & 3.8 & 46.6 & 45.4 & 8.0 & 13.7 & \\
\hline & 200 & 720 & & 60.4 & - & 32.5 & 4.1 & 16.9 & 2.2 & 3.9 & 46.7 & 45.0 & 8.3 & 13.8 & \\
\hline MS & 220 & 720 & $\begin{array}{c}100-\mathrm{mL} \\
\text { batch }\end{array}$ & 67.7 & - & 16.5 & 2.4 & 7.8 & 1.1 & 0.4 & 71.8 & 23.1 & 5.1 & 6.3 & $\begin{array}{l}\text { (He et } \\
\text { al., } \\
2019)\end{array}$ \\
\hline 11.1 & 170 & 60 & $400-\mathrm{mL}$ & 89.2 & - & 46.2 & 6.0 & 23.6 & 8.3 & - & 15.9 & 71.5 & 12.6 & 20.3 & (Khos \\
\hline \multirow[t]{3}{*}{$\% \mathrm{SS}$} & 200 & 60 & batch & 35.3 & - & 49.7 & 5.6 & 16.0 & 6.2 & - & 22.5 & 61.6 & 15.9 & 21.9 & hbouy \\
\hline & 230 & 60 & & 32.7 & - & 52.0 & 5.5 & 12.1 & 4.8 & - & 25.7 & 57.1 & 17.3 & 22.7 & et al., \\
\hline & 260 & 60 & & 31.1 & - & 53.9 & 5.2 & 9.7 & 4.7 & - & 26.6 & 18.0 & 55.4 & 23.3 & 2019) \\
\hline $3.8 \%$ & 180 & 30 & $1-\mathrm{L}$ & 93.9 & - & 28.2 & 4.2 & 33.0 & 5.1 & 0.2 & 29.4 & 62.3 & 8.4 & 10.7 & (Kim \\
\hline \multirow[t]{4}{*}{ DS } & 200 & 30 & batch & 92.6 & - & 28.4 & 4.1 & 32.8 & 5.0 & 0.1 & 29.6 & 61.1 & 9.3 & 10.7 & et al., \\
\hline & 220 & 30 & & 88.7 & - & 27.7 & 3.6 & 31.1 & 4.1 & 0.1 & 33.3 & 57.2 & 9.5 & 10.0 & 2014) \\
\hline & 250 & 30 & & 83.4 & - & 27.6 & 2.9 & 26.7 & 3.8 & 0.1 & 38.9 & 50.4 & 10.7 & 9.5 & \\
\hline & 280 & 30 & & 80.4 & - & 29.1 & 2.5 & 25.5 & 3.0 & 0.0 & 40.0 & 47.3 & 12.7 & 9.5 & \\
\hline \multirow{4}{*}{ PS } & 180 & 30 & $1-\mathrm{L}$ & 93.1 & - & 42.4 & 6.4 & 26.8 & 5.5 & 0.6 & 18.8 & 70.5 & 11.4 & 19.2 & (Lee et \\
\hline & 210 & 30 & batch & 85.8 & - & 45.0 & 5.9 & 24.2 & 5.2 & 0.5 & 19.3 & 68.4 & 12.3 & 19.7 & al., \\
\hline & 240 & 30 & & 67.9 & - & 43.6 & 5.0 & 22.2 & 5.5 & 0.4 & 23.2 & 63.3 & 13.5 & 18.3 & 2019) \\
\hline & 270 & 30 & & 40.8 & - & 39.8 & 4.5 & 17.5 & 4.2 & 0.4 & 33.5 & 52.4 & 14.1 & 16.7 & \\
\hline DS & 300 & 60 & $\begin{array}{c}1-\mathrm{L} \\
\text { batch }\end{array}$ & 63.8 & - & 26.0 & 3.4 & 5.7 & 2.0 & 0.7 & 62.1 & 30.6 & 7.3 & 11.3 & $\begin{array}{c}\text { (Liu et } \\
\text { al., } \\
\text { 2017) }\end{array}$ \\
\hline 16.7 & 160 & 600 & $100-\mathrm{mL}$ & 70.8 & - & 29.0 & 4.7 & 17.5 & 2.6 & 1.1 & 45.1 & 49.5 & 5.5 & 13.0 & (Liu et \\
\hline$\%$ & 180 & 600 & batch & 67.2 & - & 29.2 & 4.6 & 15.1 & 2.3 & 1.1 & 47.7 & 46.8 & 5.5 & 13.2 & al., \\
\hline \multirow[t]{3}{*}{ MS } & 200 & 600 & & 65.1 & - & 30.0 & 4.4 & 13.2 & 2.0 & 1.2 & 49.2 & 44.9 & 5.9 & 13.4 & 2019) \\
\hline & 220 & 600 & & 61.7 & - & 28.8 & 4.3 & 13.4 & 1.9 & 1.2 & 50.5 & 43.2 & 6.3 & 12.7 & \\
\hline & 240 & 600 & & 59.9 & - & 30.7 & 4.2 & 7.7 & 2.2 & 1.1 & 54.2 & 39.5 & 6.4 & 13.9 & \\
\hline $\begin{array}{l}8.4 \% \\
\text { MPS }\end{array}$ & 200 & $\begin{array}{l}60- \\
480\end{array}$ & $\begin{array}{c}\text { 700-mL } \\
\text { batch }\end{array}$ & $\begin{array}{c}47.9- \\
55.2\end{array}$ & - & $\begin{array}{c}32.5- \\
33\end{array}$ & $\begin{array}{c}3.7- \\
4.4\end{array}$ & $\begin{array}{c}14.3- \\
17.4\end{array}$ & $\begin{array}{c}3.1- \\
4.8\end{array}$ & - & $\begin{array}{c}40.5- \\
45.4\end{array}$ & $\begin{array}{c}47.3- \\
46.6\end{array}$ & $\begin{array}{c}2.9- \\
4.0\end{array}$ & $\begin{array}{c}13.2- \\
14.0\end{array}$ & $\begin{array}{c}\text { (Malh } \\
\text { otra }\end{array}$ \\
\hline & & & & & & & & & & & & & & & $\begin{array}{l}\text { and } \\
\text { Garg, } \\
2020)\end{array}$ \\
\hline $\begin{array}{c}16.5 \\
\%\end{array}$ & $\begin{array}{c}180- \\
240\end{array}$ & 60 & $\begin{array}{c}\text { 4-L } \\
\text { batch }\end{array}$ & $\begin{array}{c}51.8- \\
74.2\end{array}$ & - & $\begin{array}{c}30.8- \\
32.6\end{array}$ & $\begin{array}{c}4.1- \\
4.3\end{array}$ & $\begin{array}{c}10.0- \\
16.8\end{array}$ & $\begin{array}{c}4.1- \\
4.2\end{array}$ & $\begin{array}{c}1.0 \\
-\end{array}$ & $\begin{array}{c}42.9- \\
48.1\end{array}$ & $\begin{array}{c}44.0- \\
50.9\end{array}$ & $\begin{array}{c}6.2- \\
7.9\end{array}$ & $\begin{array}{c}13.2- \\
14.2\end{array}$ & $\begin{array}{c}\text { (Marin } \\
-\end{array}$ \\
\hline DS & & & & & & & & & & 1.1 & & & & & $\begin{array}{c}\text { Batista } \\
\text { et al., } \\
2020)\end{array}$ \\
\hline $\begin{array}{l}9.1 \% \\
\text { AGS }\end{array}$ & 250 & 120 & $\begin{array}{l}50-\mathrm{mL} \\
\text { batch }\end{array}$ & 80.2 & - & 38.3 & 4.3 & 29.6 & 1.1 & 0.3 & 26.7 & 53.6 & 19.7 & 19.0 & $\begin{array}{l}\text { (Mitta } \\
\text { palli et } \\
\text { al., } \\
2021 \text { ) }\end{array}$ \\
\hline $\begin{array}{l}2.9 \% \\
\text { MPS }\end{array}$ & $\begin{array}{c}190- \\
250\end{array}$ & $\begin{array}{c}30- \\
60\end{array}$ & $\begin{array}{l}50-\mathrm{mL} \\
\text { batch }\end{array}$ & $\begin{array}{c}49.4- \\
77.2\end{array}$ & $\begin{array}{c}5.3 \\
- \\
6.1\end{array}$ & $\begin{array}{c}41.2- \\
46.1\end{array}$ & $\begin{array}{c}5.0- \\
6.5\end{array}$ & $\begin{array}{c}21.6- \\
28.5\end{array}$ & $\begin{array}{l}1.9- \\
2.2\end{array}$ & $\begin{array}{c}0.3 \\
- \\
0.5\end{array}$ & $\begin{array}{c}24.4- \\
37.2\end{array}$ & $\begin{array}{c}56.7- \\
71.0\end{array}$ & $\begin{array}{c}4.3- \\
6.1\end{array}$ & $\begin{array}{c}17.3- \\
20.5\end{array}$ & $\begin{array}{c}\text { Merza } \\
\text { ri et } \\
\text { al., }\end{array}$ \\
\hline $\begin{array}{c}2.9 \% \\
\text { DS }\end{array}$ & & & & $\begin{array}{c}64.6- \\
82.8\end{array}$ & $\begin{array}{c}6.2 \\
- \\
7.3\end{array}$ & $\begin{array}{c}10.2- \\
19.2\end{array}$ & $\begin{array}{l}1.4- \\
2.6\end{array}$ & $\begin{array}{l}7.2- \\
18.9\end{array}$ & $\begin{array}{c}0.7- \\
1.6\end{array}$ & $\begin{array}{c}0.1 \\
- \\
0.2\end{array}$ & $\begin{array}{c}57.2- \\
77\end{array}$ & $\begin{array}{c}21.7- \\
41.1\end{array}$ & - & $\begin{array}{c}1.8- \\
6.7\end{array}$ & 2020) \\
\hline \multirow[t]{4}{*}{ PS } & 200 & 30 & $1-\mathrm{L}$ & 87.0 & 6.5 & 22.4 & 3.0 & 10.8 & 1.6 & - & 61.1 & - & - & 8.9 & (Paneq \\
\hline & 200 & 180 & batch & 87.0 & 6.5 & 21.4 & 2.7 & 11.0 & 1.4 & - & 62.5 & - & - & 8.2 & ue et \\
\hline & 260 & 30 & & 82.0 & 6.4 & 21.3 & 2.6 & 8.2 & 1.1 & - & 65.6 & - & - & 8.3 & al., \\
\hline & 260 & 180 & & 82.0 & 6.6 & 22.1 & 2.7 & 7.2 & 1.2 & - & 65.7 & - & - & 8.8 & 2017) \\
\hline \multirow[t]{4}{*}{ WAS } & 260 & 30 & & 83.0 & 6.7 & 23.3 & 3.0 & 12.8 & 2.5 & - & 57.0 & - & - & 9.1 & \\
\hline & 200 & 180 & & 79.0 & 6.2 & 23.3 & 2.7 & 8.9 & 2.4 & - & 61.2 & - & - & 9.1 & \\
\hline & 260 & 30 & & 76.0 & 6.3 & 22.5 & 2.6 & 6.9 & 2.0 & - & 64.5 & - & - & 8.8 & \\
\hline & 260 & 180 & & 73.0 & 6.4 & 22.4 & 2.5 & 5.7 & 1.9 & - & 66.1 & - & - & 8.8 & \\
\hline 16.7 & 150 & 60 & $600-\mathrm{mL}$ & 87.0 & - & 29.7 & 3.0 & 12.2 & 1.9 & 0.0 & 53.1 & 37.6 & 9.3 & 11.5 & (Parma \\
\hline$\%$ & 200 & 60 & batch & 76.0 & - & 32.2 & 3.3 & 13.3 & 1.6 & 0.3 & 49.4 & 41.7 & 9.0 & 12.7 & $r$ and \\
\hline DS & 250 & 60 & & 68.0 & - & 27.8 & 2.7 & 9.0 & 1.4 & 0.1 & 59.0 & 31.7 & 9.2 & 10.7 & $\begin{array}{l}\text { Ross, } \\
\text { 2019) }\end{array}$ \\
\hline $10 \%$ & 180 & 30 & $500-\mathrm{mL}$ & 66.2 & - & 21.2 & 3.5 & 4.3 & 1.6 & 0.7 & 68.5 & 22.2 & 9.3 & 9.7 & (Peng \\
\hline \multirow[t]{5}{*}{ MS } & 220 & 30 & batch & 60.6 & - & 19.6 & 3.2 & 3.3 & 1.3 & 0.6 & 72.0 & 18.8 & 9.2 & 8.8 & et al., \\
\hline & 260 & 30 & & 56.2 & - & 24.3 & 3.9 & 7.3 & 1.6 & 0.5 & 62.5 & 27.3 & 10.3 & 11.1 & 2016) \\
\hline & 300 & 30 & & 53.0 & - & 21.9 & 3.4 & 2.1 & 1.1 & 0.5 & 71.0 & 16.8 & 12.2 & 9.9 & \\
\hline & 260 & 60 & & 58.5 & - & 24.5 & 3.7 & 4.5 & 1.6 & 0.6 & 65.2 & 23.1 & 11.7 & 11.11 & \\
\hline & 260 & 90 & & 59.4 & - & 24.1 & 3.7 & 8.0 & 1.5 & 0.6 & 62.0 & 24.8 & 13.2 & 10.7 & \\
\hline
\end{tabular}




\begin{tabular}{|c|c|c|c|c|c|c|c|c|c|c|c|c|c|c|c|}
\hline $\begin{array}{c}\text { MS } \\
\text { feed }^{\text {b }}\end{array}$ & $\mathbf{T}$ & t & Reactor & Yield & pH & $\mathbf{C}$ & $\mathbf{H}$ & $\mathbf{O}$ & $\mathbf{N}$ & $\mathbf{S}$ & Ash & VM & FC & HHV & $\begin{array}{c}\text { Refere } \\
\text { nce }\end{array}$ \\
\hline & 260 & 360 & & 63.3 & - & 19.9 & 3.2 & 5.4 & 1.2 & 0.5 & 69.7 & 22.6 & 7.7 & 8.8 & \\
\hline & 260 & 480 & & 66.2 & - & 24.1 & 3.7 & 10.5 & 1.5 & 0.7 & 59.5 & 34.3 & 6.1 & 10.5 & \\
\hline $10 \%$ & 220 & 60 & $500-\mathrm{mL}$ & 68.0 & 6.6 & - & - & - & - & - & 86.0 & 13.9 & 0.1 & - & (Ren \\
\hline \multirow[t]{8}{*}{ WAS } & 220 & 120 & batch & 67.0 & 6.7 & - & - & - & - & - & 86.4 & 13.6 & 0.1 & - & et al., \\
\hline & 220 & 180 & & 66.0 & 6.7 & - & - & - & - & - & 86.5 & 13.4 & 0.1 & - & 2017) \\
\hline & 250 & 60 & & 67.7 & 6.2 & - & - & - & - & - & 86.2 & 13.2 & 0.6 & - & \\
\hline & 250 & 120 & & 66.3 & 6.6 & - & - & - & - & - & 86.3 & 13.1 & 0.7 & - & \\
\hline & 250 & 180 & & 65.7 & 6.4 & - & - & - & - & - & 86.8 & 13.1 & 0.1 & - & \\
\hline & 280 & 60 & & 66.8 & 6.6 & - & - & - & - & - & 87.4 & 12.5 & 0.1 & - & \\
\hline & 280 & 120 & & 65.3 & 6.7 & - & - & - & - & - & 87.2 & 12.1 & 0.7 & - & \\
\hline & 280 & 180 & & 65.0 & 6.7 & - & - & - & - & - & 87.3 & 12.2 & 0.5 & - & \\
\hline $25 \%$ & 200 & 120 & $1-\mathrm{L}$ & 80.7 & - & 28.2 & 3.4 & 15.6 & 1.9 & 0.5 & 49.7 & 37.9 & 12.2 & 11.2 & (Saete \\
\hline DS & 200 & 240 & batch & 78.1 & - & 29.8 & 3.3 & 15.5 & 2.2 & 0.6 & 48.7 & 37.4 & 13.9 & 11.7 & $\mathrm{a}$ and \\
\hline & 200 & 360 & & 74.2 & - & 29.5 & 3.5 & 15.3 & 2.3 & 0.5 & 48.4 & 37.2 & 14.2 & 11.8 & $\begin{array}{r}\text { Tippay } \\
\text { awong } \\
\text {, 2013) }\end{array}$ \\
\hline $9.9 \%$ & $200-$ & 60 & $50-\mathrm{mL}$ & $63.9-$ & - & $15.5-$ & $3.1-$ & $10.5-$ & $1.4-$ & 0.4 & - & - & - & $6.5-$ & (Shan \\
\hline WAS & 260 & & batch & 78.5 & & 15.9 & 3.5 & 14.0 & 1.9 & $\begin{array}{c}- \\
0.5\end{array}$ & & & & 6.9 & $\begin{array}{l}\text { et al., } \\
2020)\end{array}$ \\
\hline 18.7 & 170 & 30 & $250-\mathrm{mL}$ & 75.2 & - & 40.0 & 5.6 & 17.3 & 5.0 & 1.7 & 30.5 & - & - & 18.2 & (Shi et \\
\hline$\%$ & 200 & 30 & batch & 68.4 & - & 41.6 & 5.5 & 14.9 & 4.5 & 1.5 & 32.0 & - & - & 18.9 & al., \\
\hline \multirow[t]{3}{*}{ WAS } & 230 & 30 & & 71.0 & - & 40.6 & 5.2 & 11.2 & 4.2 & 1.2 & 37.6 & - & - & 18.5 & 2019) \\
\hline & 260 & 30 & & 59.4 & - & 41.8 & 5.2 & 8.6 & 4.1 & 1.3 & 39.0 & - & - & 19.1 & \\
\hline & 320 & 30 & & 51.3 & - & 40.3 & 4.5 & 5.0 & 3.7 & 1.0 & 45.6 & - & - & 17.9 & \\
\hline 33.3 & $100-$ & 0 & $200-\mathrm{mL}$ & $73.7-$ & - & $32.4-$ & $4.1-$ & $18.4-$ & $3.2-$ & 1.6 & $24.2-$ & $49.4-$ & $9.0-$ & $13.1-$ & (Silva \\
\hline $\begin{array}{c}\% \\
\text { MS }\end{array}$ & 200 & 60 & batch & 89.0 & & 37.2 & 5.0 & 31.7 & 4.5 & $\begin{array}{c}- \\
1.8\end{array}$ & 38.8 & 60.5 & 15.3 & 16.2 & $\begin{array}{l}\text { et al., } \\
2020)\end{array}$ \\
\hline $9.8 \%$ & 200 & 60 & $600-\mathrm{mL}$ & 73.6 & - & 13.2 & 1.8 & 5.2 & 1.1 & 0.1 & 78.7 & - & - & 4.5 & (Smith \\
\hline SS & 250 & 60 & batch & 64.5 & - & 11.6 & 1.3 & 4.6 & 0.9 & 0.1 & 81.5 & - & - & 3.4 & et al., \\
\hline $9.8 \%$ & 200 & 60 & & 63.1 & - & 14.0 & 1.4 & 9.3 & 0.5 & 0.1 & 74.8 & - & - & 4.0 & 2016) \\
\hline DS & 250 & 60 & & 52.9 & - & 22.5 & 1.8 & 7.1 & 0.7 & 0.0 & 72.2 & - & - & 7.7 & \\
\hline MS & 200 & 60 & $\begin{array}{c}3-\mathrm{L} \\
\text { batch }\end{array}$ & 65.8 & - & 45.3 & 6.1 & 16.9 & 4.7 & 0.6 & 27.6 & 59.8 & 12.5 & 20.7 & $\begin{array}{l}\text { (Song } \\
\text { et al., } \\
2019)\end{array}$ \\
\hline $\begin{array}{c}5- \\
14.4 \\
\%\end{array}$ & $\begin{array}{c}180- \\
230\end{array}$ & $\begin{array}{l}32- \\
293\end{array}$ & $\begin{array}{c}\text { 300-mL } \\
\text { batch }\end{array}$ & $\begin{array}{c}55.3- \\
68.1\end{array}$ & - & $\begin{array}{c}20.1- \\
24.2\end{array}$ & $\begin{array}{c}3.3- \\
3.9\end{array}$ & $\begin{array}{l}8.8- \\
14.7\end{array}$ & $\begin{array}{c}2.0- \\
3.5\end{array}$ & $\begin{array}{c}0.5 \\
- \\
0.9\end{array}$ & $\begin{array}{c}55.4- \\
62.3\end{array}$ & $\begin{array}{c}33.7- \\
40.7\end{array}$ & $\begin{array}{c}3.2- \\
5.7\end{array}$ & $\begin{array}{l}8.5- \\
10.4\end{array}$ & $\begin{array}{l}\text { (Tasca } \\
\text { et al., } \\
2020)\end{array}$ \\
\hline \multicolumn{16}{|l|}{ WAS } \\
\hline $\begin{array}{c}16.7 \\
\%\end{array}$ & 200 & 120 & Batch & - & - & 19 & 3 & 7.4 & 2.1 & 0.6 & 68 & 29.3 & 2.7 & 18.7 & $\begin{array}{l}\text { (Tong } \\
\text { et al., }\end{array}$ \\
\hline MS & & & & & & & & & & & & & & & 2021) \\
\hline $\begin{array}{l}15 \% \\
\text { WAS }\end{array}$ & 208 & 60 & $\begin{array}{c}\text { 4-L } \\
\text { batch }\end{array}$ & - & - & 43.1 & 5.8 & 26.5 & 4.6 & 0.2 & 19.7 & 65.4 & 14.9 & 18.7 & $\begin{array}{l}\text { (Villa } \\
\text { mil et } \\
\text { al., } \\
2020)\end{array}$ \\
\hline $\begin{array}{c}19.4 \\
\%\end{array}$ & 230 & 150 & Batch & - & - & 27.9 & 3.8 & 4.3 & 2.2 & 0.9 & 61 & - & - & 12.5 & $\begin{array}{l}\text { (Wald } \\
\text { müller }\end{array}$ \\
\hline DS & & & & & & & & & & & & & & & $\begin{array}{l}\text { et al., } \\
2021)\end{array}$ \\
\hline 14.4 & 120 & 60 & $280-\mathrm{mL}$ & 96.4 & - & - & - & - & - & - & 31.4 & 58.9 & 8.8 & - & (Wang \\
\hline$\%$ & 150 & 60 & tubular & 58.4 & - & - & - & - & 4.9 & - & 39.5 & 52.4 & 8.2 & - & et al., \\
\hline \multirow[t]{2}{*}{ WAS } & 180 & 60 & & 50.4 & - & - & - & - & 3.4 & - & 47.3 & 44.6 & 8.1 & - & 2016) \\
\hline & 210 & 60 & & 46.2 & - & - & - & - & 2.8 & - & 51.3 & 39.7 & 9.0 & - & \\
\hline $\begin{array}{c}14.4 \\
\%\end{array}$ & 180 & 60 & $\begin{array}{l}280-\mathrm{mL} \\
\text { tubular }\end{array}$ & 50.4 & - & 30.2 & 4.1 & 13.0 & 3.4 & - & 47.3 & 44.6 & 8.1 & 13.0 & $\begin{array}{l}\text { (Wang } \\
\text { et al., }\end{array}$ \\
\hline WAS & & & & & & & & & & & & & & & 2017) \\
\hline $20 \%$ & 170 & 60 & $1-\mathrm{L}$ & 88.4 & - & 16.4 & 2.0 & 21.6 & 1.3 & 1.0 & 57.6 & 39.1 & 3.3 & 4.8 & (Wang \\
\hline \multirow[t]{6}{*}{ MS } & 200 & 60 & batch & 87.1 & - & 15.8 & 1.8 & 19.6 & 1.2 & 1.1 & 60.5 & 31.0 & 8.5 & 4.5 & et al., \\
\hline & 230 & 60 & & 86.7 & - & 15.5 & 1.7 & 19.4 & 1.0 & 1.0 & 61.5 & 29.5 & 9.0 & 4.2 & 2019) \\
\hline & 260 & 60 & & 81.7 & - & 15.7 & 1.7 & 16.8 & 0.9 & 1.0 & 63.9 & 26.9 & 9.2 & 4.4 & \\
\hline & 290 & 60 & & 79.7 & - & 15.3 & 1.6 & 16.0 & 0.8 & 1.1 & 65.3 & 24.7 & 10.0 & 4.3 & \\
\hline & 320 & 60 & & 77.2 & - & 14.4 & 1.5 & 15.8 & 0.6 & 1.1 & 66.6 & 23.6 & 9.8 & 3.9 & \\
\hline & 350 & 60 & & 73.4 & - & 13.2 & 1.4 & 15.2 & 0.5 & 0.9 & 68.9 & 22.7 & 8.5 & 3.3 & \\
\hline \multirow[t]{5}{*}{ SS } & 180 & 30 & $500-\mathrm{mL}$ & 82.4 & - & 47.0 & 6.1 & 5.8 & 0.9 & 3.0 & 40.3 & 59.3 & 0.4 & 22.4 & (Wang \\
\hline & 200 & 30 & batch & 85.1 & - & 46.4 & 6.5 & 8.0 & 1.0 & 3.0 & 38.0 & 59.7 & 2.3 & 22.5 & et al., \\
\hline & 220 & 30 & & 84.8 & - & 47.7 & 6.2 & 4.4 & 0.9 & 2.9 & 40.9 & 57.3 & 1.8 & 22.9 & 2020) \\
\hline & 240 & 30 & & 84.9 & - & 47.5 & 5.0 & 6.6 & 0.7 & 2.5 & 40.3 & 56.8 & 3.0 & 21.1 & \\
\hline & 260 & 30 & & 80.8 & - & 45.4 & 5.6 & 7.0 & 0.8 & 3.0 & 41.2 & 54.8 & 4.1 & 21.2 & \\
\hline
\end{tabular}




\begin{tabular}{|c|c|c|c|c|c|c|c|c|c|c|c|c|c|c|c|}
\hline $\begin{array}{c}\text { MS } \\
\text { feed }^{\mathrm{b}}\end{array}$ & $\mathbf{T}$ & t & Reactor & Yield & pH & $\mathrm{C}$ & $\mathbf{H}$ & $\mathbf{O}$ & $\mathbf{N}$ & $\mathbf{S}$ & Ash & VM & FC & HHV & $\begin{array}{c}\text { Refere } \\
\text { nce }\end{array}$ \\
\hline & 280 & 30 & & 72.9 & - & 47.3 & 5.8 & 3.1 & 0.9 & 3.0 & 42.9 & 54.8 & 2.3 & 22.4 & \\
\hline & 300 & 30 & & 69.3 & - & 44.4 & 6.1 & 8.1 & 0.9 & 3.5 & 40.5 & 55.1 & 4.4 & 21.3 & \\
\hline $6.8 \%$ & $180-$ & $60-$ & $1-\mathrm{L}$ & 61.8- & - & $15.5-$ & $2.8-$ & 13.6- & $1.3-$ & - & 52.6- & - & - & $5.9-$ & (H. \\
\hline MS & 240 & 600 & batch & 75.0 & & 19.6 & 3.7 & 22.0 & 2.0 & & 66.7 & & & 7.8 & $\begin{array}{l}\text { Wang } \\
\text { et al., } \\
2020)\end{array}$ \\
\hline $20 \%$ & 250 & 300 & $100-\mathrm{mL}$ & 41.3 & - & 16.8 & 2.5 & 9.1 & 1.9 & 0.3 & 69.4 & - & - & 6.4 & (C. \\
\hline MS & 450 & 30 & batch & 15.4 & - & 9.6 & 1.8 & 3.2 & 1.2 & 0.0 & 84.1 & - & - & 3.4 & $\begin{array}{l}\text { Wang } \\
\text { et al., } \\
2021 \text { ) }\end{array}$ \\
\hline MS & 200 & 240 & $\begin{array}{c}1-\mathrm{L} \\
\text { batch }\end{array}$ & 64.0 & - & 26.2 & 3.1 & 11.1 & 2.3 & 1.4 & 55.8 & 34.0 & 9.0 & 10.6 & $\begin{array}{l}\text { (Wilk } \\
\text { et al., } \\
2019 \text { ) }\end{array}$ \\
\hline $\begin{array}{c}3.4 \% \\
\text { PS }\end{array}$ & 200 & 60 & $\begin{array}{c}200-\mathrm{mL} \\
\text { batch }\end{array}$ & 73.1 & - & 45.1 & 6.7 & - & 1.3 & - & - & - & - & - & $\begin{array}{c}\text { (Yu et } \\
\text { al., } \\
\text { 2019) }\end{array}$ \\
\hline $10 \%$ & 220 & 60 & $500-\mathrm{mL}$ & 57.7 & - & 22.3 & 3.3 & 11.4 & 2.2 & 0.5 & 60.3 & 30.3 & 9.4 & 9.3 & (Zhai \\
\hline \multirow[t]{2}{*}{ MS } & 240 & 60 & batch & 53.0 & - & 22.7 & 2.9 & 6.6 & 1.7 & 0.5 & 65.6 & 24.7 & 9.7 & 9.3 & et al., \\
\hline & 260 & 60 & & 48.2 & - & 23.2 & 2.3 & 2.3 & 1.2 & 0.4 & 70.6 & 19.4 & 10.0 & 9.1 & 2017) \\
\hline $\begin{array}{c}11.8 \\
\%\end{array}$ & 220 & - & $\begin{array}{c}250-\mathrm{mL} \\
\text { batch }\end{array}$ & 39.8 & - & 40.4 & 4.7 & 11.9 & 3.9 & - & 38.6 & 47.3 & 14.1 & 17.5 & $\begin{array}{l}\text { (Zhang } \\
\text { et al., }\end{array}$ \\
\hline MS & & & & & & & & & & & & & & & 2017) \\
\hline $9.1 \%$ & 120 & 30 & $300-\mathrm{mL}$ & 90.3 & - & 18.5 & 3.4 & 13.4 & 2.6 & 0.5 & 61.6 & 34.7 & 3.8 & 7.8 & (Zhuan \\
\hline \multirow[t]{3}{*}{ PS } & 180 & 30 & batch & 75.3 & - & 13.9 & 2.3 & 12.9 & 1.9 & 0.4 & 68.6 & 28.0 & 3.4 & 4.8 & $\mathrm{~g}$ et \\
\hline & 240 & 30 & & 69.7 & - & 9.7 & 1.8 & 10.1 & 1.2 & 0.3 & 77.0 & 19.5 & 3.5 & 2.9 & al., \\
\hline & 300 & 30 & & 67.2 & - & 8.8 & 1.6 & 7.8 & 0.9 & 0.3 & 80.6 & 16.1 & 3.2 & 2.5 & 2020a) \\
\hline $9.1 \%$ & 150 & 30 & $250-\mathrm{mL}$ & 79.5 & - & 17.4 & 2.9 & 11.6 & 2.2 & - & 65.4 & 31.6 & 3.1 & 6.9 & (Zhuan \\
\hline \multirow[t]{3}{*}{ MS } & 180 & 30 & batch & 75.0 & - & 15.7 & 2.3 & 7.5 & 1.7 & - & 72.5 & 24.7 & 2.8 & 5.8 & $\mathrm{~g}$ et \\
\hline & 210 & 30 & & 72.0 & - & 14.7 & 2.1 & 3.7 & 1.3 & - & 77.9 & 19.7 & 2.4 & 5.5 & al., \\
\hline & 240 & 30 & & 68.0 & - & 13.6 & 1.9 & 2.1 & 1.1 & - & 81.0 & 16.8 & 2.2 & 5.0 & 2020b) \\
\hline $9.1 \%$ & 120 & 30 & $250-\mathrm{mL}$ & 88.9 & - & 18.5 & 3.4 & 12.8 & 2.6 & 0.5 & 62.2 & 34.1 & 3.5 & 7.8 & (Zhuan \\
\hline \multirow[t]{5}{*}{ MS } & 180 & 30 & batch & 77.1 & - & 13.9 & 2.3 & 9.0 & 1.9 & 0.4 & 72.5 & 24.7 & 2.8 & 5.1 & $\mathrm{~g}$ et \\
\hline & 240 & 30 & & 70.2 & - & 9.7 & 1.8 & 6.0 & 1.2 & 0.3 & 81.0 & 16.8 & 2.2 & 3.2 & al., \\
\hline & 300 & 30 & & 66.4 & - & 8.8 & 1.6 & 3.5 & 0.9 & 0.3 & 84.9 & 14.3 & 0.8 & 2.8 & 2018) \\
\hline & 300 & 60 & & 65.8 & - & 7.6 & 1.5 & 3.0 & 0.8 & 0.3 & 86.8 & 12.2 & 1.0 & 2.3 & \\
\hline & 300 & 120 & & 65.1 & - & 7.5 & 1.4 & 2.6 & 0.8 & 0.2 & 87.5 & 11.6 & 0.9 & 2.2 & \\
\hline $3.6 \%$ & 225 & 15 & $150-\mathrm{mL}$ & 75.0 & - & 33.0 & - & - & 1.1 & - & - & - & - & - & (Aida \\
\hline \multirow[t]{11}{*}{ MS } & 225 & 30 & tube & 67.0 & - & 30.8 & - & - & 0.8 & - & - & - & - & - & et al., \\
\hline & 225 & 45 & bomb & 63.0 & - & 29.5 & - & - & 0.7 & - & - & - & - & - & 2016) \\
\hline & 225 & 60 & reactor & 63.0 & - & 29.1 & - & - & 0.7 & - & - & - & - & - & \\
\hline & 250 & 15 & & 69.0 & - & 30.8 & - & - & 0.9 & - & - & - & - & - & \\
\hline & 250 & 30 & & 56.0 & - & 27.0 & - & - & 0.7 & - & - & - & - & - & \\
\hline & 250 & 45 & & 50.0 & - & 24.8 & - & - & 0.8 & - & - & - & - & - & \\
\hline & 250 & 60 & & 48.0 & - & 24.0 & - & - & 0.8 & - & - & - & - & - & \\
\hline & 275 & 15 & & 52.0 & - & 26.1 & - & - & 0.7 & - & - & - & - & - & \\
\hline & 275 & 30 & & 38.0 & - & 20.1 & - & - & 0.9 & - & - & - & - & - & \\
\hline & 275 & 45 & & 33.0 & - & 19.3 & - & - & 0.9 & - & - & - & - & - & \\
\hline & 275 & 60 & & 34.0 & - & 19.7 & - & - & 1.0 & - & - & - & - & - & \\
\hline $\begin{array}{l}1 \% \\
\text { MS }\end{array}$ & 220 & 30 & $\begin{array}{c}\text { 300-mL } \\
\text { batch }\end{array}$ & 55.0 & 6.0 & 11.6 & 1.7 & 6.4 & 1.7 & 1.0 & 77.6 & 20.7 & 1.7 & 3.8 & $\begin{array}{c}\text { (Lai et } \\
\text { al., } \\
\text { 2018) }\end{array}$ \\
\hline $\begin{array}{l}10 \% \\
\mathrm{MS}\end{array}$ & $\begin{array}{c}240- \\
360\end{array}$ & 30 & $\begin{array}{c}250-\mathrm{mL} \\
\text { batch }\end{array}$ & - & - & $\begin{array}{c}4.7- \\
8.6\end{array}$ & $\begin{array}{c}0.3- \\
1.3\end{array}$ & $\begin{array}{l}6.5- \\
10.2\end{array}$ & $\begin{array}{c}0.6- \\
0.9\end{array}$ & - & $\begin{array}{c}80.3- \\
88.2\end{array}$ & $\begin{array}{l}7.2- \\
16.1\end{array}$ & $\begin{array}{c}2.6- \\
4.5\end{array}$ & - & $\begin{array}{l}\text { (Chan } \\
\text { g et } \\
\text { al., } \\
2021)\end{array}$ \\
\hline $2.5 \%$ & 350 & 15 & $10-\mathrm{mL}$ & 28.1 & - & 13.7 & 0.7 & 13.6 & 1.5 & - & 70.5 & - & - & 2.6 & (Conti \\
\hline SS & 400 & 15 & batch & 27.3 & - & 9.5 & 0.3 & 3.7 & 1.2 & - & 85.3 & - & - & 1.5 & $\begin{array}{l}\text { et al., } \\
2020 \text { ) }\end{array}$ \\
\hline $\begin{array}{c}17 \% \\
\text { SS }\end{array}$ & 340 & 20 & $\begin{array}{c}500-\mathrm{mL} \\
\text { batch }\end{array}$ & $16.7^{\mathrm{c}}$ & - & 26.3 & 2.6 & - & 1.2 & 1.1 & 70.0 & 24.8 & 5.1 & - & $\begin{array}{c}\text { (Li et } \\
\text { al., } \\
2018)\end{array}$ \\
\hline $\begin{array}{l}11.9 \\
\% \text { PS }\end{array}$ & $\begin{array}{c}318- \\
353\end{array}$ & 18 & $\begin{array}{l}\text { 300-mL } \\
\text { plug }\end{array}$ & 5.0 & - & 28.4 & 3.0 & 16.2 & 1.8 & 0.5 & 64.4 & - & - & 10.4 & $\begin{array}{c}\text { (Marro } \\
\text { ne, }\end{array}$ \\
\hline $\begin{array}{l}9.7 \% \\
\text { SS }\end{array}$ & $\begin{array}{c}276- \\
358\end{array}$ & 19 & flow & 12.0 & - & 26.9 & 3.2 & 20.5 & 1.5 & 0.7 & 64.5 & - & - & 9.8 & $\begin{array}{l}\text { 2016; } \\
\text { Marro }\end{array}$ \\
\hline $\begin{array}{c}16 \% \\
\text { DS }\end{array}$ & $\begin{array}{c}332- \\
358\end{array}$ & 30 & $\begin{array}{c}\text { 300-mL } \\
\text { plug } \\
\text { flow }\end{array}$ & 16.0 & - & 20.3 & 2.5 & 15.4 & 1.1 & 1.7 & 73.3 & - & - & 7.1 & $\begin{array}{l}\text { ne et } \\
\text { al., } \\
2018)\end{array}$ \\
\hline
\end{tabular}




\begin{tabular}{|c|c|c|c|c|c|c|c|c|c|c|c|c|c|c|c|}
\hline $\begin{array}{c}\text { MS } \\
\text { feed }^{\text {b }}\end{array}$ & $\mathbf{T}$ & $\mathbf{t}$ & Reactor & Yield & pH & $\mathbf{C}$ & $\mathbf{H}$ & $\mathbf{O}$ & $\mathbf{N}$ & $\mathbf{S}$ & Ash & VM & FC & HHV & $\begin{array}{c}\text { Refere } \\
\text { nce }\end{array}$ \\
\hline $\begin{array}{l}4 \% \\
\text { PS }\end{array}$ & 350 & 20 & $\begin{array}{c}20-\mathrm{L} \\
\text { continuo } \\
\text { us pilot }\end{array}$ & $\sim 10$ & - & - & - & - & 0.9 & 0.2 & 79.6 & - & - & - & $\begin{array}{c}\text { (Ovsya } \\
\text { nnikov } \\
\text { a et al., } \\
2020)\end{array}$ \\
\hline $10 \%$ & 325 & 30 & 16-mL & $27.0^{\mathrm{c}}$ & - & - & - & - & - & - & - & - & - & - & (Presti \\
\hline \multirow[t]{4}{*}{ MS } & 350 & 30 & batch & $16.0^{c}$ & - & 24.2 & 1.5 & 8.4 & 1.2 & 1.0 & 63.7 & 36.0 & - & 8.1 & giaco \\
\hline & 350 & 30 & & $22.0^{c}$ & - & 27.6 & 2.6 & 15.0 & 1.5 & 0.8 & 52.4 & 48.0 & - & 10.1 & mo et \\
\hline & 400 & 0 & & $12.0^{\mathrm{c}}$ & - & 20.3 & 1.2 & 10.3 & 0.9 & 1.1 & 66.2 & 33.0 & - & 6.1 & al., \\
\hline & 400 & 0 & & $18.0^{\mathrm{c}}$ & - & 30.1 & 1.5 & 17.5 & 1.7 & 1.1 & 48.1 & 51.0 & - & 9.6 & 2020) \\
\hline $27 \%$ & 350 & 15 & $10-\mathrm{mL}$ & $12.5^{\mathrm{c}}$ & - & 15.8 & 0.7 & 4.3 & 1.5 & - & 77.6 & - & - & 4.3 & (Shah \\
\hline SS & 400 & 15 & batch & $11.5^{\mathrm{c}}$ & - & 10.3 & 0.0 & 2.0 & 1.0 & - & 86.8 & - & - & 1.6 & $\begin{array}{l}\text { et al., } \\
2020)\end{array}$ \\
\hline $\begin{array}{c}24.2 \\
\% \\
\mathrm{DS}\end{array}$ & 350 & 15 & $\begin{array}{l}10-\mathrm{mL} \\
\text { batch }\end{array}$ & 9 & - & 11.7 & 1.3 & 9.2 & 1.4 & - & 76.3 & - & - & 3.1 & $\begin{array}{l}\text { (Ali } \\
\text { Shah } \\
\text { et al., } \\
2021 \text { ) }\end{array}$ \\
\hline $9.1 \%$ & 375 & 30 & $1-\mathrm{L}$ & 65.7 & 6.7 & - & - & - & - & - & - & 12.2 & - & - & (Li et \\
\hline \multirow[t]{3}{*}{ MS } & 375 & 60 & batch & 64.5 & 6.6 & - & - & - & - & - & - & 11.8 & - & - & al., \\
\hline & 400 & 30 & & 68.2 & 6.9 & - & - & - & - & - & - & 8.5 & - & - & 2012) \\
\hline & 400 & 60 & & 69.4 & 6.9 & - & - & - & - & - & - & 8.6 & - & - & \\
\hline $2.4 \%$ & 150 & 30 & $500-\mathrm{mL}$ & 72.2 & - & 14.2 & 2.4 & 10.1 & 2.0 & 0.5 & 70.9 & 25.3 & 3.8 & 5.2 & (Zhang \\
\hline \multirow[t]{4}{*}{ PS } & 200 & 30 & batch & 63.5 & - & 11.3 & 1.9 & 7.1 & 1.1 & 0.4 & 78.1 & 18.4 & 3.4 & 3.9 & et al., \\
\hline & 250 & 30 & & 60.5 & - & 9.5 & 1.6 & 4.7 & 0.9 & 0.4 & 83.0 & 14.2 & 2.8 & 3.0 & 2018) \\
\hline & 300 & 30 & & 54.2 & - & 7.8 & 1.4 & 4.2 & 0.8 & 0.4 & 85.5 & 12.4 & 2.2 & 2.1 & \\
\hline & 350 & 30 & & 54.5 & - & 6.6 & 1.2 & 3.7 & 0.7 & 0.3 & 87.5 & 10.9 & 1.6 & 1.5 & \\
\hline
\end{tabular}

${ }^{\mathrm{a}} \mathrm{T}=$ reaction temperature $\left({ }^{\circ} \mathrm{C}\right) ; \mathrm{t}=$ residence time $(\mathrm{min}) ; \mathrm{VM}=$ volatile matter; $\mathrm{FC}=$ fixed carbon; HHV = higher heating value $(\mathrm{MJ} / \mathrm{kg}, \mathrm{dry}$ basis); AGS = anaerobic granular sludge; FS = fecal sludge; MPS = mixed primary and secondary sludge; MS = municipal sludge (unspecified in original reference); PS = primary sludge; $\mathrm{SS}=$ secondary sludge; WAS = waste activated sludge; units are all $\%$, dry basis, unless otherwise specified.

${ }^{\mathrm{b}}$ Feedstock with solids content on a dry basis.

${ }^{\mathrm{c}}$ Yield in $\%$, dry ash free basis. 
Table 7 Total concentrations of heavy metal (ppm, dry basis) in municipal sludge-derived hydrochar from different countries versus land application criteria in Canada, the European Union (EU), and the United States (US)

\begin{tabular}{|c|c|c|c|c|c|c|c|c|}
\hline \multirow{2}{*}{$\begin{array}{l}\text { Heavy } \\
\text { metals }\end{array}$} & \multicolumn{4}{|c|}{ Measured values in: } & \multicolumn{4}{|c|}{ Limits for land application in: } \\
\hline & Canada & China & Japan & EU & US & Canada & EU & US \\
\hline As & $<50$ & $10.44-31.53$ & - & $0.9-1.8$ & - & 75 & Not limited & 75 \\
\hline $\mathrm{Cd}$ & $<50$ & $1.5-8.7$ & - & $0.2-2.4$ & - & 20 & $20-40$ & 85 \\
\hline $\mathrm{Cr}$ & $\begin{array}{l}309- \\
1070\end{array}$ & $79-1240$ & - & $23.3-303.5$ & - & 1060 & Not limited & $\begin{array}{r}\text { Not } \\
\text { limited }\end{array}$ \\
\hline $\mathrm{Co}$ & $<50$ & - & - & $0.5-13$ & - & 150 & Not limited & $\begin{array}{r}\text { Not } \\
\text { limited }\end{array}$ \\
\hline $\mathrm{Cu}$ & $\begin{array}{l}2130- \\
2340\end{array}$ & $152-11550$ & $\begin{array}{l}301- \\
879\end{array}$ & 249-1098 & $\begin{array}{l}200- \\
330\end{array}$ & 2200 & $1000-1750$ & 4300 \\
\hline $\mathrm{Hg}$ & - & $41-64$ & - & $0.1-33.2$ & - & 15 & $16-25$ & 57 \\
\hline Mo & $<50$ & - & & $0.8-4$ & - & 20 & Not limited & 75 \\
\hline $\mathrm{Ni}$ & $\begin{array}{l}749- \\
8570\end{array}$ & $41-400$ & & $12.9-530$ & - & 180 & $300-400$ & 420 \\
\hline $\mathrm{Pb}$ & $<50$ & $39-125$ & $\begin{array}{l}8.7- \\
11.3\end{array}$ & $30-108.3$ & - & 500 & $750-1200$ & 840 \\
\hline $\mathrm{Se}$ & - & - & - & - & - & 14 & Not limited & 100 \\
\hline $\mathrm{Zn}$ & $\begin{array}{l}2950- \\
3500\end{array}$ & $400-4848$ & $\begin{array}{l}2113- \\
3801\end{array}$ & $552-3380$ & $\begin{array}{l}450- \\
720\end{array}$ & 1850 & $2500-4000$ & 7500 \\
\hline $\begin{array}{l}\text { Refere } \\
\text { nce }\end{array}$ & $\begin{array}{l}\text { (Marron } \\
\text { e et al., } \\
2018 \text { ) }\end{array}$ & $\begin{array}{l}\text { (Fei et al., 2019b; } \\
\text { Leng et al., } \\
\text { 2015b; Li et al., } \\
\text { 2012; Ma et al., } \\
\text { 2019a; Ren et al., } \\
\text { 2017; Shi et al., } \\
\text { 2019; Wang et al., } \\
\text { 2016; Yue et al., } \\
\text { 2017; Zhang et } \\
\text { al., 2018) }\end{array}$ & $\begin{array}{l}\text { (Yu et } \\
\text { al., } \\
2018)\end{array}$ & $\begin{array}{l}\text { (Conti et al., } \\
\text { 2020; Escala } \\
\text { et al., 2013; } \\
\text { Ferrentino et } \\
\text { al., 2020a; } \\
\text { Merzari et } \\
\text { al., 2020; } \\
\text { Shah et al., } \\
\text { 2020; Tasca } \\
\text { et al., 2020) }\end{array}$ & $\begin{array}{l}\text { (Hua } \\
\text { ng et } \\
\text { al., } \\
2018 \\
\text { ) }\end{array}$ & $\begin{array}{r}\text { B.C. } \\
\text { Reg. } \\
\text { 18/2002 } \\
\text { (Class B } \\
\text { biosolids } \\
\text { ) }\end{array}$ & $\begin{array}{r}\text { Directive } \\
86 / 278 / \mathrm{EEC}\end{array}$ & $\begin{array}{r}40 \text { CFR } \\
\text { Part } 503 \\
\text { (Ceiling } \\
\text { limits) }\end{array}$ \\
\hline
\end{tabular}


Table 8 Band assignments of FTIR spectra for hydrochar reported in hydrothermal studies (Chen et al., 2013b; Gai et al., 2016a; He et al., 2016; Kim et al., 2017; Leng et al., 2015b; Parshetti et al., 2013; Peng et al., 2016; Zhang et al., 2014; Zhao et al., 2013).

\begin{tabular}{|c|c|c|c|}
\hline Group & Wavenumber $\left(\mathrm{cm}^{-1}\right)$ & Vibration & Functional group or component \\
\hline \multirow[t]{28}{*}{ Organics } & $3600-3200$ & $-\mathrm{OH}$ stretching & Hydroxyl or carboxyl group \\
\hline & 3280 & $-\mathrm{N}-\mathrm{H}$ stretching & Amino group compounds \\
\hline & $2930-2920$ & Asymmetric $-\mathrm{C}-\mathrm{H}$ stretching & Aliphatic compounds \\
\hline & $2860-2850$ & Symmetric $-\mathrm{C}-\mathrm{H}$ stretching & Aliphatic compounds \\
\hline & 2300-2350, 1460-1396 & $-\mathrm{C}-\mathrm{O}$ stretching & Hydroxyl, carboxylates or ether \\
\hline & 2090 & $-\mathrm{C}=\mathrm{N}$ stretching & Isonitrile \\
\hline & & $-\mathrm{C} \equiv \mathrm{N}$ stretching & Nitrile \\
\hline & 1728 & $-\mathrm{C}=\mathrm{O}$ stretching & Ester carbonyl groups \\
\hline & $\begin{array}{l}1700,1632,1620,1550 \\
1531,1460-1400\end{array}$ & $-\mathrm{C}=\mathrm{C}$ stretching & Aromatic substances \\
\hline & $1681,1651,1126$ & $-\mathrm{C}-\mathrm{N}$ stretching & Amide \\
\hline & $1660-1645$ & $-\mathrm{C}=\mathrm{O}$ stretching & Amide I \\
\hline & & -COO stretching & Carboxylates \\
\hline & 1622 & $-\mathrm{C}=\mathrm{N}$ stretching & Amides \\
\hline & 1600 & $-\mathrm{C}=\mathrm{C}$ stretching & Aromatic substances \\
\hline & & $-\mathrm{C}=\mathrm{O}$ stretching & $\begin{array}{l}\text { Aldehydes, ketones, lactones, carboxylic } \\
\text { compounds }\end{array}$ \\
\hline & $1575-1525$ & $-\mathrm{N}-\mathrm{H}$ in-plane bending & Amide II and secondary amines \\
\hline & 1543 & $-\mathrm{C}=\mathrm{O}$ stretching & Carboxylic acids \\
\hline & $1240-1230$ & $-\mathrm{C}-\mathrm{N}$ stretching & Amide III \\
\hline & & $-\mathrm{C}-\mathrm{O}-\mathrm{C}$ stretching & Esters \\
\hline & $1120-1050$ & $-\mathrm{C}-\mathrm{O}$ stretching & Alcohols or phenolics \\
\hline & 1080 & $-\mathrm{C}-\mathrm{O}-\mathrm{C}$ stretching & Aliphatic ethers \\
\hline & $1035-1030$ & $-\mathrm{C}-\mathrm{O}-\mathrm{C}$ stretching & Aliphatic ethers \\
\hline & & $-\mathrm{C}-\mathrm{O}$ stretching & Alcohols or phenolics \\
\hline & 1000 & $-\mathrm{C}-\mathrm{O}$ stretching & Alcohols or phenolics \\
\hline & & $-\mathrm{C}-\mathrm{C}$ stretching & Alkanes \\
\hline & $800-785$ & Out of plane $-\mathrm{N}-\mathrm{H}$ wagging & Amides \\
\hline & & $-\mathrm{C}-\mathrm{H}$ bending & Aromatic substances \\
\hline & 776 & $-\mathrm{C}=\mathrm{C}-$ stretching & Alkenes or aromatic substances \\
\hline \multirow[t]{10}{*}{ Inorganics } & $3600-3700$ & $-\mathrm{OH}$ stretching & Minerals \\
\hline & 1443 & $-\mathrm{C}-\mathrm{O}$ stretching & Carbonate \\
\hline & 1404 & $-\mathrm{N}-\mathrm{O}$ stretching & Nitrite \\
\hline & 1400 & $-\mathrm{N}-\mathrm{O}$ stretching & Nitrate \\
\hline & 1110 & $-\mathrm{S}-\mathrm{O}$ stretching & Sulfate \\
\hline & 1030 & $-\mathrm{Si}-\mathrm{O}$ stretching & Clay materials \\
\hline & & $-\mathrm{Si}-\mathrm{O}-\mathrm{Si}$ stretching & Silica \\
\hline & 875 & $-\mathrm{C}-\mathrm{O}$ out of plane bending & Carbonate \\
\hline & 713 & $-\mathrm{C}-\mathrm{O}$ in-plane bending & Carbonate \\
\hline & 560 & $-\mathrm{M}-\mathrm{X}$ stretching & $\begin{array}{l}\text { Organic and inorganic halogens } \\
\text { compounds }(\mathrm{M}=\text { metal, } \mathrm{X}=\text { halogen })\end{array}$ \\
\hline
\end{tabular}


Table 9 Applications of municipal sludge-derived hydrochar in energy production ${ }^{\mathrm{a}}$

\begin{tabular}{|c|c|c|c|c|}
\hline $\begin{array}{l}\text { Sludge } \\
\text { type }\end{array}$ & $\begin{array}{l}\text { HTP } \\
\text { conditions }\end{array}$ & Application & Remarks & Reference \\
\hline MS & $\begin{array}{l}200^{\circ} \mathrm{C}, 4- \\
12 \mathrm{~h}\end{array}$ & Combustion & $\begin{array}{l}\text { - Two stages of combustion }\left(150-350{ }^{\circ} \mathrm{C} \text { and } 350-\right. \\
\left.590{ }^{\circ} \mathrm{C}\right) \text { were identified for hydrochar (HHV of } 14.4- \\
15.1 \mathrm{MJ} / \mathrm{kg}) \text {; } \\
\text { - The first order was best fitted to combustion reaction; } \\
\text { - Hydrochar can provide a more stable flame and longer } \\
\text { combustion process than MS. }\end{array}$ & $\begin{array}{l}\text { (He et al., } \\
2013)\end{array}$ \\
\hline WAS & $\begin{array}{l}200^{\circ} \mathrm{C}, 30 \\
\min \end{array}$ & Combustion & $\begin{array}{l}\text { With improved devolatilization properties, hydrochar } \\
\text { during separated combustion and air-staging } \\
\text { combustion had a NO emission reduction of } 50.7 \% \text { and } \\
56.4 \% \text {, respectively, compared to MS. }\end{array}$ & $\begin{array}{l}\text { (Zhao et } \\
\text { al., 2013) }\end{array}$ \\
\hline SS & $\begin{array}{l}250{ }^{\circ} \mathrm{C}, 15 \\
\min \end{array}$ & Combustion & $\begin{array}{l}\text { - Co-combustion of hydrochar ( } \mathrm{HHV} \text { of } 15.82 \mathrm{MJ} / \mathrm{kg}) \\
\text { with low-rank coal produced less emission gas }\left(\mathrm{CO}_{2} \text {, }\right. \\
\left.\mathrm{CO} \text {, and } \mathrm{CH}_{4}\right) \text {, compared to combustion of low-rank } \\
\text { coal only. }\end{array}$ & $\begin{array}{l}\text { (Parshetti } \\
\text { et al., } \\
\text { 2013) }\end{array}$ \\
\hline MS & $\begin{array}{l}180-300{ }^{\circ} \mathrm{C} \\
0.5-8 \mathrm{~h}\end{array}$ & Combustion & $\begin{array}{l}\text { - The first-order reaction was the best fitting model for } \\
\text { hydrochar combustion; } \\
\text { - Hydrochar produced at } 260{ }^{\circ} \mathrm{C} \text { for } 1 \mathrm{~h} \text { showed the } \\
\text { optimal fuel properties with an HHV } 12.06 \mathrm{MJ} / \mathrm{kg} \text { and } \\
\text { stable combustion. }\end{array}$ & $\begin{array}{l}\text { (Peng et } \\
\text { al., 2016) }\end{array}$ \\
\hline SS & $\begin{array}{l}200 \text { and } \\
250^{\circ} \mathrm{C}, 1 \mathrm{~h}\end{array}$ & Combustion & $\begin{array}{l}\text { Due to the high alkali index }(0.88-1.67) \text {, MS-derived } \\
\text { hydrochar would probably show slagging and fouling } \\
\text { during combustion; } \\
\text { - } \mathrm{NO}_{\mathrm{X}} \text { formation at } 800-1100{ }^{\circ} \mathrm{C} \text { can be prevented due to } \\
\text { the enhanced thermal efficiency by the high } \\
\text { deformation }\left(1220-1240{ }^{\circ} \mathrm{C}\right) \text { and flow }\left(1440-1470{ }^{\circ} \mathrm{C}\right) \\
\text { temperatures of hydrochar ash. }\end{array}$ & $\begin{array}{l}\text { (Smith et } \\
\text { al., 2016) }\end{array}$ \\
\hline MS & $\begin{array}{l}120-300^{\circ} \mathrm{C} \\
30 \min \end{array}$ & Combustion & $\begin{array}{l}\text { - In terms of combustion performance, } 120-240{ }^{\circ} \mathrm{C} \text { could } \\
\text { be a suitable HTC temperature for upgrading biowastes } \\
\text { to fuel. }\end{array}$ & $\begin{array}{l}\text { (Zhuang } \\
\text { et al., } \\
\text { 2018) }\end{array}$ \\
\hline MS & $\begin{array}{l}180,230 \\
\text { and } 280^{\circ} \mathrm{C} \\
1 \mathrm{~h}\end{array}$ & Combustion & $\begin{array}{l}\text { - Co-HTC of MS with food waste produced hydrochar } \\
\text { with better combustion performance compared to HTC } \\
\text { of MS only under identical conditions: Highest HHV } \\
(22.87 \mathrm{MJ} / \mathrm{kg}) \text {, reduced ignition temperature and } \\
\text { burnout temperature, and enhanced comprehensive } \\
\text { combustion characteristic index. }\end{array}$ & $\begin{array}{l}\text { (Zheng et } \\
\text { al., 2019) }\end{array}$ \\
\hline MS & $200^{\circ} \mathrm{C}, 1 \mathrm{~h}$ & Combustion & $\begin{array}{l}\text { - Hydrochar needed 50\% lower activation energies than } \\
\text { MS. }\end{array}$ & $\begin{array}{l}\text { (Wilk et } \\
\text { al., 2019) }\end{array}$ \\
\hline MS & $\begin{array}{l}160-240{ }^{\circ} \mathrm{C}, \\
10 \mathrm{~h}\end{array}$ & Combustion & $\begin{array}{l}\text { - Compared to MS combustion, hydrochar achieved } \\
\text { lower activation energy and mitigated slagging and } \\
\text { fouling. }\end{array}$ & $\begin{array}{l}\text { (Liu et al., } \\
\text { 2019) }\end{array}$ \\
\hline MS & $220^{\circ} \mathrm{C}, 1 \mathrm{~h}$ & Combustion & $\begin{array}{l}\text { - Average activation energy for hydrochar was reduced } \\
\text { about } 50 \% \text { to } 221 \mathrm{~kJ} / \mathrm{mol} \text { compared to MS combustion }\end{array}$ & $\begin{array}{l}\text { (Ma et al., } \\
\text { 2019b) }\end{array}$ \\
\hline MS & $\begin{array}{l}170-350^{\circ} \mathrm{C}, \\
1 \mathrm{~h}\end{array}$ & Combustion & $\begin{array}{l}\text { - Emissions of } \mathrm{SO}_{2} \text { and } \mathrm{NO}_{\mathrm{X}} \text { from hydrochar combustion } \\
\text { reduced with the increase of corresponding HTP } \\
\text { reaction temperature; }\end{array}$ & $\begin{array}{l}\text { (Wang et } \\
\text { al., 2019) }\end{array}$ \\
\hline PS & $\begin{array}{l}180-270{ }^{\circ} \mathrm{C}, \\
30 \min \end{array}$ & Combustion & $\begin{array}{l}\text { - Three stages of combustion were identified: } \\
\text { dehydration }\left(<130^{\circ} \mathrm{C}\right) \text {, devolatilization and combustion } \\
\left(130-480^{\circ} \mathrm{C}\right) \text { and char combustion }\left(>480^{\circ} \mathrm{C}\right)\end{array}$ & $\begin{array}{l}\text { (Lee et al., } \\
\text { 2019) }\end{array}$ \\
\hline MS & $220^{\circ} \mathrm{C}, 12 \mathrm{~h}$ & Combustion & $\begin{array}{l}\text { By co-HTC of MS with fruit and agricultural wastes, } \\
\text { hydrochar reached an HHV of } 21.72 \mathrm{MJ} / \mathrm{kg} \text { and showed } \\
\text { balanced activation energies in }\end{array}$ & $\begin{array}{l}\text { (He et al., } \\
2019)\end{array}$ \\
\hline
\end{tabular}




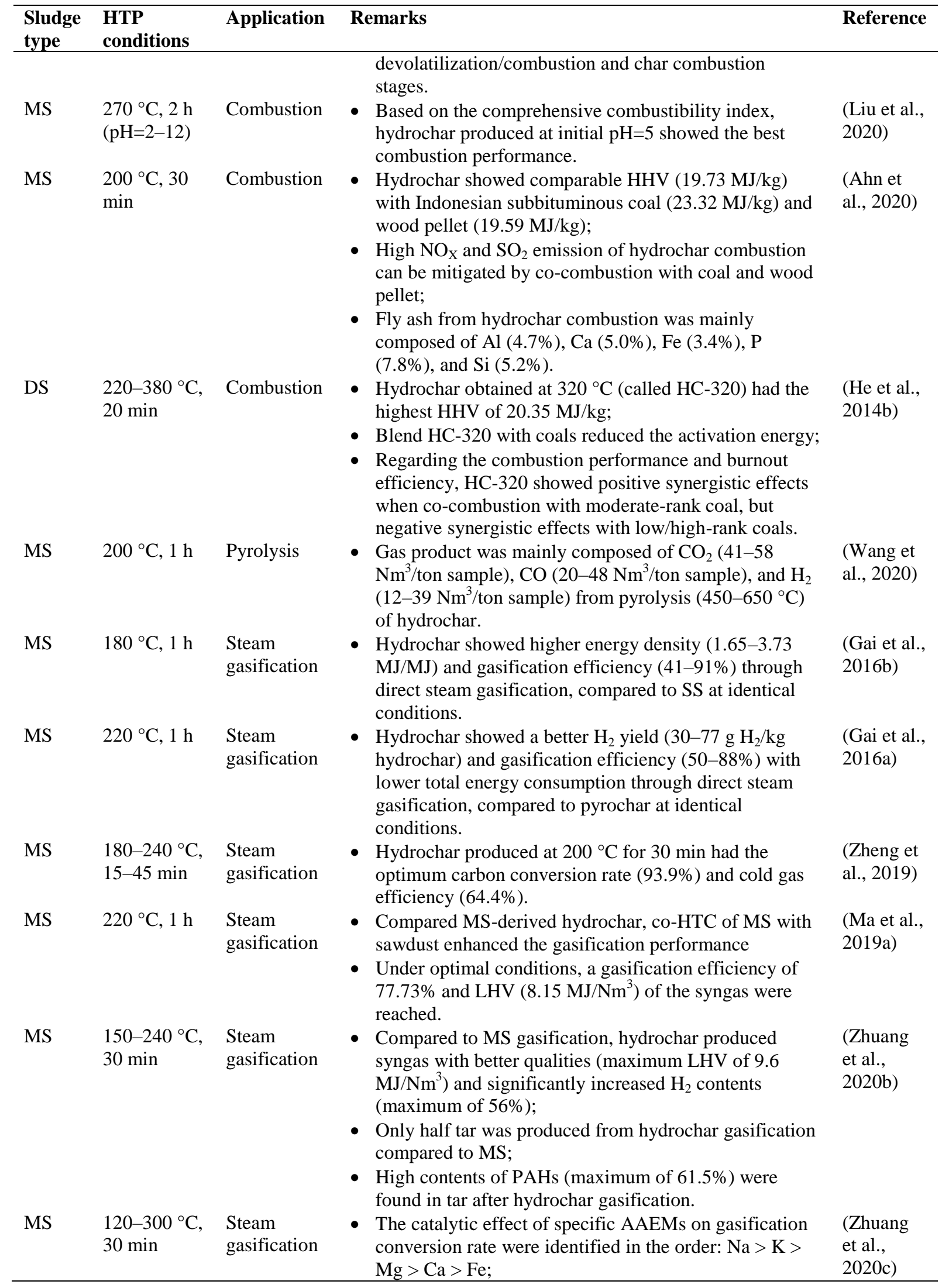




\begin{tabular}{|c|c|c|}
\hline $\begin{array}{l}\text { Sludge } \\
\text { type }\end{array}$ & $\begin{array}{ll}\text { HTP } & \text { Application } \\
\text { conditions } & \end{array}$ & Reference \\
\hline & & $\begin{array}{l}\text { - } \mathrm{Na} \text { and } \mathrm{K} \text { mainly contributed to } \mathrm{CO}_{2} \text { generation during } \\
\text { the gasification of hydrochar. }\end{array}$ \\
\hline
\end{tabular}

Table 10 Adsorption models used for examining the performance of hydrochar-based adsorbents (Alatalo et al., 2013; Aragón-Briceño et al., 2021a; El-Deen and Zhang, 2012; Khoshbouy et al., 2019; Leng et al., 2015b)

\begin{tabular}{|c|c|c|}
\hline Adsorption model & Equation & Parameters \\
\hline Langmuir isotherm & $q=q_{m} \frac{K_{L} C}{1+K_{L} C}$ & $\begin{array}{l}q: \text { Equilibrium adsorption capacity, } \mathrm{mg} / \mathrm{g} \\
q_{m}: \text { Maximum adsorption capacity, } \mathrm{mg} / \mathrm{g} \\
C: \text { Equilibrium adsorbate concentration, } \mathrm{mg} / \mathrm{L} \\
K_{L}: \text { Langmuir affinity constant of binding sites, } \mathrm{L} / \mathrm{mg}\end{array}$ \\
\hline Freundlich isotherm & $q=K_{F} C^{\left(1 / n_{F}\right)}$ & $\begin{array}{l}K_{F}: \text { Freundlich constant related to adsorption capacity, } \\
\mathrm{mg} / \mathrm{g}(\mathrm{L} / \mathrm{mg})_{\mathrm{F}}^{1 / \mathrm{n}} \\
n_{F}: \text { Freundlich constant related to adsorption intensity }\end{array}$ \\
\hline $\begin{array}{l}\text { Sips isotherm (Langmuir- } \\
\text { Freundlich) }\end{array}$ & $q=q_{m} \frac{\left(K_{S} C\right)^{n_{S}}}{1+\left(K_{S} C\right)^{n_{S}}}$ & $\begin{array}{l}K_{S}: \text { Sips affinity constant, L/mg } \\
n_{S}: \text { Sips surface heterogeneity }\end{array}$ \\
\hline Temkin isotherm & $\begin{array}{c}q=B_{T} \ln \left(K_{T} C\right) \\
B_{T}=R T / b\end{array}$ & $\begin{array}{l}K_{T}: \text { Temkin equilibrium binding constant, } \mathrm{L} / \mathrm{g} \\
B_{T}: \text { Temkin constant } \\
R: \text { Universal gas constant, } 8.314 \mathrm{~J} / \mathrm{mol} \mathrm{K} \\
T: \text { Absolute temperature, } \mathrm{K} \\
b: \text { Temkin constant related to the heat of adsorption, } \\
\mathrm{J} / \mathrm{mol}\end{array}$ \\
\hline Pseudo-first-order model & $q_{t}=q\left(1-e^{-k_{1} t}\right)$ & $\begin{array}{l}q_{t}: \text { Adsorption capacity at time } \mathrm{t}(\mathrm{min}), \mathrm{mg} / \mathrm{g} \\
q: \text { Adsorption capacity at equilibrium, } \mathrm{mg} / \mathrm{g} \\
k_{1}: \text { Pseudo-first-order rate constant, } \mathrm{min}^{-1}\end{array}$ \\
\hline Pseudo-second-order model & $q_{t}=\frac{q^{2} k_{2} t}{1+q k_{2} t}$ & $k_{2}:$ Pseudo-second-order rate constant, $\mathrm{g} /(\mathrm{mg} \min )$ \\
\hline Intraparticle-diffusion model & $q_{t}=k_{I D} t^{0.5}+C$ & $\begin{array}{l}k_{I D}: \text { Rate constant of intraparticle diffusion, } \mathrm{mg} /(\mathrm{g} \\
\left.\min ^{0.5}\right) \\
C \text { : Thickness of the boundary layer, } \mathrm{mg} / \mathrm{g}\end{array}$ \\
\hline
\end{tabular}


Table 11 Comparison of the physicochemical properties and adsorption performance of hydrochar-based adsorbents ${ }^{\mathrm{a}}$

\begin{tabular}{|c|c|c|c|c|c|c|c|c|c|c|c|c|c|c|c|c|c|c|}
\hline \multirow{2}{*}{$\begin{array}{l}\text { MS } \\
\text { type }\end{array}$} & \multicolumn{4}{|c|}{ Hydrothermal conditions } & \multirow[t]{2}{*}{ Activation } & \multirow{2}{*}{$\begin{array}{l}\text { Point } \\
\text { of zero } \\
\text { charge }\end{array}$} & \multirow{2}{*}{$\begin{array}{l}\begin{array}{l}\text { SET } \\
\left(\mathrm{m}^{2} / \mathrm{g}\right)\end{array} \\
\end{array}$} & \multirow{2}{*}{$\begin{array}{l}\text { Pore } \\
\text { volume } \\
\left(\mathrm{cm}^{3} / \mathrm{g}\right)\end{array}$} & \multirow{2}{*}{$\begin{array}{l}\begin{array}{l}\text { Pore } \\
\text { diameter } \\
(\mathrm{nm})\end{array} \\
\end{array}$} & \multirow{2}{*}{$\begin{array}{l}\begin{array}{l}\text { OFG } \\
(\mathrm{mmol} / \\
\mathrm{g})\end{array} \\
\end{array}$} & \multirow{2}{*}{$\begin{array}{l}\text { Effective } \\
\text { adsorbate } \\
(\mathrm{pH})\end{array}$} & \multirow[t]{2}{*}{$q_{m}$} & \multirow[t]{2}{*}{$K_{L}$} & \multirow[t]{2}{*}{$K_{F}$} & \multirow[t]{2}{*}{$n_{F}$} & \multirow[t]{2}{*}{$k_{l}$} & \multirow[t]{2}{*}{$k_{2}$} & \multirow[t]{2}{*}{ Reference } \\
\hline & $\begin{array}{l}\mathrm{T} \\
\left({ }^{\circ} \mathrm{C}\right)\end{array}$ & $\begin{array}{l}\mathrm{t} \\
\text { (h) }\end{array}$ & Solvent & Catalyst & & & & & & & & & & & & & & \\
\hline DS & 200 & 24 & Water & No & No & 3.2 & 18 & 0.09 & - & - & $\begin{array}{l}\mathrm{Pb}(\mathrm{II}) \\
\text { (5) }\end{array}$ & $\begin{array}{l}11.3- \\
13\end{array}$ & 0.11 & - & - & 0.38 & 0.05 & $\begin{array}{l}\text { (Alatalo et } \\
\text { al., 2013) }\end{array}$ \\
\hline $\begin{array}{l}\text { WA } \\
\text { S }\end{array}$ & 120 & 24 & Water & $\begin{array}{l}\mathrm{Al} / \mathrm{Mg} \\
\text { salts }\end{array}$ & No & - & - & - & - & - & $\begin{array}{l}\mathrm{Pb}(\mathrm{II}) \\
(4.3)\end{array}$ & 62.4 & 2.48 & 33.5 & 0.19 & $\begin{array}{l}0.01- \\
0.05\end{array}$ & $\begin{array}{l}0.02- \\
0.08\end{array}$ & $\begin{array}{l}\text { (Luo et al., } \\
2020 \text { ) }\end{array}$ \\
\hline MS & 200 & 24 & Water & $\begin{array}{l}\text { Glucose } \\
+ \\
\mathrm{FeSO}_{4} \cdot 7 \\
\mathrm{H}_{2} \mathrm{O}\end{array}$ & Ethanol washing & - & - & - & - & - & $\begin{array}{l}\mathrm{As}(\mathrm{V}) \\
(5)\end{array}$ & 2.2 & 0.61 & 0.68 & 2.0 & 0.03 & 1.6 & $\begin{array}{l}\text { (El-Deen } \\
\text { and Zhang, } \\
\text { 2012) }\end{array}$ \\
\hline \multirow[t]{3}{*}{ SS } & 260 & 1 & Water & No & No & - & 6 & 0.015 & 2.98 & 2.08 & Methylen & 63.3 & 0.35 & 24.1 & 4.3 & 0.03 & 0.01 & (Khoshbou \\
\hline & 200 & & & & $\begin{array}{l}\text { Thermal } \\
\left(900^{\circ} \mathrm{C}\right) \text { with } \\
\mathrm{CO}_{2}\end{array}$ & - & 262 & 0.195 & 3.08 & 1.12 & $\begin{array}{l}\text { e blue } \\
(8.1-8.6)\end{array}$ & 122.4 & 0.14 & 9.7 & 58.3 & 0.04 & 0.03 & $\begin{array}{l}\text { y et al., } \\
\text { 2019) }\end{array}$ \\
\hline & 260 & & & & $\begin{array}{l}\text { Thermochemical } \\
\left(\mathrm{KOH}+700^{\circ} \mathrm{C}\right) \\
+ \text { chemical }(\mathrm{HCl})\end{array}$ & - & 1614 & 0.877 & 2.01 & 1.6 & & 588.2 & 1.89 & 8.7 & $\begin{array}{l}340 . \\
9\end{array}$ & 0.24 & 0.02 & \\
\hline \multirow[t]{6}{*}{ DS } & 190 & 3 & Water & No & No & - & 31 & - & - & - & Methylen & 70.5 & 0.05 & 5.8 & 5.8 & 0.01 & 0.004 & (Ferrentino \\
\hline & 220 & & & & & - & 8.8 & - & - & - & e blue & 54.3 & 0.38 & 9.7 & 2.4 & 0.005 & 0.001 & et al., \\
\hline & 250 & & & & & - & 11.9 & - & - & - & $(6.2-6.6)$ & 37.6 & 0.14 & 5.8 & 2.5 & 0.002 & $\begin{array}{l}0.000 \\
3\end{array}$ & 2020a) \\
\hline & 190 & & & & Chemical (2M & - & 0.3 & - & - & - & & - & - & 3.6 & 1.2 & - & -0.01 & \\
\hline & 220 & & & & $\mathrm{KOH}$ for $1 \mathrm{~h}$ ) & - & 2.7 & - & - & - & & 140.1 & 0.06 & 10.7 & 1.5 & 0.07 & 0.02 & \\
\hline & 250 & & & & & - & 13.4 & - & - & - & & - & - & 13.9 & 1.2 & 0.03 & 0.003 & \\
\hline $\begin{array}{l}\text { MS/ } \\
\text { coco } \\
\text { nut } \\
\text { shell }\end{array}$ & 180 & 4 & Water & No & $\begin{array}{l}\text { Chemical ( } 2 \mathrm{M} \\
\mathrm{KOH} \text { for } 30 \mathrm{~min}) \\
+ \text { thermal } \\
\left(700^{\circ} \mathrm{C} \text { for } 50\right.\end{array}$ & - & 874 & 0.57 & 2.51 & - & $\begin{array}{l}\text { Methylen } \\
\text { e blue } \\
(7 \text { at } 20- \\
\left.40^{\circ} \mathrm{C}\right)\end{array}$ & $\begin{array}{l}588- \\
652\end{array}$ & $\begin{array}{l}10.7 \\
- \\
40.8\end{array}$ & $\begin{array}{l}559- \\
621\end{array}$ & $\begin{array}{l}52- \\
102\end{array}$ & 0.13 & $\begin{array}{l}0.007 \\
6\end{array}$ & $\begin{array}{l}\text { (Tu et al., } \\
\text { 2021) }\end{array}$ \\
\hline $\begin{array}{l}\text { (1:1, } \\
\text { db) }\end{array}$ & & & & & $\min )$ & & & & & & $\begin{array}{l}\text { Congo } \\
\text { Red } \\
(7 \text { at } 30- \\
\left.40^{\circ} \mathrm{C}\right)\end{array}$ & $\begin{array}{l}248- \\
295\end{array}$ & $\begin{array}{l}0.34 \\
- \\
0.46\end{array}$ & $\begin{array}{l}86- \\
136\end{array}$ & $\begin{array}{l}4.2- \\
3.3\end{array}$ & 0.19 & 0.011 & \\
\hline \multirow[t]{2}{*}{ MS } & 280 & 0.3 & $\begin{array}{l}\text { Acetone } \\
\text { Ethanol }\end{array}$ & No & No & 6.9 & 12 & 0.058 & 18.7 & 3.61 & Malachite & 49.3 & 41 & $\begin{array}{l}5.37 \\
8.78\end{array}$ & 8.8 & - & 0.14 & (Leng et al., \\
\hline & & & $\begin{array}{l}\text { Ethanol } \\
\text { Methanol }\end{array}$ & & & 6.7 & 17 & 0.081 & 18.1 & 2.71 & green & 34.2 & 48 & 8.78 & 5.4 & - & 0.15 & 2015b) \\
\hline \multirow[t]{2}{*}{ MS } & 220 & 1 & Water & No & $\begin{array}{l}\text { Chemical } \\
\left(\mathrm{ZnCl}_{2}\right)+ \\
\text { thermal }\left(650{ }^{\circ} \mathrm{C}\right) \\
\text { + chemical }(\mathrm{HCl})\end{array}$ & 4.3 & 417 & 0.38 & 3.7 & 0.56 & $\begin{array}{l}\text { Acid } \\
\text { orange } 7 \\
(6.2-6.6)\end{array}$ & - & - & - & - & - & - & $\begin{array}{l}\text { (Liu et al., } \\
\text { 2017b) }\end{array}$ \\
\hline & & & & & $\begin{array}{l}\text { Chemical } \\
\left(\mathrm{ZnCl}_{2}\right)+ \\
\text { thermal }\left(650{ }^{\circ} \mathrm{C}\right) \\
+ \text { chemical }(\mathrm{HCl} \\
+\mathrm{HF})\end{array}$ & 6.4 & 519 & 0.59 & 4.8 & 0.49 & & 440.5 & 1.5 & 240 & 7.7 & 0.15 & 0.01 & \\
\hline
\end{tabular}


${ }^{\mathrm{a}} \mathrm{DS}=$ digested sludge; WAS $=$ waste activated sludge; $\mathrm{MS}=$ municipal sludge; $\mathrm{SS}=$ secondary sludge; $\mathrm{T}=$ hydrothermal temperature; $\mathrm{t}=$ residence time; $\mathrm{S}_{\mathrm{BET}}=\mathrm{Brunauere-Emmette-Teller}(\mathrm{BET})$ surface area; $\mathrm{OFG}=$ oxygen-containing functional groups; $q_{m}=$ maximum adsorption capacity $(\mathrm{mg} / \mathrm{g}) ; K_{L}=$ Langmuir affinity constant of binding sites, $\mathrm{L} / \mathrm{mg} ; K_{F}=$ Freundlich constant related to adsorption capacity, $\mathrm{mg} / \mathrm{g}$ $(\mathrm{L} / \mathrm{mg})^{1 / \mathrm{n}} ; n_{F}=$ Freundlich constant related to adsorption intensity; $k_{1}=$ pseudo-first-order rate constant $\left(\mathrm{min}^{-1}\right) ; k_{2}=$ pseudo-second-order rate constant, $\mathrm{g} /(\mathrm{mg} \mathrm{min})$. 
Table 12 Comparisons of various nutrient recovery methods for municipal sludge-derived hydrochar ${ }^{\mathrm{a}}$

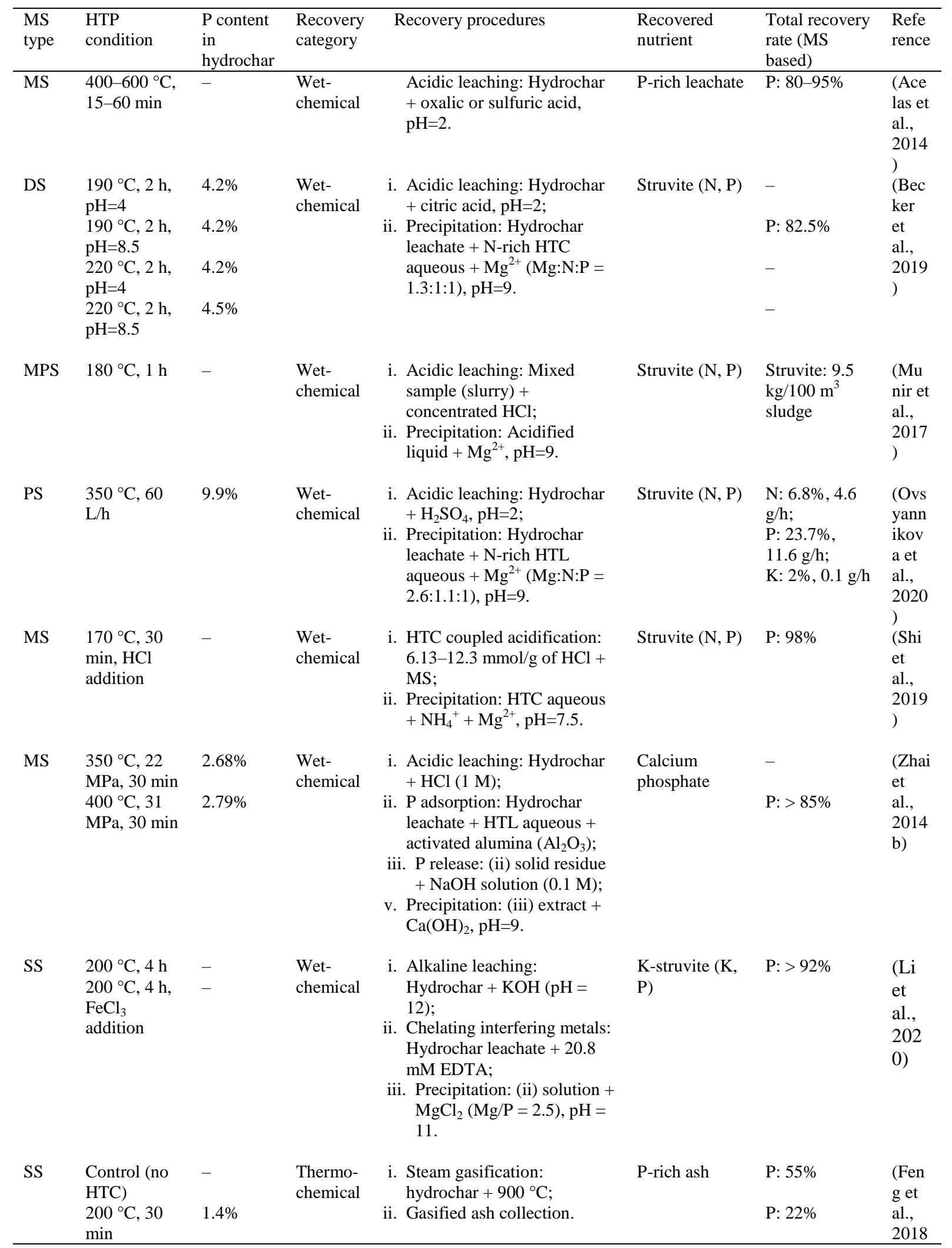




\begin{tabular}{|c|c|c|c|c|c|c|c|}
\hline $\begin{array}{l}\text { MS } \\
\text { type }\end{array}$ & $\begin{array}{l}\text { HTP } \\
\text { condition }\end{array}$ & $\begin{array}{l}\text { P content } \\
\text { in } \\
\text { hydrochar }\end{array}$ & $\begin{array}{l}\text { Recovery } \\
\text { category }\end{array}$ & Recovery procedures & $\begin{array}{l}\text { Recovered } \\
\text { nutrient }\end{array}$ & $\begin{array}{l}\text { Total recovery } \\
\text { rate (MS } \\
\text { based) }\end{array}$ & $\begin{array}{l}\text { Refe } \\
\text { rence }\end{array}$ \\
\hline & $\begin{array}{l}220^{\circ} \mathrm{C}, 30 \\
\min \end{array}$ & $1.6 \%$ & & & & P: $56 \%$ & \multirow[t]{3}{*}{ ) } \\
\hline & $\begin{array}{l}240^{\circ} \mathrm{C}, 30 \\
\min \end{array}$ & $1.6 \%$ & & & & P: $55 \%$ & \\
\hline & $\begin{array}{l}260^{\circ} \mathrm{C}, 30 \\
\min \end{array}$ & $1.6 \%$ & & & & P: $35 \%$ & \\
\hline MPS & $\begin{array}{l}225-275^{\circ} \mathrm{C} \\
15-60 \mathrm{~min}\end{array}$ & - & $\begin{array}{l}\text { Integrated } \\
\text { biological }\end{array}$ & $\begin{array}{l}\text { i. Acidic saccharification: } \\
\text { hydrochar + sulfuric acid; } \\
\text { ii. Algae cultivation: } \\
\text { saccharified liquid } \\
\text { (neutralized) + HTC aqueous } \\
\text { + algae. }\end{array}$ & $\begin{array}{l}\text { Recycled N, P } \\
\text { (microalgae) }\end{array}$ & - & $\begin{array}{l}\text { (Aid } \\
\text { a et } \\
\text { al., } \\
2016 \\
\text { ) }\end{array}$ \\
\hline
\end{tabular}

${ }^{a} \mathrm{DS}=$ digested sludge; MPS = mixed primary and secondary sludge; $\mathrm{MS}=$ municipal sludge; $\mathrm{PS}$ = primary sludge; $\mathrm{SS}=$ secondary sludge; HTP = hydrothermal processing; HTC = hydrothermal carbonization; HTL = hydrothermal liquefaction. 

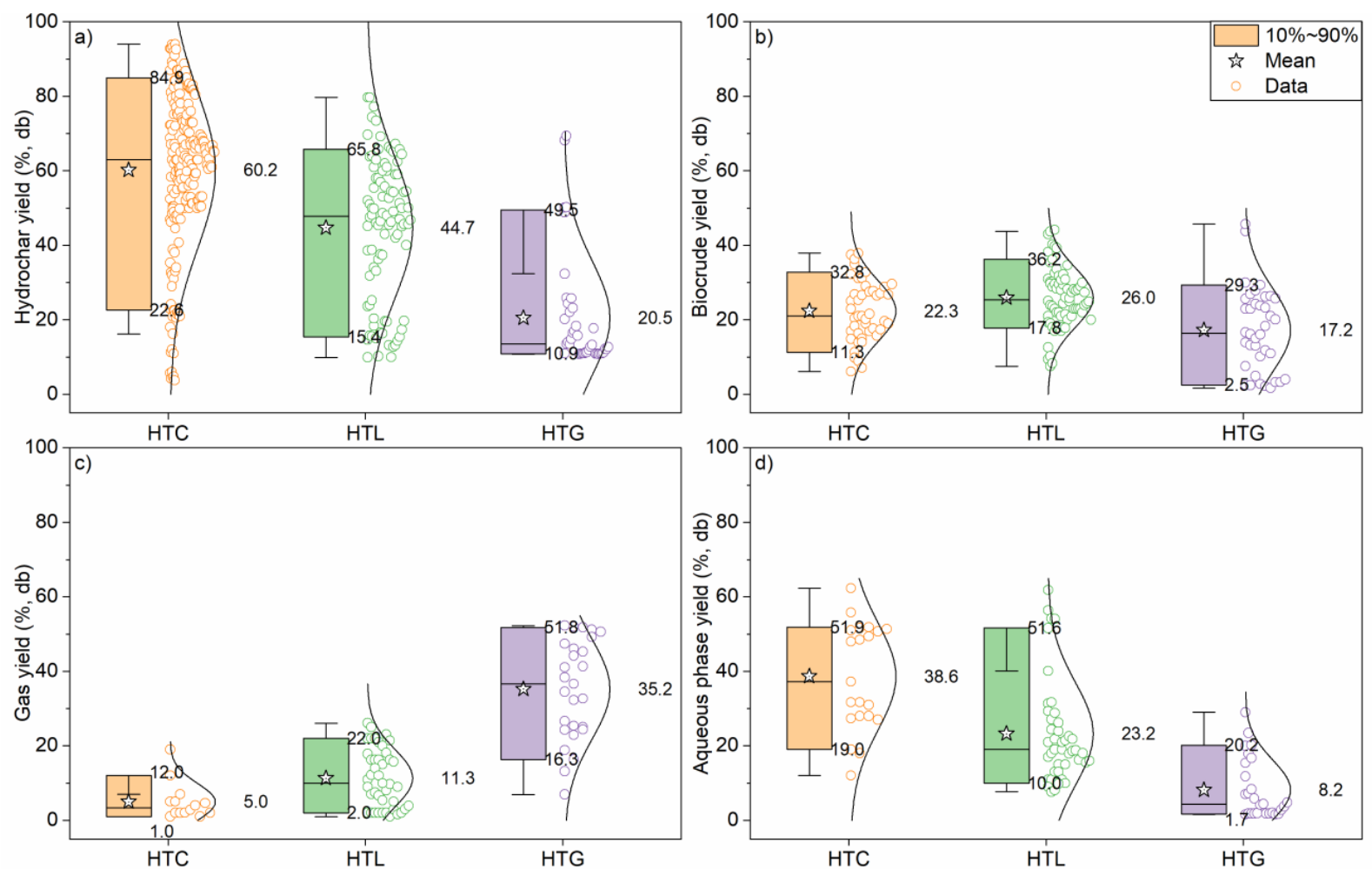

Fig. 1 Bar normal distributions depicting yields of (a) hydrochar, (b) biocrude, (c) gas, and (d) aqueous phase from various hydrothermal processes. Data collected from references in Table 1 . HTC = hydrothermal carbonization; HTL = hydrothermal liquefaction; HTG = hydrothermal gasification; $\mathrm{db}=$ dry basis. 


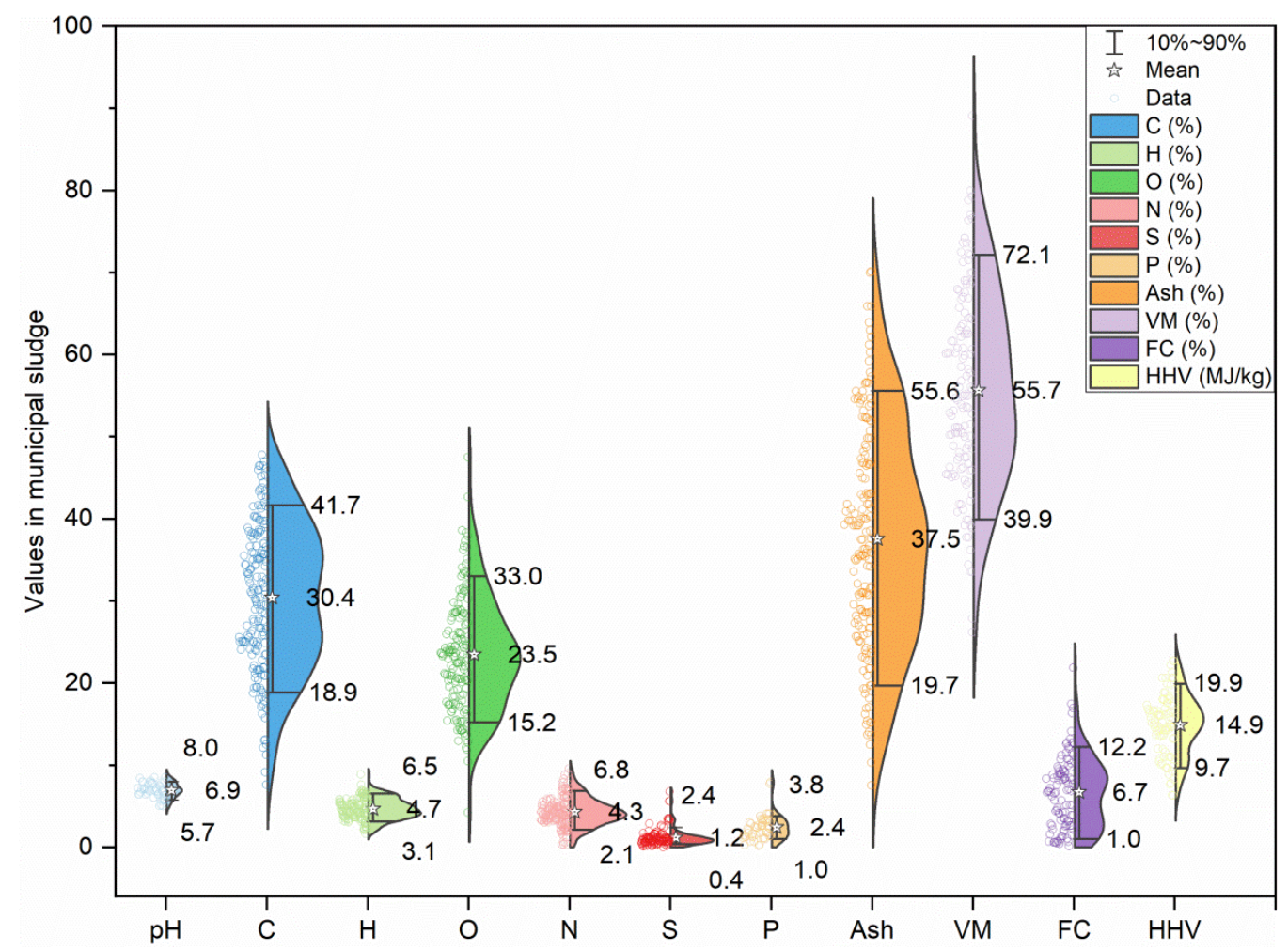

Fig. 2 Violin distribution plot of various properties (data in dry basis except for $\mathrm{pH}$ ) of municipal sludge reported in hydrothermal studies. Data collected from references in Table $2 . \mathrm{VM}=$ volatile matter; FC = fixed carbon; $\mathrm{HHV}=$ higher heating value. 


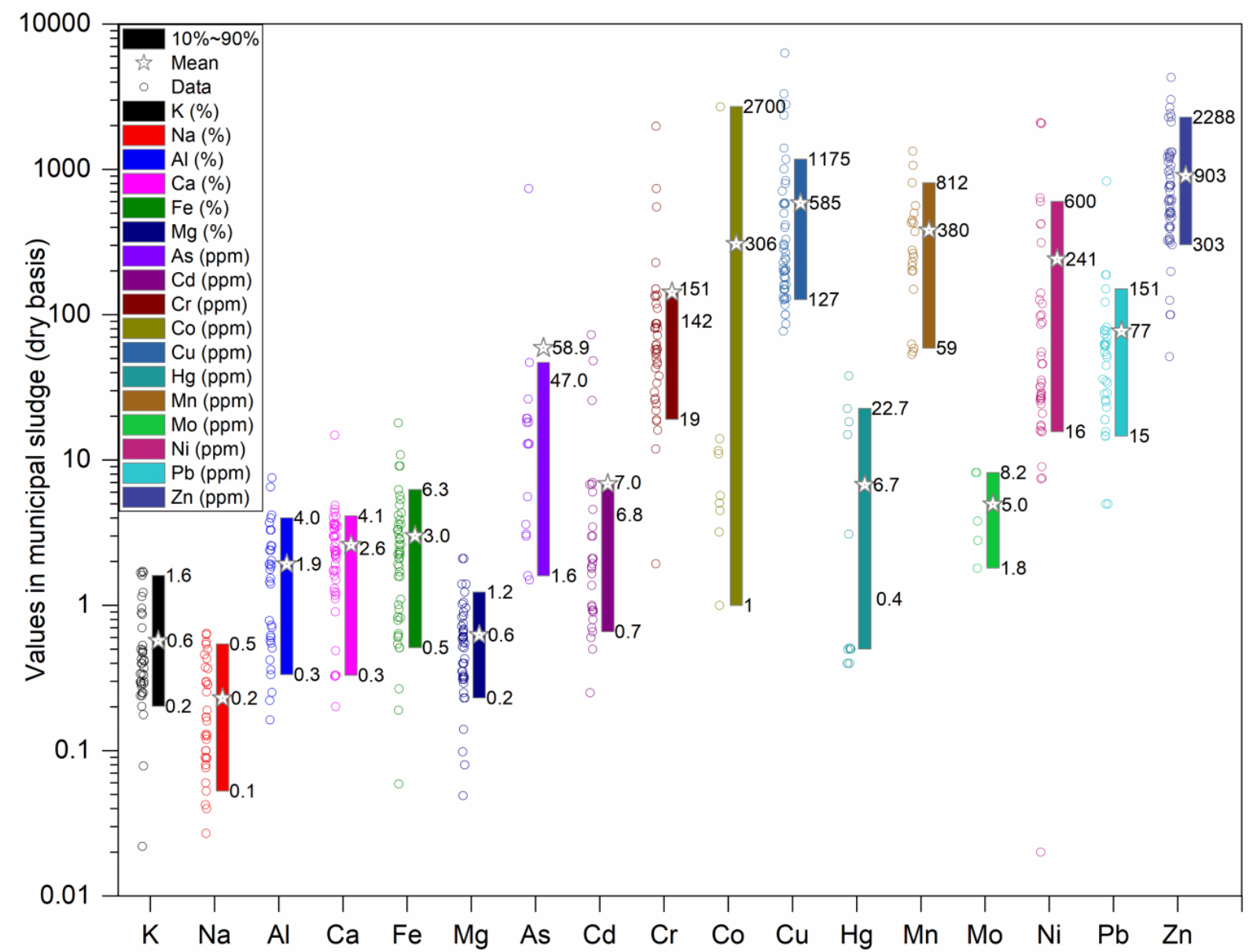

Fig. 3 Distribution plot of metals in municipal sludge reported from hydrothermal studies. Data collected from references in Table 2. 


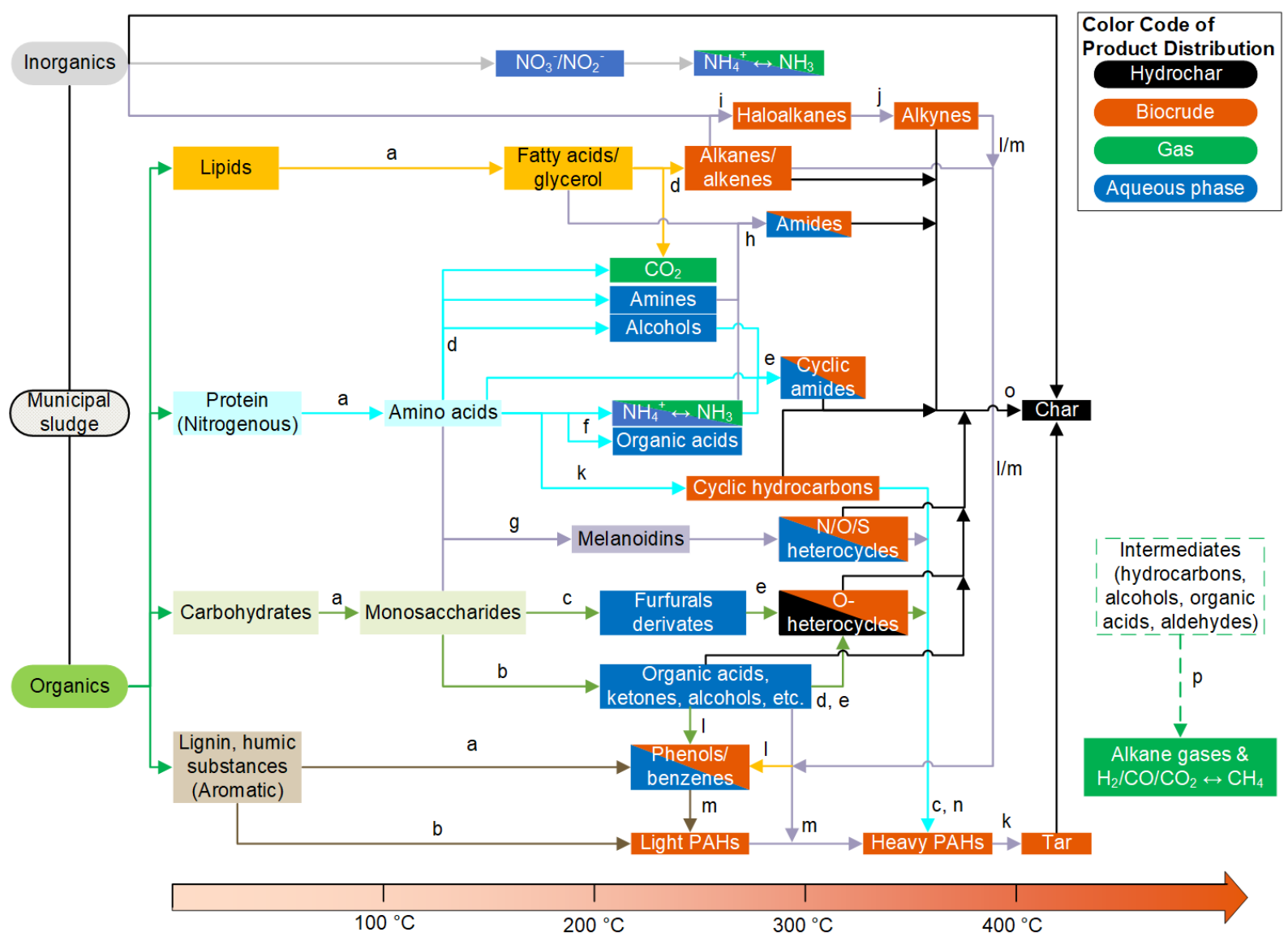

Fig. 4 Possible reaction pathways and corresponding products distribution for the hydrothermal processing of municipal sludge: (a) hydrolysis; (b) decomposition; (c) dehydration; (d) decarboxylation; (e) cyclization; (f) deamination; (g) Maillard reaction; (h) aminolysis; (i) halogenation; (j) dehydrohalogenation; (k) condensation; (l) Diels-Alder reaction; (m) hydrogen abstraction acetylene addition reaction; (n) aromatization; (o) polymerization; (p) free radical reactions or metal-catalyzed CC/C-O cleavage (Azadi et al., 2013; Chen et al., 2014; Gong et al., 2018, 2017, 2016b; He et al., 2015b, 2014a; Inoue et al., 1997; Liu et al., 2017a; Paneque et al., 2017; Sevilla and Fuertes, 2009; Su et al., 2019; Usman et al., 2019a; Wang et al., 2019a; Wang et al., 2018; Wang et al., 2012; Watson et al., 2020; Zhuang et al., 2017). PAHs = polycyclic aromatic hydrocarbons. Note: Metal ions have a potential catalytic or inhibitory role on reactions a-c. 

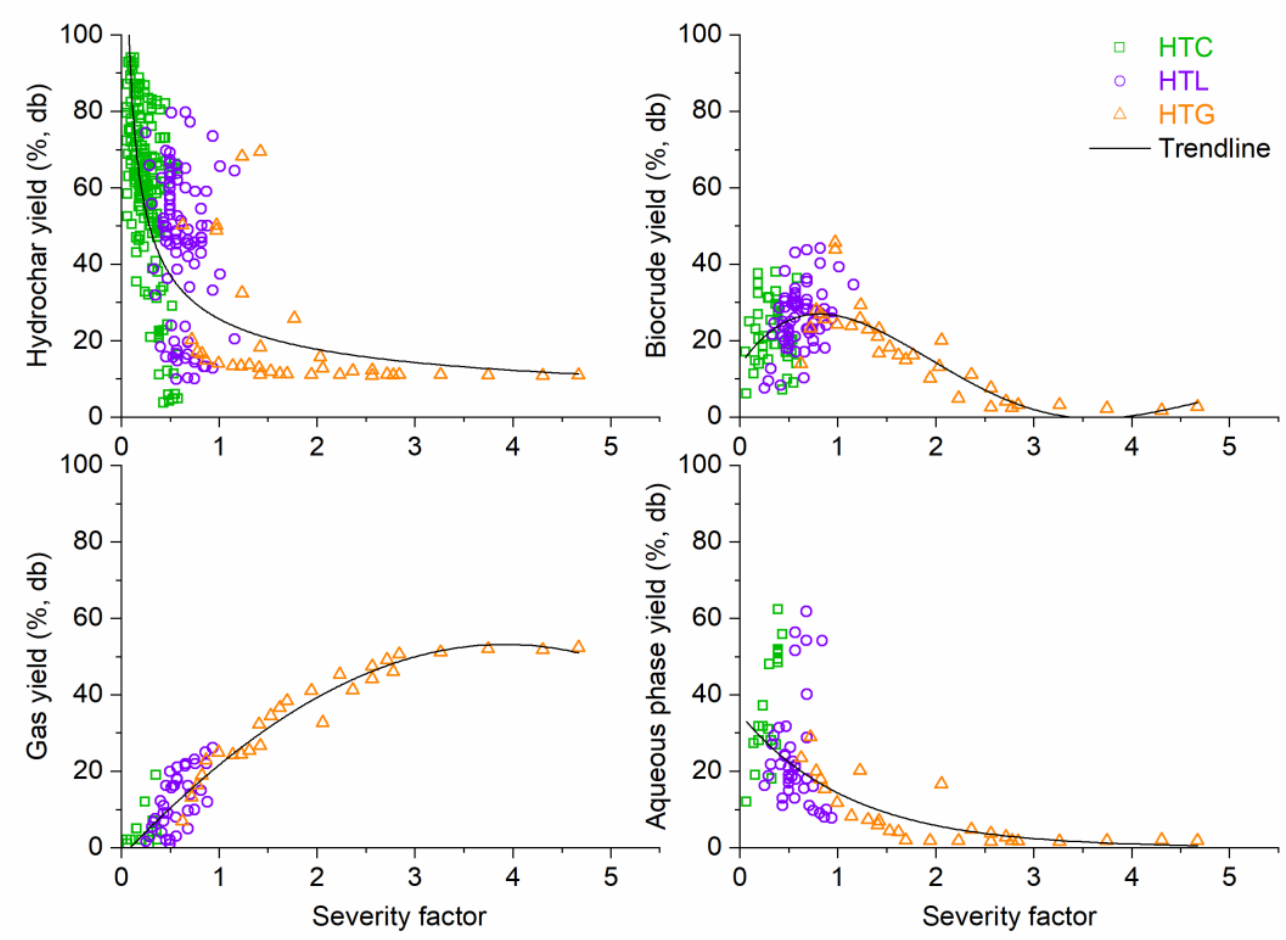

Fig. 5 Influence of the reaction severity on the product yields from the hydrothermal processing of municipal sludge. Data collected from references in Table 1 . HTC $=$ hydrothermal carbonization; HTL = hydrothermal liquefication; HTG = hydrothermal gasification; $\mathrm{db}=$ dry basis. 


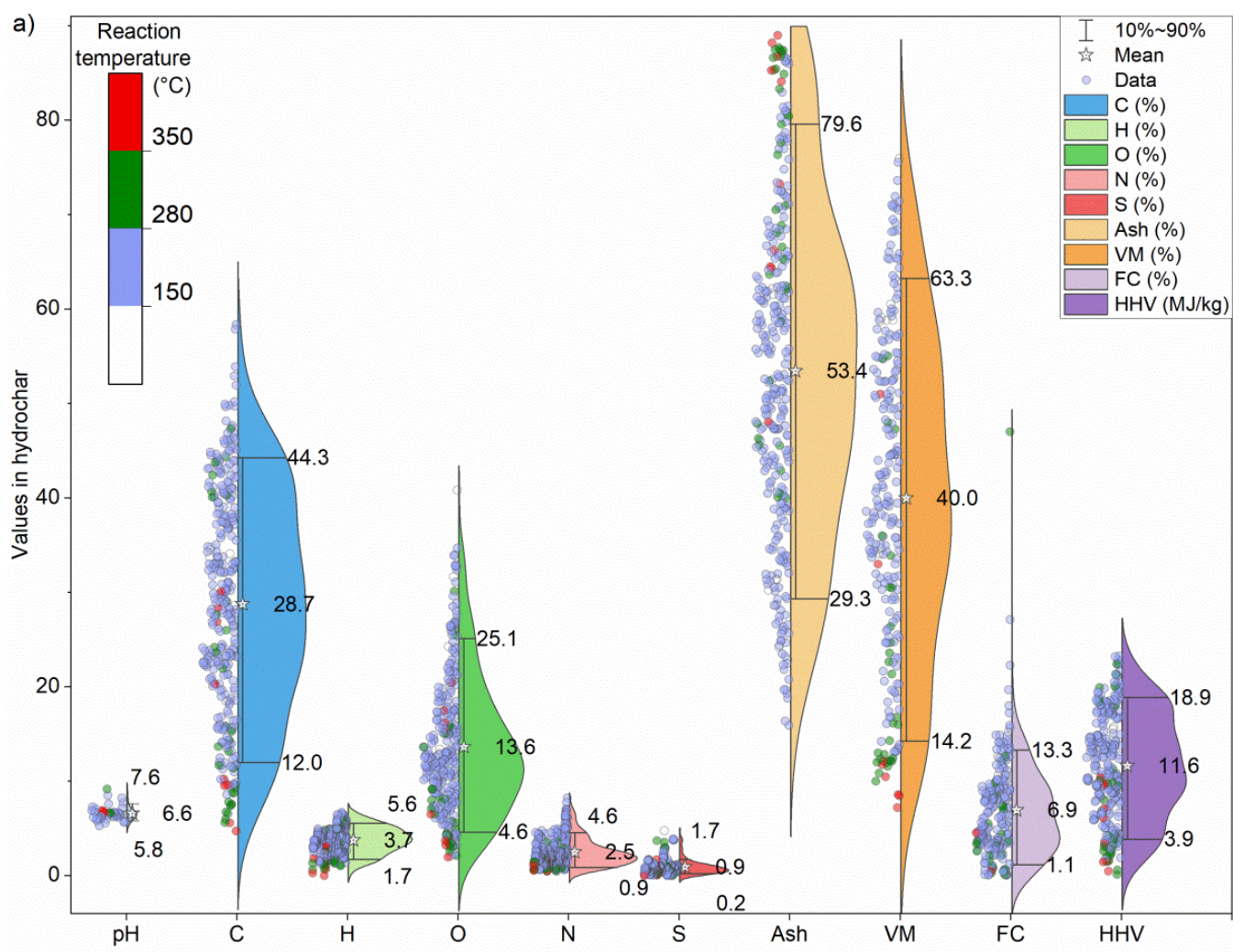



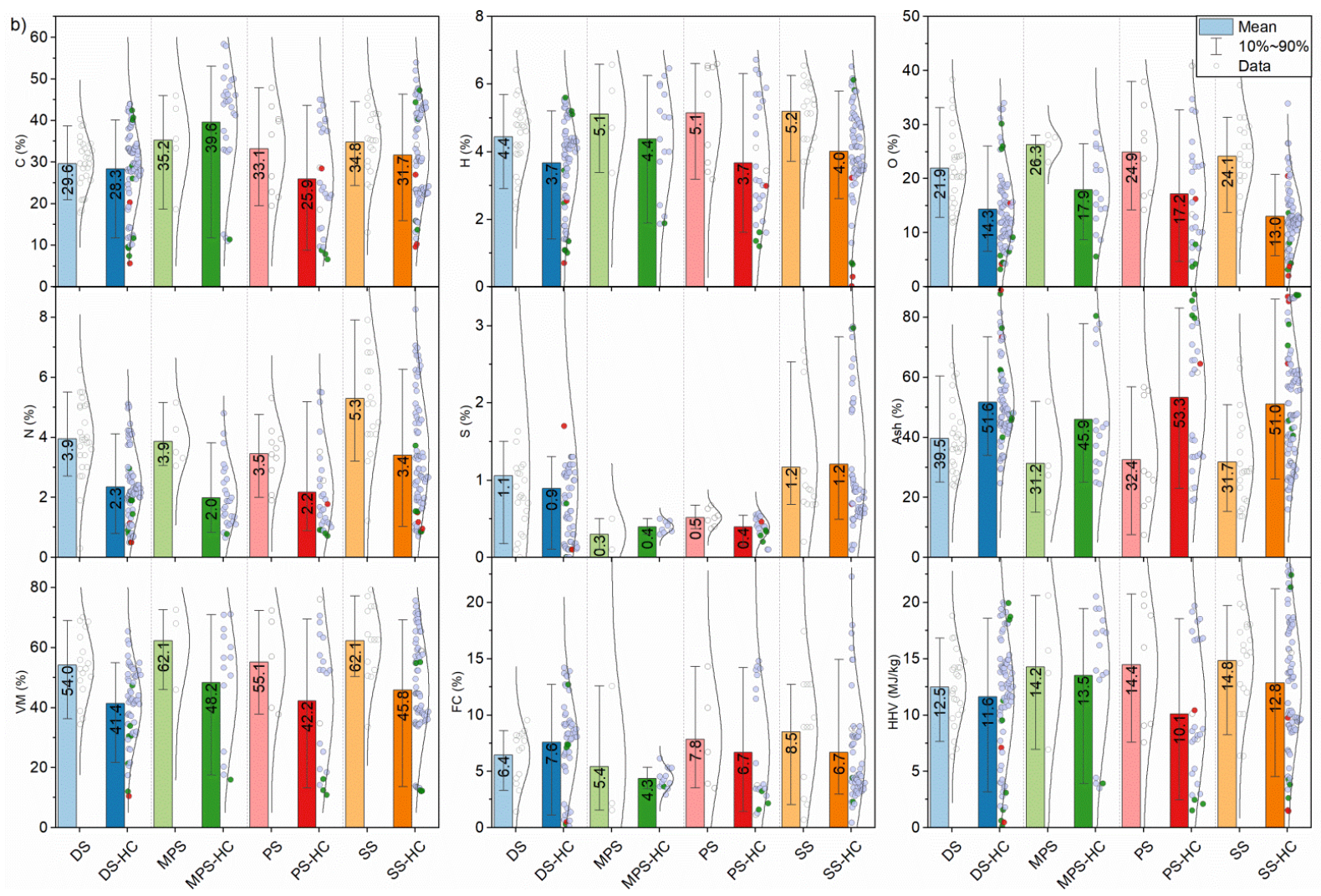


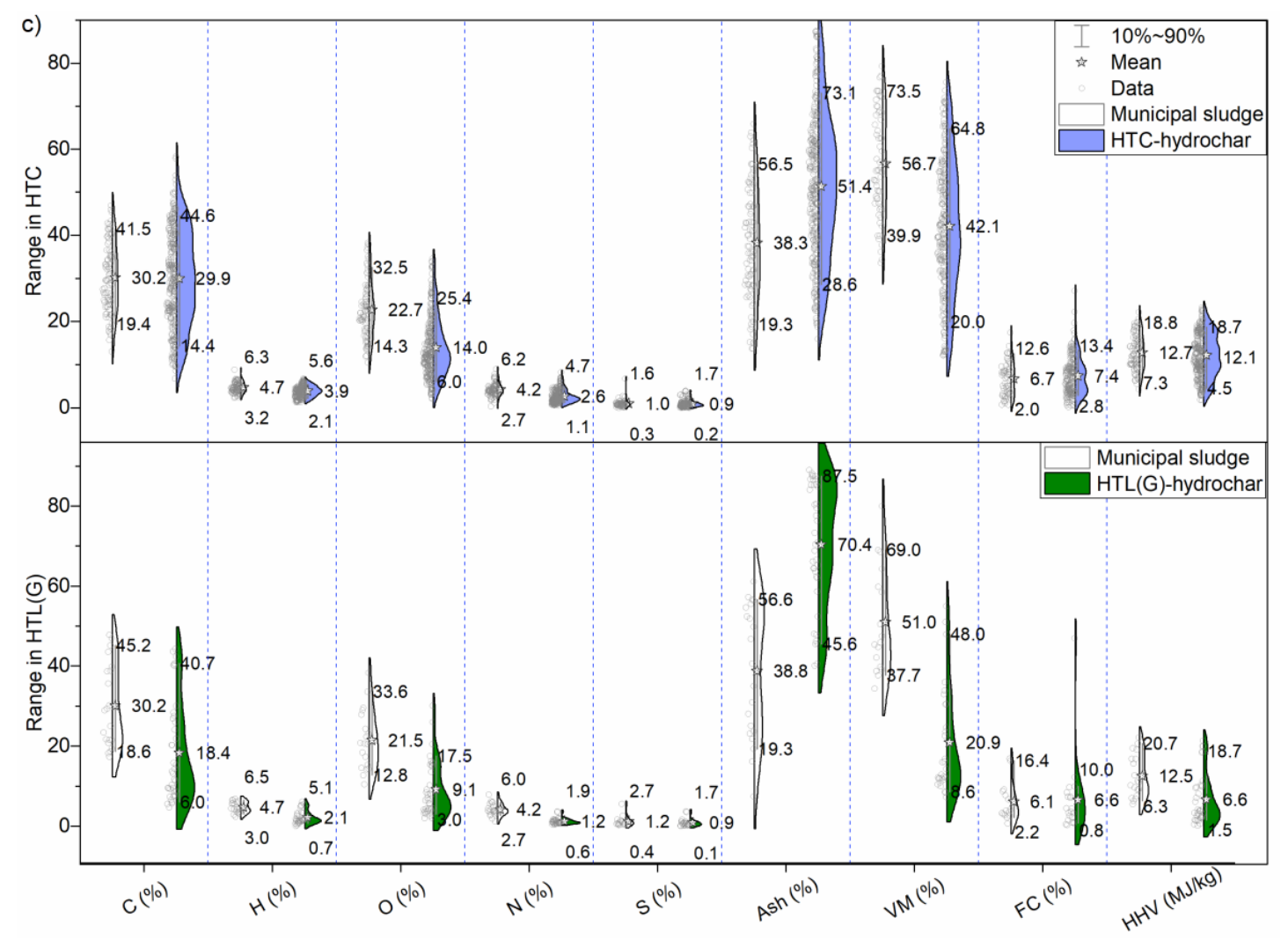

Fig. 6 (a) Violin distribution plot of various properties of hydrochar and comparisons of sludge to its derived hydrochar (b) based on feedstock sludge type and (c) hydrothermal processes (all values on the dry basis except for $\mathrm{pH}$, data from Table 6). $\mathrm{VM}=$ volatile matter; $\mathrm{FC}=$ fixed carbon; $\mathrm{HHV}=$ higher heating value; $\mathrm{DS}=$ digested sludge; $\mathrm{MPS}$ = mixed primary and secondary sludge; $\mathrm{PS}$ = primary sludge; SS = secondary sludge (including waste activated sludge); HTC = hydrothermal carbonization; HTL $(\mathrm{G})=$ hydrothermal liquefaction/gasification. 


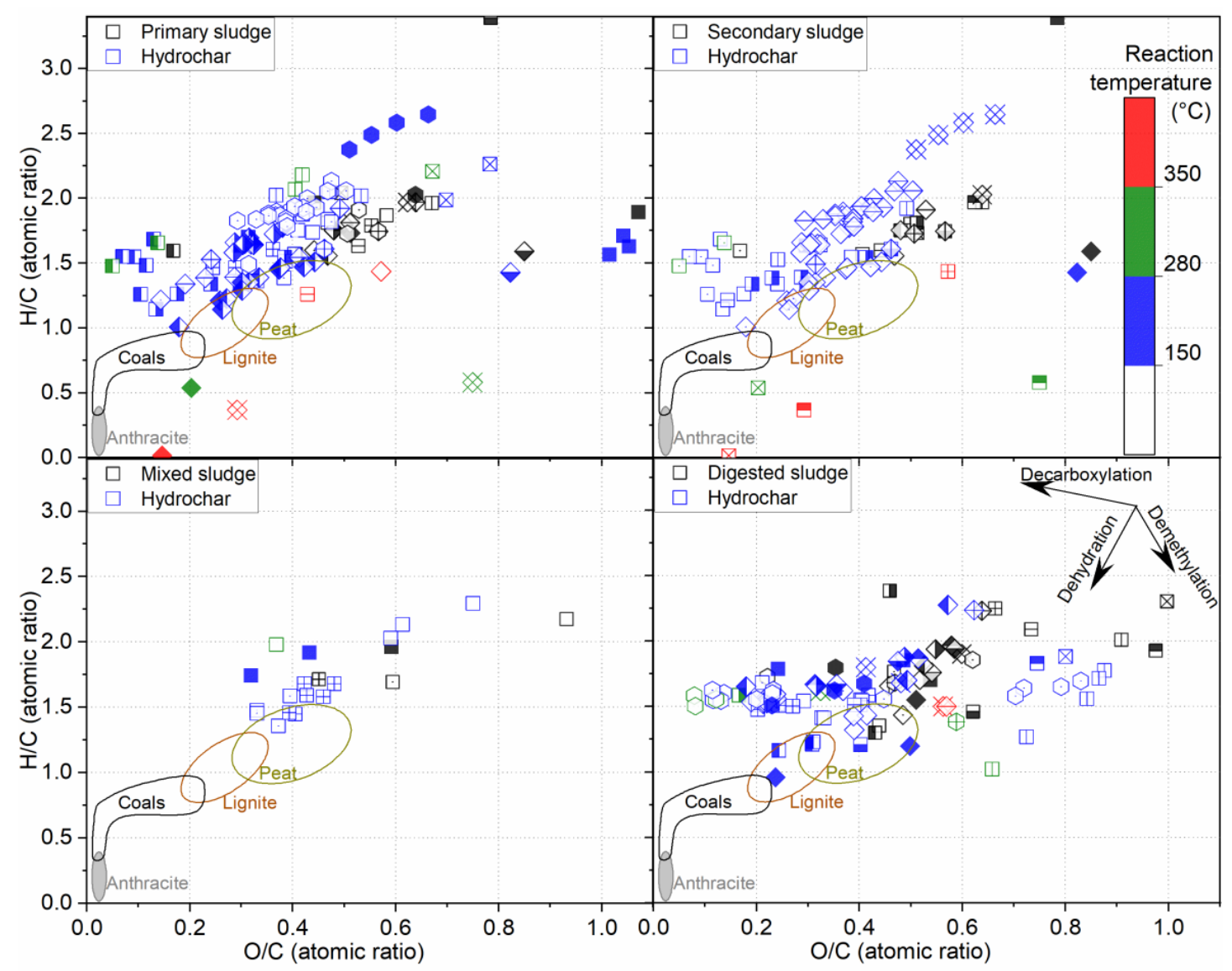

Fig. 7 van Krevelen diagram of municipal sludge (in black color) and the corresponding hydrochar (in other colors depending on reaction temperature) (data from Table 6). Same data shape donates from the same study. 

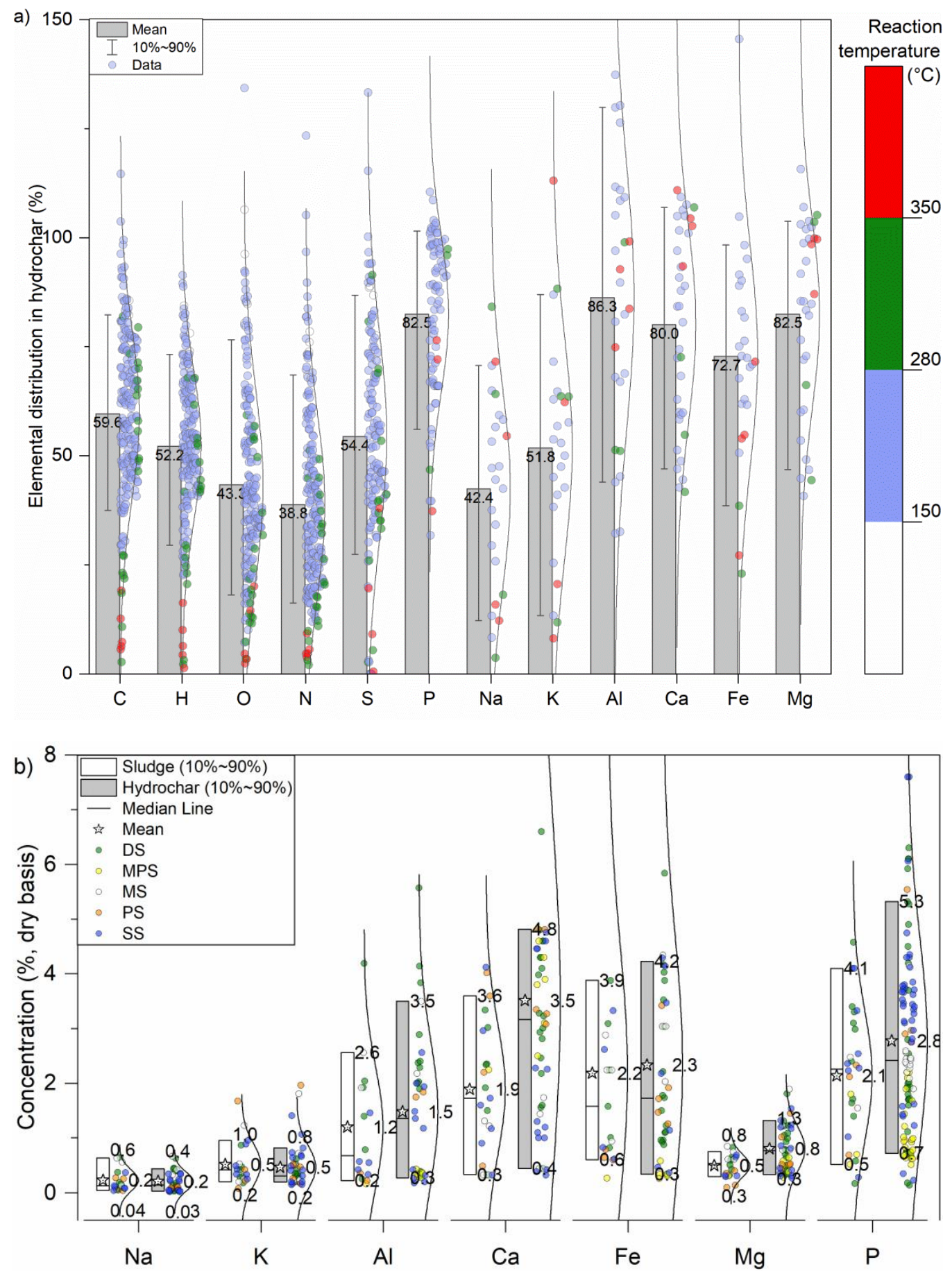

Fig. 8 (a) Bar normal distribution of macro elements in hydrochar and (b) concentrations of macronutrients in various sludge and its derived hydrochar (data from references in Table 6). Elemental distribution $=$ elemental mass in hydrochar/elemental mass in sludge feedstock $\times 100 \% ; \mathrm{DS}=$ digested sludge; $\mathrm{MS}$ = municipal sludge (non-specified); $\mathrm{PS}$ = primary sludge; $\mathrm{SS}=$ secondary sludge (including waste activated sludge); MPS = mixed PS and SS. 

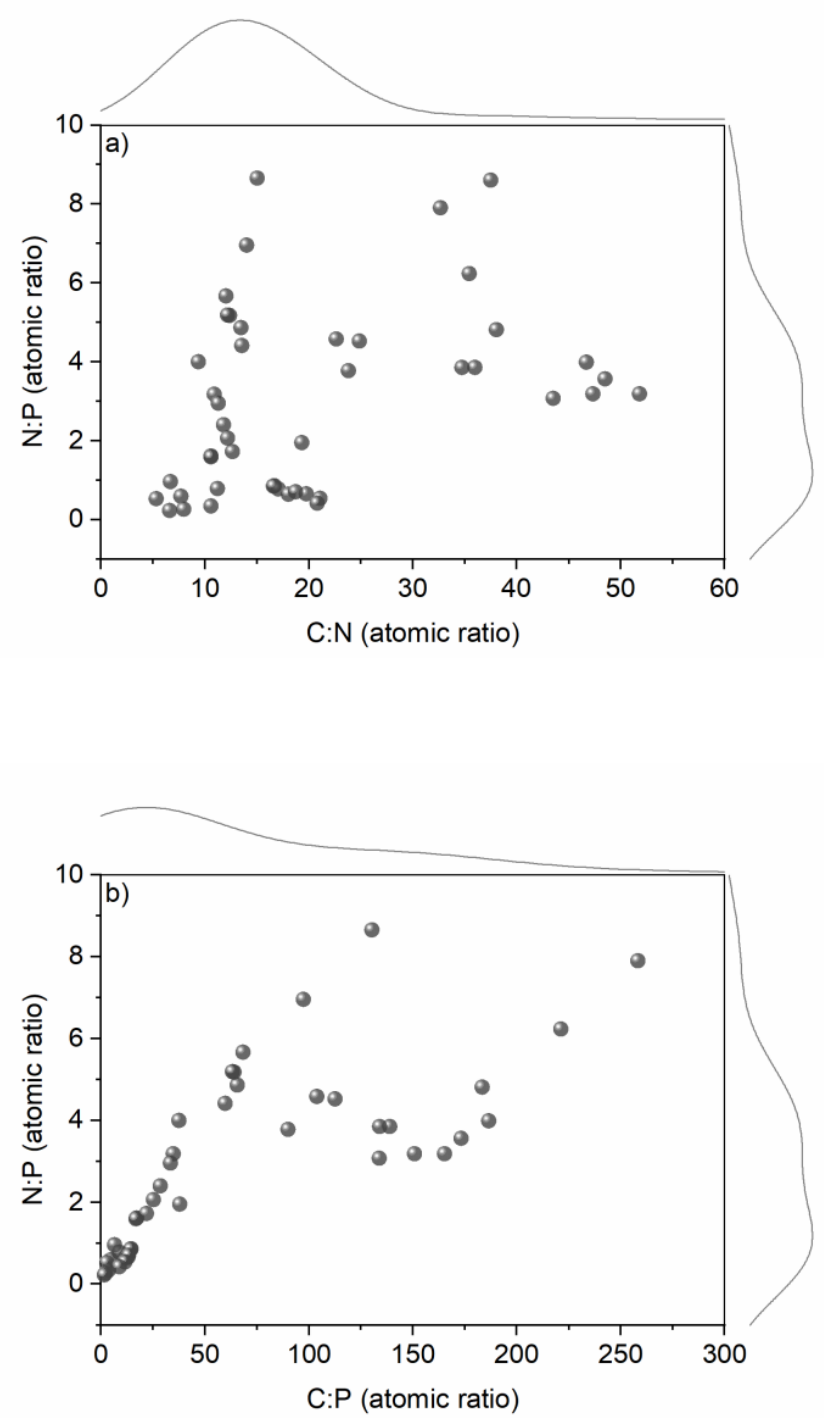

Fig. 9 Atomic ratios of (a) N:P versus C:N and (b) N:P versus C:P in municipal sludge-derived hydrochar with Kernel smooth distribution (data from references in Table 6). 


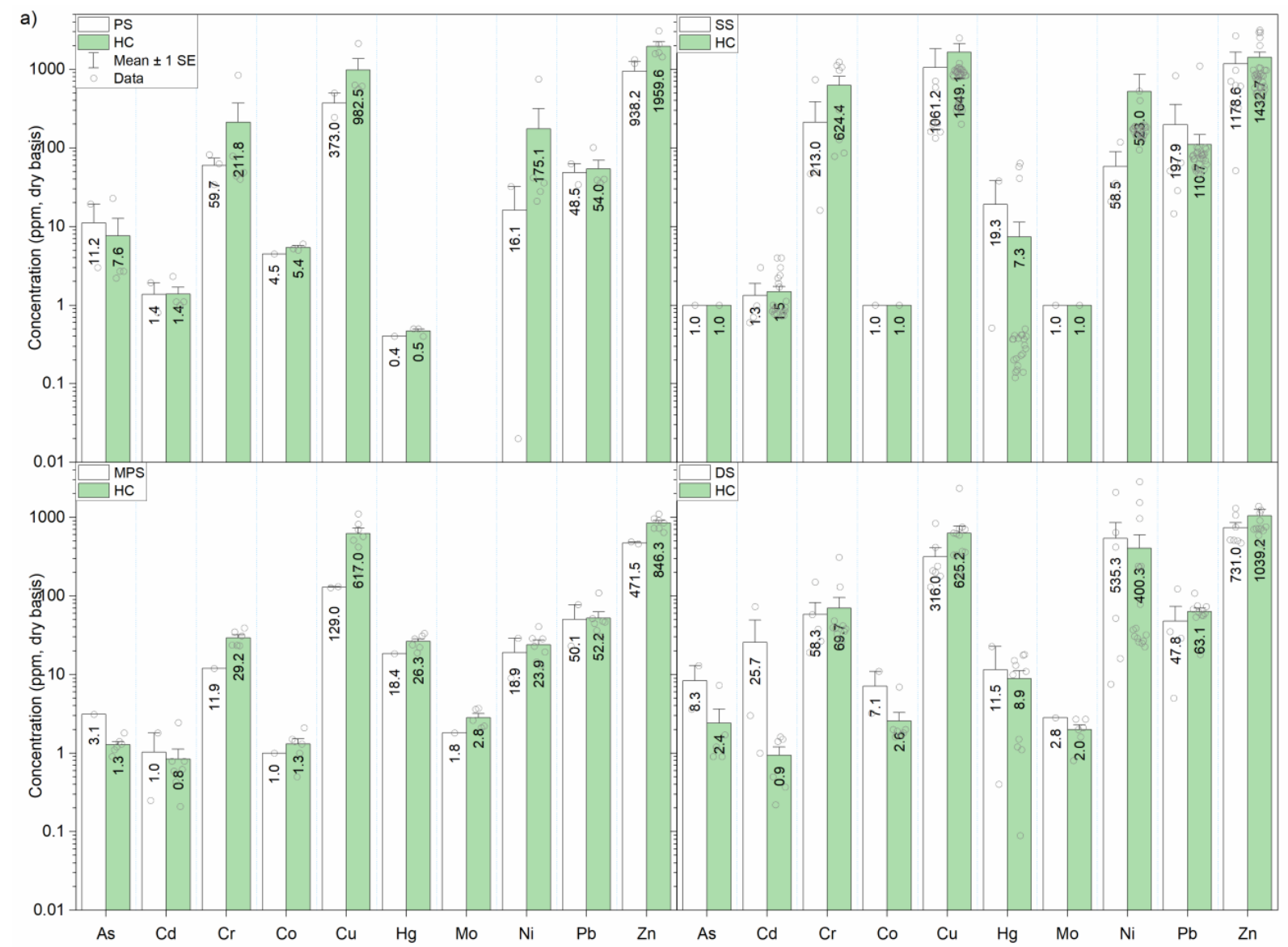



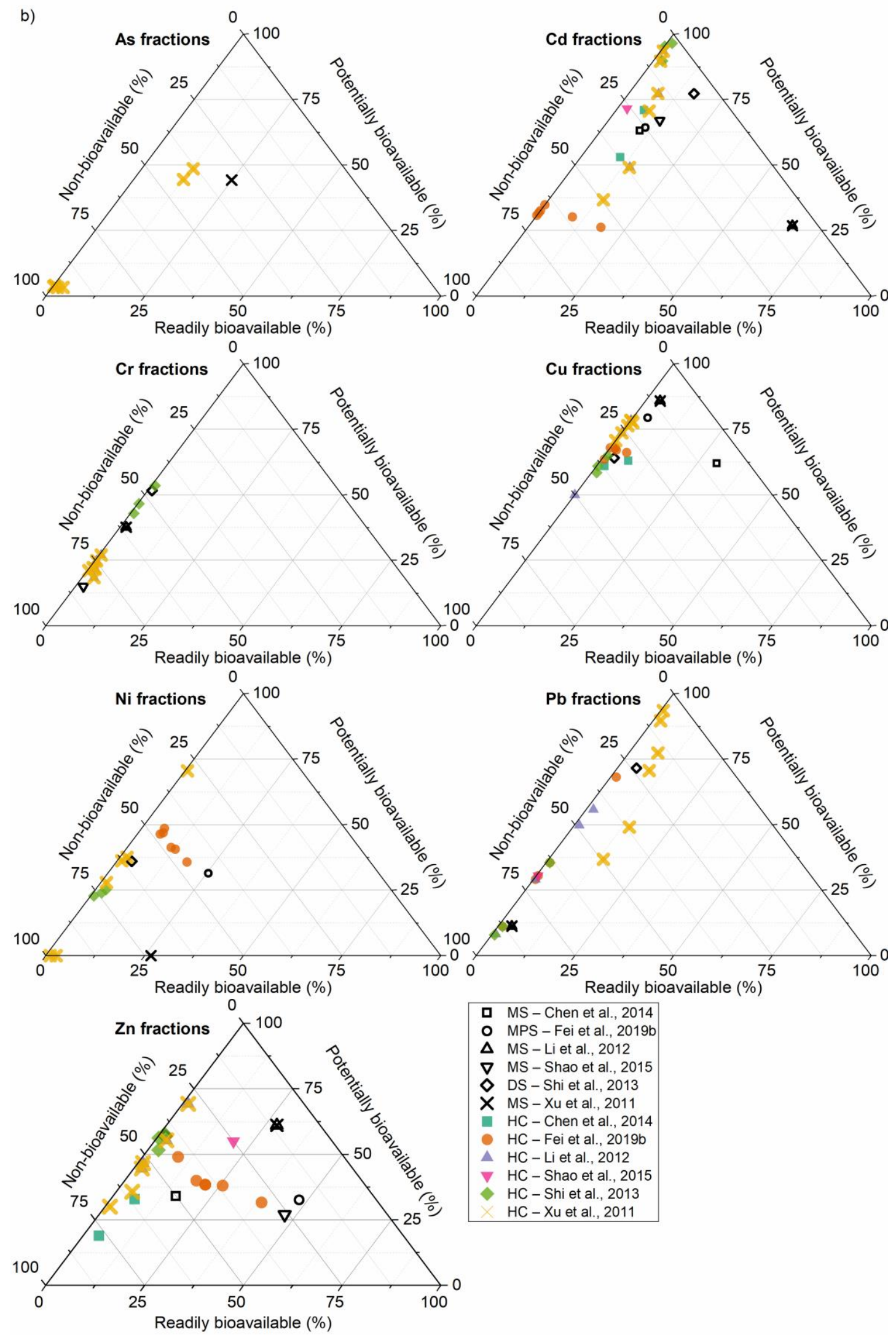
Fig. 10 (a) Total concentrations (data from Table 7) and (b) fractional distribution of heavy metals in various municipal sludge (MS) and the corresponding hydrochar (HC). DS = digested sludge; PS = primary sludge; SS = secondary sludge (including waste activated sludge); MPS = mixed PS and SS. 


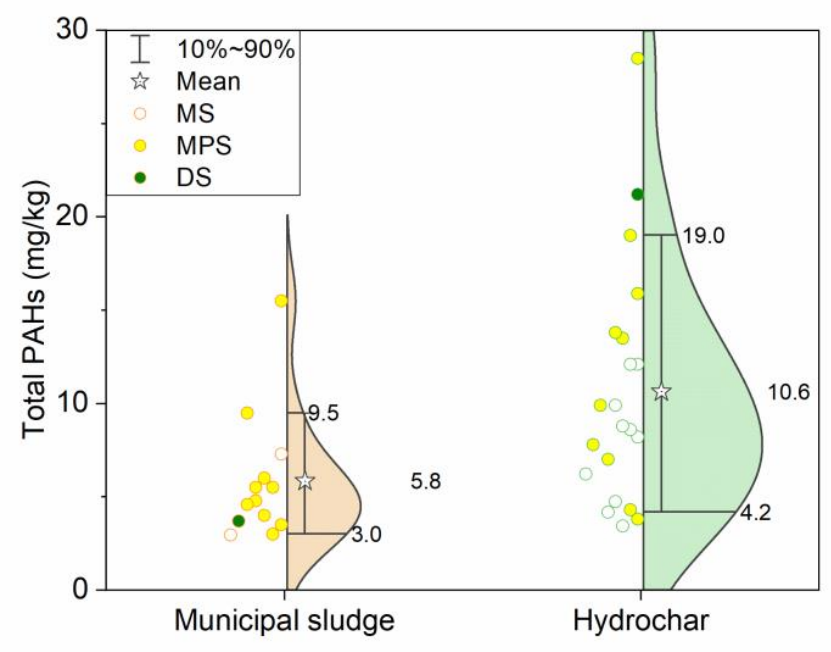

Fig. 11 Violin distribution of total polycyclic aromatic hydrocarbons (PAHs) in municipal sludge and the corresponding hydrochar (Gong et al., 2016b, 2018; T. Liu et al., 2021; Melo et al., 2019; Wiedner et al., 2013). 

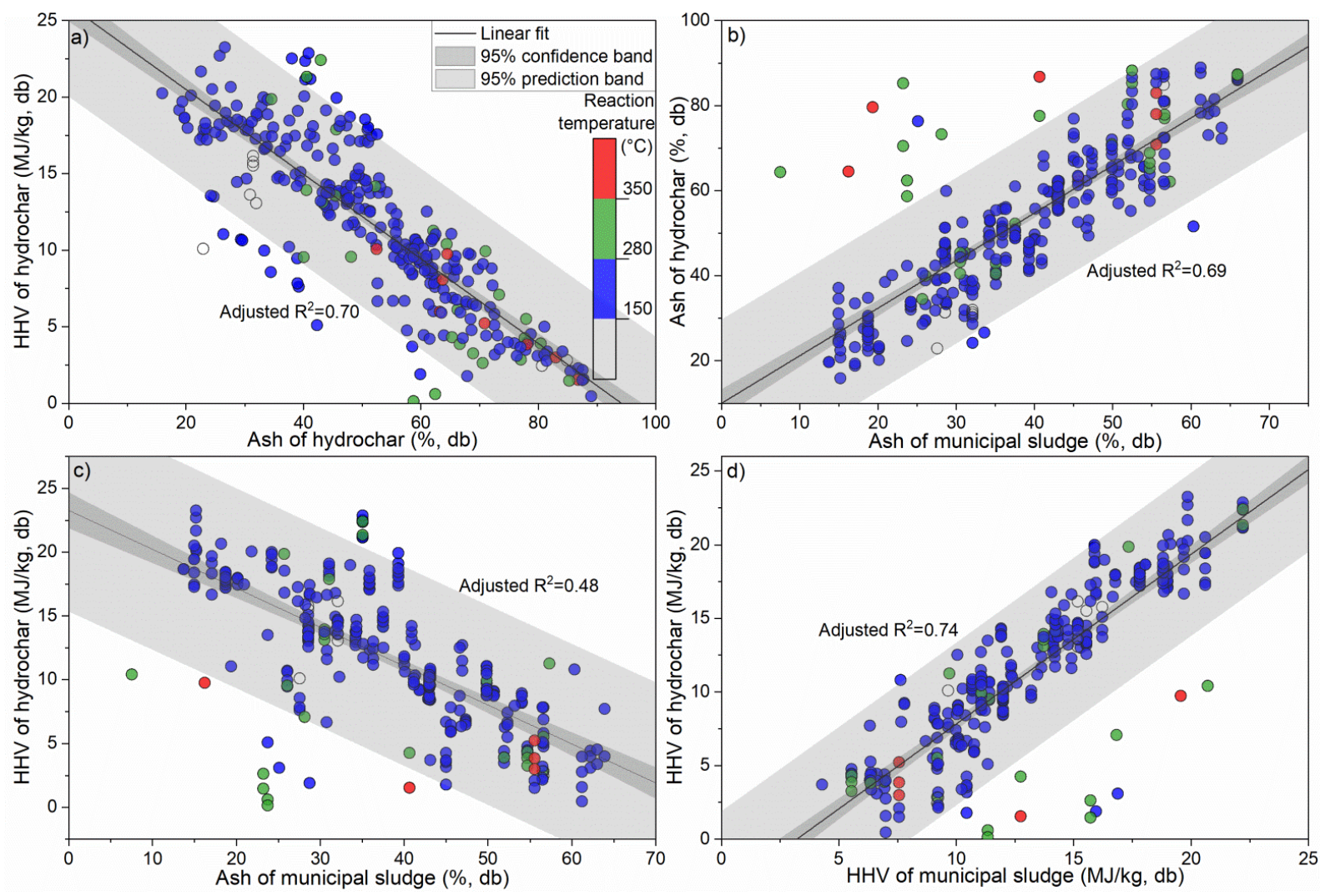

Fig. 12 Correlations among properties of hydrochar and municipal sludge (data obtained from Table 6). $\mathrm{HHV}=$ higher heating value; $\mathrm{db}=$ dry basis . 


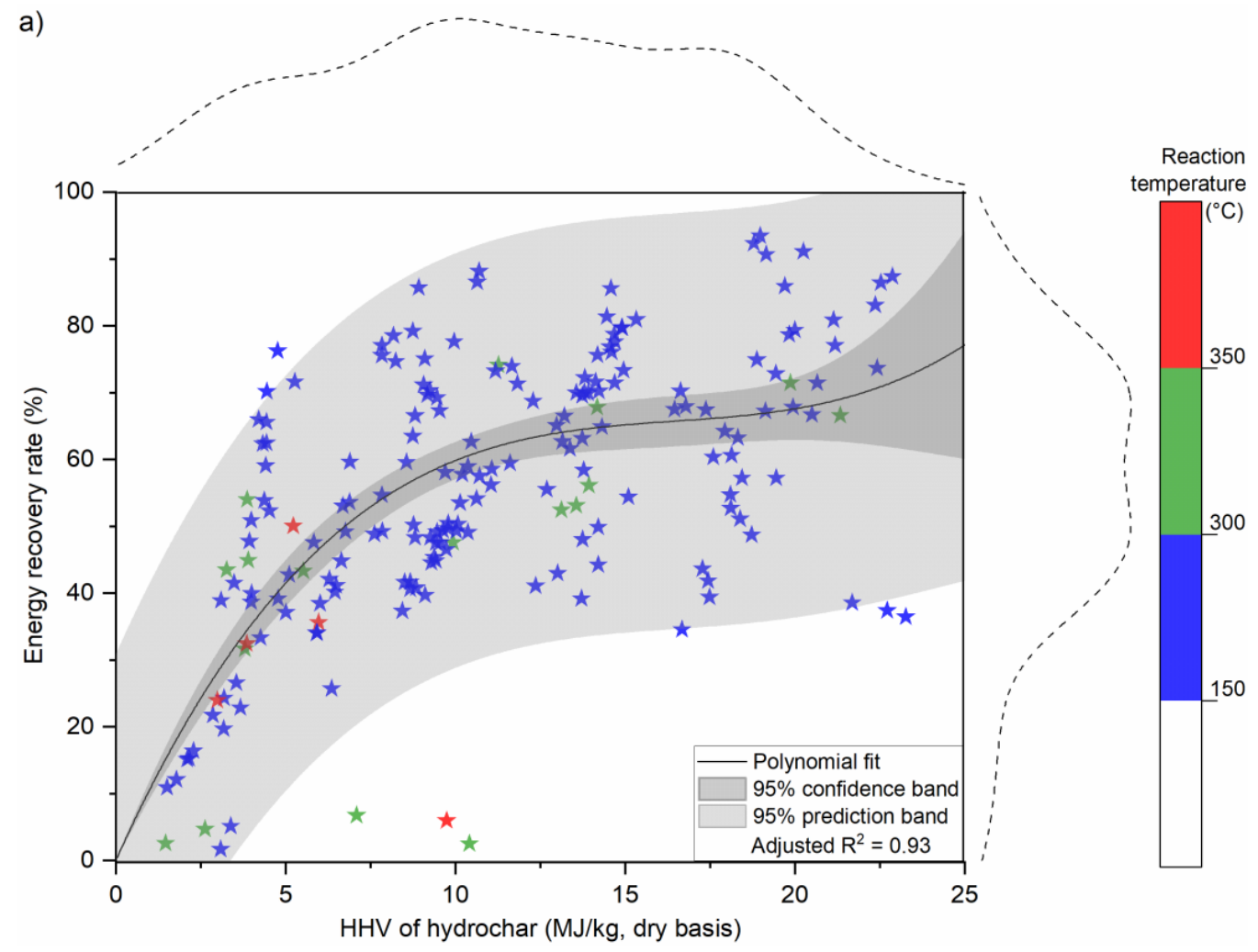




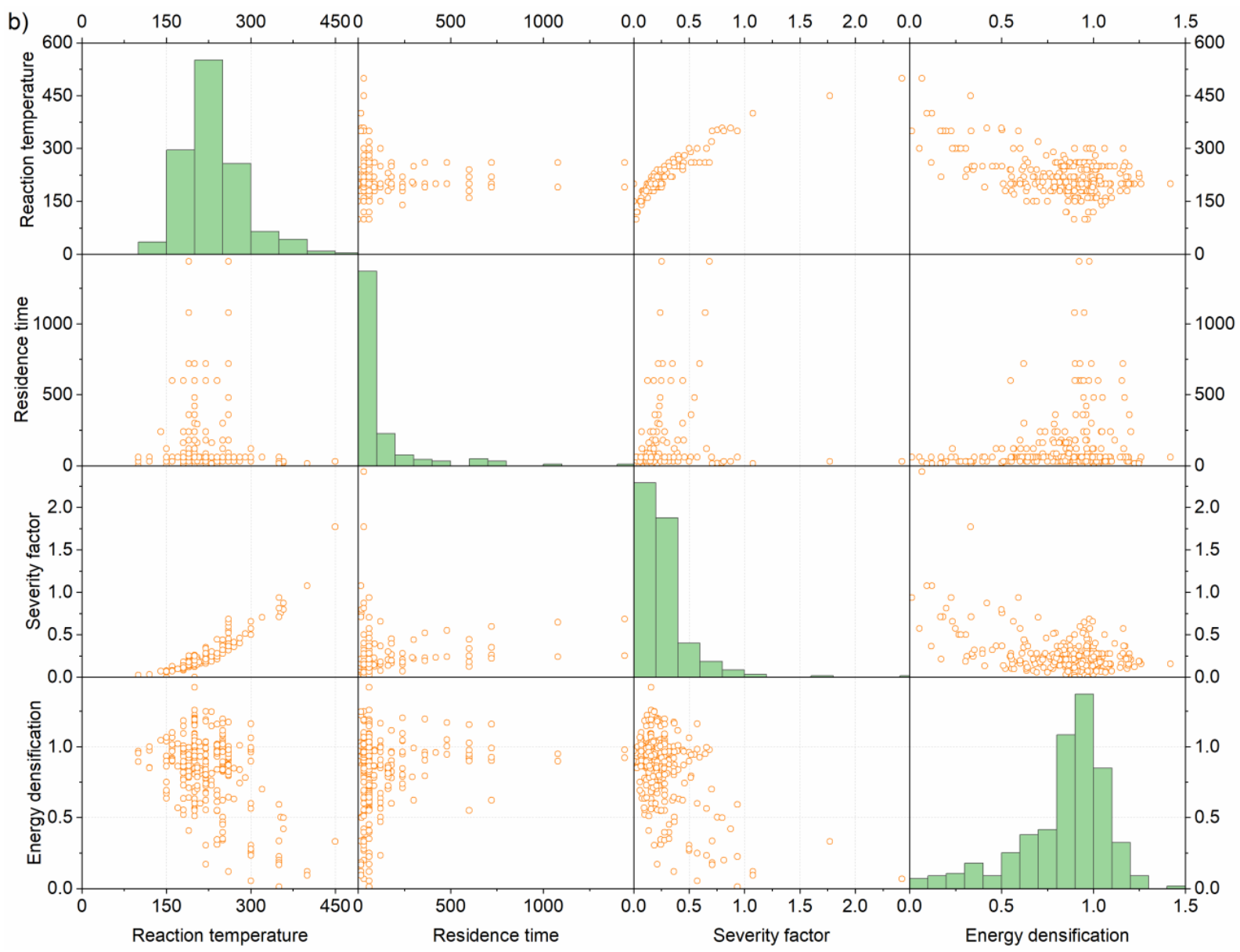

Fig. 13 (a) Plot of energy recovery rate versus higher heating value (HHV) of hydrochar with Kernel distribution and (b) scatter matrix of energy densification and hydrothermal conditions (data obtained from Table 6). Energy recovery rate $(\%)=$ hydrochar $\mathrm{HHV} /$ sludge $\mathrm{HHV} \times$ hydrochar yield (\%); energy densification = hydrochar HHV/sludge HHV. 

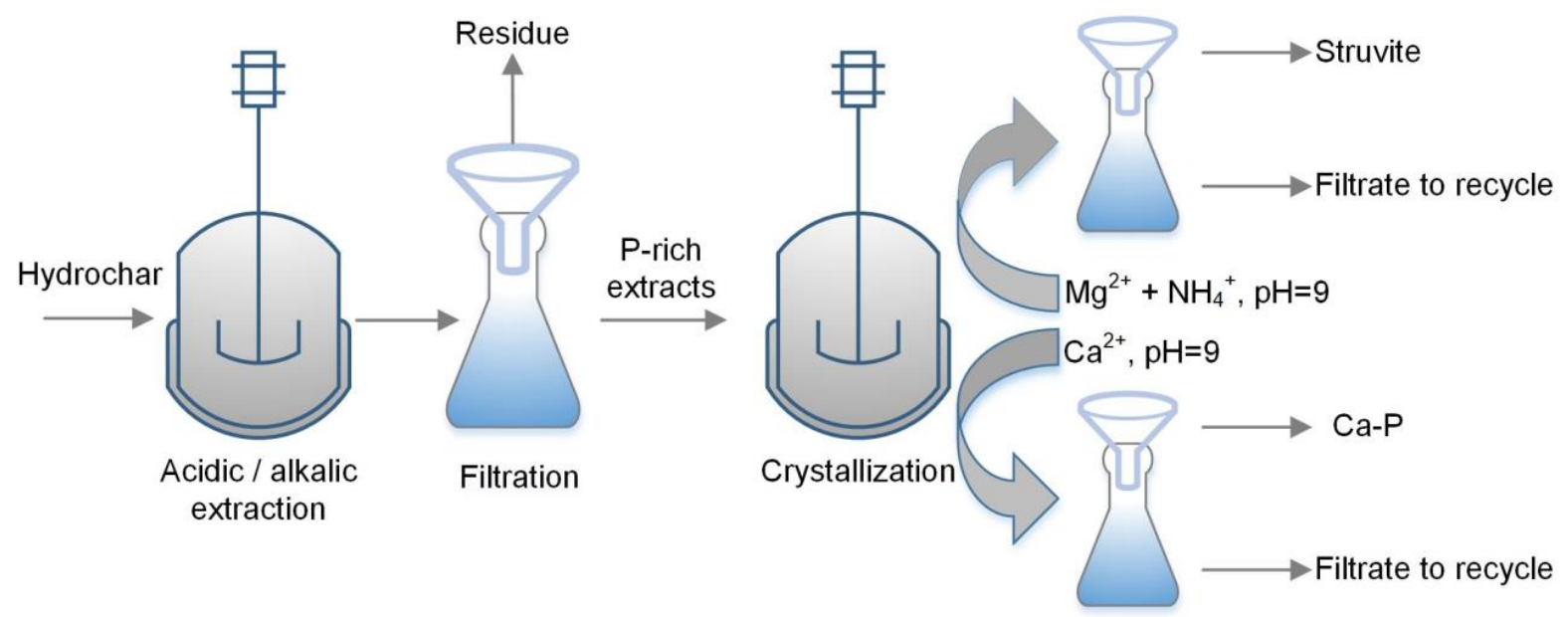

Filtration

Fig. 14 Typical nutrient recovery process from sludge-derived hydrochar through wet chemical extraction and crystallization 


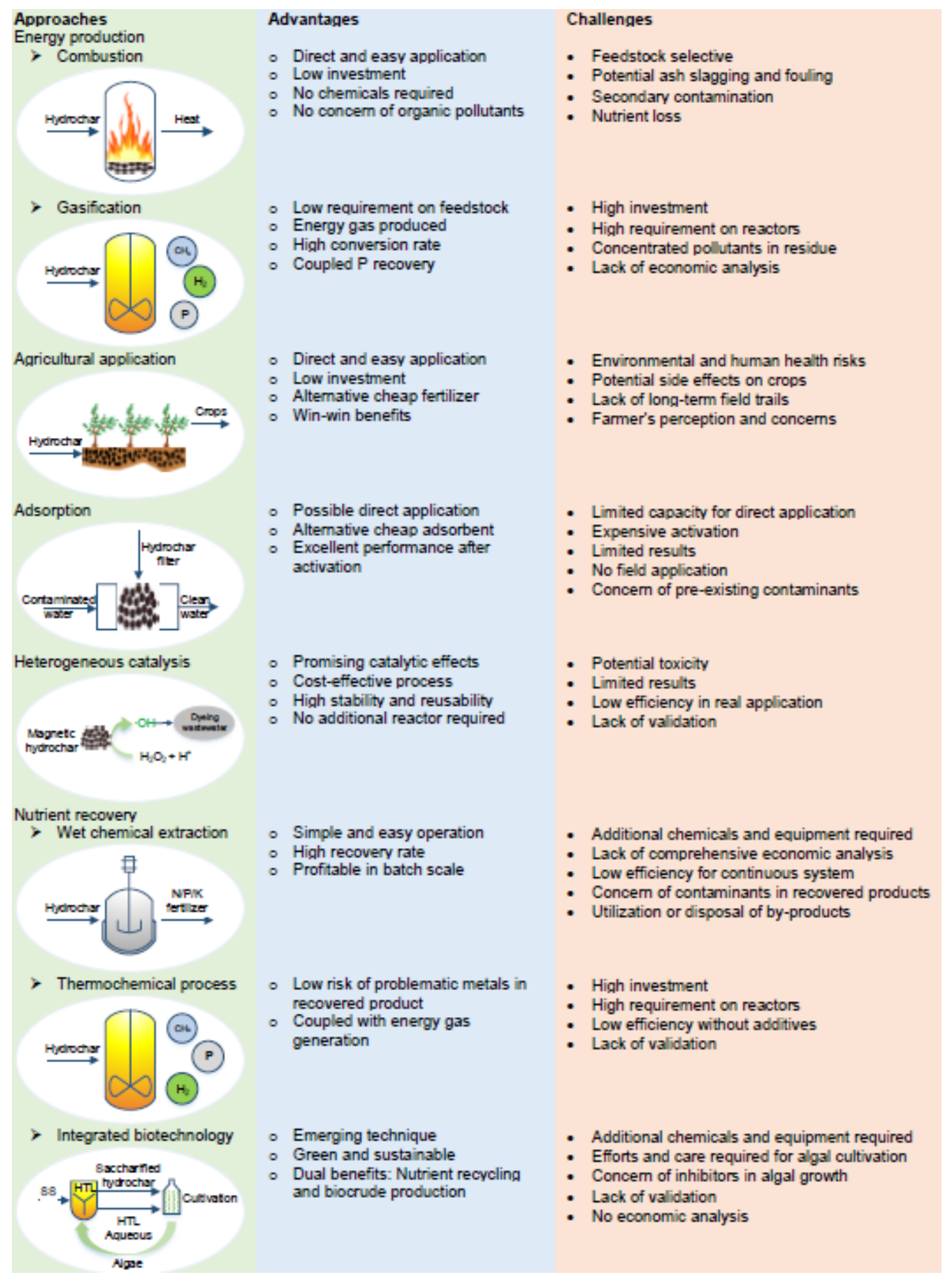

Fig. 15 Evaluations of the state of different sludge-derived hydrochar valorization approaches. 


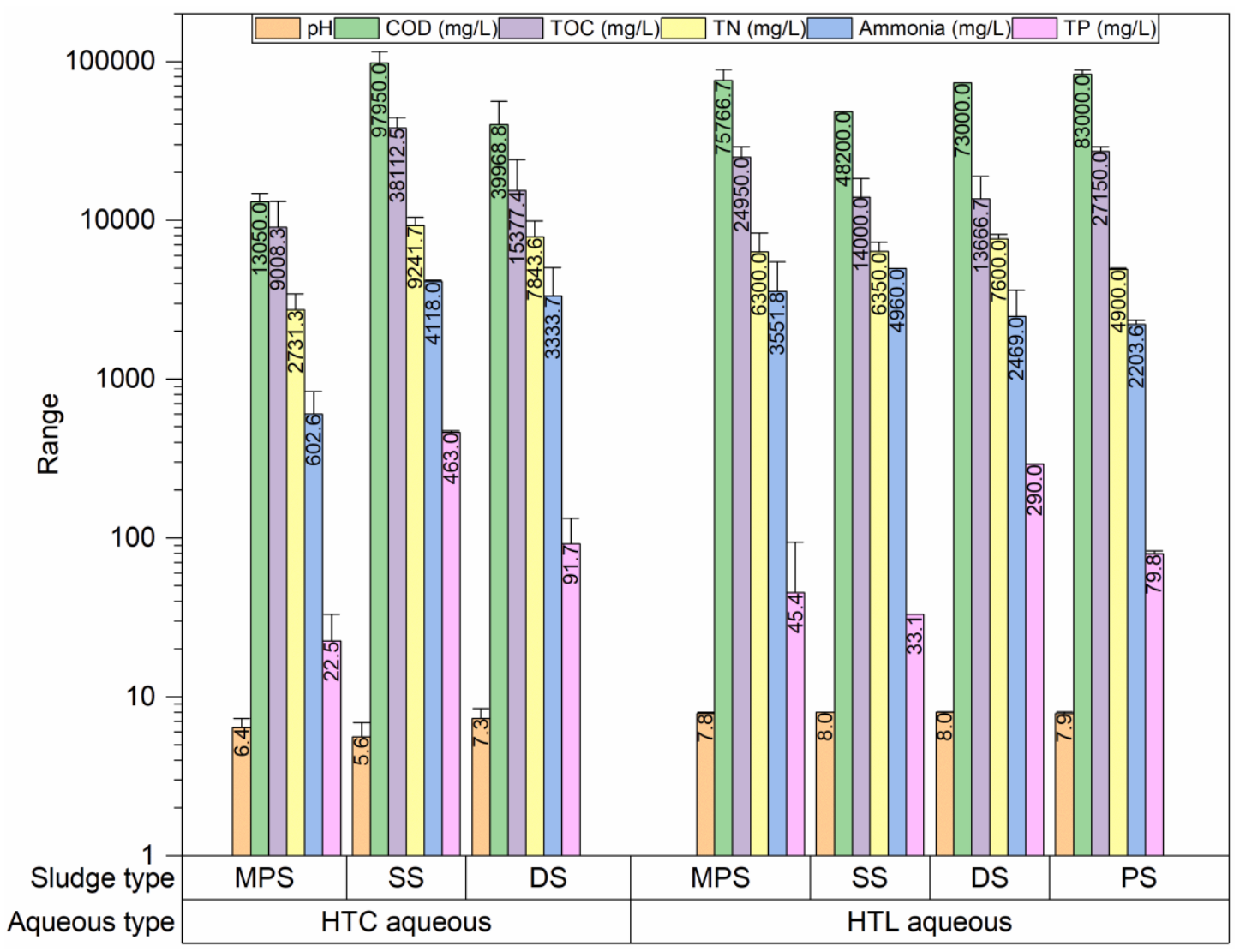

Fig. 16 Characteristics of aqueous phase from hydrothermal carbonization (HTC) and liquefaction (HTL) of various sludge (Ahmed et al., 2021a; Aragón-Briceño et al., 2017, 2020; Belete et al., 2019; Chen et al., 2019; Ferrentino et al., 2020b; Gaur et al., 2020; Lu et al., 2017; Maddi et al., 2017; Marin-Batista et al., 2020; Marrone et al., 2018; Merzari et al., 2020; Ovsyannikova et al., 2020; Snowden-Swan et al., 2017; Villamil et al., 2019, 2020; Xu et al., 2020a, 2020b). PS = primary sludge; SS = secondary sludge; MPS = mixed PS and SS; DS = digested sludge; $\mathrm{COD}=$ chemical oxygen demand; $\mathrm{TOC}=$ total organic carbon; $\mathrm{TN}=$ total nitrogen; $\mathrm{TP}=$ total phosphorus . 


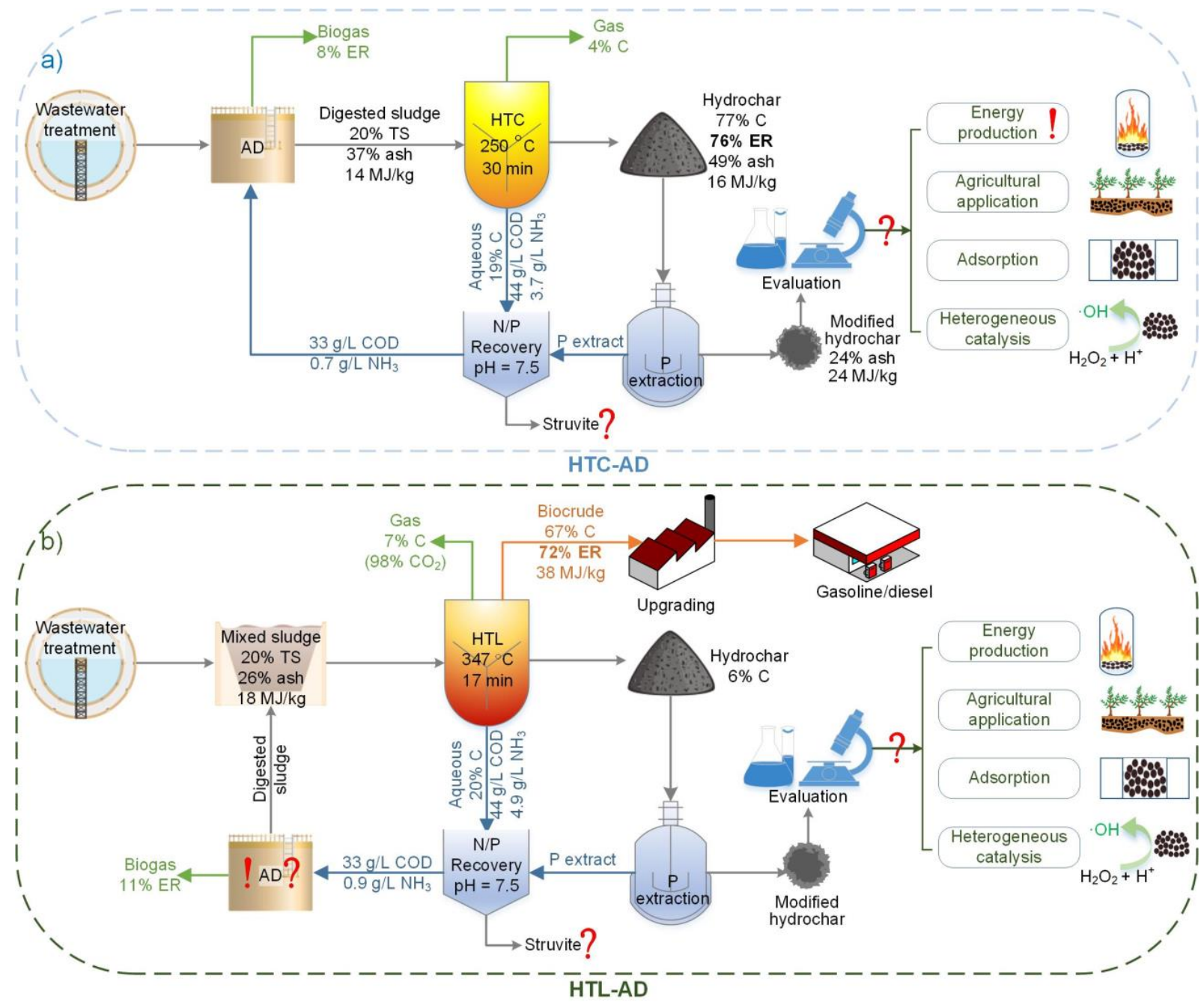

Fig. 17 Concepts of developing a sustainable waste treatment system for municipal sludge. Data adapted from (Aragón-Briceño et al., 2020; Li et al., 2021; Posmanik et al., 2017a; Snowden-Swan et al., 2017). Distribution of $\mathrm{C}$ and energy recovery (ER) is based on the feedstock (sludge). Assumptions: Struvite precipitation removed $82 \%$ ammonia and $25 \% \mathrm{COD}$ (P. Wang et al., 2021); acid washing during $\mathrm{P}$ extraction removed 50\% ash (Marin-Batista et al., 2020). $\mathrm{AD}=$ anaerobic digestion; $\mathrm{COD}=$ chemical oxygen demand; $\mathrm{HTC}=$ hydrothermal carbonization; $\mathrm{HTL}=$ hydrothermal liquefaction. 